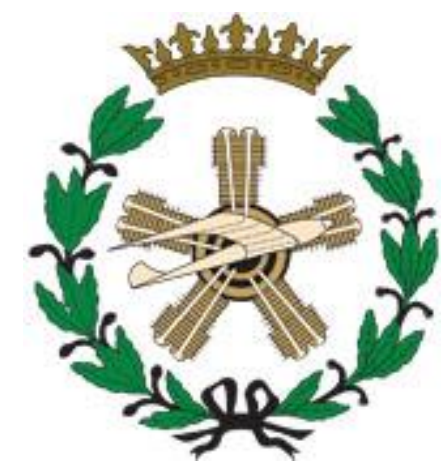

Universidad Politécnica de Madrid

Escuela Técnica Superior de Ingenieros Aeronáuticos

\title{
MONITORIZACIÓN DE ESTRUCTURAS AERONÁUTICAS MEDIANTE TÉCNICAS DE INTELIGENCIA ARTIFICIAL
}

Tesis Doctoral

Jaime García Alonso - Ingeniero Aeronáutico

Enero 2016 

Departamento de Materiales y Producción Aeroespacial

Escuela Técnica Superior de Ingenieros Aeronáuticos

MONITORIZACIÓN DE ESTRUCTURAS AERONÁUTICAS MEDIANTE TÉCNICAS DE INTELIGENCIA ARTIFICIAL

Autor:

Jaime García Alonso - Ingeniero Aeronáutico

Directores de la Tesis:

Jesús Alfredo Güemes Gordo - Doctor Ingeniero Aeronáutico

Antonio Fernández López - Doctor Ingeniero Aeronáutico

2016 



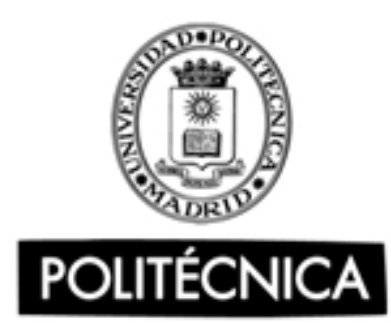

Tribunal nombrado por el Sr. Rector Magfco. de la Universidad Politécnica de Madrid, el día de. de $20 \ldots$.

Presidente:

Vocal:

Vocal:

Vocal:

Secretario:

Suplente:

Suplente:

Realizado el acto de defensa y lectura de la Tesis el día. de. de $20 \ldots$. en la E.T.S.I. /Facultad.

Calificación

EL PRESIDENTE

LOS VOCALES

EL SECRETARIO 



\section{$\underline{\text { Resumen }}$}

Una de las barreras para la aplicación de las técnicas de monitorización de la integridad estructural (SHM) basadas en ondas elásticas guiadas (GLW) en aeronaves es la influencia perniciosa de las condiciones ambientales y de operación (EOC). En esta tesis se ha estudiado dicha influencia y la compensación de la misma, particularizando en variaciones del estado de carga y temperatura. La compensación de dichos efectos se fundamenta en Redes Neuronales Artificiales (ANN) empleando datos experimentales procesados con la Transformada Chirplet.

Los cambios en la geometría y en las propiedades del material respecto al estado inicial de la estructura (lo daños) provocan cambios en la forma de onda de las GLW (lo que denominamos característica sensible al daño o DSF). Mediante técnicas de tratamiento de señal se puede buscar una relación entre dichas variaciones y los daños, esto se conoce como SHM. Sin embargo, las variaciones en las EOC producen también cambios en los datos adquiridos relativos a las GLW (DSF) que provocan errores en los algoritmos de diagnóstico de daño (SHM). Esto sucede porque las firmas de daño y de las EOC en la DSF son del mismo orden. Por lo tanto, es necesario cuantificar y compensar el efecto de las EOC sobre la GLW.

Si bien existen diversas metodologías para compensar los efectos de las EOC como por ejemplo "Optimal Baseline Selection" (OBS) o "Baseline Signal Stretching" (BSS), estas, se emplean exclusivamente en la compensación de los efectos térmicos. El método propuesto en esta tesis mezcla análisis de datos experimentales, como en el método OBS, y modelos basados en Redes Neuronales Artificiales (ANN) que reemplazan el modelado físico requerido por el método BSS.

El análisis de datos experimentales consiste en aplicar la Transformada Chirplet (CT) para extraer la firma de las EOC sobre la DSF. Con esta información, obtenida bajo diversas EOC, se entrena una ANN. A continuación, la ANN actuará como un interpolador de referencias de la estructura sin daño, generando información de referencia para cualquier EOC. La comparación de las mediciones reales de la DSF con los valores simulados por la ANN, dará como resultado la firma daño en la DSF, lo que permite el diagnóstico de daño.

Este esquema se ha aplicado y verificado, en diversas EOC, para una estructura unidimensional con un único camino de daño, y para una estructura representativa de un fuselaje de una aeronave, con curvatura y múltiples elementos rigidizadores, sometida a un estado de cargas complejo, con múltiples caminos de daños. Los efectos de las EOC se han estudiado en detalle en la estructura unidimensional y se han generalizado para el fuselaje, demostrando la independencia del método respecto a la configuración de la estructura y el tipo de sensores utilizados para la adquisición de datos GLW. Por otra parte, esta metodología se puede utilizar para la compensación simultánea de una variedad medible de EOC, que afecten a la adquisición de datos de la onda elástica guiada.

El principal resultado entre otros, de esta tesis, es la metodología CT-ANN para la compensación de EOC en técnicas SHM basadas en ondas elásticas guiadas para el diagnóstico de daño. 



\section{$\underline{\text { Summary }}$}

One of the open problems to implement Structural Health Monitoring techniques based on elastic guided waves in real aircraft structures at operation is the influence of the environmental and operational conditions (EOC) on the damage diagnosis problem. This thesis deals with the compensation of these environmental and operational effects, specifically, the temperature and the external loading, by the use of the Chirplet Transform working with Artificial Neural Networks.

It is well known that the guided elastic wave form is affected by the damage appearance (what is known as the damage sensitive feature or DSF). The DSF is modified by the temperature and by the load applied to the structure. The EOC promotes variations in the acquired data (DSF) and cause mistakes in damage diagnosis algorithms. This effect promotes changes on the waveform due to the EOC variations of the same order than the damage occurrence. It is difficult to separate both effects in order to avoid damage diagnosis mistakes. Therefore it is necessary to quantify and compensate the effect of EOC over the GLW forms.

There are several approaches to compensate the EOC effects such as Optimal Baseline Selection (OBS) or Baseline Signal Stretching (BSS). Usually, they are used for temperature compensation. The new method proposed here mixes experimental data analysis, as in the OBS method, and Artificial Neural Network (ANN) models to replace the physical modelling which involves the BSS method.

The experimental data analysis studied is based on apply the Chirplet Transform (CT) to extract the EOC signature on the DSF. The information obtained varying EOC is employed to train an ANN. Then, the ANN will act as a baselines interpolator of the undamaged structure. The ANN generates reference information at any EOC. By comparing real measurements of the DSF against the ANN simulated values, the damage signature appears clearly in the DSF, enabling an accurate damage diagnosis.

This schema has been applied in a range of EOC for a one-dimensional structure containing single damage path and two dimensional real fuselage structure with stiffener elements and multiple damage paths. The EOC effects tested in the one-dimensional structure have been generalized to the fuselage showing its independence from structural arrangement and the type of sensors used for GLW data acquisition. Moreover, it can be used for the simultaneous compensation of a variety of measurable EOC, which affects the guided wave data acquisition.

The main result, among others, of this thesis is the CT-ANN methodology for the compensation of EOC in GLW based SHM technique for damage diagnosis. 



\section{$\underline{\text { Agradecimientos }}$}

Quería agradecer a todas las personas que han hecho posible esta tesis de un modo u otro. A Antonio y a Alfredo por hacer que este estudio haya sido posible gracias a sus ideas, a las discusiones constructivas e infinitas, y sobre todo por su paciencia. A toda la gente del departamento con la que he colaborado, a Ángel, a Ángel Renato, a Beatriz y a Patricia. A Borja, sin su colaboración muchos de los resultados no habrían sido posibles. A Maricarmen y Amor. También me gustaría agradecer la ayuda prestada durante estos años a José Ignacio, a Javier, a Manolo y a todos mis compañeros de trabajo, sin su apoyo y ánimo constante tampoco habría sido posible terminar.

Finalmente quiero agradecer a mi familia todo su apoyo durante estos años. En especial a mis padres, Ramón y Feli, a ellos va dedicado este trabajo de casi una década. 



\section{$\underline{\text { Índice }}$}

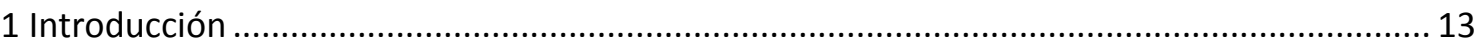

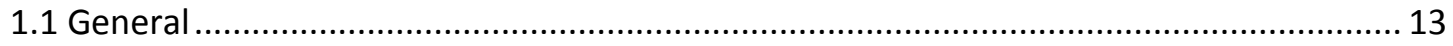

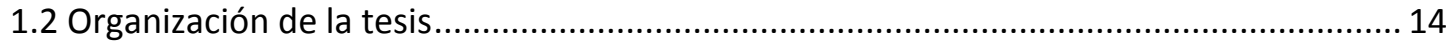

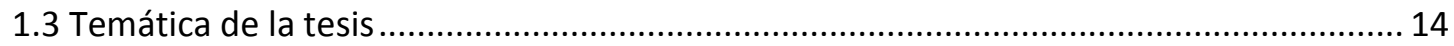

1.4 Medios disponibles para la realización de la tesis. .......................................................... 17

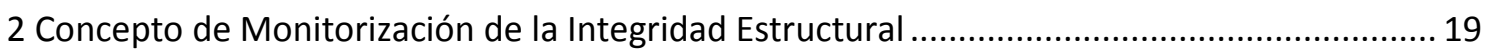

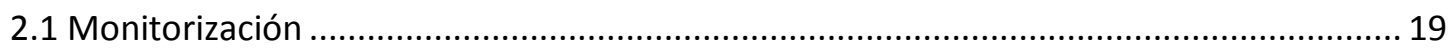

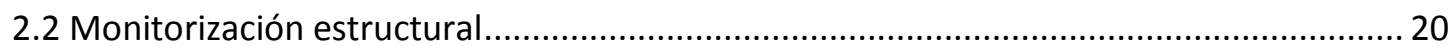

2.3 Definición de SHM y su encuadre en la Monitorización de la Integridad Estructural ...... 21

2.4 Ámbitos de aplicación de la monitorización de la integridad estructural ......................... 25

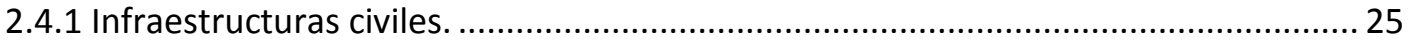

2.4.2 Infraestructuras de producción energética........................................................... 27

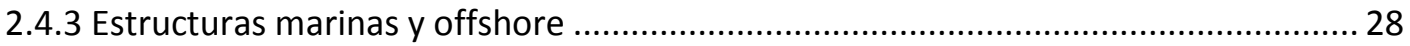

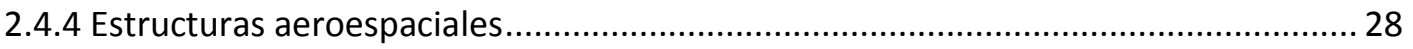

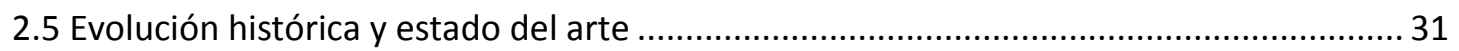

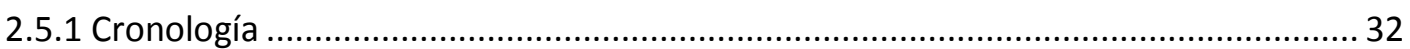

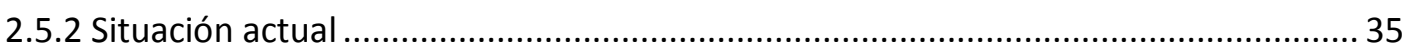

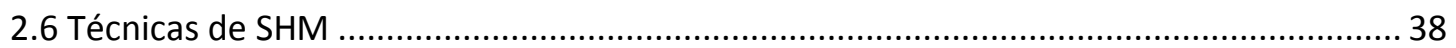

2.7 Aplicación de SHM en estructuras aeronáuticas........................................................... 42

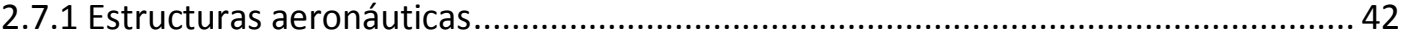

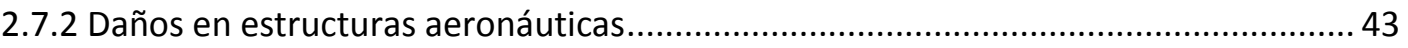

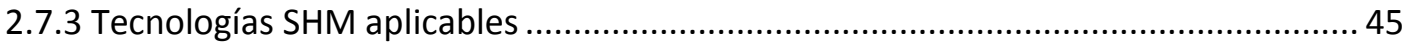

2.8 Razones de uso y ventajas, inconvenientes y problemas abiertos .................................. 47

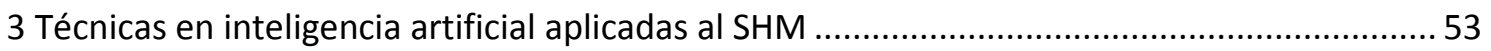

3.1 Inteligencia Artificial y Redes Neuronales Artificiales......................................................... 54

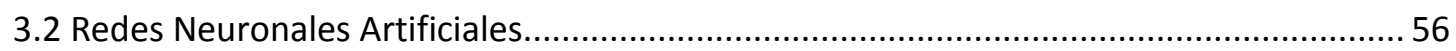

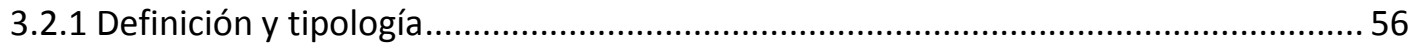

3.2.2 Arquitectura, ajuste y funcionamiento …............................................................ 57

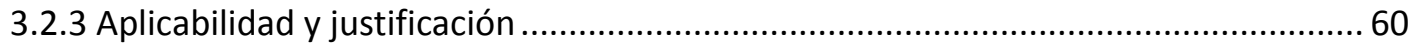

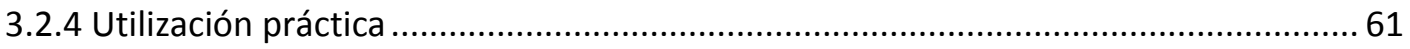

3.3 Aplicaciones típicas de Redes Neuronales Artificiales en SHM........................................62

4 Análisis de la influencia de las EOC en la propagación de ondas elásticas ................................65

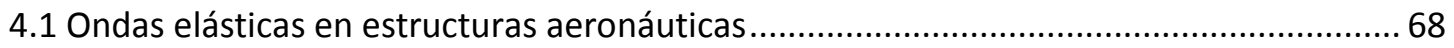


4.2 Detección de daño mediante ondas elásticas guiadas

4.3 Efecto de las condiciones ambientales y de operación ............................................ 77

5 Compensación de EOC mediante redes neuronales artificiales ...................................... 81

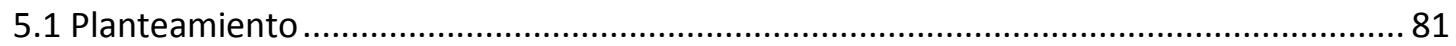

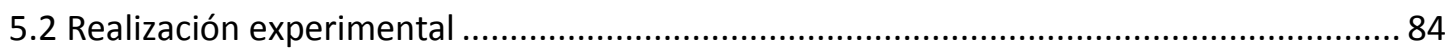

5.3 Estudios unidimensionales en pletinas, camino de daño .......................................... 87

5.3.1 Definición de la estructura ..................................................................... 88

5.3.2 Instalación de sensores y sistema de adquisición de datos ................................... 89

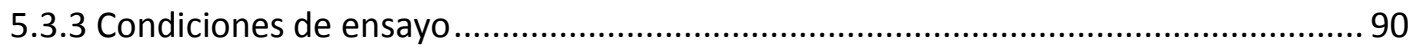

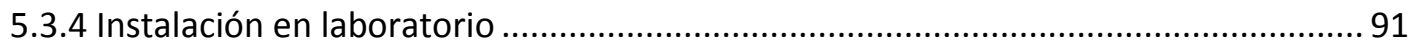

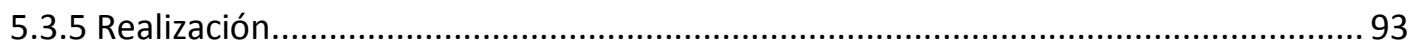

5.3.6 Revisión preliminar de resultados.......................................................... 94

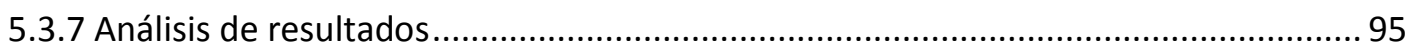

5.4 Estudios bidimensionales en fuselaje, múltiples caminos de daño ............................ 116

5.4.1 Definición de la estructura .................................................................. 117

5.4.2 Instalación de sensores y sistema de adquisición de datos .................................. 118

5.4.3 Condiciones de ensayo...................................................................... 124

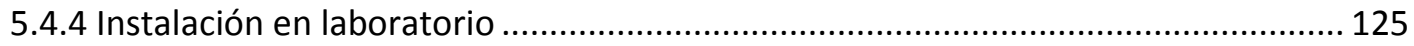

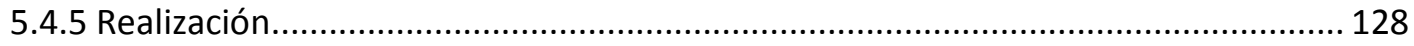

5.4.6 Revisión preliminar de resultados........................................................ 129

5.4.7 Análisis de resultados.......................................................................... 136

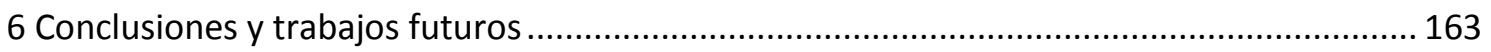

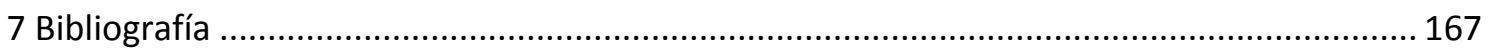

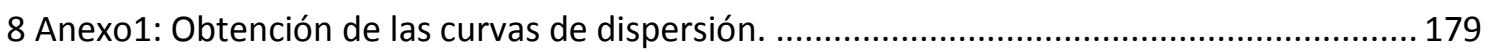

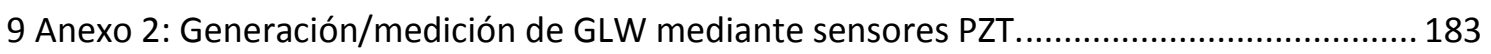

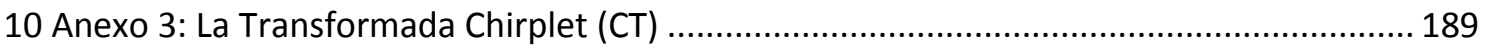

11 Anexo 4: Sistemas de adquisición de datos .................................................... 193

11.1 DAQ Acellent Technologies ScanGenie para GLW ............................................ 194

11.2 DAQ propio basado en National Instruments para GLW .................................... 196

11.3 DAQ propio basado en Arduino UNO para temperatura y deformación..................... 200

12 Anexo 5: Medición de GLW mediante sensores FBG ................................................. 205 


\section{$\underline{\text { Acrónimos }}$}

ACMS Airframe Control and Monitoring System

AE Acoustic Emission

AI Artificial Intelligence

ANN Artificial Neural Networks

AEWAC Airborne Early Warning and Control

CBM Condition Based Maintenance

CVM Comparative Vacuum Monitoring

CPU Central Processing Unit

CT Chirplet Transfrom

DARPA Defense Advanced Research Projects Agency

DAQ Data Acquisition System

DD Damage Diagnosis

DP Damage Prognosis

DSF Damage Sensitive Feature

EOC Environmental and Operational Conditions

ETFS Eddy current Testing Foil Sensor

FBG Fibre Bragg Grating

FEM Finite Element Model

GLW Guided Lamb Waves

GPU Graphical Processing Unit

HUMS Health and Usage Monitoring System

IA Inteligencia Artificial

IDE Integrated Development Environment

MRD Minimum Resolvable Distance

NDE Non Destructive Evaluation

NDI Non Destructive Inspection

NDT Non Destructive Techniques 
OBR Optical Backscatter Reflectometer

OLM Operational Loads Monitoring

PZT Lead Zirconate Titanate Piezoelectric

RID Reduced Interference Diagram

SHM Structural Health Monitoring

SHMS Structural Health Monitoring System

SNR Signal to Noise Ratio

UM Usage Monitoring

WFD Widespread Fatigue Damage 


\section{Definiciones y nomenclatura}

Big Data

Blind Test

Baudios

Data Mining

Hot-Spot Monitoring

Phased-Array

MRD

$\operatorname{Re}()$

$\operatorname{Im}()$
Extracción de información útil de grandes conjuntos de datos

Simulación de un modelo con datos nuevos para verificar su capacidad de generalización.

Bits por segundo transferidos por un canal de comunicación

Concepto similar al big data pero anterior al mismo y que incluye también la modelización de los datos

Monitorización de detalles locales de la estructura

Conjunto de sensores piezoeléctricos trabajando conjuntamente para generar un haz de ondas elásticas

$M R D=\frac{V_{\text {group }}}{t}\left(l\left(\frac{1}{v_{\text {group }} \text { min }}-\frac{1}{v_{\text {group }} \text { max }}\right)+T_{\text {burst }}\right)$

Parte real.

Parte imaginaria 


\section{Índice de figuras}

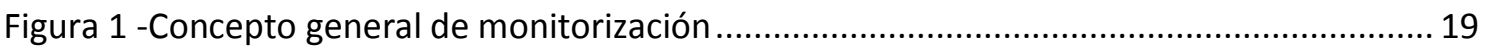

Figura 2 - Sistema de monitorización como un sistema realimentado....................................... 20

Figura 3 . Ejemplos de diversos tipos de estructuras de plantas a monitorizar tanto fijas como

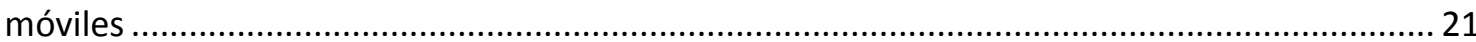

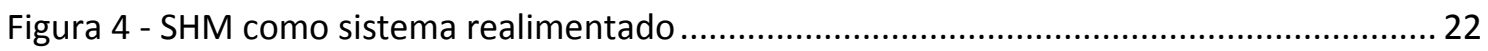

Figura 5 - SHM como parte de un proceso temporal para la monitorización de la integridad

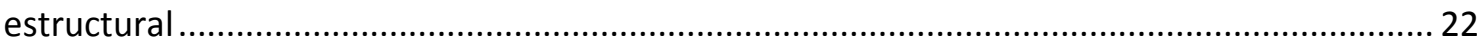

Figura 6 - SHM integrado en el proceso de mantenimiento de la estructura. mantenimiento ambiente diagnosis etc., sería como se encuadra en la actualidad.

Figura 7 - Evolución histórica de las técnicas de monitorización de la integridad estructural de

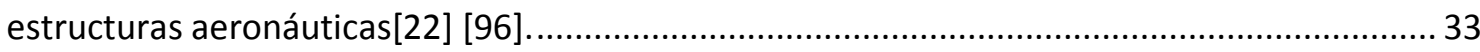

Figura 8-Diferentes tipos de SHM en función escalas temporales y dimensionales [50] ........ 39

Figura 9 - Técnicas SHM en función de la detectabilidad [103] ............................................... 40

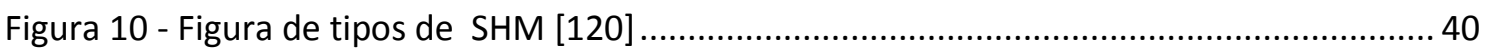

Figura 11 - Diferentes partes de la estructura de una aeronave y sus problemas asociados

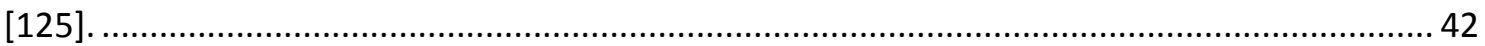

Figura 12 - Criterios de diseño en fatiga de una estructura aeronáutica [121] . ........................ 43

Figura 13 - Encuadre de las Redes Neuronales Artificiales dentro de las técnicas de Inteligencia

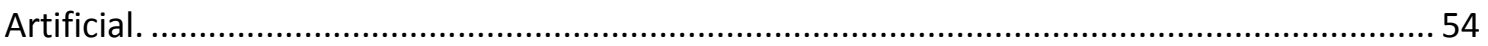

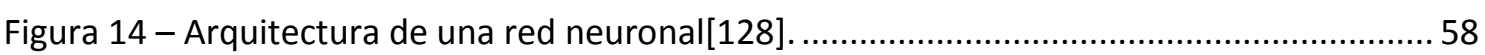

Figura 15 - Ejemplo de utilización de una red neuronal como modelo de una planta[128] ...... 58

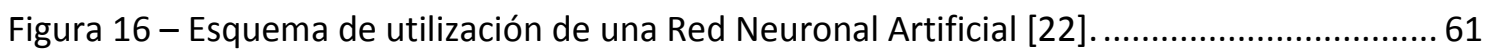

Figura 17 - Técnica SHM basada en piezoeléctricos trabajando en modo pitch-catch................6 65

Figura 18 - Fenómenos que sufren las ondas elásticas al encontrarse con un daño.................. 66

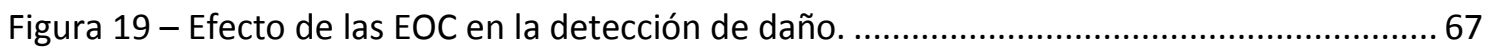

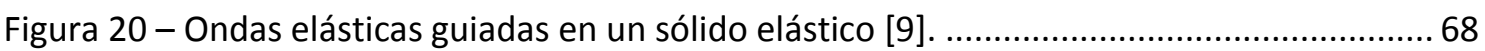

Figura 21 - Velocidades de fase. Modos simétricos en azul y modos antisimétricos en rojo.... 70

Figura 22 - Velocidades de grupo de los dos primeros modos de las ondas de Lamb............... 71

Figura 23 - Modo tracción compresión (S0, arriba) y flexión (A0, abajo) ................................... 71

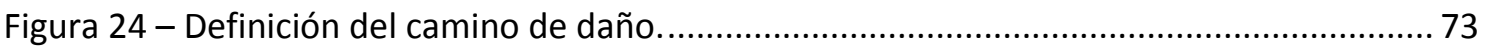

Figura 25 - Señal de interrogación de $200 \mathrm{kHz}$ introducida en el PZT actuador .......................... 75

Figura 26 - Espectro en frecuencia de la señal de interrogación. ............................................ 75

Figura 27 - Efecto de las condiciones ambientales y de operación en el camino de daño........ 77

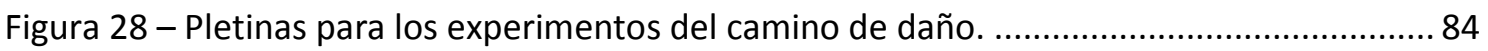

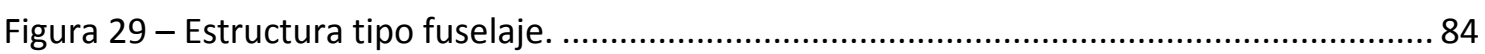

Figura 30 - Dimensiones de las pletinas y sensores piezoeléctricos. ...................................... 88

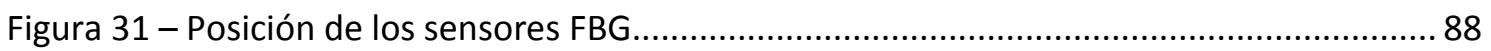

Figura 32 - Esquema completo del experimento con las pletinas......................................... 91

Figura 33 - Curvas de dispersión para las pletinas de aluminio $\mathrm{t}=2 \mathrm{~mm}$ obtenidas con $\mathrm{mi}$

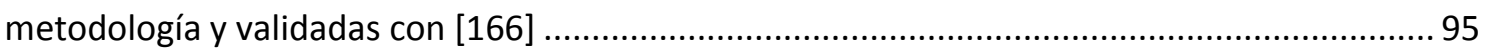

Figura 34 - Efecto de la temperatura en la llegada de la onda al sensor PZT ............................ 96

Figura 35 - Efecto de la temperatura en la llegada de la onda al sensor FBG.......................... 97

Figura 36 - Efecto de la presencia del daño en la onda elástica medida por PZT4 ...................... 98 
Figura 37 - Efecto de la presencia de daño en la onda elástica medida por FBG3

Figura 38 - Valores experimentales del retraso frente al incremento de temperatura.

Delay $(\mathrm{ns})=49 \cdot \Delta \mathrm{T}(\mathrm{\circ} \mathrm{C})+29$. 100

Figura 39 - Coeficiente Time Shift de la CT frente a los incrementos de temperatura. Time-

Shift $(n s)=48 \cdot \Delta T(\stackrel{\circ}{ })+22$. 101

Figura 40 - Relación entre el coeficiente de Time Shift y el retraso del modo SO de la GLW. . 101

Figura 41 - Delay y Time Shift calculados con sensores FBG 102

Figura 42 - Atenuación medida en la primera llegada del modo SO de la GLW para diferentes tamaños de daño.

Attenuation $=-0.012 \cdot \operatorname{DamageSize}(\mathrm{mm})+1.4$ 103

Figura 43 - Atenuación medida mediante sensores FBG para diferentes tamaños de daño. .. 104 Figura 44 - Parte real del Scaling frente al tamaño del daño, Re(Scaling) | = -

$0.0035 \cdot$ DamageSize $(\mathrm{mm})+0.44$. 104

Figura 45 - Parte real del Scaling frente al tamaño del daño para sensores FBG 105

Figura 46 - Relación entre el coeficiente de Scaling y la atenuación del modo S0.

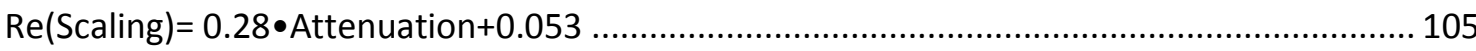

Figura 47 - Relación entre Scaling y la atenuación del modo S0 para sensores FBG............... 106

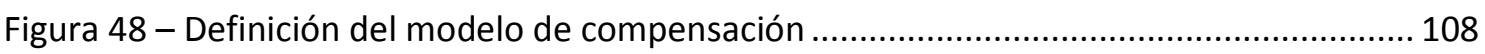

Figura 49 - Valores objetivo frente a los simulados por el modelo ANN para su entrenamiento

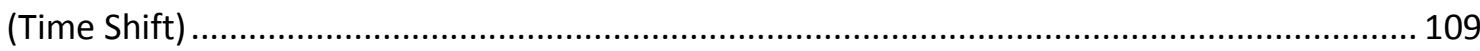

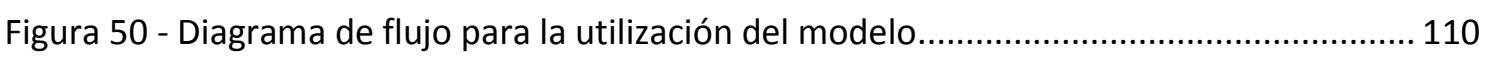

Figura 51 - Aplicación del modelo de compensación simplificado .......................................... 111

Figura 52 - Resultados de entrenamiento del modelo ANN ................................................. 113

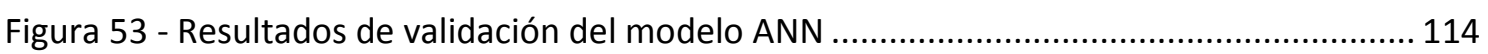

Figura 54 -Blind test del modelo con datos de daño bajo condiciones variables de temperatura

Figura 55 - Dimensiones principales del segmento de fuselaje .......................................... 117

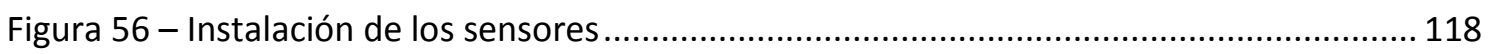

Figura 57 - Instalación de los sensores en la zona seleccionada del fuselaje ............................ 118

Figura 58 - Posicionamiento de sensores en la pieza de fuselaje. .......................................... 119

Figura 59 - Caminos de daño para la configuración de sensores instalada en la pieza de

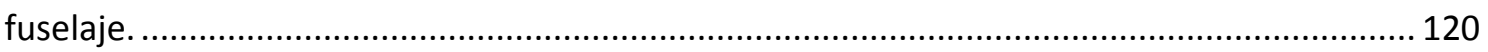

Figura 60 - Posicionamiento de los extensímetros y del termopar. ........................................ 121

Figura 61 -Extensímetros situados en ambas caras de la pieza y termopar. ............................ 121

Figura 62 - Esquema de los sistemas de adquisición de datos utilizados. ............................... 122

Figura 63 - Sistemas de adquisición de datos conectados para las pruebas preliminares. ..... 123

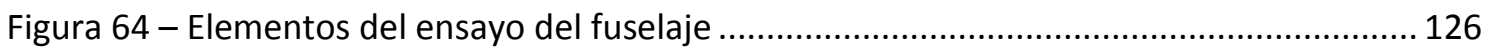

Figura 65 - Pieza de fuselaje instalada en la máquina de tracción (izquierda) y zona de

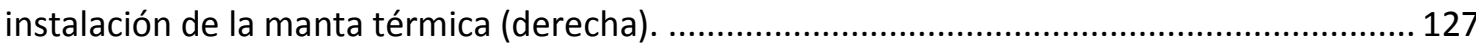

Figura 66 - Sistema de control de la manta térmica en primer plano. Instalación del fuselaje, equipo de control y máquina de tracción en segundo plano. ............................................... 127

Figura 67 - Análisis preliminar de los datos de fuselaje, caso de muestra, caminos 1 a $30 \ldots . .130$

Figura 68 - Análisis preliminar de los datos de fuselaje, caso de muestra, caminos 31 a 60. .. 131

Figura 69 - Análisis preliminar de los datos de fuselaje, caso de muestra, caminos 61 a 90... 132

Figura 70 - Evolución de la temperatura y la deformación para el experimento 3. ................. 133

Figura 71 - Datos de temperatura y carga corregidos y filtrados........................................... 133 
Figura 72 - Temperatura y estado de carga para cada una de las interrogaciones .................. 134

Figura 73 - Situación de daño para cada una de las interrogaciones..................................... 134

Figura 74 - Definición de las zonas de análisis y descarte, caminos de daño 1 a 30................ 137

Figura 75 - Definición de las zonas de análisis y descarte, caminos de daño 31 a 60.............. 138

Figura 76 - Definición de las zonas de análisis y descarte, caminos de daño 61 a 90............... 139

Figura 77 - RID del camino de daño 1-10 y la serie temporal asociada (crosstalk inicial

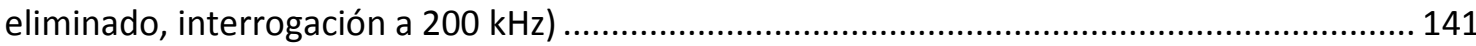

Figura 78 - Velocidades de grupo para los diferentes caminos de daño para $200 \mathrm{kHz}$............ 142

Figura 79 - Variación del coeficiente de Time Shift con la temperatura para todos los caminos

de daño.

Figura 80 - Variación del CT-TS con la temperatura, aproximaciones lineales para cada camino

de daño.

Figura 81 - Variación de CT-TS frente al retraso de la llegada del modo SO de la GLW........... 145

Figura 82 - Aproximación lineal entre el retraso y CT-TS para todos los caminos de daño....... 145

Figura 83 - Relación entre CT-TS y estado de carga. ................................................................ 146

Figura 84 - Relación CT-TS/estado de carga, aproximación lineal para cada camino de daño. 146 Figura 85 - Efecto de la presencia de daño para los diferentes caminos de daño sobre el coeficiente de la CT, Re(Scaling)

Figura 86 - Camino de daño PZT-1 $\rightarrow$ PZT-10 junto con los dos daños efectuados en la pieza.

Figura 87 - Variación de Re(Scaling) para el camino de daño PZT1/10-PZT10/1 ..................... 150

Figura 88 - Comparativa de variación de Re(Scaling) para los caminos PZT1-PZT10 y PZT1-PZT9.

Figura 89 - Diagrama del modelo de compensación ANN.

Figura 90 - Aplicación del modelo de compensación para el fuselaje.

153

Figura 91 - Errores de entrenamiento de los modelos ANN de compensación del fuselaje para diferentes frecuencias.

Figura 92 - Comparación entre salidas obtenidas y deseadas para el modelo ANN a $200 \mathrm{kHz} .155$ Figura 93 - Comparación entre salidas obtenidas y deseadas para el modelo ANN a $250 \mathrm{kHz} .156$ Figura 94 - Comparación entre salidas obtenidas y deseadas para el modelo ANN a $300 \mathrm{kHz}$.

Figura 95 - Resultados de entrenamiento para Re(Scaling) y Time Shift a 200kHz................. 157

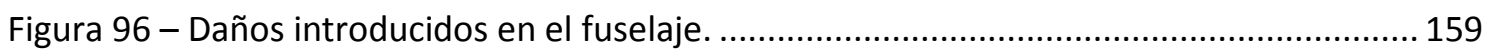

Figura 97 - Comparativa de Re(Scaling), escala de color, para el daño 1, 40 mm. ................... 159

Figura 98 - Comparativa de Re(Scaling), escala de color, para el daño 2, 10 mm. .................. 160

Figura 99 - Comparativa de Re(Scaling), escala de color, para el daño 2, 20 mm. ................. 160

Figura 100 - Dominio de cálculo para las ondas elásticas ....................................................... 179

Figura 101 - Sensor PZT en forma de disco pegado sobre la estructura ................................. 183

Figura 102 - Efecto piezoeléctrico inverso, PZT como sensor, medición de GLW.................... 183

Figura 103 - Efecto piezoeléctrico directo, PZT como actuador generación de GLW. .............. 184

Figura 104 - Generación y medición de GLW en la estructura con sensores PZT..................... 186

Figura 105 - Representación en el plano tiempo-frecuencia de la CT de un chirp [158][159] 189

Figura 106 - Set de señales teóricas para la evaluación de los coeficientes de la CT. .............. 191

Figura 107 - Coefientes de la CT obtenidos para cada una de las señales teóricas propuestas. 
Figura 108 - ScanGenie con sus conexiones para las pruebas en fuselaje.

Figura 109 - Tarjeta de adquisición NI-6366, vista general (izquierda) y panel de conexionado

(derecha).

Figura 110 - Programa de adquisición de datos y preproceso para NI-6366 ............................ 198

Figura 111 - Gráfica típica generada por el programa de adquisición para NI-6366 ................ 198

Figura 112 - Conexionado de Arduino UNO y la placa de prototipaje. ....................................... 201

Figura 113 - Arduino UNO con el termopar conectado en el lado izquierdo............................. 202

Figura 114 - Sistema Arduino UNO adquiriendo temperatura (azul) y carga (verde) durante un

ensayo.

Figura 115 - Sistema híbrido PZT-FBG.

205 


\section{Índice de tablas}

Tabla 1 - Daños típicos en estructuras aeronáuticas y la característica sensitiva al daño......... 44

Tabla 2 - Diferentes sensores SHM............................................................................. 45

Tabla 3 - Relación entre los diferentes sensores SHM, técnica SHM y la característica sensitiva

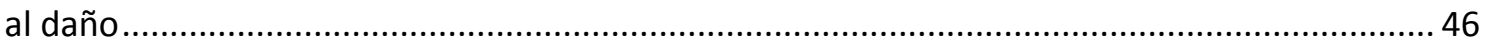

Tabla 4 - Tipología de Redes Neuronales Artificiales. ................................................... 56

Tabla 5 - Ensayos realizados para las pletinas........................................................... 87

Tabla 6 - Configuración de los sistemas de adquisición para las pletinas...............................89

Tabla 7 - Descripción de los ensayos térmicos para las pletinas.......................................... 90

Tabla 8 - Descripción de los ensayos de daño para las pletinas......................................... 90

Tabla 9 - Comparativa de dispersiones introducidas por la temperatura y por el daño...........97

Tabla 10 - Estructura del modelo de compensación ........................................................ 107

Tabla 11 - Definición del modelo para evaluar la factibilidad ............................................... 108

Tabla 12 -Valores para comprobar el modelo................................................................. 109

Tabla 13 - Parámetros de definición del modelo de compensación. ..................................... 112

Tabla 14 - Ensayos realizados para el fuselaje. ....................................................... 116

Tabla 15 - Posicionamiento de los sensores en el fuselaje. .............................................. 120

Tabla 16 - Configuración de los sistemas de adquisición para las pletinas............................. 123

Tabla 17 - Ensayos realizados para el fuselaje. ............................................................. 124

Tabla 18 - Número de adquisiciones realizadas en cada ensayo del fuselaje......................... 125

Tabla 19 - Longitudes de los diferentes caminos de daño. ............................................... 140

Tabla 20 - Velocidades de grupo medias para las diferentes interrogaciones........................ 142

Tabla 21 - Modelo de compensación para el fuselaje..................................................... 152

Tabla 22 - Parámetros de definición del modelo de compensación. ..................................... 153

Tabla 23 - Segmentación de los datos experimentales para entrenamiento del modelo ANN en

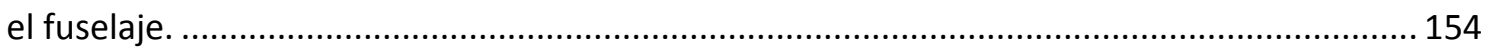

Tabla 24 - Características prácticas de uso de cada sistema de adquisición. ......................... 193

Tabla 25 - Especificaciones del equipo de adquisición ScanGenie [175] ............................. 195

Tabla 26 - Especificaciones técnicas tarjeta de adquisición NI-6366................................. 197

Tabla 27 - Especificaciones técnicas del Arduino UNO. .................................................. 201 


\section{Introducción}

\subsection{General}

El objetivo fundamental de esta tesis es el estudio, mediante técnicas de inteligencia artificial, de la monitorización de estructuras aeronáuticas con sensores integrados para detectar daños que pudieran comprometer su integridad durante su operación.

Durante la última década ha habido un rápido desarrollo de sistemas cuya misión es evaluar el estado de la estructura de una aeronave en operación [1]," in situ" y en tiempo real, mediante sensores ligados de manera permanente a dicha estructura. Son los Sistemas de Monitorización de la Integridad Estructural [2] o Structural Health Monitoring Systems (SHMS). Los SHMS permitirán optimizar el mantenimiento programado clásico (fundamentado en inspecciones conservativas obtenidas en el proceso de certificación de la aeronave) y evolucionar hasta un mantenimiento "on-demand". Adaptado a la situación concreta de cada estructura, sin la intervención de inspectores y sin desmontar la estructura. Este nuevo concepto de mantenimiento se denomina Condition Based Maintenance (CBM).

Sin embargo, a día de hoy, la madurez del SHM aún no es completa. Para poder aplicar esta tecnología es necesario resolver una serie de problemas clave característicos del campo de aplicación. Para descubrir los problemas clave que obstaculizan la implantación del SHM debemos poner el foco en los casos donde se ha logrado aplicar industrialmente: por ejemplo, la aplicación del SHM a maquinaria industrial rotativa (rotating machinery vibration monitoring).

Así, un sistema SHM funcional es aquel que cumple cuatro condiciones [14]:

- Aplicabilidad con un claro beneficio económico: Coste del sistema versus beneficio.

- Definición precisa de los modos de fallo a detectar: No es posible detectarlo todo.

- Amplia base de datos experimentales: Se requiere información real.

- Variabilidad operacional y ambiental mínima: Compensación o minimización de su efecto.

Esta tesis contempla las dos condiciones finales de la lista anterior. Se realizarán soluciones que permitan la implementación de técnicas de monitorización para la detección de daños en las estructuras aeronáuticas en operación, priorizando la compensación del efecto que introducen las condiciones de operación y ambientales. Para ello, se valorará la influencia, en la detección de daño, de dichos efectos, mediante una amplia base de datos experimentales. Estos datos, procesados adecuadamente, permiten desarrollar instrumentos basados en inteligencia artificial: redes neuronales artificiales (ANN). Estos modelos permitirían optimizar la funcionalidad de un SHM compensando los efectos de las condiciones ambientales y de operación. 


\subsection{Organización de la tesis}

El estudio general de la tesis presenta tres perfiles o características fundamentales:

El primer perfil es teórico. Aborda el ámbito científico que sustenta la tesis. Se establecen los objetivos. También se determinan los recursos necesarios. Se plantean los ensayos para obtener los datos experimentales y su procesamiento posterior. También pertenece a esta parte la generación de los modelos de compensación (basados en IA, redes neuronales artificiales).

El segundo perfil es experimental. Incluye los ensayos realizados para la detección de daños, hardware, software y procesos complementarios al uso que se requieren. El objetivo de esta parte es la obtención de información experimental útil planteada en la parte teórica.

El tercer perfil es operativo. En esta parte se comprueba, utilizando el sustento teórico y usando los datos experimentales, si modelos propuestos cumplen su función.

Finalmente, todo el contenido se organiza mediante seis capítulos principales y seis más complementarios o anexos.

\subsection{Temática de la tesis}

La tesis se ocupa de evaluar como las técnicas de Inteligencia Artificial pueden ayudar a resolver el problema de la compensación del efecto de las condiciones ambientales y operacionales (EOC) en la detección de daño en estructuras aeronáuticas mediante ondas elásticas guiadas (GLW).

Las EOC pueden llegar a interferir notablemente en las características sensibles al daño (DSF) impidiendo que la firma utilizada para la detección del daño pueda cumplir su función produciendo falsos positivos o falsos negativos. Esto hace que la técnica SHM seleccionada para la diagnosis de daño no funcione correctamente.

En primer lugar, el tipo de estructura aeronáutica seleccionada. En este caso se trata de revestimientos rigidizados metálicos principalmente. Seleccionamos este tipo de estructura por su gran ocurrencia de daños. Algunos estudios indican que hasta 90\% de los daños que aparecen en la estructura de una aeronave suelen aparecer en estas zonas (fuselajes principalmente) [94]. Más concretamente en zonas de alta concentración de esfuerzos. Esto indica que son zonas susceptibles de ser monitorizadas con un sistema SHM de diagnosis que permita detectar grietas en dichas zonas.

Esta tesis versa pues de estructuras de pared delgada rigidizadas y el daño que nos interesa controlar son fundamentalmente grietas.

Ya tenemos seleccionada la estructura y el daño. Ahora hay que ver que característica sensitiva al daño podemos utilizar. Para estos daños y tipo de estructuras se pueden usar las 
deformaciones inducidas por ondas elásticas guiadas [21], cuyas características se ven modificadas por la presencia de daño. Luego nuestra DSF serán las ondas elásticas guiadas, que en estructuras de pared delgada son ondas de Lamb guiadas, GLW. Y la firma del daño serán las modificaciones en las características de la onda producidas por la presencia del daño.

Una de técnica SHM que permite trabajar con la DSF seleccionada es la basada en sensores piezoeléctricos. Estos sensores pueden interrogar la estructura de modo tanto activo como pasivo y captar la respuesta de la misma en términos de ondas elásticas. Una de las metodologías activas, la denominada pitch-catch, consiste en evaluar la diferencia entre las señales recibidas por un PZT receptor emitidas por un PZT emisor, estando el daño situado entre ambos. Esto implicar la utilización de una red de sensores puesto que el daño puede estar en cualquier parte de la estructura.

Hasta este punto, existen multitud de estudios para este tipo de técnica SHM y para estos daños típicos en estructura de pared delgada rigidizada. Aquí es donde entran los estudios realizados en esta tesis, esta técnica SHM, aplicada en una estructura real en operación, no se puede utilizar sin una compensación de los efectos ambientales y operacionales, EOC. Este será el hilo conductor de esta tesis, la manera de compensar estos efectos para que esta técnica pueda ser utilizada en una estructura real donde intervienen un número arbitrario de condiciones ambientales y de operación (EOC) cuya influencia habrá que compensar para tener éxito en la detección de daño. En el modo de compensación es donde entrarán los modelos redes neuronales artificiales (ANN) para ayudar a separar los efectos que producen las EOC en la DSF y el que produce el daño. Una vez separados se podrá utilizar la firma del daño en la DSF para poder cumplir con los diferentes niveles del SHM, sin interferencias. Las premisas de la técnica propuesta para su aplicación general y que se tratarán de demostrar en esta tesis son las siguientes:

- Independencia de la complejidad de la estructura donde se aplique la técnica siempre que cumpla las condiciones de existencia de la DSF seleccionada.

- Independencia del tipo de sensor utilizado siempre que permita medir la DSF seleccionada y la influencia de las EOC sean similares.

Para estudiar este problema se han seguido los siguientes pasos:

- Planteamiento del problema:

- Se estudia la medición de ondas elásticas en estructuras de pared delgada rigidizada. Tanto la teoría subyacente tras la física del problema como los aspectos prácticos de su medición. Podríamos denominar esta parte como 
comprensión y medición de la DSF. Para esto se utilizarán tanto modelos analíticos como FEM.

- Se comprueba también la influencia de las EOC y del daño sobre la DSF. Es esta la parte en la que vemos las características que modifican estos efectos en la DSF. La firma del daño y de las EOC. Se revisan las aproximaciones existentes en la literatura para resolver este problema.

- Proposición de solución. Una vez revisado el problema y analizadas las aproximaciones existentes se plantea una solución para la compensación de temperatura:

- Extracción de las firmas de EOC y daño en la DSF mediante una transformada al plano Tiempo-Frecuencia. La transformada seleccionada es la transformada Chirplet (Chirplet Transform, o CT). Permite extraer información relativa a dichas firmas y además reducir notablemente la cantidad de datos presentes en las mediciones de la DSF sin eliminar la información contenida.

- Utilización de una Red Neuronal Artificial para el modelado de la relación entre las firmas extraídas y los parámetros que las gobiernan:

- Relación entre firma sobre la DSF y EOC: parámetros ambientales y de operación como podrían ser la temperatura de operación y el estado de cargas de la estructura.

- Relación entre firma sobre la DSF y el daño: fundamentalmente el tamaño del daño, que para esta experimentación es conocido y que para la utilización en servicio se obtiene por eliminación del resto de variables.

- Realización experimental. Una vez propuesta la aproximación a la solución del problema se realizan una serie de experimentos de complejidad creciente para evaluar la factibilidad de la misma:

- Justificación de la interferencia producida en la firma del daño sobre la DSF por las EOC. En este punto se comprueba como efectivamente la presencia de las EOC cambia de tal modo la medida de la DSF que hace imposible la detección de la presencia del daño.

- Ensayos unidimensionales sobre pletinas de aluminio. Aquí se evalúa la influencia de una condición ambiental, la temperatura, sobre la presencia del daño. Se elige la configuración más sencilla posible en la que se tiene una pletina de referencia y otra dañada cada una con dos sensores piezoeléctricos. Con este experimento se comprueba la factibilidad de la aproximación 
propuesta. Además se utilizan otro tipo de sensores para contrastar la independencia de la técnica del tipo de sensor utilizado mientras mida la misma DSF (se evalúan las redes de Bragg, FBG).

- Además se plantea todo lo relativo a los sistemas de medición utilizados y toda la problemática de trabajar con datos reales.

- Análisis de resultados. Contiene todos los resultados obtenidos a modo de resumen. Se revisa punto por punto si los resultados obtenidos son los esperados.

- Validación de los modelos. Una vez comprobado que todo funciona de un modo adecuado se plantea una situación más compleja con una estructura real, en condiciones lo más realistas posibles, para verificar si la aproximación propuesta funciona realmente. Las características del ensayo de validación son las siguientes:

- Estructura real. Segmento de fuselaje rigidizado con cuadernas y larguerillos.

- EOC combinadas. En este caso temperatura y carga.

\subsection{Medios disponibles para la realización de la tesis.}

La tesis se realiza en el laboratorio de Structural Health Monitoring \& Smart Structures del Departamento de Materiales y Producción Aeroespacial de la Escuela Técnica Superior de Ingenieros Aeronáuticos de Madrid.

En el laboratorio se dispone de todo lo necesario para la realización de los ensayos:

- Pletinas de aluminio para la realización de las pruebas unidimensionales.

- Piezas típicamente aeronáuticas como el panel de aluminio rigidizado simulando un segmento de fuselaje.

- Sensores para la instrumentación de las piezas:

○ Piezoeléctricos PZT para la medida de ondas elásticas.

- Fibras ópticas con los sensores FBG integrados.

- Extensímetros para la medida de deformación.

- Termopares para la medida de temperatura.

- Equipos para la adquisición de datos:

- Tarjeta de Nacional Instruments NI 6366 para la adquisición de datos de los PZT y FBG.

- Acellent Technologies ScanGenie[28]. Equipo comercial para la interrogación activa de estructuras. 
- Arduino UNO para la adquisición de los datos de los sensores adicionales, tales como termopares y extensímetros.

- Computadoras para el control de adquisición procesado de datos y generación de los modelos, con los entornos de software necesario para estas tareas:

- The Mathworks, MATLAB ${ }^{\mathrm{R}}$ para la adquisición de datos y el procesado de la información.

- Acellent software $\operatorname{ACCES}^{\mathrm{R}}$ para la adquisición de datos con el equipo ScanGenie.

- Software de apoyo de Arduino para la configuración y adquisición de datos. 


\section{Concepto de Monitorización de la Integridad Estructural}

Para definir la monitorización de la integridad estructural se va a desarrollar y ampliar la idea desde la monitorización general hasta las particularidades de los sistemas SHM aeronáuticos.

\subsection{Monitorización}

Adaptando al campo la ingeniería la definición de monitorización del diccionario de la Real Academia Española de la Lengua se estaría hablando de observar mediante aparatos especiales el curso de uno o varios parámetros fisiológicos o de otra naturaleza para detectar posibles anomalías [64]. En este caso se observaría una planta o sistema y los parámetros a tener en cuenta serían características medibles de la misma, siendo la anomalía el resultado de algún tipo de funcionamiento o estado considerado erróneo. En la Figura 1 se pueden observar los elementos básicos que tendría cualquier sistema de monitorización en general.

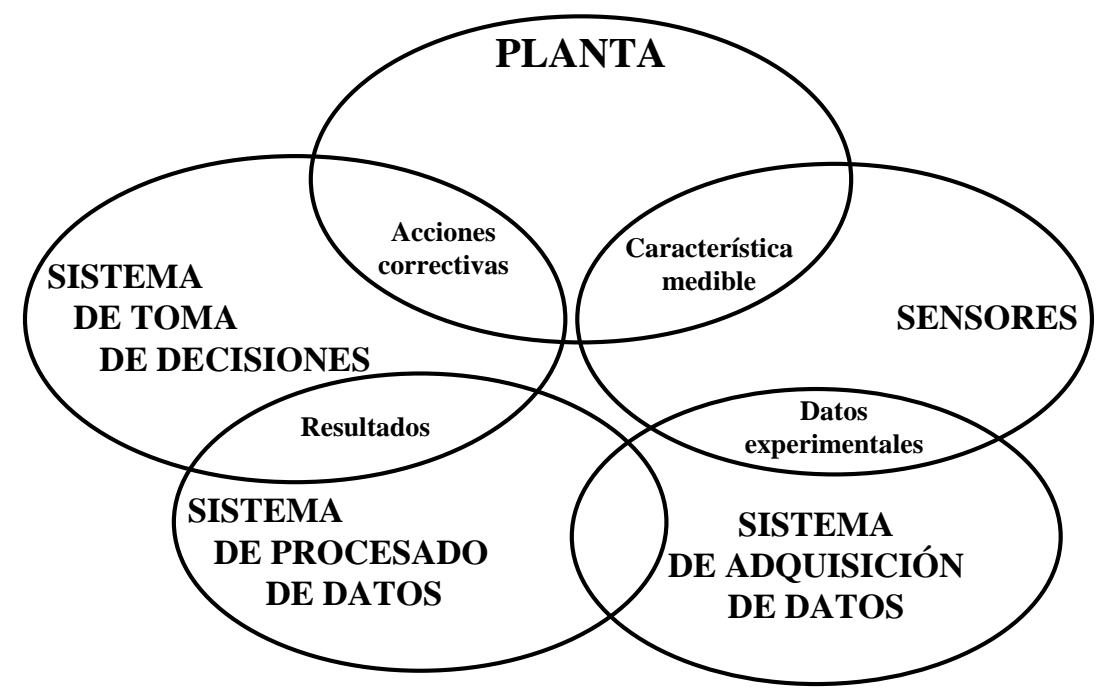

Figura 1 -Concepto general de monitorización

Desde un punto de vista más matemático, los sistemas de monitorización se pueden considerar como sistemas de control realimentados. Diferenciándose de estos en los tiempos característicos y en el modo de actuación sobre la planta.

Para funcionar, un sistema de monitorización medirá todas las entradas que afecten a la planta monitorizada además de las salidas. Con toda esa información realizará una serie de acciones para asegurar la operación de la planta dentro de unos límites predeterminados de seguridad y eficiencia. 


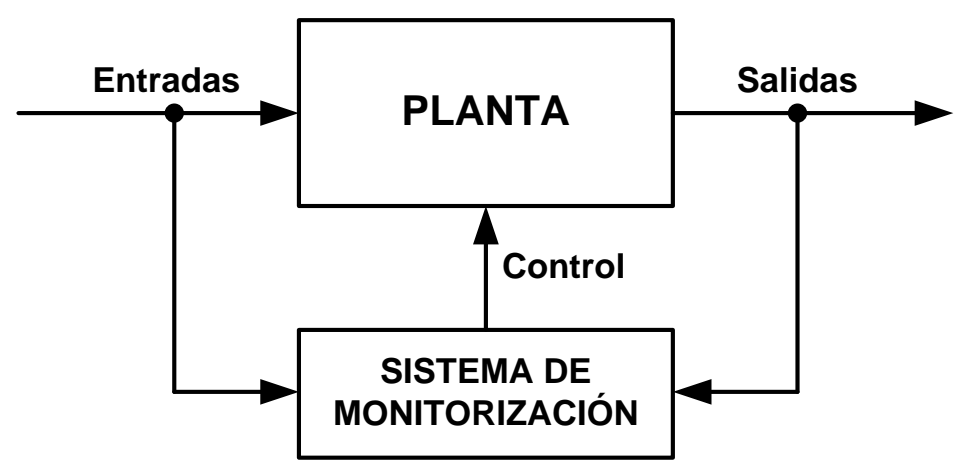

Figura 2 - Sistema de monitorización como un sistema realimentado

En este punto es importante indicar, desde el punto de vista físico, las escalas temporales y espaciales en las que se encuadra este tipo de sistemas como sistemas realimentados.

Respecto a escalas temporales, los sistemas de monitorización de los que nos vamos a ocupar evolucionan en tiempos lentos [87]. Y, en cuanto a escalas espaciales, los sistemas de monitorización se ocupan de cambios que se producen a nivel microscópico en el material y evolucionan hasta un nivel macroscópico detectable. En ese momento, cuando el cambio sea de suficiente entidad como para afectar a algún parámetro medible de la planta será cuando el sistema de monitorización comience a controlarlo [87].

Así pues los sistemas de monitorización objeto de estudio son aquellos que tienen las siguientes características:

- Tiempos característicos lentos, del orden de la vida operativa de la planta.

- Escala espacial macroscópica. Son los cambios o eventos que tienen algún efecto medible y por lo tanto susceptible de modificar la operación de la planta los que nos interesarán

\subsection{Monitorización estructural}

En esta tesis se centra en los sistemas de monitorización de la estructura. En este caso el sistema a controlar es la estructura de la planta, entendiéndose como tal aquel cuya función es soportar o transmitir cargas. Planta que puede ser fija o móvil. Los parámetros de observación serían sus parámetros característicos de operación propios y aquellos relativos al entorno, los ambientales. La situación anómala sería aquella que comprometiese la integridad estructural (la capacidad de soportar o transmitir las cargas), presente o futura, impidiendo a la planta, en su conjunto, operar dentro de los márgenes de diseño. Estos márgenes de operación pueden estar determinados fundamentalmente por consideraciones de seguridad, económicas o ambas, dependiendo del tipo de planta. En inglés, esto se denomina "fitness for purpouse" [63]. 


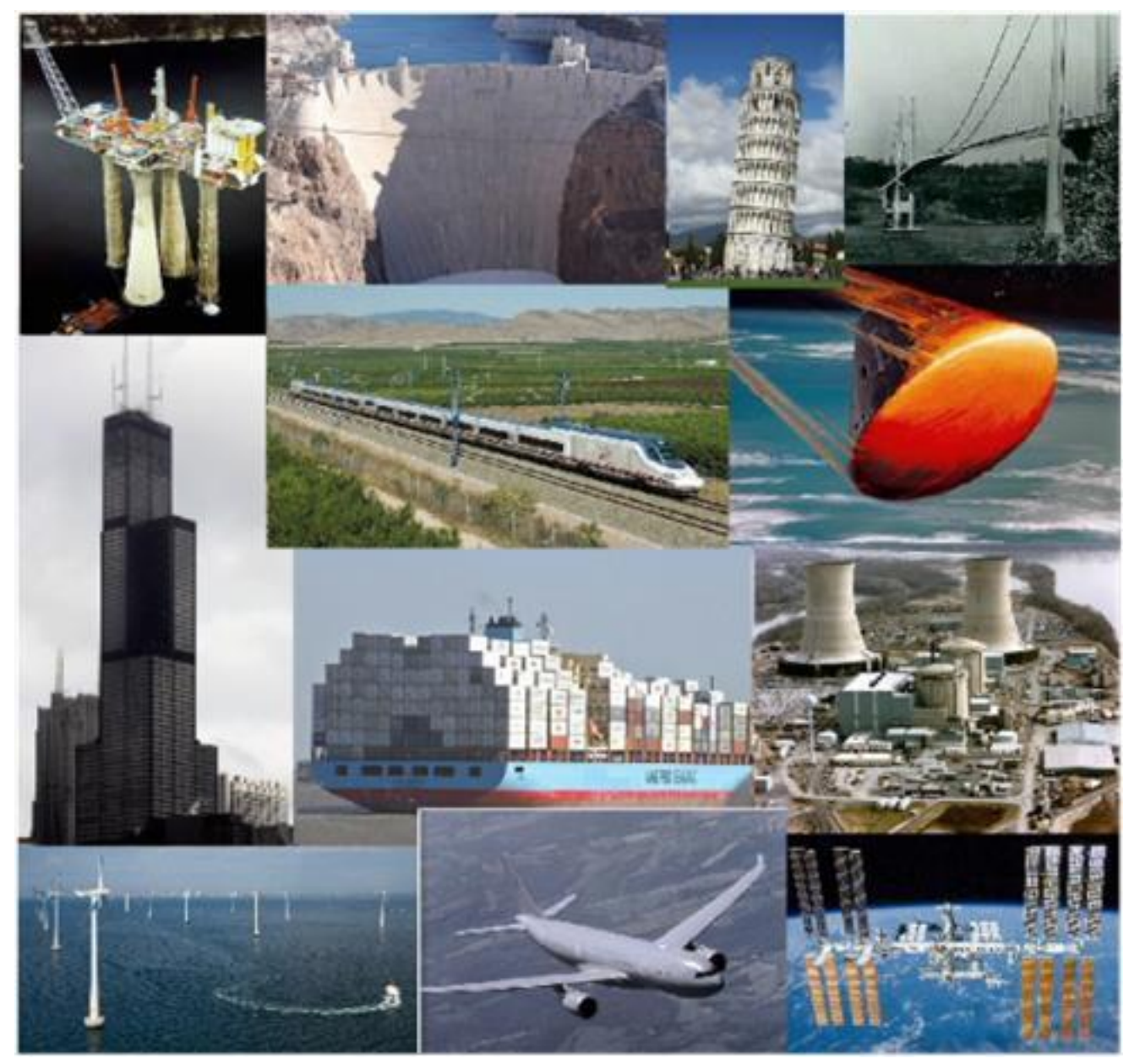

Figura 3 . Ejemplos de diversos tipos de estructuras de plantas a monitorizar tanto fijas como móviles

En cierto modo, la monitorización estructural consiste en garantizar la integridad estructural sea cual sea el tipo de planta y su estructura [13], diferenciándose en los parámetros que hay que medir para ello. En la Figura 3 se puede comprobar la diversidad de estructuras de plantas que se pueden monitorizar.

\subsection{Definición de SHM y su encuadre en la Monitorización de la Integridad Estructural}

Existen muchas maneras de definir el SHM dependiendo del campo de aplicación. Algunas de ellas serían las siguientes. Se puede considerar un sistema ligado a la estructura, un proceso temporal incluido dentro de una estrategia global de mantenimiento, o, atendiendo a su operativa como una técnica o conjunto de técnicas. A continuación se abordan las particularidades de cada una de las definiciones de SHM.

Si lo consideramos un sistema, el SHM es, en esencia, un sistema autónomo para monitorizar, inspeccionar y detectar daños en estructuras con una mínima intervención humana [28]. Tal y como se ha visto en el apartado anterior esto podría considerarse un sistema realimentado [63]: "SHM is a continous system identification of a physical or parametric model of the structure 
using time-dependent data". Esta definición casa bien con la consideración de los sistemas SHM como sistemas realimentados.

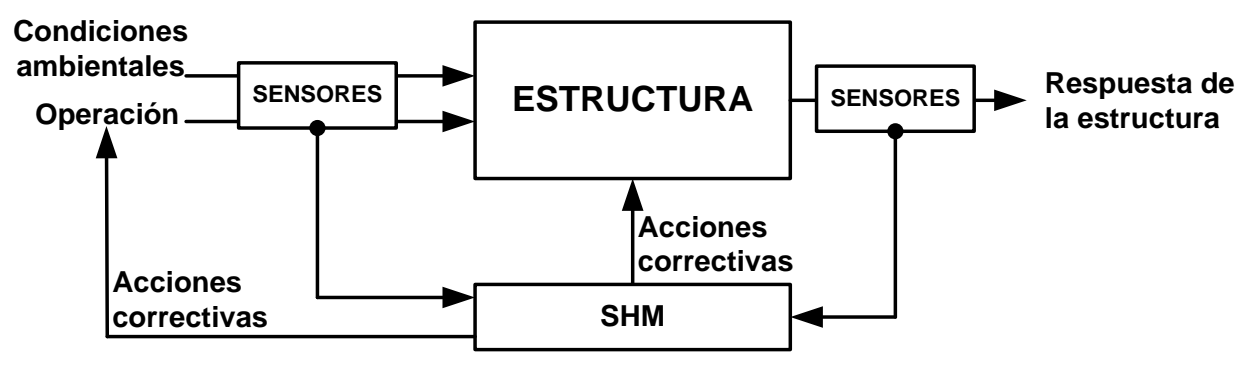

Figura 4 - SHM como sistema realimentado

También se puede considerar como parte de un proceso de implementación de una estrategia de identificación de operación anómala de una infraestructura, planta o estructura aeroespacial, civil o mecánica [14]. En esta definición está implícita la comparación entre dos estados de dicha estructura, uno de referencia considerado "sano" y otro que se verifica y el sistema decide si se considera "sano" o dañado. También implica una observación periódica de dicha estructura. Dicho proceso o estrategia tendría tres elementos fundamentales [14], entre los cuales se encuentra el SHM:

- Monitorización de uso, Usage Monitoring. Histórico de uso de la estructura.

- Diagnosis de daño, Damage Diagnosis. Estado actual de la estructura. La mayoría de los autores consideran que el SHM consiste fundamentalmente en esta tarea.

- Prognosis de daño, Damage Prognosis. Estado futuro de la estructura

Insertando estos tres elementos dentro de un proceso temporal desde el pasado hasta el futuro, operarían tal y como indica la Figura 5 [5].

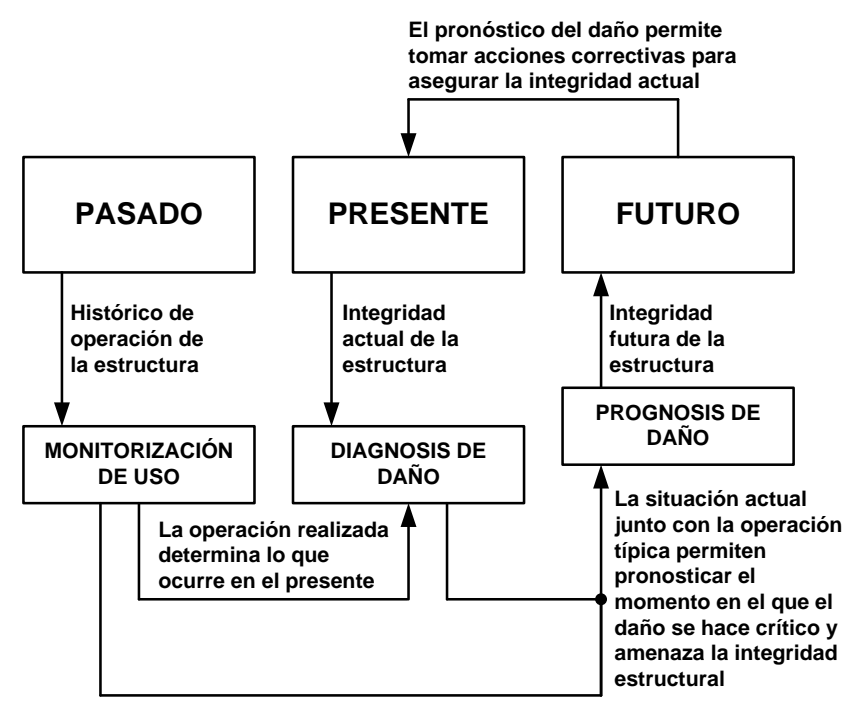

Figura 5 - SHM como parte de un proceso temporal para la monitorización de la integridad estructural 
Sin embargo, desde un punto de vista operativo, como sistema, los elementos descritos anteriormente no operan aislados, sino que deben integrarse con el programa de mantenimiento de la estructura, ver Figura 6.

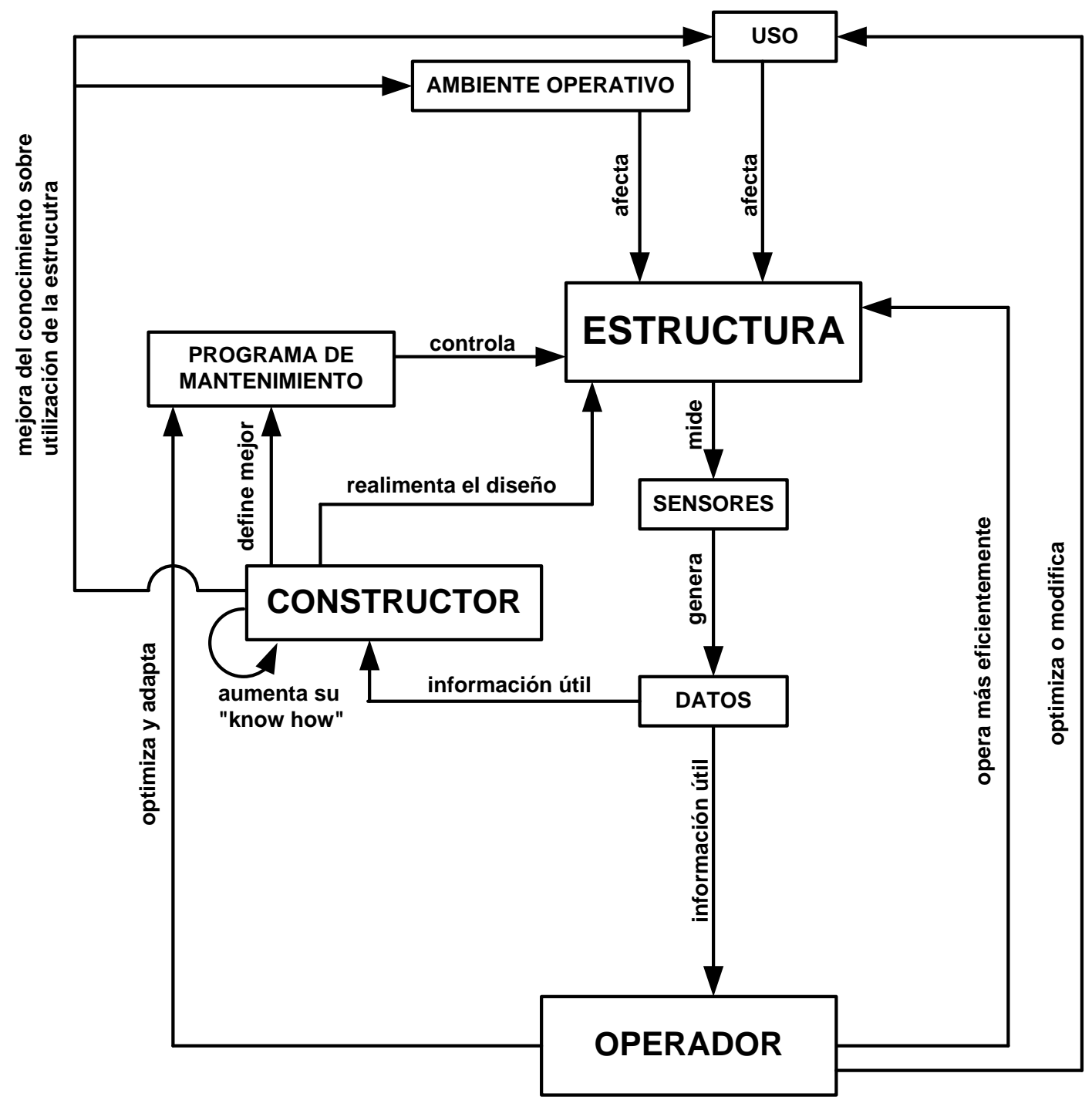

Figura 6 - SHM integrado en el proceso de mantenimiento de la estructura. mantenimiento ambiente diagnosis etc., sería como se encuadra en la actualidad

Desde un punto de vista práctico, no tan general como los anteriores y centrándonos en lo que realmente hace a bajo nivel. Se puede considerar el SHM una técnica dividida en cinco niveles de actuación [14][71]:

1. Existencia de un daño. Alerta sobre la presencia de una anomalía.

2. Localización del daño. Situación espacial de la anomalía detectada.

3. Caracterización. Tipo de anomalía detectada y su severidad

4. Prognosis. Evaluar el momento en el que dicha anomalía se vuelve crítica.

5. Reparación. Corrección de la anomalía. 
Esta definición se ajusta a la consideración que se tiene al SHM como una evolución de las técnicas de inspección no destructiva (NDI, Non-Destructive Inspection) [47], en la cual los sensores están permanentemente ligados a la estructura. Las técnicas NDI, cuyo objetivo es inspeccionar los elementos estructurales de una manera no intrusiva, asumen que los resultados de las inspecciones realizadas en la estructura son independientes entre sí, sin embargo, las técnicas SHM suponen que todos los resultados obtenidos de las inspecciones están relacionados entre sí, y además con la operación y el estado de la estructura. Algunos autores denominan esto como la evolución de una era puramente industrial de la inspección representada por las técnicas NDI a una era de la información representada por los sistemas SHM [65]. La normativa aeroespacial civil recientemente aprobada [68] define el SHM como el proceso de adquirir y analizar datos de sensores instalados permanentemente en la estructura para determinar su 'salud', es decir, su integridad. Según esta normativa, el hecho de que los sensores están permanentemente ligados a la estructura, es esta la característica que hace al SHM diferente de otros procesos para determinar la integridad. Este concepto ignora décadas de aplicación de la monitorización de la integridad estructural en el mundo militar. Sin embargo están trabajando en recomendaciones equivalentes para el mundo militar en proceso de estudio [69].

Las técnicas NDI permiten encontrar discontinuidades en solidos (en general corresponden con grietas en la estructura). Las técnicas SHM de diagnosis comparan la respuesta de la estructura en su estado actual a una solicitación externa, con su respuesta obtenida anteriormente, sobre la estructura sana; un cambio de respuesta significa un cambio en la estructura, presumiblemente un daño. Sin embargo las técnicas SHM de diagnosis no sirven para hacer una inspección de 'primer artículo', como si hacen las NDI, por lo que para establecer la situación de estructura "sana" siempre será necesario el apoyo de estas últimas.

Según lo que se ha dicho hasta el momento un SHM opera en un intervalo de tiempo, proporcionando durante toda la vida de una estructura un diagnóstico presente o previsto (si incluimos la prognosis), y en el espacio, ya que dicho diagnóstico se ofrece en términos de daños en los materiales constituyentes, partes o ensamblajes [66].

La definición no sería completa sin citar los elementos constitutivos que suele tener un SHM, para realizar las tareas necesarias que necesitan los cinco niveles de actuación [67]:

- Estructura.

- Tipo. Configuración geométrica, materiales, criticidad de la misma.

- Utilización de la misma. Bajo qué condiciones opera.

- Daños. Tipología, ocurrencias, severidad, detectabilidad. 
- Característica sensitiva al daño y medible.

- Sistema de adquisición de datos y sensores.

- Sistema de análisis de datos y toma de decisiones.

Estos elementos constitutivos servirán para diferenciar y definir sistemas SHM en diferentes ámbitos.

\section{4 Ámbitos de aplicación de la monitorización de la integridad estructural}

El SHM tiene multitud de ámbitos de aplicación según el tipo de estructura a que se aplique y el objetivo que persiga. En este epígrafe se tratan, de un modo general, los más importantes describiendo algunos ejemplos de aplicación práctica.

Atendiendo al tipo de estructura monitorizada y en líneas generales -ya que algunos tipos de estructuras pueden caer en más de una categoría según se consideren- los ámbitos de aplicación son los siguientes:

- Infraestructuras civiles tales como edificios, torres, puentes, túneles, estadios, puertos, minas, excavaciones, líneas férreas o los propios trenes, etc.

- Infraestructuras de producción energética o grandes factorías. Centrales nucleares, aerogeneradores, refinerías o presas entrarían en esta categoría.

- Estructuras marinas y offshore. Por ejemplo barcos, plataformas extractivas, cables marinos, aerogeneradores o cualquier estructura relacionada con el ambiente marino.

- Estructuras aeroespaciales. Aeronaves y vehículos espaciales

Normalmente cada grupo de estructuras perteneciente a un ámbito de aplicación suele tener problemas en común susceptibles de ser solventados por medio de la aplicación de SHM. A continuación se describe someramente cada uno de los ámbitos de aplicación y los problemas propios que comparten.

\subsubsection{Infraestructuras civiles.}

La monitorización siempre ha existido en ingeniería civil, pero solo cuando tiene por objeto evaluar el daño se denomina técnica SHM. La técnica clásica más empleada es el estudio experimental de sus modos de vibración, y a continuación hacer un 'model updating' o resolución del problema inverso: como modificar localmente la rigidez de elementos locales estructurales para mejor adaptarse a la realidad experimental.

Las infraestructuras civiles tienen problemas relacionados con asegurar su integridad ante eventos extremos como puede ser un terremoto. Desde otro punto de vista puede ser necesario 
validar un diseño nuevo o asegurar el progreso correcto de una nueva técnica constructiva. Otras infraestructuras, por el tipo de solicitaciones que tienen, necesitan asegurar en todo momento su integridad ante las mismas una vez construidas, bien sea por la dificultad de su modelado e inclusión en el diseño, bien porque no se pueden predecir directamente de un modo sencillo. Estos elementos comunes hacen necesario incluir de forma permanente sensores para medir el comportamiento de las mismas (y en algunos casos controlarlo). En algunos países la ley obliga a utilizarlos. Algunos ejemplos de sistemas SHM en infraestructura civil podrían ser los siguientes.

En edificaciones tales como torres o rascacielos es muy importante controlar el comportamiento desde la construcción de la misma. El control de la respuesta de la estructura ante cargas de viento o evaluar la integridad de la misma tras un terremoto son elementos que puede verificar un sistema SHM [63]. En el sudeste asiático y otras zonas sísmicas se evalúan los amortiguamientos de las estructuras de los rascacielos periódicamente para diagnosticar posibles problemas. Uno de los mejores ejemplos de aplicación sería la construcción y operación del Burj Khalifa [70] donde se ha utilizado SHM desde la construcción hasta el control de cargas de viento e incluso para conocer mejor la respuesta del edificio ante terremotos.

Los puentes son también susceptibles de ser monitorizados ya que son estructuras sensibles a eventos como puedan ser terremotos [111] o para validar las hipótesis efectuadas en su diseño sobre las solicitaciones que van a sufrir [82]. Uno de los primeros ejemplos es la monitorización del puente de Tacoma Narrows ante cargas de viento [63] y aumentar el conocimiento sobre fenómenos aeroelásticos. También son importantes los programas de control de la corrosión en estas estructuras puesto que suelen operar en ambientes de alta salinidad. En este último aspecto el tiempo juega un papel esencial puesto que cuanto más envejecida este la estructura del puente más importante es monitorizarla para asegurar su integridad.

En túneles, excavaciones o minas es importante mantener las deformaciones de la estructura dentro de unos límites tanto durante su construcción como en su operación. En túneles que pertenezcan a un sistema de transporte es fundamental asegurar su integridad en todo momento para mantener los niveles de seguridad para los viajeros o las mercancías. En excavaciones o minas hay que mantener su integridad ante las detonaciones o la modificación del sustrato en el que se integra la estructura [63]. Los túneles son casos muy interesantes, puesto que durante su construcción es imprescindible monitorizar la posición del mismo, y la trayectoria de la tuneladora, para asegurar que su construcción se efectúa según el diseño previsto. 
En presas, puertos, o estructuras offshore es importante monitorizar elementos en tiempo real tales como la presión ejercida por el agua, su nivel, las condiciones meteorológicas o eventos extremos como terremotos. Grandes factorías.

También entran dentro de esta categoría grandes infraestructuras científicas como puede ser la monitorización estructural del anillo del CERN [76] o la estructura de grandes telescopios astronómicos en los que es fundamental mantener la estructura dentro de unas deformaciones controladas para su correcta operación[77].

Edificios históricos como por ejemplo la Torre de Pisa [78], o el conjunto histórico de L'Alguila[79] también requieren monitorización estructural para asegurar la integridad de los mismos y permitir su durabilidad y accesibilidad.

Las infraestructuras civiles a monitorizar no tienen por qué ser todas fijas, ejemplo de ello, son por ejemplo los sistemas de transporte como trenes de alta velocidad también se monitorizan para asegurar que operan de modo seguro [80] y que no se producen accidentes debido a la degradación de la estructura no detectada por el sistema de mantenimiento clásico [81].

Finalmente, para este tipo de estructuras, se aplican conceptos novedosos como sistemas de sistemas SHM [72] en los que cada infraestructura tiene su SHM propio, adaptado a sus particularidades. Existiendo un sistema de evaluación sobre todos estos que gestiona la respuesta ante un evento común a las infraestructuras monitorizadas, por ejemplo un terremoto.

\subsubsection{Infraestructuras de producción energética}

Cualquier infraestructura de producción energética suele ser crítica, por lo tanto susceptible de ser monitorizada. Además son doblemente críticas, ya que si dejan de operar, no producen energía y pueden causar desabastecimiento energético y si se pone en riesgo su integridad pueden llegar a causar una catástrofe proporcional al tamaño y tipo de la planta.

Dentro de esta categoría y en primer lugar estarían las centrales nucleares, y en especial la vasija del reactor y el edificio de contención [82]. Es bien conocido lo que sucede cuando la estructura de la misma falla ya sea por un funcionamiento anómalo [73][74] o por un evento de magnitud extrema como puede ser un terremoto, o un maremoto [75]. Además, toda la información generada por la monitorización de la estructura suele utilizarse para el mantenimiento de la misma y para la verificación y validación del diseño.

Todo tipo de tuberías ya estén instaladas en centrales de todo tipo o pertenezcan a la distribución energética de gases e hidrocarburos también son susceptibles de ser monitorizadas con todo detalle[106].

Además de entran también en este grupo los aerogeneradores, centrales térmicas, termo-solares, etc. 


\subsubsection{Estructuras marinas y offshore}

Dentro de esta categoría existe una gran diversidad de tipos de estructuras. Pueden ser fijas, puertos, aerogeneradores, plataformas de extracción, laboratorios subacuáticos, diques de contención, etc., y también móviles como barcos, submarinos, etc., sin embargo, comparten una problemática común que las hace ser a sus estructuras susceptibles de ser monitorizadas. Operan en ambientes no estacionarios, difíciles de modelar, lo que hace su diseño complejo [63]. Estos entornos son los más complicados, especialmente para las estructuras fijas, donde históricamente, el entorno de operación, no ha sido considerado en profundidad. Estos ambientes son especialmente hostiles y de difícil acceso para su mantenimiento lo que hace necesario establecer un sistema de mantenimiento lo más autónomo posible y que permita anticipar lo que pueda ocurrirle a la estructura.

Normalmente, este tipo de estructuras suelen ser únicas lo que hace que los sistemas estén completamente adaptados a las mismas y sean de difícil generalización [63]. Aunque muchas de las ideas utilizadas en las mismas sí que sean de aplicación general.

Los ejemplos más interesantes para este tipo de estructuras quizá sean las plataformas de extracción de gas o petróleo, en el mundo civil, y ciertos tipos de barcos en el mundo militar.

En el primero de los casos, las estructuras offshore, sea cual sea su función, se controla especialmente la respuesta estructural en el ambiente marino. La exposición prolongada a un ambiente hostil, con gran variabilidad, corrosivo y además susceptible de recibir impactos de otras naves circundantes, combinado con la extracción de productos potencialmente explosivos hace sus estructuras candidatas a ser monitorizadas [85]. De hecho en algunos países como Noruega es obligatorio desde los años 70 [63].

En el segundo caso se encuentran múltiples ejemplos publicados. En EEUU la ONR (Office of Naval Research) introduce la monitorización de la estructura dentro de los programas de mantenimiento. Utiliza estas técnicas en sus más modernas naves para la detección temprana de daños y asegurar la máxima disponibilidad de las mismas [83]. En otros casos se aplica, dentro del mismo ámbito para la extensión de vida operativa de las naves o para asegurar la operación segura en estructuras muy demandadas. Uno de los casos de aplicación más completos se puede encontrar en como gestiona la monitorización de las estructuras la Navy de los EEUU, incluyendo tanto barcos como aeronaves [86]. Se tienen en cuenta desde las cargas que actúan sobre la estructura hasta los efectos de la corrosión, los modos de fallo, su predicción y la introducción en los programas de mantenimiento de las estructuras.

\subsubsection{Estructuras aeroespaciales}

Dentro del mundo de las estructuras aeroespaciales se pueden encontrar múltiples ejemplos de SHM ya se centren en el uso, la diagnosis, la prognosis o cualquier combinación de ambas. Se 
describirán atendiendo a los diferentes tipos de vehículos existentes, en este caso todas las estructuras son móviles.

En primer lugar, y por ser uno de los casos de mayor éxito y donde primero se implantaron están los HUMS, Health and Usage Monitoring Systems, de helicópteros o aeronaves de ala rotatoria en general. En este caso se ha combinado uso, diagnosis y prognosis, de ahí el nombre que se suele utilizar, HUMS. Este tipo de sistemas se vienen aplicando desde los años 70 del siglo 20 y son unos de los que mayor recorrido tiene y por eso han alcanzado mayor desarrollo [13]. En helicópteros se puede encontrar desde monitorización de cargas [88], que sería un caso combinado de uso con prognosis, hasta diagnosis de funcionamientos anómalos[32] o diagnosis directa sobre la propia estructura[95].

El caso de los aviones o aeronaves de ala fija es más limitado, comparado con los anteriores. Aunque ha existido un gran desarrollo de los sistemas de monitorización de uso [12], y de prognosis, fundamentalmente monitorización de fatiga [89], todo ello en el campo militar [11]. Estos se vienen aplicando con éxito desde el principio de la aviación y en general son exigidos por las normativas militares [90], mención especial merecen los programas de monitorización de cargas u OLM (Operational Loads Monitoring) que han venido alimentado estos sistemas con información para su desarrollo [96]. Gran parte de la información derivada de los programas OLM es o debería ser la base de la introducción del SHM en aeronaves tanto civiles como militares [97]. En el campo civil y en la diagnosis de daño ha habido menos aplicaciones históricamente, aunque en las últimas décadas el desarrollo está siendo exponencial dando lugar a la aparición de normativas y recomendaciones específicas para este tipo de sistemas [68] y al aumento del número de patentes relacionadas con SHM [91][92][93]. Esto se debe fundamentalmente a factores como la mayor solicitación de las estructuras con nuevos diseños y materiales o a los intentos de extensión de vida de las mismas debido al envejecimiento de las flotas y la aparición de nuevos problemas como el Widespread Fatigue Damage [94][105].

Finalmente repasamos algunas de las aplicaciones SHM dentro de las estructuras espaciales, quizá uno de los puntos más interesantes dentro de este ámbito de aplicación debido a la grandísima diversidad estructural [118] y de ambientes operativos [119]; las estructuras espaciales, son con diferencia, las más solicitadas, en casi todos los casos y las que tienen ambientes de operación más adversos [98]. Empezamos con los vehículos de transferencia orbital ya sean reutilizables como el Shuttle o no, como cualquiera de las cápsulas de reentrada. En estos casos tenemos sistemas SHM de detección de impactos en las superficies térmicas de reentrada, susceptibles de recibir impactos durante el lanzamiento, en caso del Shuttle o de micrometeoritos durante la órbita [100]. Estos impactos podrían dañar dichas superficies y poner en riesgo la integridad estructural de la nave espacial durante la reentrada como ocurrió en el caso del transbordador espacial Columbia [101]. Otro ejemplo, también para el 
transbordador espacial, es uno de los primeros sistemas SHM, el de la integridad del motor, que aunque está aplicado a un sistema es un ejemplo claro de control de la integridad estructural [99]. En el caso de los cohetes existe otro tipo de SHM, que es el que controla la forma de la estructura durante el lanzamiento del mismo, es lo que se denomina Shape Sensing, y es de gran utilidad tanto para asegurar que se encuentra dentro de unos límites de operación seguros como para ayudar al sistema de guiado [100]. Volviendo al sistema SHM de detección de impactos de micrometeoritos, estos también se aplican en la Estación Espacial Internacional, no tanto para asegurar la integridad estructural de la misma, sino para asegurar la habitabilidad de la misma en todo momento [100]. Finalmente, estructuras como satélites o sondas espaciales, tienen una característica que hace un sistema SHM fundamental, la operación durante largos periodos de tiempo sin intervención humana, lo que hace necesario implementar una lógica de control en la propia nave, de modo que, ésta, conozca en todo momento la situación de su estructura y detecte posibles anomalías estructurales que le impidan cumplir con su misión. Ya sea el apuntado de una antena, el control térmico espacial, o el impacto de micrometeorito con algún elemento de la estructura [102].

En lo sucesivo todo lo que se refiera a sistemas SHM, aun siendo de aplicación general a cualquier tipo de estructura (con las correspondientes modificaciones) se centrará fundamentalmente en estructuras típicamente aeronáuticas. 


\subsection{Evolución histórica y estado del arte}

Las aplicaciones SHM aparecieron ya a principios del siglo XX y han ido evolucionando en sus diferentes tipos hasta la actualidad.

Desde el comienzo de la aviación comercial los temas referidos a la seguridad del vuelo y la integridad estructural han tenido un papel clave en los procesos de diseño, cálculo, construcción y control de operación de las aeronaves [1][3][4]. Secundariamente y ligado a este ha evolucionado una filosofía del menor coste de operación posible manteniendo unos niveles de seguridad muy estrictos [1][4]. Uno de los mayores costes de operación de una aeronave son los gastos derivados de las acciones de mantenimiento preestablecidas respecto a unos criterios siempre muy conservativos [5]. Su objetivo es asegurar que la estructura siempre está en perfectas condiciones de operación [6].

El control de las operaciones de mantenimiento ha vendido evolucionando desde mediados del siglo pasado [7]. Para aeronaves civiles controles de horas de vuelo o ciclos de presurización además de los ACMS (Aircraft Condition Monitoring System, Controlan desde el estado de los sistemas de la aeronave y a nivel de estructura detectan aterrizajes dañinos, Hard Landings). En el caso de la aviación militar por los mismos elementos y en ciertas ocasiones por diversos tipos de sistemas de monitorización estructural. Las acciones de mantenimiento se apoyan por una serie de técnicas de inspección no destructiva, NDT-NDI (NDT, Non-Destructive Techniques, NDI, Non-Destructive Inspections. Técnicas de inspección no destructivas), utilizadas para las revisiones estructurales previstas[8].

La monitorización de la integridad de estructuras (SHM) aeronáuticas consiste en un conjunto de técnicas orientadas a la evaluación de la presencia de daños en las mismas y cómo estos afectan a su integridad. La información generada se utiliza para tomar una decisión relativa a las operaciones de mantenimiento requeridas [9].

En algunos casos los SHM no son más que una evolución de las técnicas de inspección no destructiva introduciendo sensores en la estructura [8][15][27]. De este modo se puede controlar en todo momento la presencia de daños y no únicamente en las paradas de mantenimiento o inspecciones visuales, y así se aplicar las operaciones de mantenimiento cuando se detecten daños. Esta es la principal ventaja de estos sistemas, se denomina Condition Based Maintenance (CBM).

El CBM tiene una doble utilidad en cuanto a seguridad y reducción de costes se refiere[4]. En primer lugar permite la detección de daños accidentales o no previstos en las hipótesis de diseño que, por su carácter aleatorio, pueden no ser detectados durante las operaciones de mantenimiento habituales. En segundo lugar se puede evaluar si en los elementos estructurales 
cuya inspección o sustitución están planeadas, están realmente dañados y son necesarias dichas acciones.

Por otro lado, ciertos tipos de sistemas de monitorización permiten evaluar, utilizando históricos de cargas o parámetros de vuelo, si la operación de la aeronave ha sido más o menos severa para la estructura que lo que se supuso en su diseño y ensayos [11]. Consecuentemente se puede acelerar o ralentizar la evolución de los daños previstos y ajustar el mantenimiento a cada circunstancia particular [12][25]. Esto es relativamente poco importante en aviones civiles ya que su uso suele ser muy similar al previsto. Sin embargo es un gran problema en aviación militar ya que puede existir una gran dispersión entre las misiones de diseño de la aeronave y las de operación real. Es igualmente útil cuando se construyen derivados militares de aviones civiles [13] ya que no se van a usar para lo que fueron diseñados originalmente, como por ejemplo en aviones cisterna, patrulla marítima, AWACS . Algunos países exigen en su normativa militar sistemas de monitorización, aunque no se concretan de que tipo, simplemente se indica que debe haber un control de operación en servicio de este tipo de aeronaves.

Desde un punto de vista práctico un sistema de monitorización de la integridad estructural es altamente multidisciplinar ya que involucra multitud de campos tecnológicos [9]. Implica introducir sensores en la estructura y o captar parámetros de operación de la aeronave que deben grabados a bordo por sistemas de adquisición [14]. Posteriormente descargar todos esos datos para su posterior análisis en tierra [14]. El siguiente paso es la búsqueda de ciertas características en los datos adquiridos que sean sensibles al daño estructural que se quiera monitorizar para alimentar modelos físicos (model-based) [14][9] o estadísticos (data-driven) [9][14] para la extracción de información relativa al estado de la estructura en diferentes niveles:

En el siguiente apartado se muestra una cronología resumida y a continuación se muestra una breve disertación sobre la situación actual

\subsubsection{Cronología}

Los sistemas de monitorización de la integridad estructural han estado presentes desde que se comenzaron a fabricar aviones. Pronto, se hizo patente, que era necesario controlar de algún modo el estado de la estructura en función de la operación del avión [7]. En la Figura 7 se muestran algunos de los hitos más importantes hasta la actualidad desde las técnicas de monitorización más rudimentarias hasta el SHM como se concibe en la actualidad. 


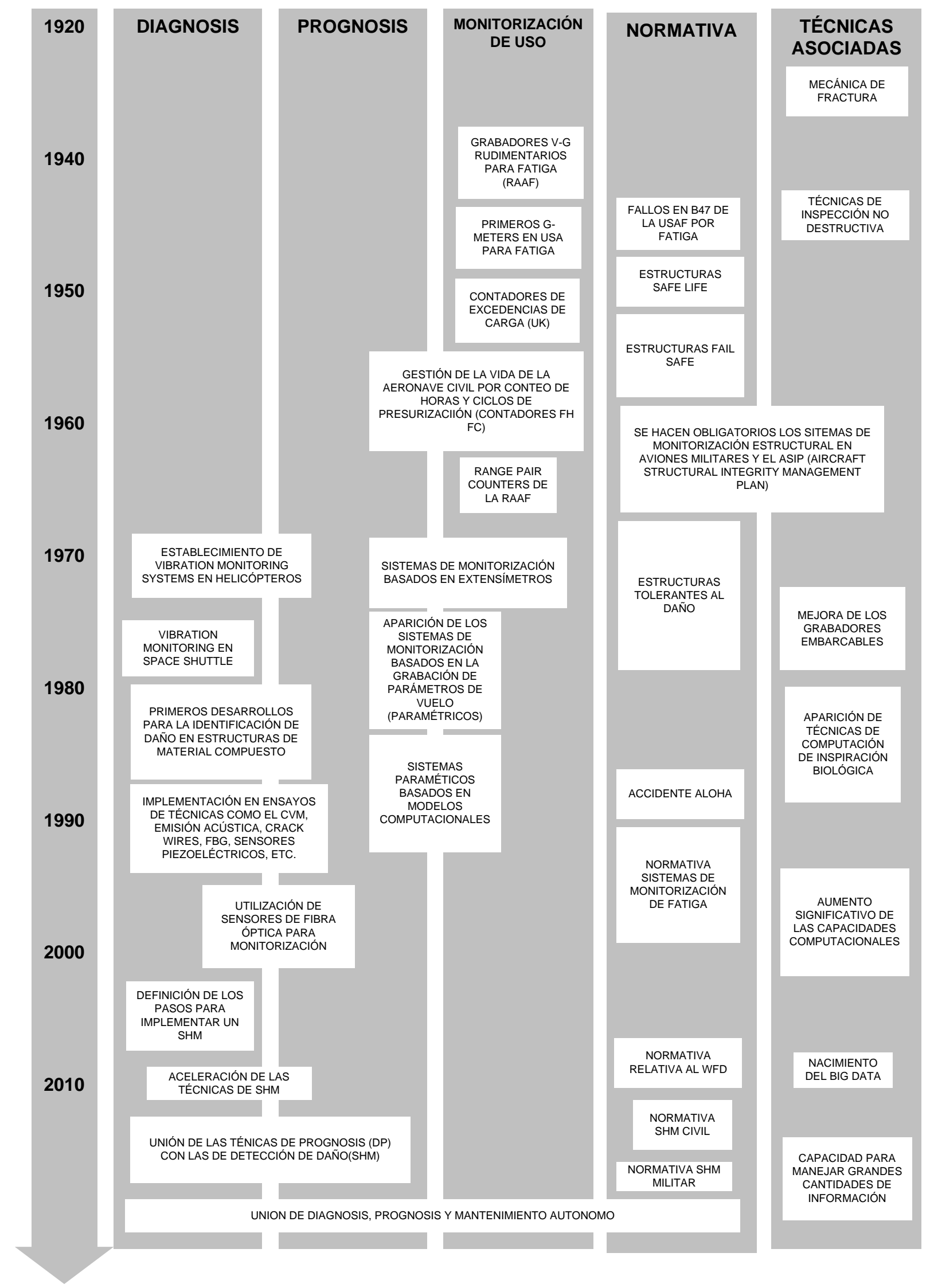

Figura 7 - Evolución histórica de las técnicas de monitorización de la integridad estructural de estructuras aeronáuticas[22] [96]. 
La monitorización de uso es la primera que aparece. Los primeros sistemas aparecen en los años 40 del siglo pasado y prácticamente hasta los años 80 están basados en grabadores para el conteo de excedencias de carga y controles de uso basados en parámetros de vuelo en el caso de los aviones militares, o control de ciclos de presurización y horas de vuelo para los civiles. Estos indicadores sirven para controlar los umbrales e intervalos de inspección establecidos para esa aeronave basándose en unas hipótesis de diseño[96].

Los sistemas de prognosis aparecen posteriormente a los de uso soportándose en los datos obtenidos por estos últimos. A partir de mediados de los años 70 para helicópteros, y principios de los 80 para los aviones militares, se introducen extensímetros en la estructura lo que permite un mejor control en operación de la misma. Desde los años 80 la evolución se ha centrado fundamentalmente en la mejora de los sistemas paramétricos mediante nuevos modelos validados mediante sistemas extensométricos. Uno de los casos de mayor éxito es la monitorización de cargas de helicópteros que en los últimos años se ha combinado con las técnicas de inteligencia artificial obteniendo resultados interesantes [108]. En el caso de los aviones también existen actualmente sistemas en servicio con similares características [113] [112]. Como se ha visto anteriormente los sistemas de prognosis se fundamentan además de en los datos de uso de la aeronave, en el estado actual de la misma. Actualmente este tipo de sistemas utilizan el estado actual de la misma basado en los datos de diseño teóricos y su futuro pasa por utilizar los datos de estado actual de la estructura proveniente de un sistema de diagnosis.

A principios de los años 80 empiezan a aparecer los primeros estudios sobre sistemas de monitorización de diagnosis. Éstos, no solo estiman la posible presencia de daños en la estructura sino que los detectan. Y ya en las últimas dos décadas se ha producido un notable desarrollo de las técnicas de monitorización no sólo orientadas a la detección de daño sino también, en combinación con los sistemas anteriores, a la prognosis de daño, a la estimación de cómo va a evolucionar el daño detectado [23].

La normativa relativa a los sistemas de monitorización de la integridad estructural ha ido surgiendo como consecuencia de accidentes inesperados la mayoría de las veces. A parte de la normativa relativa a la fatiga y tolerancia al daño de la estructura en los últimos años se ha desarrollado normativa específica para sistemas de monitorización. En primer lugar en el mundo militar y relativa a los sistemas de monitorización de fatiga [180][69]. Y posteriormente en aviación civil relativa ya directamente al SHM, en lo que sería sistemas de diagnosis[68].

En cuanto a las técnicas asociadas, los sistemas de monitorización han estado ligados desde su aparición al estado de la tecnología de los sistemas aeronáuticos y a las capacidades de análisis de datos disponibles en cada momento. Según fueron apareciendo sistemas grabadores de mayor 
capacidad y ordenadores con un mayor rendimiento, que permiten hacer un análisis posterior de toda esa información fueron evolucionando estos sistemas haciendo posible la implementación de sistemas de uso, prognosis y diagnosis.

Como se puede comprobar en los párrafos anteriores los sistemas de monitorización estructural no son un elemento aislado sino que han ido evolucionando ligados a elementos como la tecnología disponible en cada época, los cambios de normativa y las necesidades particulares de las nuevas estructuras. Finalmente, con esta información disponible se puede predecir cómo va a afectar el daño a la integridad de la estructura y si es necesaria una acción de mantenimiento.

\subsubsection{Situación actual}

En el momento actual estos sistemas presentan un notable desarrollo en todos los niveles debido a los beneficios potenciales en cuanto a la reducción de costes de operación de la aeronave manteniendo los niveles de seguridad requeridos e incluso incrementándolos[16][17]. Sin embargo, es aún una tecnología emergente que necesita amplio desarrollo en todos sus campos tecnológicos especialmente en los modelos que interpretan los datos obtenidos de los sensores introducidos en la estructura[18][19].

En lo que respecta a los sistemas de monitorización de la integridad estructural aeronáutica, existen tres grandes líneas de trabajo convergentes, ya que son complementarias [5].

1. Usage monitoring o monitorización de uso. Esta línea incluye toda la adquisición de datos relativa a la operación de la aeronave. Estos incluyen parámetros de vuelo, ambiente de operación, cargas (OLM, Operational Loads Monitoring). Actualmente se aplica aeronaves militares principalmente para estimar los efectos de la operación de la misma sobre los diferentes componentes de la misma, se suele denominar también [24][25][26]. También comienza a aplicarse a aeronaves civiles para optimizar su mantenimiento.

2. Damage diagnosis o diagnosis de daño (SHM). Incluye las técnicas de detección y cuantificación de daño mediante sensores integrados en la estructura. En estos momentos aún no se aplica a aeronaves completas sino a elementos muy particulares de la estructura. Aquellos elementos donde se conoce muy bien el modo de fallo y por lo tanto su detección, evaluando posteriormente los efectos sobre el resto de la aeronave mediante el programa de mantenimiento clásico, se suele denominar Hot-Spot Monitoring [8][28].

3. Damage prognosis o prognosis de daño. Esta tercera línea se alimenta de las dos anteriores posibilitando dos modos de trabajo. Basándonos en la monitorización de uso y utilizando los daños teóricos y experimentales provenientes de la certificación de la aeronave y los ensayos se puede calcular la vida consumida por una aeronave y estimar la vida remanente teórica [11]. Este modo de trabajo ya está implementado dentro de los sistemas actuales de monitorización de uso convirtiéndolos también en sistemas de 
prognosis de daño [11]. Si en el caso anterior se complementa con diagnosis de daño real en la propia aeronave se obtiene el segundo modo de trabajo que se encuentra actualmente en desarrollo [5]. Esto no ha tenido aún aplicación comercial salvo en helicópteros con los sistemas denominados HUMS, Health and Usage Monitoring Systems [4][10][32].

En paralelo a las tres líneas de desarrollo existen grupos de trabajo y discusión para generar la normativa relativa al impacto este tipo de sistemas dentro de los programas de mantenimiento [47] y las implicaciones derivadas de su uso [48][16][17][18][19]. De hecho ya existen prácticas recomendadas para sistemas SHM civiles [68] y se encuentran en desarrollo las equivalentes para el mundo militar [69] que complementarían a la normativa ya existente relativa a sistemas de monitorización de fatiga [180]. Actualmente se habla de una evolución de la era industrial de la detección de daño mediante técnicas de inspección no destructiva a la era de la información del SHM [65]. En este contexto aparece el objetivo final, que consiste en pasar de un mantenimiento programado a lo que se denomina Condition Based Maintenance o mantenimiento a demanda [10]

De aquí en adelante nos vamos a centrar en las técnicas SHM de detección de daño o Damage Diagnosis. Es por ello que siempre que nos refiramos a SHM será a este subtipo y como ya se ha comentado anteriormente dentro del ámbito de las estructuras aeronáuticas.

La evolución actual ha permitido generar una serie de axiomas (no en el sentido matemático estricto sino a modo de normas generales) aplicables al SHM que serán de gran utilidad a la hora de caracterizar los diferentes tipos de SHM y su aplicación [122]. Revisamos aquí algunas de ellas que serán utilizadas a lo largo de la tesis.

Primer axioma. Todos los materiales presentan imperfecciones, de tal modo que se pueden considerar dañados. No existen materiales ni estructuras perfectas. A este axioma habría que añadir un corolario indicando que los daños comprometen la integridad estructural y por ello los estudiamos.

Segundo axioma. La evaluación del daño requiere una comparación entre dos estados de la estructura. En nuestro caso la comparación entre un estado considerado sano, en el cual hay daños en la estructura que no comprometen su integridad, y un estado dañado, que compromete la integridad de la misma (como ya se ha mencionado anteriormente presente o futura).

Tercer axioma. La existencia y localización (niveles 1 y 2 del SHM) puede realizarse de manera no supervisada. Sin embargo la caracterización y evaluación de la severidad del daño (nivel 3 del SHM) debe realizarse de modo supervisado. La supervisión o no supervisión se discutirá ampliamente en el apartado de los modelos de inteligencia artificial.

Cuarto axioma, parte primera. Los sensores disponibles actualmente no miden daño, sino que miden alguna característica sensible al daño, Damage Sensitive Feature (DSF). Por ejemplo, 
tampoco tenemos sensores que midan directamente el esfuerzo en una estructura directamente sino que se mide la deformación de la misma, se hacen hipótesis sobre la relación esfuerzosdefomaciones y se obtienen los esfuerzos estructurales.

Cuarto axioma, parte segunda. Cuanto más sensible es la DSF a la presencia del daño, más lo es a la variación inducida por las condiciones ambientales y operacionales, Environmental and Operational Conditions (EOC). Este axioma se puede juntar con el sexto axioma, indicando que cuanta mayor sensibilidad tiene la DSF al daño más sensible es al ruido.

Quinto axioma. Tamaño y tiempos característicos de la evolución del daño definen el SHM a utilizar para su detección. De nuevo se puede juntar con el séptimo axioma que establece una proporcionalidad inversa entre el tamaño del daño a detectar y la frecuencia de trabajo de la técnica SHM seleccionada.

A lo largo de la tesis se irán utilizando esto axiomas para definir los elementos del sistema SHM y cuando sea necesario se efectuará una descripción más detallada de cada uno de ellos. 


\subsection{Técnicas de SHM}

Vista la evolución histórica y la situación actual se pasa a describir los diferentes tipos de SHM de diagnosis de daño (Hot-Spot Monitoring) disponibles en la actualidad.

Existen diversas maneras de clasificar las técnicas SHM. La mayoría de técnicas de SHM están muy enfocadas al elemento a monitorizar [33]. En función de los tipos de daños que sean más habituales en un elemento de la estructura se utilizará una técnica u otra [29]. Habrá zonas sensibles a fatiga, daños accidentales, corrosión, sobrecargas, impacto de rayo, etc., y cada una de ellas tendrá una su manera óptima de monitorizar.

Históricamente y considerándolas como una evolución de las técnicas de inspección no destructiva se clasifican del siguiente modo [29]:

- Técnicas derivadas de NDT:

- Con origen en la inspección ultrasónica:

- Emisión acústica. Detección de impactos utilizando el patrón de ondas elásticas que se produce durante los mismos.

- Basadas en piezoeléctricos [30]. Detección de daños mediante ondas elásticas guiadas [31].

○ Con origen en Eddy Current:

- Técnicas de inducción [8]. Detección de grietas mediante ondas electromagnéticas.

- Otros:

- Sensores de fibra óptica. Redes de Bragg.

- Crack wires.

○ Extensímetros.

○ CVM. Comparative Vacumm Monitoring.

Sin embargo esta clasificación es incompleta ya que el SHM no es únicamente una evolución del NDT sino que incluye muchos más aspectos relacionados con el tratamiento de la información. Es por ello que según como sea el análisis de los datos y la interpretación de los mismos mediante modelos se pueden clasificar las técnicas SHM en dos grandes grupos [14][9]:

- Model-based SHM. Fundamentado en modelos físicos [34]. En este caso los sensores alimentan con datos un modelo físico que ofrece información acerca del estado de la 
estructura. Únicamente son válidos para elementos estructurales muy sencillos ya que los modelos de estructuras con la influencia de la presencia de daño alcanzan gran complejidad debido a la gran diferencia de escalas características de evolución del daño y comportamiento estructural. Imaginemos por ejemplo un modelo de elementos finitos y cómo cambian sus resultados en función de un pequeño defecto.

- Data-driven SHM. Fundamentado en modelos estadísticos. Aquí el modelo se genera a partir de los propios datos medidos directamente en la estructura por los sensores. Conceptualmente es más sencillo de aplicar que en el caso anterior pero se paga el peaje de un análisis más exhaustivo de los datos que alimentan los modelos y la interpretación de los resultados del mismo [35][36][37][38][39][40][41].

También según domo se ajusten dichos modelos se obtiene otra clasificación [122]:

- Supervisado. En un modelo supervisado se proporciona información al modelo sobre situaciones con y sin daño. A partir de estos datos el modelo genera una suerte de clasificador en el que si se le presentan situaciones semejantes las clasificará como sanas o dañadas.

- No supervisado. En un modelo no supervisado únicamente se presenta información con daño. No se indica al cual es la influencia del daño sobre la DSF, sino que se deja que el propio modelo infiera dicha relación a partir de los datos de los datos medidos y reglas generales.

Otro modo de clasificar las técnicas SHM es en función del tamaño de daño que son capaces de detectar, es decir en función de su escala dimensional (Figura 8) característica o la detectabilidad (Figura 9) (si consideramos la herencia NDT) [50][103].

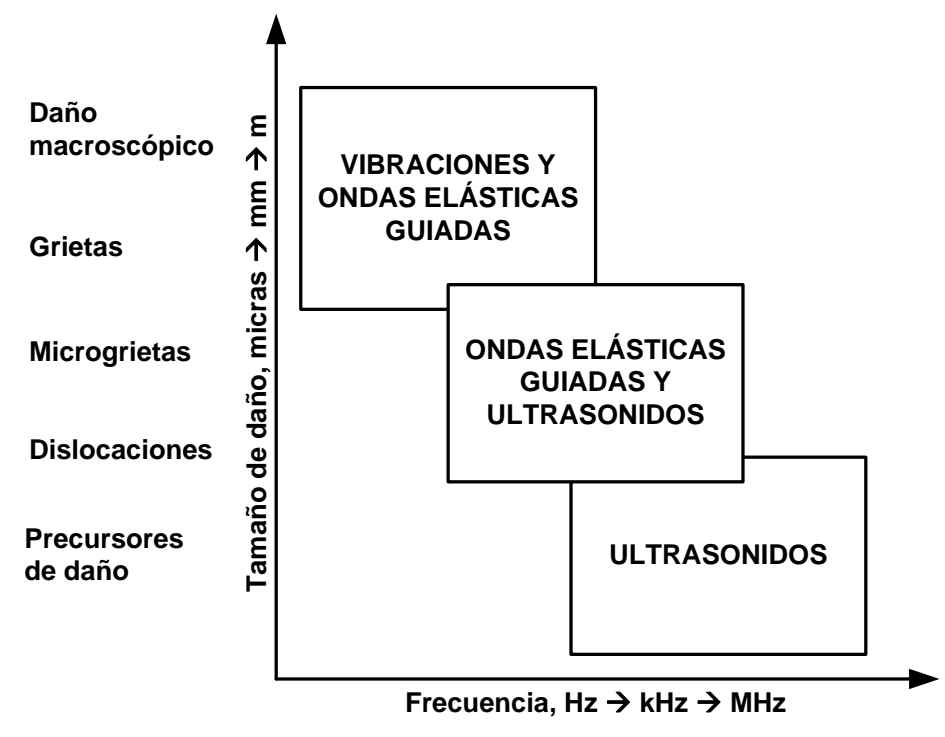

Figura 8 - Diferentes tipos de SHM en función escalas temporales y dimensionales [50]. 


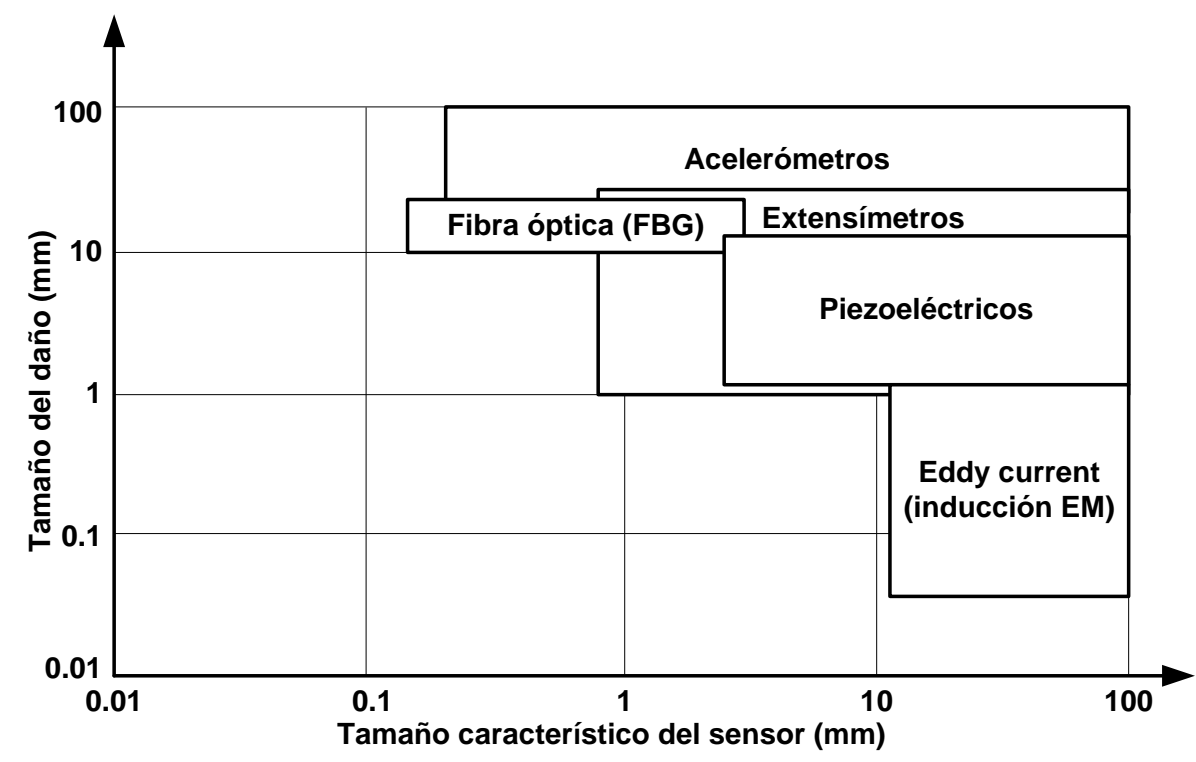

Figura 9 - Técnicas SHM en función de la detectabilidad [103].

Otra manera de clasificar las diferentes técnicas SHM consiste en evaluar la parte de la física que hay detrás de cada una de ellas [120]. Teniendo en cuenta esto se genera el mapa conceptual de la Figura 10 en la que se encuadran desde métodos acústicos basados en ondas elásticas y sensores piezoeléctricos hasta métodos electromagnéticos fundamentados en corrientes inducidas.

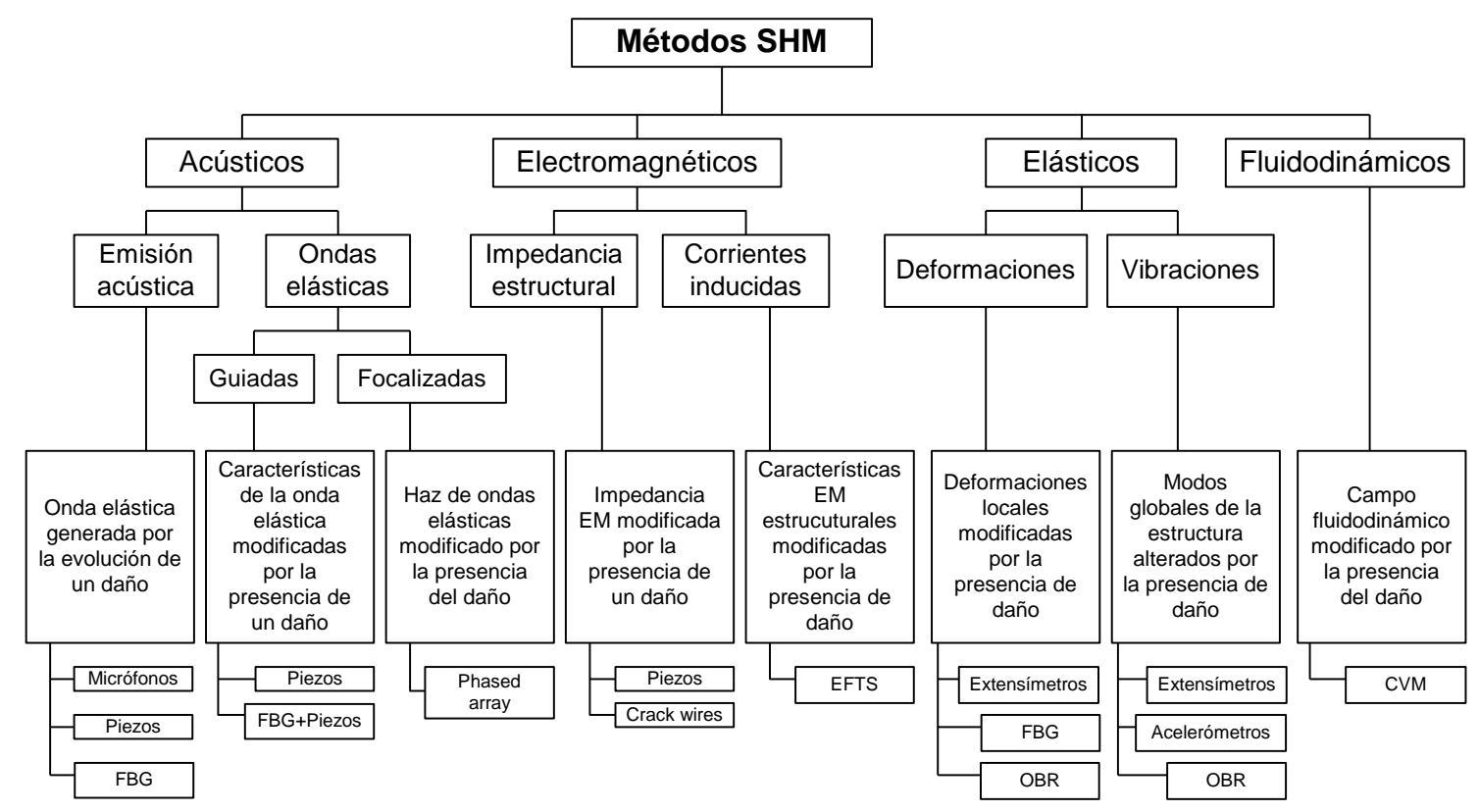

Figura 10 - Figura de tipos de SHM [120]

En esta Tesis el tipo de SHM que se realizará será mediante sensores piezoeléctricos y ondas elásticas guidadas. Si bien es cierto que nunca se utiliza un único sensor en el SHM puesto que es necesario medidas adicionales para compensar efectos ambientales y operacionales, como se comprobará más adelante. 
Dentro de las características físicas también se puede clasificar según sus escalas características, como se indica en el quinto axioma del SHM:

- Tiempos característicos.

- Largos. Un sistema para controlar la evolución de una grieta tendría tiempos característicos de años. Muchas veces de un orden equivalente a la vida operativa de la estructura.

- Cortos. Un sistema de alerta y localización de impactos tendría tiempos característicos muy pequeños del orden de la duración del impacto, apenas unas decenas de ms.

- Longitudes características. Dependiendo fundamentalmente de la criticidad del daño.

- Grandes. Allí donde la tolerancia al daño permita daños de tamaños considerables. Por ejemplo el control de caminos de carga múltiples en estructuras donde la estructura tiene que aguantar las solicitaciones con uno de los caminos de carga totalmente rotos.

- Pequeñas. En este caso los daños permitidos serían mínimos, por ejemplo una grieta en el fuselaje que pueda derivar en una despresurización.

Otra clasificación posible es atendiendo a si el sistema se ocupa de vigilar la integridad de la estructura completa o de una zona determinada:

- Local. En este caso se evaluaría la integridad de un detalle estructural problemático. Los parámetros a controlar serían locales.

- Global. Toda la estructura de la aeronave se evaluaría. Se utilizan parámetros globales de la estructura para evaluar su integridad.

Según la manera en que monitoriza la estructura:

- Pasivo. Una técnica SHM de este tipo no perturba la estructura para hacer la medición únicamente mide su respuesta en operación. Por ejemplo un sistema de emisión acústica. En este caso la entrada que tiene la estructura es, a priori, desconocida.

- Activo. Perturba la estructura y evalúa posibles cambios en la respuesta. En este caso la perturbación, la entrada que se hace a la estructura es conocida.

Como se puede ver existen muchos tipos de SHM y multitud de maneras de clasificarlos. 


\subsection{Aplicación de SHM en estructuras aeronáuticas}

Teniendo en cuenta que estamos trabajando con estructuras aeronáuticas existe una jerarquía que permite definir el tipo de sistema SHM idóneo para cada tipo de estructura de entre todos los que se han definido.

Habrá que tener en cuenta los siguientes pasos:

1. Tipo de estructura.

2. Tipos de daño que afectan a la integridad dicha estructura.

3. Característica sensitiva al daño o Damage Sensitive Feature (DSF). Sería alguna característica o parámetro medible de la estructura modificado por la presencia del daño

4. Firma de daño. De qué modo el daño influye en la característica sensible al daño.

Una vez definidos estos elementos estaríamos en condiciones de seleccionar una estrategia de monitorización. Si particularizamos al caso que nos ocupa, seleccionar una técnica SHM u otra.

En los siguientes apartados se irán recorriendo cada uno de los puntos

\subsubsection{Estructuras aeronáuticas}

En primer lugar nos fijamos en las estructuras aeronáuticas. Cada parte de la estructura se verá afectada por problemas diferentes, como se puede ver en la Figura 11.

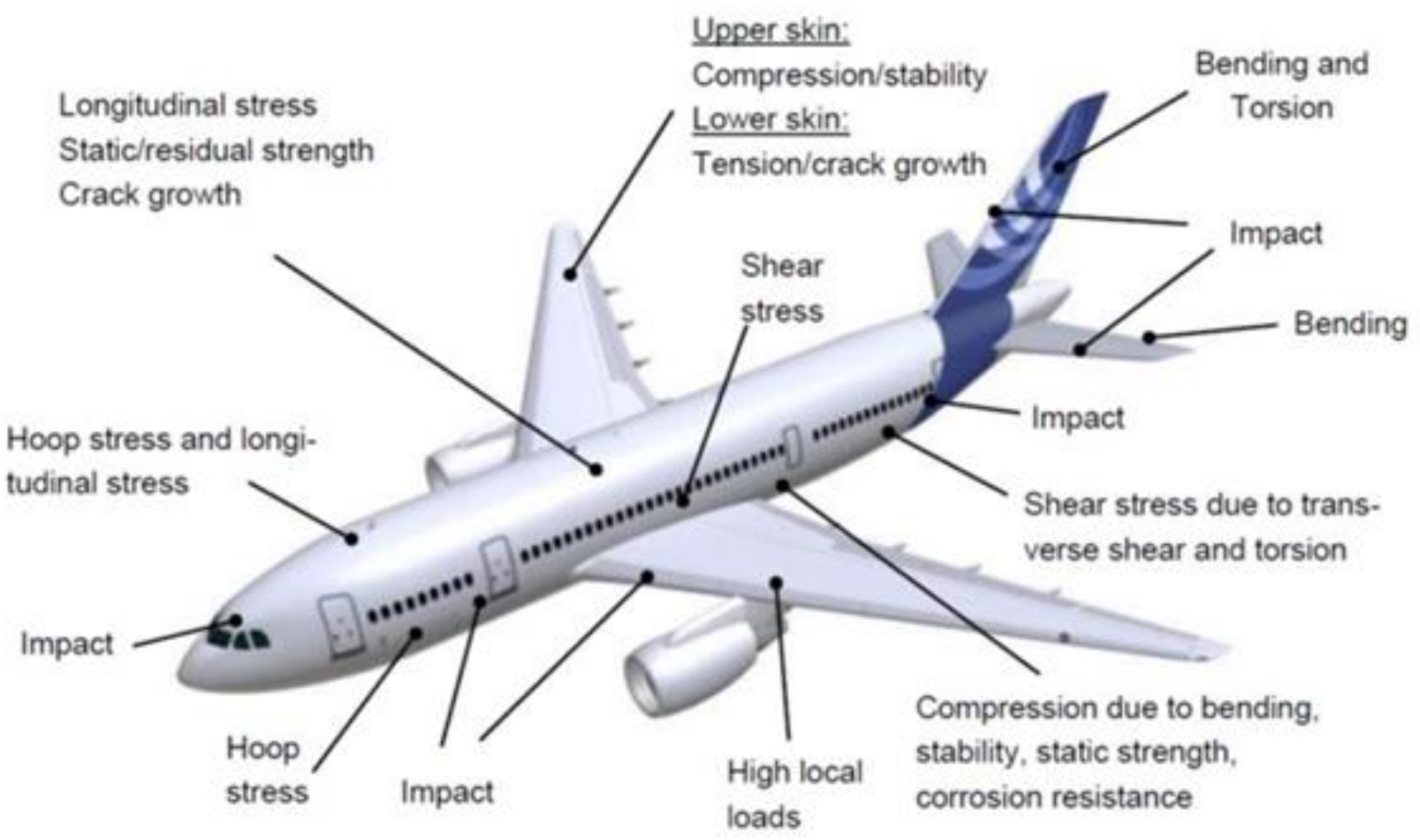

Figura 11 - Diferentes partes de la estructura de una aeronave y sus problemas asociados [125]. 
Además no todas las partes de la estructura tienen una igual criticidad frente la integridad global de la misma. Existe una jerarquía en la que se diferencia entre estructura primaria, secundaria, etc. en función de si el fallo de la misma puede provocar un fallo global [121]. Esto implica que habrá zonas más susceptibles de ser monitorizadas que otras en función del criterio de diseño que se haya seguido en la misma [121].

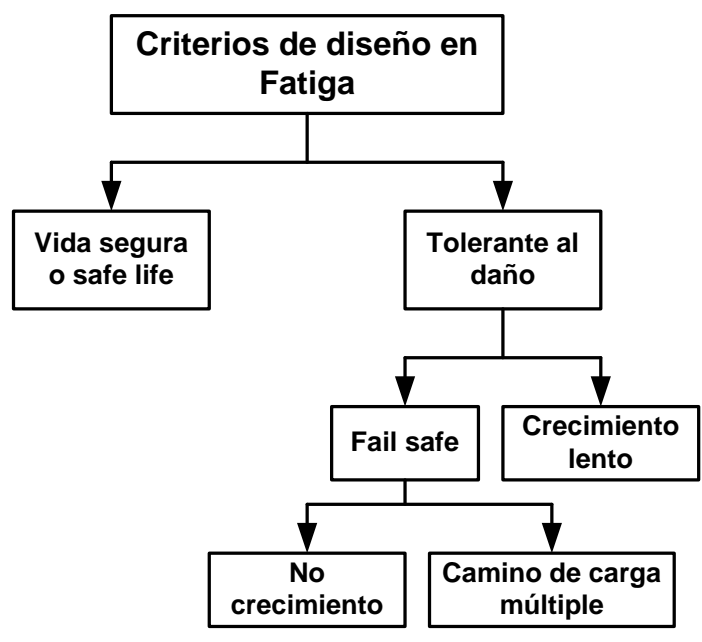

Figura 12 - Criterios de diseño en fatiga de una estructura aeronáutica [121].

Cada tipo de estructura tendrá sus daños asociados, así que, una vez seleccionada la estructura que queremos monitorizar hay que revisar los tipos de daños que afectan a la misma.

\subsubsection{Daños en estructuras aeronáuticas}

Un daño en una estructura aeronáutica puede considerarse como algún cambio en el material, propiedades geométricas, conectividad o condiciones de contorno de la misma que afecta de manera adversa al funcionamiento actual o futuro[122].

De modo general los daños que afectan a las estructuras aeronáuticas caen dentro de las siguientes categorías:

- Daño accidental. Daño fortuito y no predecible que se produce en la estructura. Por ejemplo un impacto de pájaro.

- Daño por fatiga. Daño predecible que se produce en la estructura derivado de la acción de cargas cíclicas sobre la misma. Por ejemplo una grieta que aparece en el borde de un agujero.

- Daño ambiental. Daño no predecible que se produce en la estructura por la acción del medio ambiente en el que opera la estructura. Por ejemplo la corrosión.

- Daño operacional. Daño fortuito no predecible que se produce en la estructura derivado de una operación anómala de la misma. Por ejemplo una sobrecarga en la maniobra de aterrizaje. 
Esta clasificación no genera grupos disjuntos sino que los daños pueden caer en más de una categoría. Por ejemplo la corrosión bajo tensiones es un fenómeno que genera grietas similares a las de fatiga cuando la zona donde aparece además de sufrir cargas cíclicas opera en un ambiente de alta salinidad.

Sin embargo, es una clasificación que nos permite correlacionar los daños con las técnicas SHM de un modo más sencillo y por ello la utilizaremos.

Estos daños no se producen con la misma frecuencia de hecho, el $95 \%$ de los mismos aparecen en fuselajes o elementos de pared delgada.

En este punto interesa saber además de los daños que van a afectar al tipo de estructura que se va a monitorizar, la DSF que permite monitorizarlos. A continuación se presentan algunos daños típicos en estructuras aeronáuticas y su característica sensitiva que permite su evaluación [109].

\begin{tabular}{|l|c|c|c|c|c|c|}
\hline \multicolumn{1}{|c|}{$\begin{array}{c}\text { CARANOS } \\
\text { TÍPICOS }\end{array}$} & $\begin{array}{c}\text { Forma } \\
\text { estructural }\end{array}$ & $\begin{array}{c}\text { Deformación } \\
\text { estructural } \\
\text { puntual }\end{array}$ & $\begin{array}{c}\text { Campo de } \\
\text { deformación }\end{array}$ & $\begin{array}{c}\text { Interferencia } \\
\text { electromagnética }\end{array}$ & $\begin{array}{c}\text { Deformación- } \\
\text { desplazamiento } \\
\text { por } \\
\text { Vibraciones }\end{array}$ & $\begin{array}{c}\text { Deformación- } \\
\text { desplazamiento } \\
\text { por } \\
\text { Ondas Elásticas }\end{array}$ \\
\hline Grietas fatiga & NO & SI & SI & SI & SI & SI \\
\hline Corrosión & NO & NO & NO & SI & NO & SI \\
\hline Sobrecarga & SI & SI & SI & NO & SI & NO \\
\hline Delaminación & NO & SI & SI & SI & SI & SI \\
\hline $\begin{array}{l}\text { Despegado } \\
\begin{array}{l}\text { Fidespread } \\
\text { Damage }\end{array}\end{array}$ & SI & SI & SI & SI & SI & SI \\
\hline Impactos & SI & SI & SI & NO & SI & SI \\
\hline Abolladuras & NO & NO & SI & NO & NO & SI \\
\hline $\begin{array}{l}\text { Impacto de } \\
\text { rayo } * \text { (*) }\end{array}$ & NO & NO & NO & NO & NO & NO \\
\hline $\begin{array}{l}\text { Pérdida } \\
\text { remache }\end{array}$ & NO & SI & SI & NO & SI & SI \\
\hline Porosidad & NO & NO & NO & SI & NO & SI \\
\hline $\begin{array}{l}\text { Tenso- } \\
\text { corrosión }\end{array}$ & NO & SI & SI & SI & NO & SI \\
\hline Erosión & SI & SI & SI & SI & SI & SI \\
\hline $\begin{array}{l}\text { Pandeos } \\
\text { locales }\end{array}$ & SI & SI & NO & NO & SI & NO \\
\hline $\begin{array}{l}\text { Deformaciones } \\
\text { plásticas }\end{array}$ & SI & SI & SI & SI & NO & NO \\
\hline
\end{tabular}

Tabla 1 - Daños típicos en estructuras aeronáuticas y la característica sensitiva al daño

(*) Se detectarían sus daños derivados.

Además de la característica sensible al daño hay que tener en cuenta, cómo, la presencia de daño, modifica dicha característica. Lo que denominamos la firma de daño. Dicha firma puede ser el cambio de algún valor relacionado con la medida o señal que obtenemos de la característica sensible al daño, como por ejemplo la amplitud, la frecuencia, la energía, etc.

La DSF junto con la firma que nos interesa para una estructura y unos determinados daños definirá la tecnología SHM que podemos aplicar. 


\subsubsection{Tecnologías SHM aplicables}

Normalmente la DSF llevará asociado uno o varios sensores típicos relacionados directamente con las diferentes técnicas SHM (Figura 10). A continuación se describen que tecnologías son aplicables a cada tipo de daño y/o cada tipo de estructura. Sus ventajas e inconvenientes relacionados con la estructura en la que se va a instalar y con la DSF que tiene que medir.

\begin{tabular}{|c|c|c|c|}
\hline $\begin{array}{l}\text { SENSOR } \\
\text { SHM }\end{array}$ & FORTALEZAS & LIMITACIONES & POTENCIAL DE UTILIZACIÓN \\
\hline Extensímetros & $\begin{array}{l}\text { Montaje en superficie } \\
\text { Procesado de datos sencillo } \\
\text { Bajas frecuencias de trabajo }\end{array}$ & $\begin{array}{l}\text { Peso elevado } \\
\text { Información limitada } \\
\text { Interferencia } \\
\text { electromagnética }\end{array}$ & $\begin{array}{l}\text { Resultados globales y locales } \\
\text { Sistema pasivo } \\
\text { Combinación con sistemas OLM } \\
\text { Permite hot-spot monitoring }\end{array}$ \\
\hline FBG & $\begin{array}{l}\text { Embebible y conformable } \\
\text { Montaje en superficie } \\
\text { Medición en geometrías } \\
\text { complejas Bajo peso } \\
\text { Sin interferencia } \\
\text { electromágnética }\end{array}$ & $\begin{array}{l}\text { Procesado complejo } \\
\text { Coste elevado } \\
\text { Altas frecuencias de trabajo } \\
\text { Requiere equipamiento óptico } \\
\text { Sensibilidad a condiciones } \\
\text { ambientales y de operación }\end{array}$ & $\begin{array}{l}\text { Permite hot spot monitoring } \\
\text { Permite OLM } \\
\text { Sistema pasivo } \\
\text { Resultados locales y globales }\end{array}$ \\
\hline Eddy current & $\begin{array}{l}\text { Muy sensible al daño } \\
\text { Montaje en superficie }\end{array}$ & $\begin{array}{l}\text { No embebible } \\
\text { Coste elevado } \\
\text { Procesado complejo } \\
\text { Sensibilidad a condiciones } \\
\text { ambientales y de operación }\end{array}$ & $\begin{array}{l}\text { Permite hot spot monitoring } \\
\text { Sistema activo o pasivo } \\
\text { Capacidad de diferenciación de tipos } \\
\text { de daño } \\
\text { Alta potencia de alimentación }\end{array}$ \\
\hline Micrófonos & $\begin{array}{l}\text { Bajo coste } \\
\text { Montaje en superficie }\end{array}$ & $\begin{array}{l}\text { No embebible } \\
\text { Posproceso de resultados } \\
\text { complejo } \\
\text { Altas frecuencias de trabajo } \\
\text { Sensibilidad a condiciones } \\
\text { ambientales y de operación }\end{array}$ & $\begin{array}{l}\text { Sistema pasivo } \\
\text { Baja potencia de alimentación } \\
\text { Triangulación de posición de daño } \\
\text { Permite hot spot monitoring } \\
\text { Resultados locales y globales }\end{array}$ \\
\hline Acelerómetros & $\begin{array}{l}\text { Amplia cobertura estructural } \\
\text { Montaje en superficie. }\end{array}$ & $\begin{array}{l}\text { Peso elevado } \\
\text { Procesado de datos complejo }\end{array}$ & $\begin{array}{l}\text { Baja potencia de alimentación } \\
\text { Hot spot monitoring } \\
\text { Combinación con OLM } \\
\text { Sistema pasivo } \\
\text { Resultados locales y globales } \\
\text { Detección de impactos }\end{array}$ \\
\hline Phased arrays & Montaje en superficie & $\begin{array}{l}\text { Coste elevado } \\
\text { Procesado muy complejo } \\
\text { Altas frecuencias de trabajo } \\
\text { Peso elevado } \\
\text { Sensibilidad a condiciones } \\
\text { ambientales y de operación } \\
\text { Cobertura muy limitada } \\
\text { Interferencia EM }\end{array}$ & $\begin{array}{l}\text { Permite hot spot monitoring } \\
\text { Permite diferenciar tipos de daño }\end{array}$ \\
\hline Piezoeléctricos & $\begin{array}{l}\text { Montaje en superficie } \\
\text { Cobertura amplia }\end{array}$ & $\begin{array}{l}\text { Procesado complejo } \\
\text { Peso elevado } \\
\text { Interferencia EM } \\
\text { Sensibilidad a condiciones } \\
\text { ambientales y de operación } \\
\end{array}$ & $\begin{array}{l}\text { Permite hot spot monitoring } \\
\text { Sistema activo o pasivo } \\
\text { Detección de impactos } \\
\text { Diferenciación de tipos de daño }\end{array}$ \\
\hline OBR & $\begin{array}{l}\text { Montaje en superficie } \\
\text { Muy buena cobertura } \\
\text { estructural } \\
\text { Peso bajo }\end{array}$ & $\begin{array}{l}\text { Procesado muy complejo } \\
\text { Sensibilidad a condiciones } \\
\text { ambientales y de operación }\end{array}$ & $\begin{array}{l}\text { Permite hot spot monitoring } \\
\text { Combinable con OLM } \\
\text { Sistema pasivo } \\
\text { Detección de impactos } \\
\text { Control de forma }\end{array}$ \\
\hline CVM & $\begin{array}{l}\text { Embebible } \\
\text { Montaje en superficie } \\
\text { Bajo peso }\end{array}$ & $\begin{array}{l}\text { Instalación muy compleja } \\
\text { Baja cobertura estructural }\end{array}$ & $\begin{array}{l}\text { Crecimiento de grietas } \\
\text { Sistema pasivo } \\
\text { Detección de impactos } \\
\text { Permite hot spot monitoring }\end{array}$ \\
\hline Crack wires & Montaje en superficie & Peso elevado & $\begin{array}{l}\text { Crecimiento de grietas } \\
\text { Permite hot spot monitoring } \\
\text { Método local } \\
\text { Sistema pasivo }\end{array}$ \\
\hline
\end{tabular}

Tabla 2 - Diferentes sensores SHM 
Una vez vistos los sensores/tecnologías SHM disponibles y los daños típicos se cruzan ambas tablas para comprobar que tecnologías son mejores o peores para aplicar en estructuras aeronáuticas.

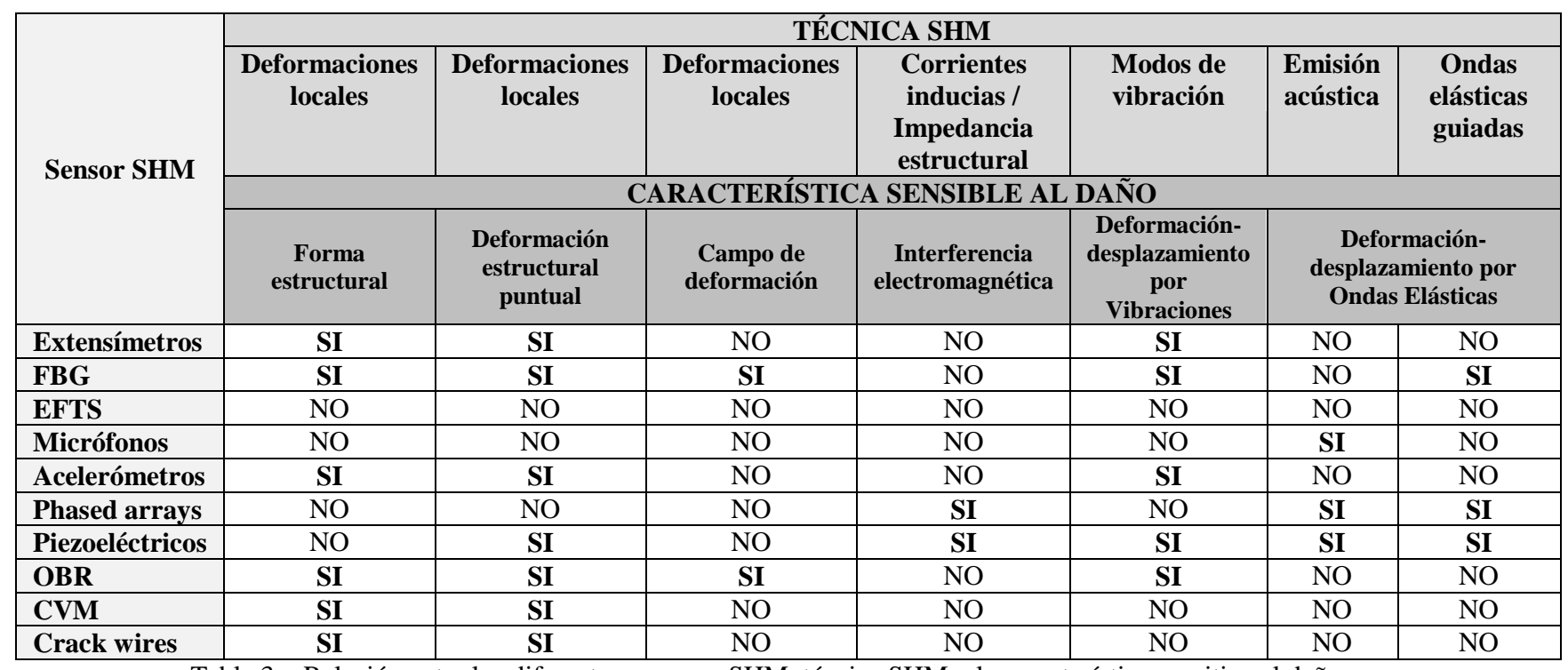

Tabla 3 - Relación entre los diferentes sensores SHM, técnica SHM y la característica sensitiva al daño

Con la combinación de FBG, piezoeléctricos y OBR se cubren la mayoría de las posibilidades sensitivas para cualquier tecnologías SHM. 


\subsection{Razones de uso y ventajas, inconvenientes y problemas abiertos}

En este apartado revisaremos las ventajas e inconvenientes que tiene la implantación de un sistema SHM en la estructura de una aeronave. Además de esto enumeramos también los problemas abiertos que actualmente impiden la industrialización completa de estas técnicas.

Desde un punto de vista general las estructuras se degradan y en función del valor de la misma o las consecuencias de su fallo es necesario someterlas a costosas inspecciones periódicas para asegurar su operación segura [103]. Es por ello que el uso o no de un sistema SHM dependerá del equilibrio entre el ahorro potencial de coste que supondría su introducción frente a su propio coste manteniendo mejorando o como mínimo manteniendo los niveles de seguridad requeridos para dicha estructura. Además de este primer equilibrio de pros y contras existen otros factores adicionales que recomiendan su introducción frente a problemas de implementación o desventajas no resueltas que lo impiden y que pasamos a revisar en detalle.

En primer lugar se revisan algunas de las ventajas.

Seguridad [66]. La seguridad de una estructura aeronáutica se mantiene al introducir un sistema SHM. Esta no es la razón principal de la utilización de un sistema de este tipo porque actualmente los niveles de seguridad son adecuados [181]. No obstante, existen casos en que la seguridad de operación de una aeronave hace necesario o incluso obligatorio un sistema de este tipo:

- Aeronaves militares. Ya sean diseños puramente militares o derivados de aviones civiles [96]. Algunas normativas militares obligan a utilizar sistemas de monitorización en sus aeronaves, sin especificar la naturaleza de los mismos.

- Aeronaves con solicitaciones especialmente severas. Por ejemplo aeronaves de lucha contra incendios, búsqueda y rescate, etc. Control de operación en ambientes extremos o fuera de la envuelta de diseño. Esto normalmente no está incluido en los programas de mantenimiento estándar y un SHM puede proporcionar información sobre el comportamiento de la estructura en estas situaciones y permitir tomar acciones de mantenimiento adicionales.

- Aeronaves en programas de extensión de la vida útil [4][123][121].

- Control de las reparaciones más críticas efectuadas en la estructura [67].

- Detección temprana de daños [50].

- Detección de nuevos tipos de daños a considerar como el Widespread Fatigue Damage (WFD) [126]. 
Relacionado con la seguridad está también la minimización de la intervención humana en el proceso de control de la estructura que permite la introducción de una técnica SHM.

Coste [66] para aeronaves civiles y disponibilidad [47] en el mundo militar, allí el coste es secundario y prima la disponibilidad de la aeronave. Un sistema de esta clase permite conocer el estado de la estructura en todo momento y evolucionar de un mantenimiento planificado a un mantenimiento a demanda (planificado, CBM), lo que reduce el coste operativo[123] y aumenta la disponibilidad. De hecho se podría generar un mantenimiento adaptado a las particularidades operativas de cada aeronave eliminando inspecciones innecesarias [67]. En general los estudios realizados y las aplicaciones preliminares de este tipo de sistemas indican un ahorro potencial del coste operativo de la aeronave [87]. Algunos estudios estiman una reducción entre un tercio y un $50 \%$ en los costes de mantenimiento de la aeronave[124], que suponen hasta una cuarta parte del coste de operación total de la aeronave[50] .

Realimentación al diseño [47].Permite un conocimiento más completo de cómo es el comportamiento en servicio de la estructura de la aeronave. Esto posibilita también realimentaciones al diseño de dicha estructura en sus versiones futuras. También proporciona información de gran utilidad para nuevos diseños. Esta información sirve también para confirmar las solicitaciones que tiene la estructura además de la susceptibilidad al daño de las diferentes zonas y proceder a una optimización de la misma, eliminando conservadurismos, con el consiguiente ahorro en peso.

Sin embargo existen también inconvenientes que impiden, a día de hoy su aplicación. A continuación se indican algunos[121]:

- Los beneficios de aplicación aún no se han demostrado de manera clara en aeronaves civiles de ala fija.

- La validación y certificación de este tipo de sistemas no están estandarizadas. Aunque se han establecido una serie de requerimientos para su calificación [125] que han derivado en una serie de recomendaciones [68] en los siguientes términos:

- Fiabilidad del sistema. Aún no está demostrada completamente. Robustez de las metodologías [42].

- Probabilidad de detección del daño.

○ Durabilidad. Fallos de sensores [43][44].

○ Manufactura.

- Integración en la aeronave con el resto de sistemas.

○ Mantenibilidad. 
- Reparabilidad.

- Autodiagnóstico.

- Muchas de las tecnologías que dan soporte a las técnicas de SHM se encuentran actualmente en desarrollo. Dichas técnicas sustentan los elementos de la enumeración anterior con lo que su desarrollo es necesario.

- La implantación de estos sistemas aún no es generalizada y por ello su coste es muy elevado.

- Son sistemas muy complejos que normalmente tratan de resolver un problema inverso[103]. Este tipo de problemas son muy complejos y requieren de herramientas muy especializadas

De los puntos anteriores revisamos en detalla la madurez de las tecnologías soporte o lo que algunos autores denominan problemas abiertos o desafíos del SHM [87]. Dichas tecnologías aún necesitan desarrollo en los siguientes campos:

- Sensores para SHM. Como se ha visto anteriormente existe multitud de sensores para aplicar diversas técnicas SHM y a día de hoy aunque existe un cierto consenso en cuanto al sensor que hay que aplicar en cada técnica, no existe la misma unanimidad en los siguientes aspectos:

○ Posicionamiento óptimo y número de sensores a utilizar.

- Industrialización de los mismos. La mayoría de los sensores disponibles tienen una validez limitada a los laboratorios y no podrían instalarse en una aeronave.

- En muchas ocasiones se deben diseñar ad hoc para la técnica SHM aplicada a una estructura en particular lo que hace difícil su generalización a estructuras diferentes.

- En cuanto a la característica sensitiva al daño o DSF, las metodologías analíticas para evaluar su comportamiento frente a la presencia de daño son muy limitadas. Muchas veces la selección de la DSF y de la firma del daño en la DSF procede de los resultados de los propios experimentos e implica la utilización de ciertas aproximaciones de modelización:

- Técnicas model-based. Como por ejemplo los modelos de elementos finitos.

- Técnicas data-driven. Como las técnicas de inteligencia artificial y en particular los modelos de redes neuronales artificiales o ANN que se utilizan en esta tesis. 
Estas metodologías de modelización ayudan a establecer relaciones entre los cambios que se producen en la firma del daño sobre la DSF y el propio cambio del daño o la tipología del mismo. Relaciones que actualmente son difíciles de obtener mediante modelos analíticos, incluso para estructuras simples.

- Sobre la DSF no solo interactúa el daño sino que también intervienen las condiciones ambientales y de operación (EOC, Environmental and Operational Conditions). Esta interacción produce cambios en la firma de la DSF similares a los que produciría la presencia de daño lo que implica la aparición de dos problemas relacionados con el sistema de toma de decisiones derivado de un SHM [42]:

- Falsos positivos. Cuando dicha interferencia produce un cambio similar al que produciría el daño de tal modo que la técnica SHM indicaría la presencia de un daño inexistente. Esto produciría un problema de coste ya que implicaría cambiar o reparar una estructura no dañada.

- Falsos negativos. Cuando la interferencia enmascara la presencia de daño produciendo un resultado de estructura sin daño cuando realmente está dañada. Este problema es más grave que el anterior ya que entra en juego la seguridad de la estructura.

Al igual que en el caso anterior es necesario un análisis en detalle de la DSF para comprender los cambios que las EOC producen en la firma de la DSF que está utilizando la técnica SHM seleccionada. Sin embargo, en este caso existen más herramientas para poder abordar dicha interacción y compensarla de algún modo:

- Modelos analíticos. Aunque su aplicación es bastante limitada su utilidad es grande en las etapas preliminares de diseño de un sistema SHM en el que se incluya la compensación de las EOC.

- Técnicas model-based. De nuevo los modelos de elementos finitos permiten simular, de forma simplificada el comportamiento de la DSF de la estructura ante las EOC.

- Técnicas data-driven. En este caso está muy extendido el uso de técnicas de procesado de señal especiales. Estos modelos estadísticos responden mejor ante las anomalías introducidas por las EOC[45], siempre que se haya sido cuidadoso y se hayan incluido estas situaciones a la hora de elegir los datos para crearlo [46].

De hecho una de las razones por las cuales este tipo de sistemas no están siendo utilizados de manera generalizada es la dificultad de compensación de los efectos 
ambientales y operacionales [114], tales como la temperatura [106], especialmente cuando las condiciones de operación son extremas [110].

- Grandes cantidades de información. Son necesarias técnicas de Data Mining o Big Data con se denominan últimamente. Las técnicas SHM generan grandes cantidades de información siendo su procesamiento y presentación de la información un desafío actualmente.

Resumiendo, se podría decir que actualmente con los nuevos diseños de aeronaves -con unos márgenes de diseño cada vez más optimizados- un sistema SHM es fundamental para mantener los niveles de seguridad y eficiencia - reduciendo potencialmente el coste de mantenimiento de la aeronave - no obstante, a día de hoy, no se puede aplicar, de modo generalizado, ya que existen una serie de problemas tecnológicos no resueltos. De entre ellos destacamos dos, aquellos en los que se centra esta tesis, la modelización de la relación entre la característica sensitiva al daño (DSF) - daño junto con la interacción sobre esa relación de las condiciones ambientales y de operación. 


\section{Técnicas en inteligencia artificial aplicadas al SHM}

En el apartado anterior hemos hablado de algunos de los problemas abiertos que impiden el desarrollo de las técnicas SHM, y entre ellos se han destacado dos relaciones difíciles de modelar:

- Relación entre daño y firma DSF para estructuras complejas.

- Relación entre firma DSF y EOC para cualquier tipo de estructura.

Puesto que en esta tesis versa de las técnicas de inteligencia artificial aplicadas a la monitorización de estructuras aeronáuticas se va a efectuar una introducción a este campo. De entre las diferentes técnicas disponibles se proponen las redes neuronales artificiales. Se utilizarán para buscar relaciones entre EOC y la firma de daño. Por ello se va a presentar una breve introducción. El objetivo de esta introducción es conocer los conceptos básicos de esta metodología como ayuda para comprender los modelos utilizados más adelante, en el cuerpo de la tesis.

En este capítulo se revisan tres puntos fundamentales en este capítulo:

- Un repaso de lo que son las técnicas de Inteligencia Artificial y el encuadre de las redes neuronales artificiales dentro de las mismas.

- Seguidamente se presenta la introducción a las Redes Neuronales Artificiales. En esta parte se revisarán los conceptos básicos y la justificación de su utilización.

- Finalmente se revisan algunos ejemplos de aplicación de las Redes Neuronales Artificiales en el mundo del SHM similares a los de esta tesis y de otra naturaleza. 


\subsection{Inteligencia Artificial y Redes Neuronales Artificiales.}

Las técnicas de inteligencia artificial son aquellas que se ocupan de estudiar los sistemas inteligentes. Un sistema inteligente podría definirse como un cierto sistema que percibe su entorno y actúa en consecuencia [129].

Es una disciplina relativamente reciente[130], de mediados de la década de 1950, y surge como aglutinante de una serie de técnicas novedosas que fueron surgiendo durante la primera mitad del siglo XX.

La capacidad de percibir y actuar en un entorno concreto de estos sistemas puede efectuarse de cuatro modos diferentes:

- Pensando como un ser humano.

- Pensando racionalmente.

- Comportándose como un ser humano.

- Comportándose de modo racional.

Esta subdivisión permite clasificar las diferentes técnicas pertenecientes al ámbito de la Inteligencia Artificial, tanto las disciplinas en las que se fundamenta como aquellas que genera. Esto se resume en la Figura 13 [134].

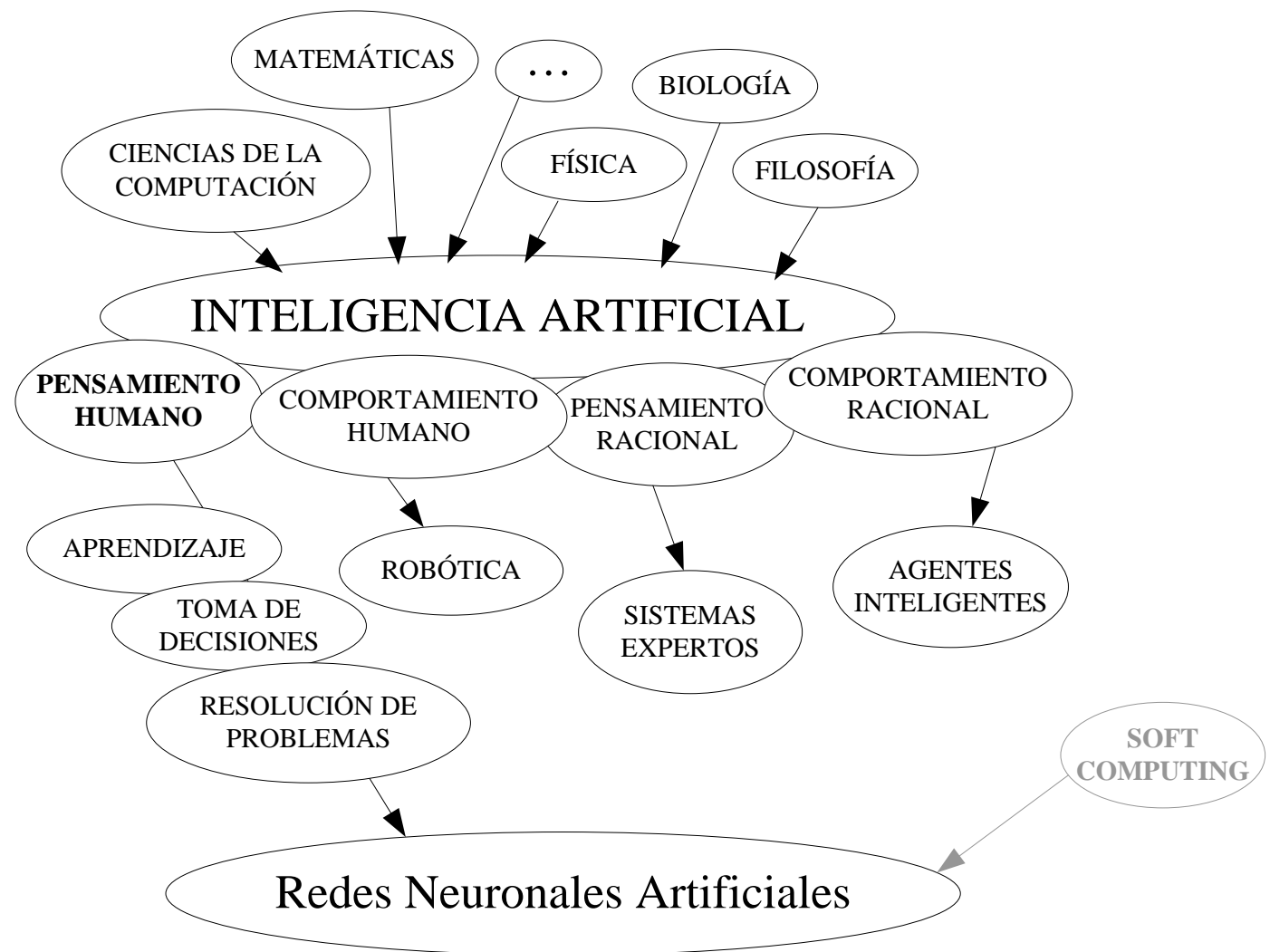

Figura 13 - Encuadre de las Redes Neuronales Artificiales dentro de las técnicas de Inteligencia Artificial. 
Las Redes Neuronales Artificiales formarán parte de la disciplina de la Inteligencia Artificial encuadrándose dentro de la categoría de reproducción del pensamiento humano. Los problemas típicos de esta rama de la IA comprenden el aprendizaje, la toma de decisiones y la resolución de problemas todo ello, a través de los datos.

Al igual que la IA, las Redes Neuronales Artificiales son altamente multidisciplinares, aquí las hemos clasificado dentro de las técnicas IA pero pertenecen a otros muchos ámbitos, de hecho son anteriores a la fundación de la IA como tal en 1956 [130][20]. En la Figura 13 se indica que las ANN pertenecen también a las técnicas de Soft Computing[130] formando parte de un conjunto de técnicas diferentes pero también con elementos en común orientados principalmente a la resolución de problemas según criterios novedosos:

- Lógica Difusa [135].

- Algoritmos genéticos.

- Teoría del caos.

No se profundiza más en las diferentes técnicas de IA puesto que queda fuera del objetivo de esta tesis. Se puede encontrar más información en las referencias proporcionadas [129][130] principalmente, o en versiones reducidas de las mismas [133][132]. Para la evolución conjunta de las ANN y la IA con los personajes implicados en la misma se puede consultar [131].

A partir de este punto se describen las ANN desde un punto práctico para su utilización. 


\subsection{Redes Neuronales Artificiales}

\subsubsection{Definición y tipología}

Las redes neuronales artificiales (Artificial Neural Networks, ANN) son herramientas matemáticas que sirven para resolver problemas de diverso tipo (ver Tabla 4) a modo de red de procesamiento paralelo, masivo y distribuido de unidades de proceso simple denominadas neuronas que guaran la información en las conexiones entre ellas [20]. Son modelos estadísticos de inspiración biológica [127] ya que tienen una arquitectura similar a la red neuronal biológica.

Se han seleccionado como elementos de modelización en esta tesis debido a su capacidad de inferir relaciones ocultas complejas entre grandes cantidades de datos de un modo sencillo, rápido y de bajo coste, allí donde los modelos analíticos clásicos no llegan o son muy costosos de desarrollar [22][128] [127].

Los diferentes tipos de redes surgen han ido surgiendo de los diferentes problemas que son capaces de resolver [20].

\begin{tabular}{|c|c|c|c|}
\hline PROBLEMÁTICA & DESCRIPCIÓN & $\mathbf{A N N}$ & EJEMPLO \\
\hline Aproximación funcional & $\begin{array}{l}\text { Infiere relaciones entre } \\
\text { entradas y salidas siempre } \\
\text { que estén determinadas } \\
\text { biunívocamente }\end{array}$ & $\begin{array}{l}\text { FeedForward Backpropagation } \\
\text { Elman } \\
\text { De regresión } \\
\text { De Base Radial }\end{array}$ & $\begin{array}{l}\text { Modelización de } \\
\text { sistemas dinámicos }\end{array}$ \\
\hline Clasificación & $\begin{array}{l}\text { Busca agrupaciones dentro } \\
\text { de los datos según un } \\
\text { criterio predeterminado }\end{array}$ & Learning Vector Quantization & $\begin{array}{l}\text { Sintetizadores de } \\
\text { voz }\end{array}$ \\
\hline $\begin{array}{l}\text { Reconocimiento de } \\
\text { patrones }\end{array}$ & $\begin{array}{l}\text { Buscan pautas en los datos } \\
\text { diferenciándolas entre sí de } \\
\text { un modo automático }\end{array}$ & $\begin{array}{l}\text { Self Organizing Maps } \\
\text { Kohonen Maps }\end{array}$ & $\begin{array}{l}\text { Reconocimiento de } \\
\text { caracteres } \\
\text { Reconocimiento de } \\
\text { imágenes }\end{array}$ \\
\hline Optimización & $\begin{array}{l}\text { Buscan un cierto óptimo } \\
\text { dentro de un conjunto de } \\
\text { datos }\end{array}$ & $\begin{array}{l}\text { Competitive Neural Networks } \\
\text { Feedforward Backpropagation }\end{array}$ & Problema del viajero \\
\hline Predicción & $\begin{array}{l}\text { Deduce comportamientos } \\
\text { futuros a partir de una } \\
\text { condición inicial }\end{array}$ & $\begin{array}{l}\text { Elman } \\
\text { Dynamic Backpropagation } \\
\text { Recurrentes }\end{array}$ & $\begin{array}{l}\text { Evoluciones de } \\
\text { índices bursátiles } \\
\text { Predicción del } \\
\text { consumo eléctrico }\end{array}$ \\
\hline Control & $\begin{array}{l}\text { Reproduce un sistema de } \\
\text { control de una planta a } \\
\text { partir de sus datos }\end{array}$ & $\begin{array}{l}\text { Dynamic Backpropagation } \\
\text { Predictive Control Networks }\end{array}$ & DARPA Dog \\
\hline Compresión de datos & $\begin{array}{l}\text { Reduce redundancias en los } \\
\text { datos sin modificar la } \\
\text { información que contienen }\end{array}$ & Probabilistic Neural Networks & $\begin{array}{l}\text { Algoritmos de } \\
\text { reducción de datos }\end{array}$ \\
\hline
\end{tabular}

Tabla 4 - Tipología de Redes Neuronales Artificiales. 
Existe otro modo de clasificación más riguroso en función de si dichas redes tienen realimentaciones o no [49]:

- Estáticas. No tienen realimentaciones. La salida de la red depende de la entrada que se presente en ese momento.

- Dinámicas. Presentan realimentaciones y por lo tanto la salida de la red en un determinado momento depende de las entradas en ese instante y de las anteriores. Se comporta como un sistema dinámico.

\subsubsection{Arquitectura, ajuste y funcionamiento}

La arquitectura de una red neuronal se define por los elementos y reglas que forman parte de la misma y de su ajuste [127]:

1. Unidad elemental de procesado de información o neurona, se define por la función de activación neuronal que realiza el cálculo.

2. Estado de activación neuronal. El resultado del cálculo que realiza la neurona.

3. Conexiones entre las diferentes neuronas denominadas pesos. Define el flujo de datos dentro de la red neuronal. Según como sea este flujo se tendrán redes estáticas o dinámicas.

4. Regla de propagación. Define los valores de entrada a la neurona con los que se alimenta la función de activación neuronal.

5. Función de activación neuronal. Compara según una cierta regla el estado de activación de la neurona con el estado de activación previo, que será un umbral fijo denominado bias en las redes estáticas o un valor cambiante en el caso de las dinámicas.

6. Capas. Las diferentes agrupaciones de neuronas, definen la topología de la red.

7. Regla de aprendizaje. Algoritmo que se utiliza para ajustar los parámetros libres de la red y obtener el resultado deseado. En el caso de las redes estáticas los pesos y conexión y los umbrales de activación neuronal.

8. Entorno de trabajo. Los datos exteriores a la red y que interactúan con la misma: datos de entrada y de salida; errores; control externo, etc. 


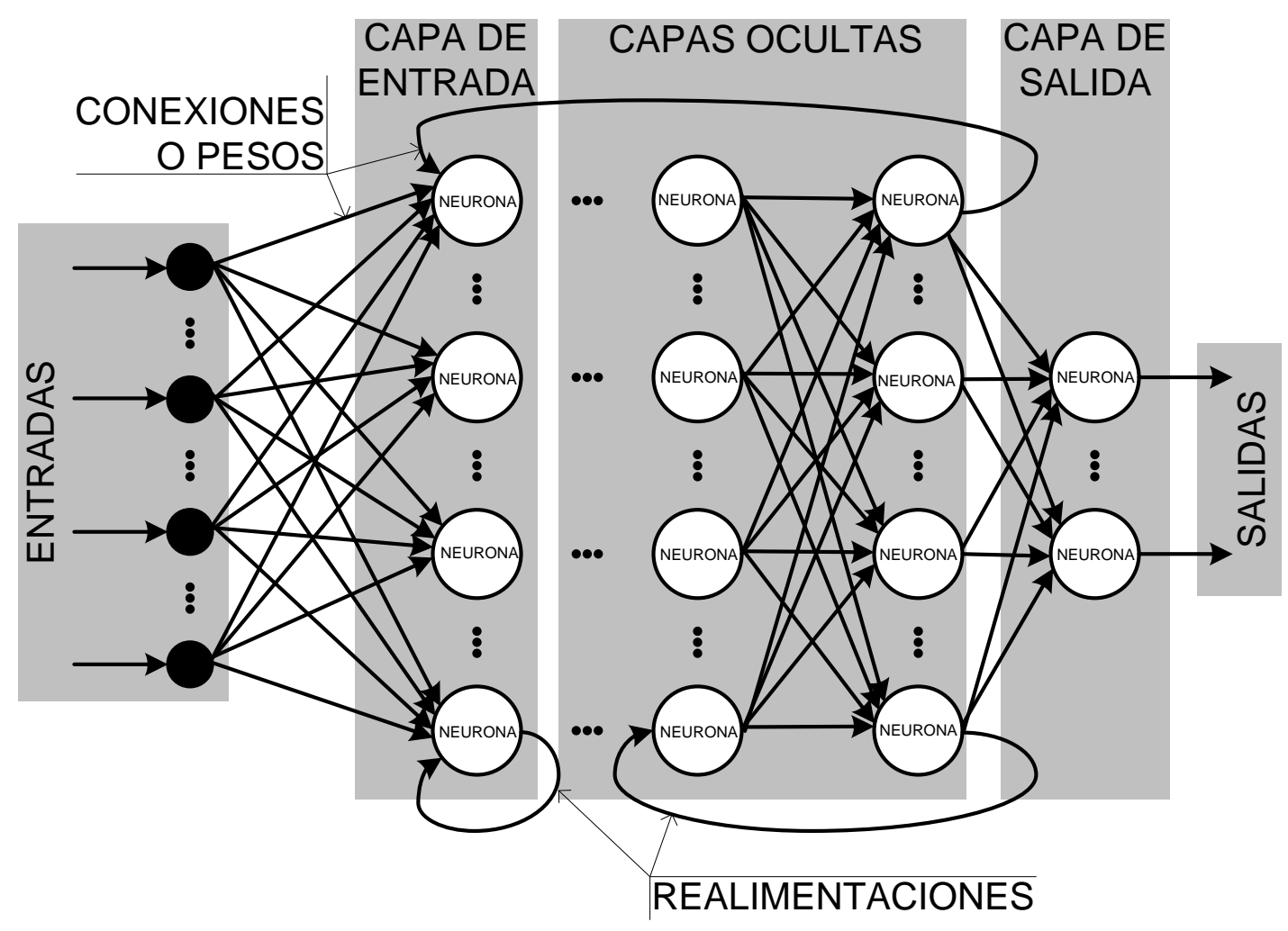

Figura 14 - Arquitectura de una red neuronal[128].

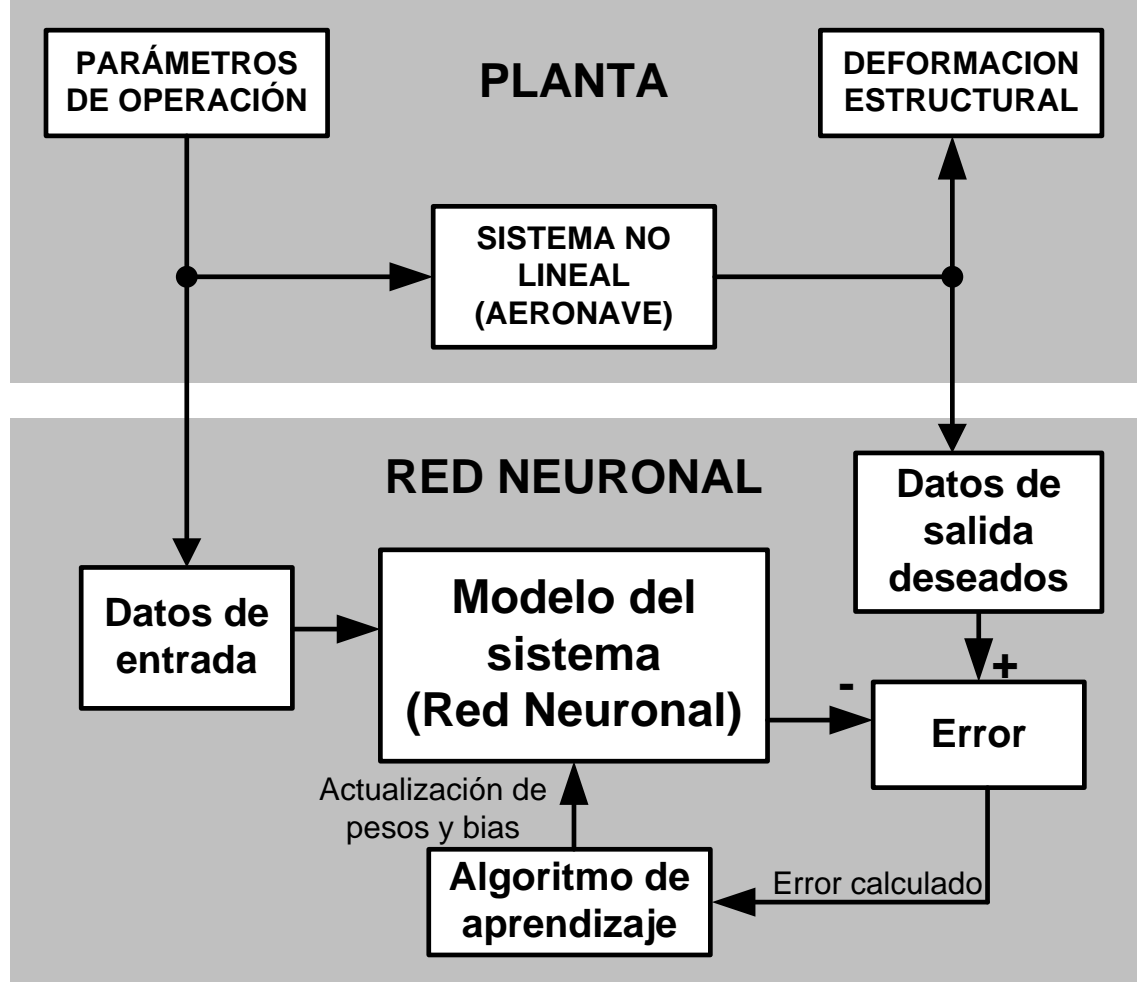

Figura 15 - Ejemplo de utilización de una red neuronal como modelo de una planta[128]. 
El funcionamiento de la red una vez ajustada es el siguiente. Cada neurona de una capa procesa las entradas utilizando la función de activación. Las salidas o estado de activación se proporcionan a otras neuronas procesadas mediante la regla de propagación utilizando los pesos de conexión. Este proceso se repite desde los datos de entrada hasta las salidas de la red.

En el ajuste el proceso es similar pero con un flujo de datos adicional. En primer lugar se inicializan todos los parámetros libres de la red, pesos y umbrales de activación. Seguidamente se propagan los datos de entrada a través de la red según el funcionamiento descrito en el párrafo anterior. Las salidas producidas no serán las deseadas, ya que la red no está ajustada, así que se compararán con las salidas deseadas produciendo un error. Al presentar varias entradas en el ajuste de la red se calcularán diferentes valores de error, cuya evolución utilizará el algoritmo de aprendizaje para minimizarlo ajustando lo pesos y umbrales. Cuando el error sea inferior a un valor predeterminado la red estará ajustada y se podrá utilizar. 


\subsubsection{Aplicabilidad y justificación}

En el contexto de esta tesis nos interesan fundamentalmente las redes de aproximación funcional (Feedforward Backpropagation).

Pero, surge la pregunta de qué condiciones debe de cumplir el problema que nos ocupa, y la ANN seleccionada, para asegurar la existencia de soluciones. Por esta razón se presenta en este apartado un breve resumen del cimiento matemático que hay bajo esta decisión, una descripción más detallada se puede encontrar en [128].

Para las redes seleccionadas, si se desea encontrar una relación funcional entre dos conjuntos de datos, hay que cumplir lo siguiente [20][49]:

- En primer lugar, que dicha relación exista (principio de causalidad) y esté definida de modo biunívoco aunque analíticamente no se pueda obtener. Esto se denomina identificación del sistema.

- Teorema de Stone-Weierstrass. Establece condiciones necesarias, pero no suficientes, para que la red neuronal elegida pueda efectuar la aproximación. Dichas condiciones se establecen para la función de activación neuronal ya que el resto de condiciones se cumplirán automáticamente si la selección es adecuada. Para el uso en aproximación de funciones de redes feedforward backpropagation se pueden utilizar entre otras:

- Tangente-sigmoidea (una tangente hiperbólica).

- Función de base radial (una gaussiana).

- Teorema de existencia de Kolmogorov para redes neuronales (Hetch-Nielsen). Si la red neuronal tiene un mínimo de tres capas puede reproducir cualquier función continua multivariable. En nuestro caso, al trabajar con datos discretos, dicha aproximación tendrá un error que se puede calcular.

Estos teoremas permiten seleccionar de entre todas las ANN disponibles aquellas que tienen más posibilidades para ajustar los modelos que necesitemos. No olvidemos que, dichos modelos, definidos por sus datos experimentales, deben tener una relación biunívoca entre entradas y salidas. Esto nos obligará a controlar el mayor número de variables del problema que tengan una influencia significativa en el mismo. 


\subsubsection{Utilización práctica}

El uso de una ANN para resolver un problema de aproximación funcional se puede ver en la Figura 16. Partiendo de unos datos experimentales ya preparados, sin errores y divididos entre entradas y salidas consta de los siguientes pasos:

- Ajuste o entrenamiento. Parte de los datos se utilizan para ajustar los parámetros libres de la red y captar las relaciones entre entradas y salidas.

- Validación. Otra parte de los datos de la red se proporcionan a la vez que los de ajuste para ir simulándolos durante el proceso de ajuste y controlar que este se realice correctamente.

- Test o blind test. Finalmente una red ya entrenada se alimenta con datos nuevos, no presentados en el proceso de ajuste ni validación pero dentro de los rangos de ajuste y validación.

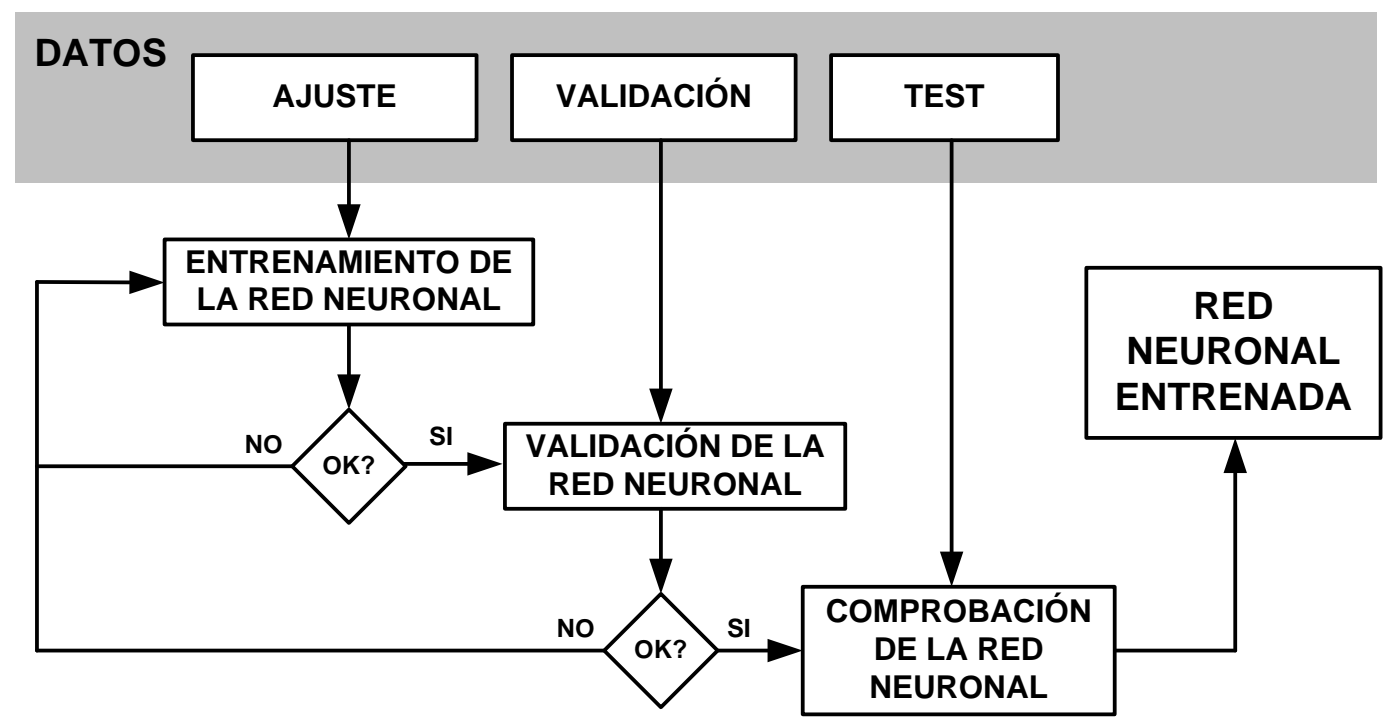

Figura 16 - Esquema de utilización de una Red Neuronal Artificial [22].

Las etapas presentadas, ajuste, validación y test, producen los respectivos errores de salida. Cada uno de estos errores nos informa de la calidad del modelo efectuado en los siguientes aspectos a tener en cuenta:

- Error de ajuste o entrenamiento. Un valor bajo de este error indica que la red capta las relaciones entre entradas y salidas, pero no se puede saber si efectuando un modelo de los mismos (nuestro objetivo) o actuando como una memoria (situación a evitar).

- Error de validación. Un valor bajo indica que la red capta las relaciones entre entradas y salidas, no actuando como una memoria.

- Error de blind test. Un valor bajo indica la capacidad de generalización del modelo. Es decir, no sólo ha captado las relaciones entre entradas y salidas sino que además tiene una capacidad de generalización buena ante entradas nuevas. Siempre, dentro de los rangos de ajuste 


\subsection{Aplicaciones típicas de Redes Neuronales Artificiales en SHM}

El último punto de esta pequeña introducción a las técnicas de Inteligencia Artificial, concretamente a las Redes Neuronales Artificiales consiste en un repaso de algunas de las aplicaciones de estas técnicas a los diferentes problemas de monitorización de la integridad estructural.

La aplicación de estas técnicas es muy variada y abarca desde la generación de modelos de la propia estructura hasta modelos de detección de daño.

En primer lugar veremos algunas aplicaciones para monitorización de uso o prognosis. Fundamentalmente se aplican en la modelización de cargas a partir de parámetros de vuelo de la aeronave. Esta área es una de las más prolíficas en la aplicación de las ANN. Se encuentran ejemplos para todo tipo de aeronaves desde aviones militares [11][112][113][96] hasta helicópteros [88][108], donde suelen combinarse con los algoritmos genéticos. Una descripción más detallada de la aplicación de ANN y otras técnicas de IA se puede encontrar en [149].

En segundo lugar aplicaciones de las ANN a las diferentes técnicas SHM de diagnosis:

- En sistemas SHM pasivos:

- Detección de impactos a partir de las señales de los sensores instalados. En este tipo de sistemas las ANN utilizan como entrada alguna característica de la DSF y su salida sería directamente la posición del daño[104]. La razón de uso de este tipo de modelos es que es muy complicado aplicar directamente un algoritmo de triangulación a partir de los ecos del impacto en estructuras de material compuesto debido a la anisotropía de propagación de las ondas y su interacción con los diferentes detalles estructurales.

- Caracterización de energía de un impacto y del daño potencial producido. Se entrena una ANN con impactos a diferentes energías. Utilizando los datos de los sensores se crea una correlación mediante una ANN entre la firma del impacto en la DSF para diferentes energías. Se crea así una suerte de clasificador que en función de la modificación de los modos propios establece un tipo de daño u otro en la estructura [147].

- Muy similar a la detección de impactos es la aplicación de ANN para detectar patrones de emisión acústica [150] (AE) y clasificarlos[144]. Existen ejemplos de aplicación en las que las redes neuronales se utilizan de un modo no supervisado para efectuar dicha clasificación, patrones de AE provenientes de una estructura sana y patrones AE de una estructura dañada.

- En sistemas SHM activos, vibración, GLW, etc.: 
- Dentro del campo de las técnicas SHM de vibración hay ejemplos en los que se utilizan las ANN para detectar las variaciones en los parámetros modales de la estructura producidas por la presencia de daños [138]. En este tipo de aplicaciones se ajusta la red neuronal en multitud de situaciones con daño, de un modo supervisado, y utilizando modelos FEM. Seguidamente se mide en la estructura dañada y se alimenta la red para comprobar si detecta el daño ensayado. Dentro de esta misma técnica se utiliza la potencia de las ANN para clasificar los diferentes tipos de daño detectados en una estructura bajo el efecto de condiciones ambientales y de operación. Esta es una situación de las más complejas puesto que las EOC interfieren notablemente en las firmas de daño en la DSF confundiendo a las metodologías clásicas [137].

- Los sistemas basados en ondas elásticas guidadas GLW, también se sirven de las ANN para las tareas más complejas. Por ejemplo para la identificación y localización de la presencia del daño [139][140]. También se intentan utilizar para cubrir todos los niveles de SHM llegando incluso a cuantificación de la severidad del daño [141], aunque entrenando los modelos con FEM y simulando con la estructura real. En cuanto a los sistemas no supervisados, se utilizan redes auto-asociativas para poder diferenciar la situación sin daño de la presencia de daño y dentro de la presencia de daño, los diferentes tipos [142]. Este último es un ejemplo de como las ANN, aplicadas a este tipo de problemas, suelen necesitar de un pre-procesado adicional complejo, como puede ser un análisis de componentes principales, algún tipo de transformada, etc., que ayudan al modelo a realizar la clasificación. Estos procesados adicionales ayudan a extraer lo que hemos denominado firma del daño en la DSF [143]. Son de gran utilidad en detalles complejos de estructuras reales [145] utilizando directamente los datos medidos y los modelos meramente como soporte de diseño para el modelo.

- Para la técnica de impedancia estructural. En la que se acopla el comportamiento estructural y eléctrico del sensor para la detección del daño también se han utilizado ANN. Es una aplicación muy similar a la detección de patrones o clasificación. En este tipo de sistemas una ANN clasifica los cambios en el patrón de impedancia estructural en una serie de daños predefinidos, de modo supervisado [146].

Una fuente de información para este tipo de aplicaciones, que no suele utilizarse mucho consiste en las patentes publicadas. En las patentes se encuentra mucha información e indica el camino 
que sigue la industria en la aplicación de estas técnicas dentro del SHM. Se observa como la industria las utiliza como modelos [136], como detectores de daño [92].

En resumen, se pueden ver dos grandes líneas de trabajo. En la primera se ajustan los modelos ANN mediante modelos físicos como pueden ser los modelos de elementos finitos FEM [103], y posteriormente se alimentan con datos reales para comprobar su funcionamiento. $\mathrm{Y}$ en la segunda directamente se utilizan los datos experimentales para ajustar el modelo ANN y también para comprobar su funcionamiento. Estos segundos suelen combinarse con técnicas complejas de análisis de señal para preparar la información como pueden ser la Transformada de Wavelet y otras.

Esta tesis se centra en la segunda de las líneas de trabajo. Los modelos ANN se ajustan directamente utilizando datos experimentales de la estructura real. Las condiciones de obtención de dichos datos son los más realistas posibles, lo más parecidas a la operación que tendrá el modelo en el mundo real. Esta manera de trabajar tiene sus ventajas e inconvenientes. La ventaja de usar datos reales y tener que realizar un menor número de hipótesis de modelización. Los inconvenientes de utilizar datos reales, con el procesado y análisis adicional que conllevan. Como hemos dicho anteriormente, se suele necesitar algún tipo de transformación adicional para que dichos datos puedan ser utilizados para ajustar el modelo.

Habrá que asegurar que la parte elegida para ser modelada cumpla con las condiciones para su realización. En la literatura se establece que niveles del SHM pueden realizarse de un modo automático o no supervisado y cuales necesitan ser supervisados. En nuestro caso todos los ajustes que se realizarán será mediante ANNs en modo supervisado con lo que se cumple con la aplicabilidad en todos los niveles del SHM [148]. 


\section{Análisis de la influencia de las EOC en la propagación de ondas elásticas}

El problema a resolver consiste en efectuar un modelo que permita compensar los efectos ambientales para una técnica SHM de diagnosis de daño.

Ya se ha comentado anteriormente que el tipo de estructura seleccionada son paneles rigidizados de pared delgada, fundamentalmente metálicos (aunque, el esquema propuesto, puede valer, con mínimos cambios, para estructuras similares de material compuesto).

Los daños a detectar son grietas, que pueden aparecer debido al uso de la estructura, producirse de un modo fortuito debido a un daño accidental o proceder de la manufactura de la pieza.

Para este tipo de estructura y este tipo de daños se ha seleccionado una técnica SHM que tiene como característica sensitiva al daño la deformación inducida por ondas elásticas en la estructura, es conocido que este tipo de defectos interfieren con las ondas [57].

La técnica SHM elegida consiste en un sistema activo basado en sensores piezoeléctricos. Los sensores piezoeléctricos permiten perturbar la estructura con ondas elásticas de un modo controlado (ondas elásticas guiadas, GLW, Guided Lamb Waves) y además medir la respuesta de la misma, también en términos de ondas elásticas. Este modo de trabajar se denomina pitchcatch, y siempre se tiene un piezoeléctrico emitiendo ondas y otro midiéndolas.
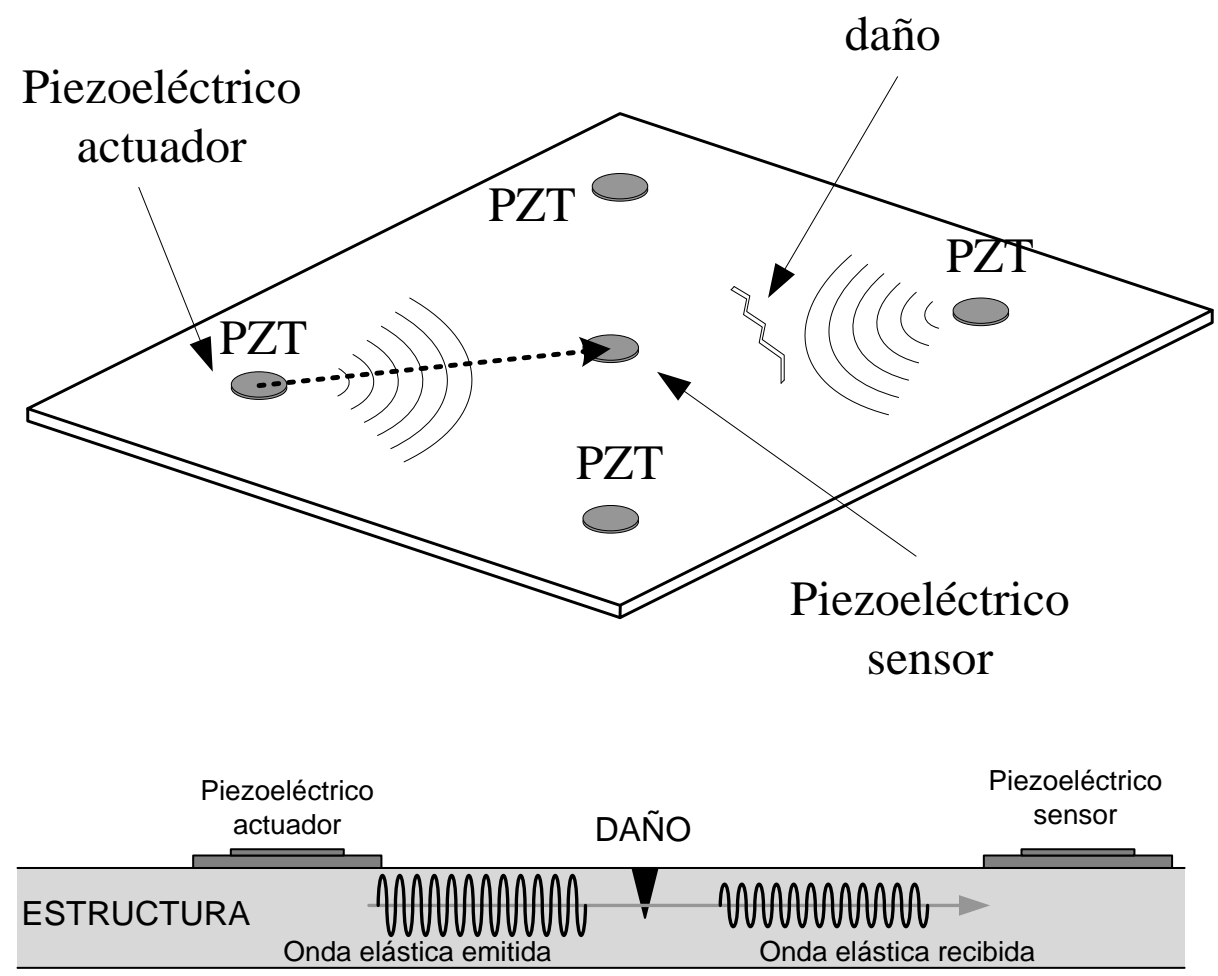

Figura 17 - Técnica SHM basada en piezoeléctricos trabajando en modo pitch-catch 
Dichas ondas elásticas producidas por los sensores PZT se encuentran con los daños presentes en la estructura y sufren cambios, presentamos algunos de los más importantes:

- Atenuaciones

- Retrasos

- Reflexiones

- Refracciones

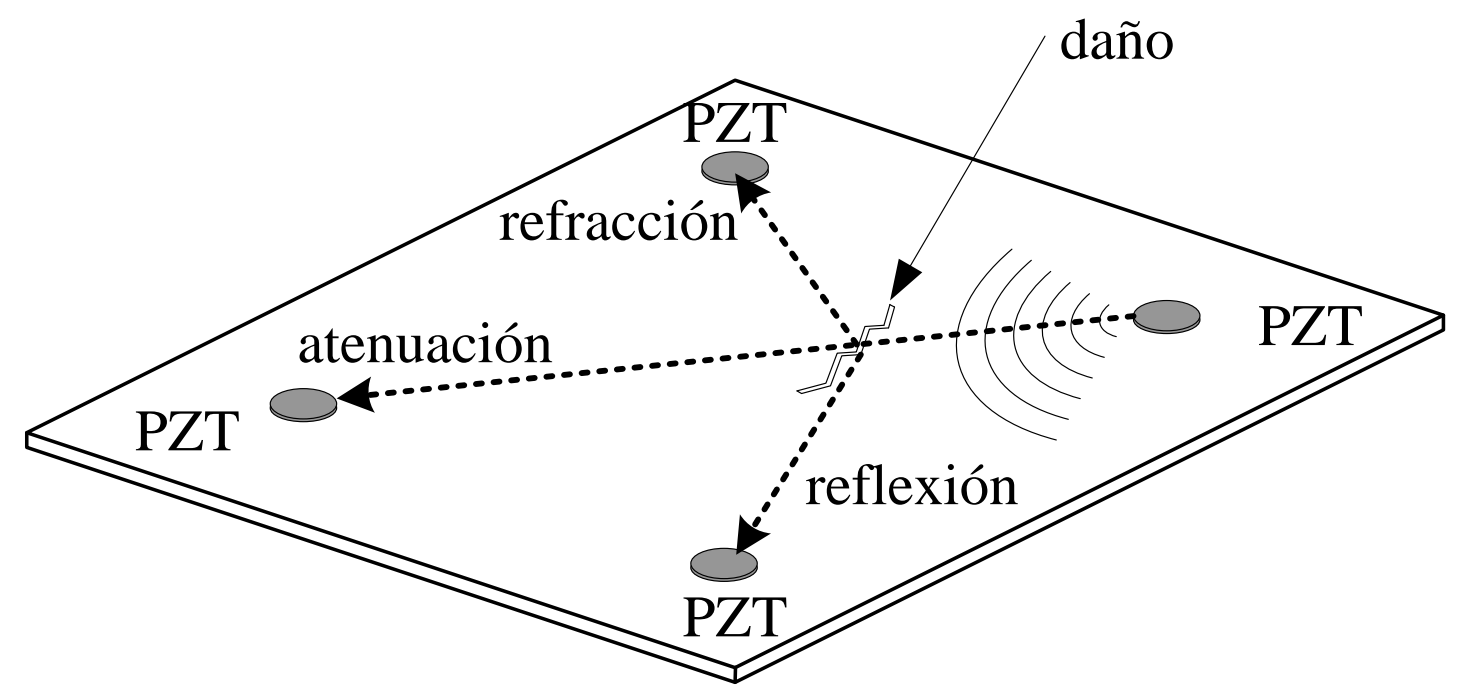

Figura 18 - Fenómenos que sufren las ondas elásticas al encontrarse con un daño.

La onda elástica modificada se mide en un PZT sensor y comparando con una situación de referencia, se infiere la presencia/posición/características de daño.

Sin embargo en el mundo real, la presencia de condiciones ambientales y de operación también modifica el problema introduciendo incertidumbres:

- Modificando la estructura. Cambios de temperatura o de estado de cargas modifican la geometría y conectividad de la misma cambiando el medio por el que se propagan las ondas.

- Modificando el comportamiento del sensor. De nuevo los cambios en el propio sensor pueden hacer que respuesta ante la misma onda elástica cambie según las condiciones de trabajo. 
Todo lo anterior modifica las características de propagación de las ondas elásticas guiadas. Este cambio produce resultados equivalentes a los que produce la presencia del daño, haciendo indistinguible su presencia.

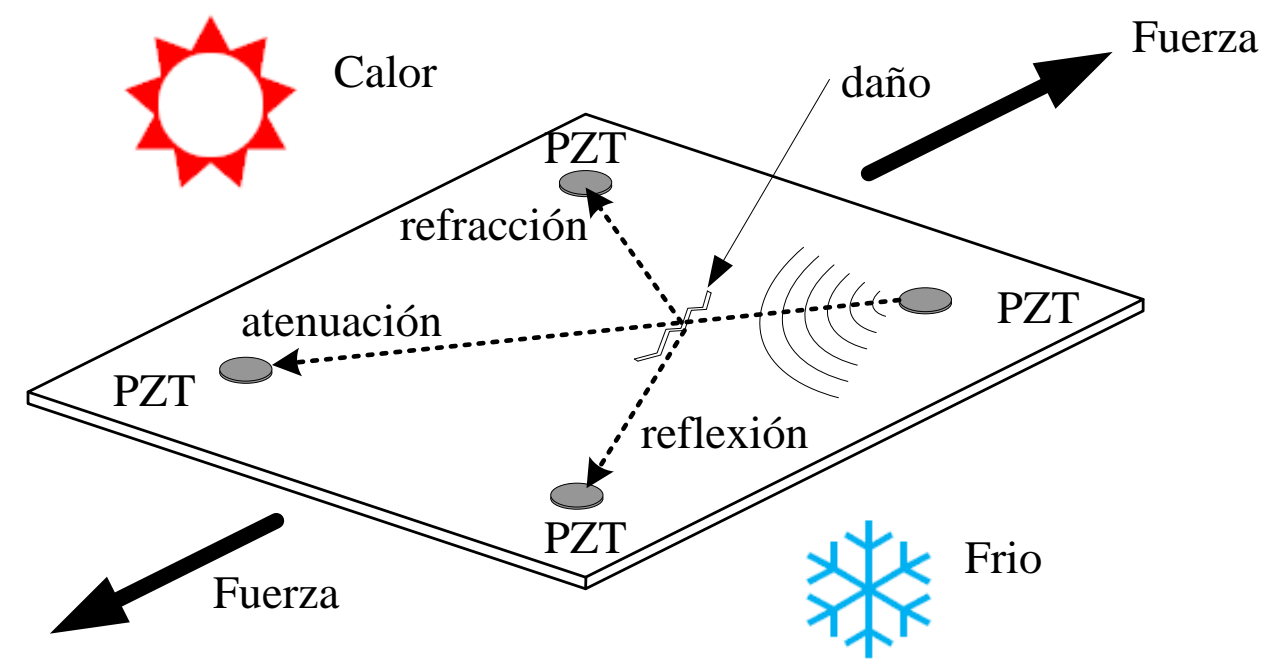

Figura 19 - Efecto de las EOC en la detección de daño.

Nuestro objetivo será medir todos los parámetros que tengan que ver con las condiciones ambientales y de operación de la estructura (EOC) simultáneamente con la firma del daño en la DSF. Con estos datos se efectúa un modelo para compensar el efecto de las EOC y dejar únicamente el efecto del daño sobre la DSF.

Para comprender el problema en profundidad se van a estudiar los elementos que forman parte del mismo:

- Ondas elásticas en estructuras.

- Detección de daño mediante ondas elásticas.

- Interacciones entre el daño y las ondas elásticas. Efecto del daño sobre la DSF.

- Interacción entre las EOC y las ondas elásticas. Efecto sobre la DSF.

- Aproximaciones existentes para solucionar el problema. Eliminar el efecto que producen las EOC sobre la DSF. 


\subsection{Ondas elásticas en estructuras aeronáuticas}

Cuando se perturba un sólido elástico sacándolo de su situación de equilibrio se generan ondas en el mismo[62]. Las ondas pueden ser de diversos tipos[59]:

- Ondas viajeras, cuando el medio es infinito

- Ondas estacionarias. Cuando el sólido es finito y la solución alcanzada tras la perturbación es estacionaria. Durante un breve intervalo de tiempo. Son los denominados modos propios del sólido.

- Ondas guiadas. De nuevo cuando el sólido es finito y la solución es una onda que se propaga por el sólido.

En esta tesis nos interesan las ondas del tercer tipo. Este tercer tipo de ondas también tienen subtipos en función de cómo sea el sólido en el que se propagan [60].

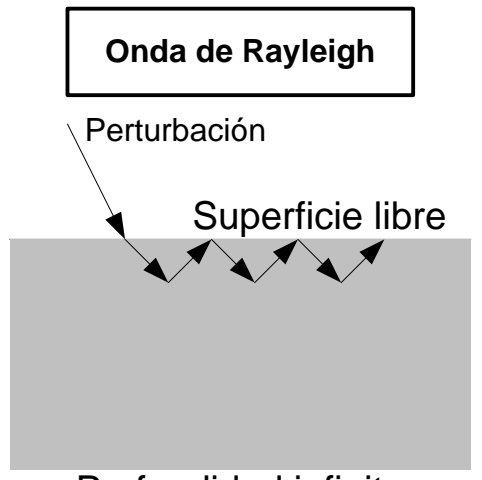

Profundidad infinita

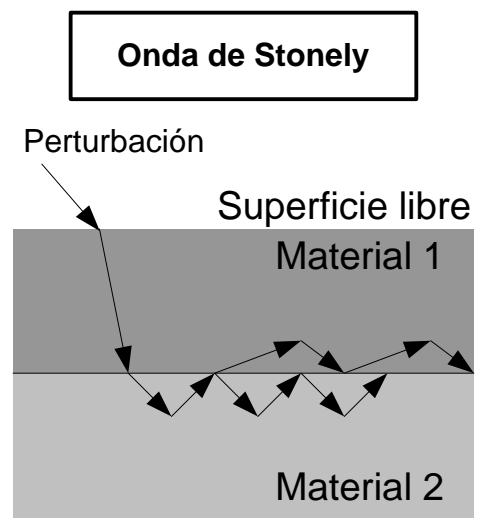

Onda de Lamb

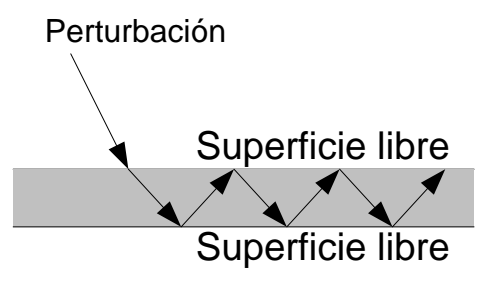

Figura 20 - Ondas elásticas guiadas en un sólido elástico [9].

Los tres tipos de ondas guiadas son las siguientes:

- Ondas de Rayleigh. Aparecen superficialmente en la superficie libre de un sólido elástico de gran espesor. De modo equivalente a este tipo de ondas aparecen otras similares pero con polarización horizontal, en el planto superficial, denominadas ondas de Love.

- Ondas de Stonely. Aparecen cuando hay dos sólidos en contacto diferentes.

- Ondas de Lamb. Aparecen en un sólido de pequeño espesor.

Debido al tipo de estructura con la que trabajamos nos interesarán las últimas las ondas elásticas guiadas de Lamb. Este tipo de ondas será el que utilizaremos para la detección de daño, al igual que en otros muchos estudios desde que dicha factibilidad se demostró por parte de Worlton en 1961[151]. 
Hasta este punto, sabemos qué tipo de ondas vamos a utilizar, sin embargo es necesario analizar su naturaleza de un modo más profundo. Para ello echaremos un vistazo a las soluciones que ofrece la literatura para la ecuación elasto-dinámica para el tipo de estructuras de pared delgada que nos ocupan. Indicamos la existente en [152] aunque se pueden encontrar otros desarrollos semejantes y más simples [62] y [115]

En líneas generales, partimos de la ley de Hooke.

$$
\sigma_{i j}=c_{i j k l} \epsilon_{k l}
$$

Considerando la ecuación del movimiento, segunda ley de newton (ecuación elastodinámica).

$$
\rho \ddot{u}_{\imath}=\frac{\partial}{\partial x_{i}} \sigma_{i j}=c_{i j k l} \partial_{j} \partial_{l} u_{k}
$$

Se buscan soluciones de ondas guiadas del siguiente tipo.

$$
\bar{u}=\bar{g} e^{i w(t-\bar{s} \cdot \bar{x})}
$$

Siendo g, la polarización de la onda, s el vector de velocidades y x el vector de posición. Y se introduce en la ecuación elastodinámica.

$$
\left(c_{i j k l} s_{j} s_{l}-\rho \delta_{i k}\right) g_{k}=0
$$

Y se definen los siguientes parámetros:

$$
\Gamma_{i j k l}=\frac{c_{i j k l}}{\rho} \quad y \quad M_{i k}=\Gamma_{i j k l} \tilde{s}_{j} \tilde{s}_{l}
$$

Introduciéndolos en la ecuación se obtiene la ecuación de Christoffel:

$$
\left(\Gamma_{i j k l} \tilde{s}_{j} \tilde{s}_{l}-c^{2} \delta_{i k}\right) g_{k}=0
$$

Siendo c la velocidad de fase de las ondas elásticas.

Según el medio en el que se solucione esta ecuación se obtendrán un tipo de ondas u otras.

En el caso que nos ocupa son placas de pared delgada, que fue la solución que desarrolló $\mathrm{H}$. Lamb en 1917 [56].

Una discusión de la solución de dicha ecuación de un modo menos matemático y más compresible se puede encontrar en el Anexo 1, capítulo 8.

Tal y como indica Lamb en su artículo (y como se desarrolla con detalle en el Anexo 1, capítulo 8) la solución de esta ecuación para paneles de pequeño espesor metálicos isotrópicos nos proporciona las velocidades de las ondas con las que vamos a trabajar: 
- Velocidad de fase. Se obtiene directamente como solución de la ecuación de Christoffel: $v_{\text {fase }}=\frac{\omega}{k}=\frac{2 \pi f}{k}$

- Velocidad de grupo. Que se calcula a partir de la velocidad de fase: $v_{\text {grupo }}=\frac{\partial w}{\partial k}$

Para nuestro material de trabajo, aluminio, isotrópico y un espesor de placa típico se obtienen dos tipos de soluciones (se puede encontrar más información sobre el proceso de obtención en el Anexo 1) simétricas y antisimétricas.

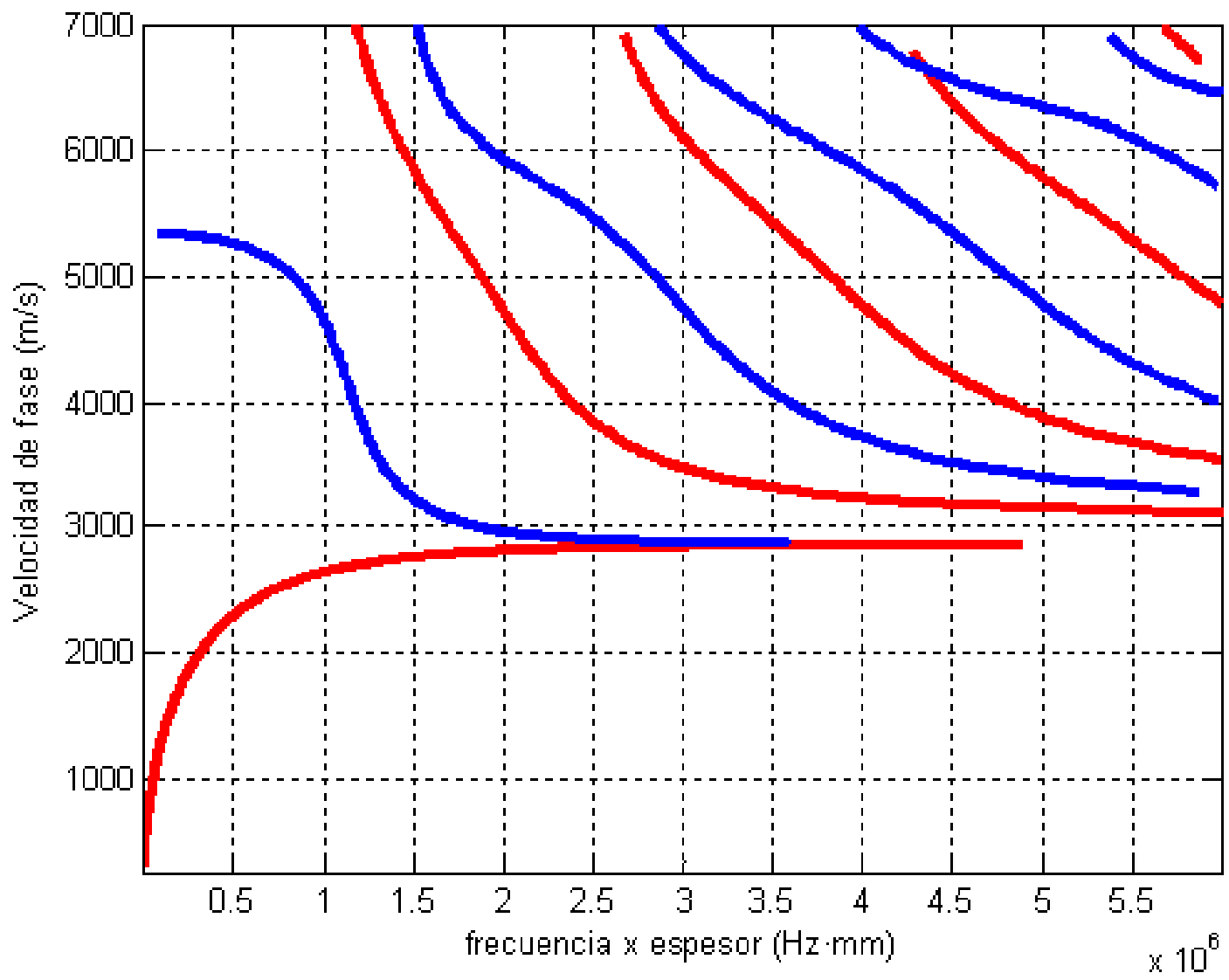

Figura 21 - Velocidades de fase. Modos simétricos en azul y modos antisimétricos en rojo.

La zona de interés, para el trabajo de la presente tesis se encuentra hasta $1 \mathrm{MHz} \cdot \mathrm{mm}$, por encima de esa zona no se suele trabajar.

En dicha zona existen dos modos de propagación, denominados A0 y SO. Primer modo anstisimétrico y primer modo simétrico. El modo simétrico corresponde a la solución de la onda de presión (modo de tracción compresión) y es el más rápido. El modo antisimétrico corresponde a la onda de flexión de polarización vertical, en el espesor de la placa. Se denomina primer modo de flexión y es un poco más lento que el anterior. 
Cuando perturbamos una estructura tipo placa, estamos excitando estos modos de propagación que coexistirán propagándose por la estructura según sus velocidades.

Podemos comprobar también que se trata de un problema dispersivo ya que la velocidad de propagación depende de la frecuencia del modo. Siendo mucho más dispersivo el modo de flexión que el de presión, en la zona de interés.

Para dicha zona se calculan adicionalmente las velocidades de grupo de este tipo de ondas, que será las que posteriormente utilizaremos para trabajar, es la velocidad a la que se propaga la energía de la onda y por lo tanto la información [57].

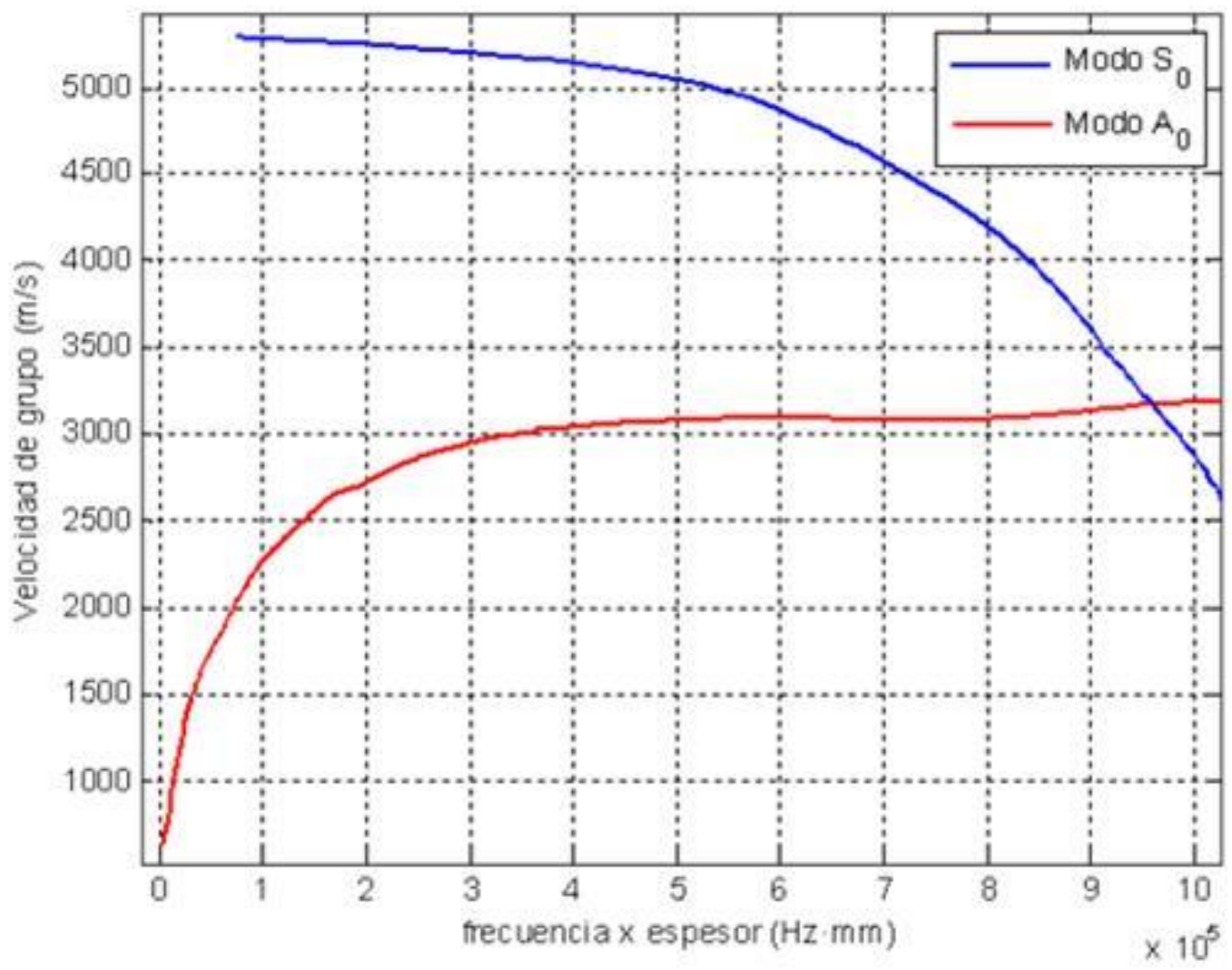

Figura 22 - Velocidades de grupo de los dos primeros modos de las ondas de Lamb.

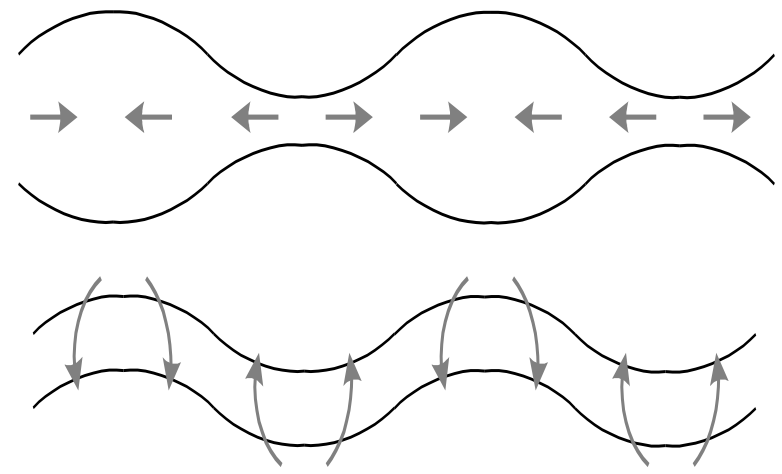

Figura 23 - Modo tracción compresión (S0, arriba) y flexión (A0, abajo) 
El objetivo de esta tesis es fundamentalmente práctico. Por lo tanto, el interés en cuanto a las ondas elásticas y los modos de propagación se limita a su utilización para la detección de daño y todos los fenómenos colaterales.

En este punto hemos obtenido las denominadas curvas de dispersión, dibujadas en las figuras anteriores. Estas curvas indican dos factores necesarios a la hora de empezar a trabajar con ondas elásticas guiadas de Lamb para la detección de daño, dada una determinada perturbación definida por su frecuencia y el espesor de la placa que se perturba:

- Definen los modos de propagación que existen en esas condiciones. En esta tesis se utilizarán frecuencias por espesores que mantengan este parámetro por debajo de $1 \mathrm{MHz}$ por mm asegurando la existencia de únicamente dos modos de propagación A0 y S0.

- Indican la velocidad a la que se propagarán las ondas (cada uno de los modos). Este dato será de gran ayuda a la hora de efectuar el análisis de las señales.

Este tipo de ondas, generadas adecuadamente se propagan largas distancias [151] sufriendo una atenuación inversamente proporcional a la distancia recorrida, permitiendo inspeccionar amplias áreas de la estructura con cierto detalle. Es la diferencia fundamental con los métodos de inspección no destructiva (NDI, NDT) los cuales son muy locales. Es por lo tanto la razón fundamental de su selección, ofrecen una metodología de detección muy similar a las NDT pero en un área más amplia.

Existen aspectos fundamentales relacionados con su generación. Se han seleccionado sensores PZT para dicha tarea y respecto al hilo conductor de esta tesis solo indicaremos en este punto que dichos sensores permiten generar pulsos controlados de este tipo de ondas y medirlos.

En el Anexo 2, capítulo 9, se hace una breve disertación de porqué se han elegido este tipo de sensores para generar ondas elásticas guiadas de Lamb y medir la respuesta de la estructura en los mismos términos.

Los aspectos prácticos de la generación de dichas ondas y la medición se indican en los apartados correspondientes a la realización experimental.

En este punto solo es necesario saber que generamos GLW mediantes un sensor PZT, dicha onda se transmite por la estructura. En dicha transmisión sufrirá modificaciones relacionadas con la presencia de daño y las EOC hasta llegar al PZT receptor que convertirá dicha GLW modificada en una señal que analizaremos.

En los siguientes apartados veremos como el daño y las EOCs modifican las características de la onda, las diversas metodologías existentes para separar ambos efectos y que se propone en esta tesis para hacerlo de una manera más eficiente. 


\subsection{Detección de daño mediante ondas elásticas guiadas}

La detección de daño mediante GLW se fundamenta en el análisis del camino de daño. Este camino es la distancia que recorre la onda entre un actuador y un sensor. En este apartado se estudia la interacción de las GLW con los defectos estructurales y que modificaciones producen en la DSF para establecer la firma del daño en la misma.

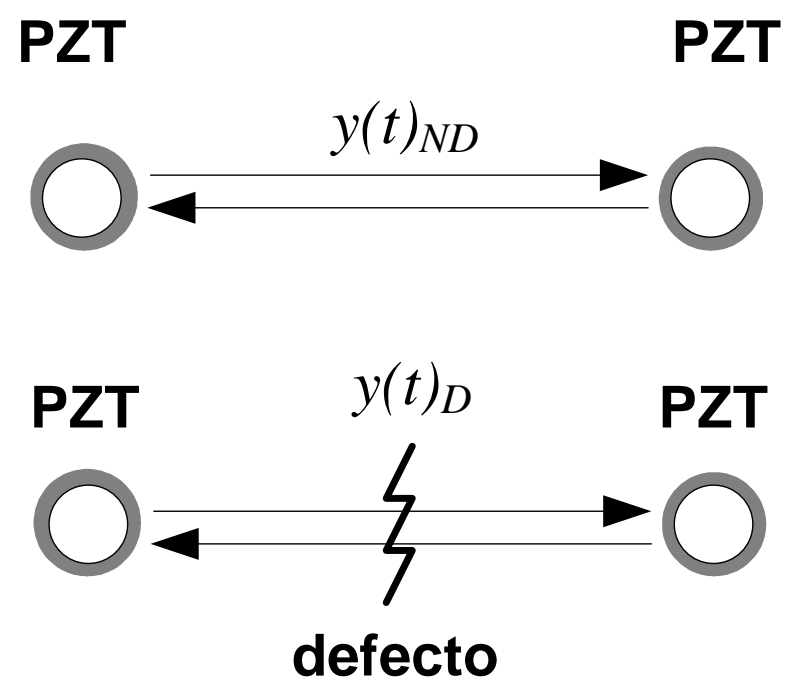

Figura 24 - Definición del camino de daño.

Según la definición indicada en la Figura 24 las GLW recorrerán ese camino en situaciones con y $\sin$ daño. A partir de las señales adquiridas en situaciones de referencia y en situaciones de daño se pueden generar indicadores de daño. En la literatura se denominan índices de daño [28][151]. Estos índices comparan la firma del daño en la DSF en dos situaciones diferentes a partir de los datos de señales adquiridas, presentando un determinado valor cuando una de las situaciones presenta daño. Para que este esquema se pueda aplicar ha de cumplirse la siguiente condición [22]:

$$
\text { dispersión }(N D-N D) \sim \operatorname{dispersión}(D-D) \ll \operatorname{dispersión}(N D-D)
$$

Esto quiere decir que si comparamos situaciones sin daño la dispersión es similar las que tienen las situaciones sin daño entre sí. Sin embargo son mucho menores que la comparación entre la situación sin daño y con daño. Esto se ha verificado anteriormente para esta misma técnica SHM [22].

En esta tesis se utilizará como DSF la primera llegada del modo GLW S0 al piezoeléctrico sensor. De esta primera llegada se extraerán las firmas que produce el daño en esa zona de la señal medida. La utilización de este modo S0 y la influencia del daño sobre el mismo ha sido ampliamente estudiada para el caso de grietas, que serán los defectos que utilizaremos [167][151]. Más adelante se indicará el tipo de análisis que se realiza sobre los datos de dicho 
modo que incluirá tanto análisis en el plano del tiempo como en el plano tiempo-frecuencia. En estos estudios se indica la idoneidad de utilización de este modo de propagación por las siguientes razones[172]:

- En las frecuencias de trabajo presenta baja dispersión de velocidades de grupo lo que permite que su propagación alcance grandes distancias con pequeñas atenuaciones.

- Es el modo más rápido, en la zona de trabajo. Llegará antes al sensor minimizando las interacciones con elementos de la estructura fuera de la zona de análisis.

- Existe una relación comprobada entre su atenuación y la presencia de daños, en el camino de daño.

A la hora de evaluar la influencia del daño en la GLW no solo hay que tener en cuenta la presencia del daño (junto con las EOC) sino que las ondas se propagan por una estructura real en la que existen rigidizadores, cambios de espesor, distintos materiales, etc. En nuestro caso esto no será de vital importancia puesto que los valores que se utilizarán para evaluar la presencia incluyen la influencia de todos estos elementos de modo indirecto a través de los datos experimentales. Mientras toda esa configuración estructural no cambie (conectividad de la estructura al que se aplica la técnica SHM) su influencia no aparecerá reflejada en los resultados, y si cambia se deberá a un cambio en la conectividad, que como se ha comentado anteriormente, se considera un daño y por lo tanto lo detectaremos.

Resumiendo, y teniendo en cuenta que la DSF seleccionada es la deformación inducida por las ondas elásticas:

- Utilizaremos la primera llegada del modo S0 de la GLW. Analizando una porción de señal que dependerá de la longitud del pulso de interrogación que se haya utilizado para generar dicha GLW en el actuador.

- La firma del daño en la DSF será, principalmente, una atenuación en la misma.

De modo particular se generan pulsos eléctricos en el PZT actuador con las siguientes características [28]:

- Frecuencia de interrogación, la frecuencia principal portadora del pulso, $f$.

- Amplitud de interrogación amplitud total del pulso, $V_{0}$

- Número de picos del pulso, el número de periodos de la frecuencia de interrogación, $n_{\text {burst }}$.

- Ventana de modulación, distribución de valores que modula la portadora, Hanning $(t)$. Estos parámetros se pueden visualizar en la Figura 25. 


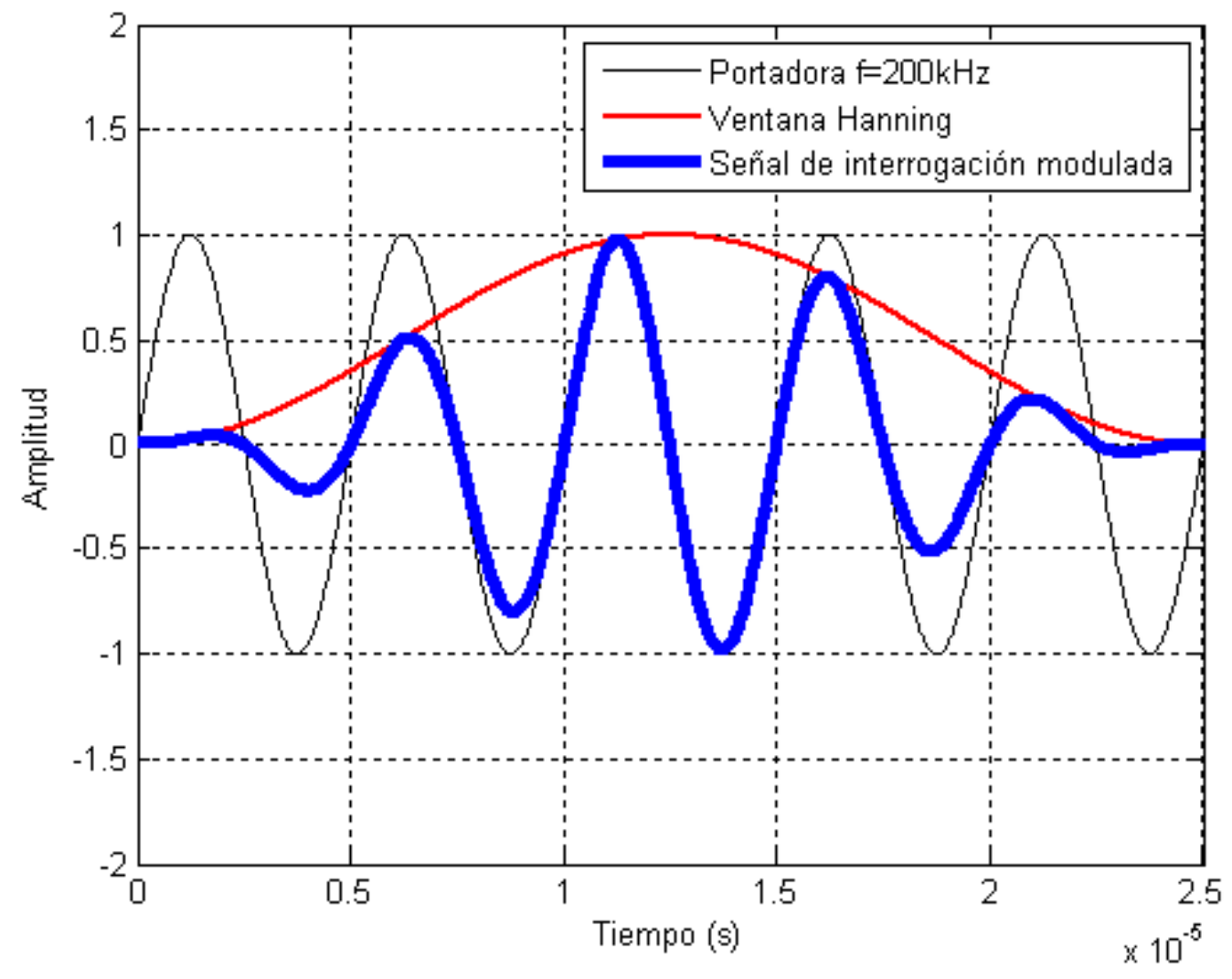

Figura 25 - Señal de interrogación de $200 \mathrm{kHz}$ introducida en el PZT actuador

Para este tipo de señales de interrogación, la frecuencia de interrogación será la de la portadora. La amplitud de interrogación vendrá dada por la moduladora tipo Hanning. El tipo de burst (el número de picos) se consigue modulando un determinado número de periodos de la portadora, en nuestro caso 5 .

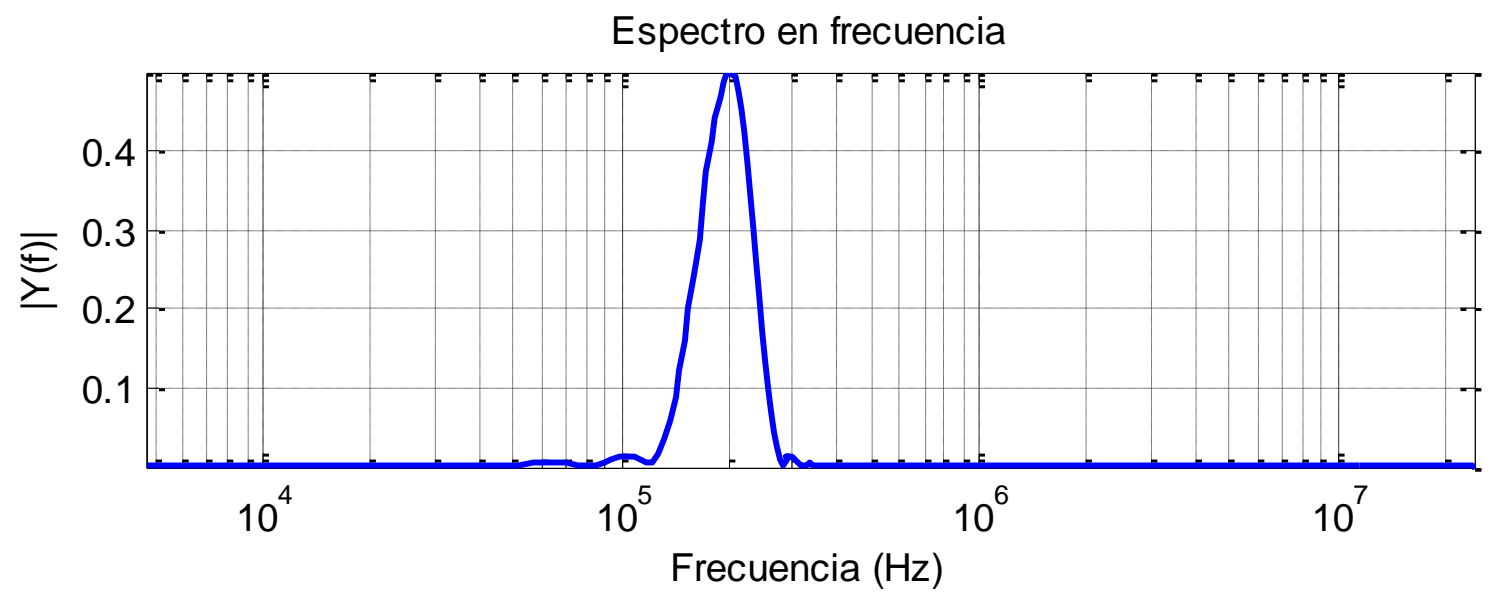

Figura 26 - Espectro en frecuencia de la señal de interrogación. 
La razón de uso de este tipo de señales es fundamentalmente su ancho de banda controlado, lo que permite una dispersión en las velocidades dependientes de la frecuencia mínima (ver Figura 21) maximizando la longitud de propagación del pulso con una atenuación pequeña debida al carácter dispersivo de la misma. Esto se puede comprobar en la Figura 26 comprobando la anchura del espectro en frecuencia. Si se introduce el ancho de banda de la señal en las curvas de dispersión del material (corregido con el valor correspondiente del espesor) se pueden calcular la diferencia entre la velocidad máxima y mínima del pulso enviado. Cuanta mayor sea la diferencia sea la diferencia entre ambas velocidades más dispersivo será el comportamiento del pulso enviado y menor distancia recorrerá antes de desaparecer.

Asociado a este tipo señales de interrogaciones aparece un parámetro que permite evaluar la resolución en términos de detectabilidad de daño. La resolución o MRD ( Minimum Resolvable Distance) [173][151]. Este parámetro permite establecer un orden de magnitud para el tamaño de daño mínimo detectable mediante una señal de interrogación concreta. Es un parámetro que está asociado al comportamiento dispersivo del pulso enviado.

$$
M R D=\left.\frac{V_{0}}{t}\left(l\left(\frac{1}{v_{\min }}-\frac{1}{v_{\max }}\right)+T_{\text {initial }}\right)\right|_{\min }
$$

Siendo $v_{0}$ la velocidad de grupo del pulso para la frecuencia de interrogación. El espesor característico $t$. La distancia típica de propagación $l$.Las velocidades $\left(v_{\min }, v_{\max }\right)$ las velocidades de grupo del pulso enviado acorde a las frecuencias máxima y mínima de actuación teniendo en cuenta el ancho de banda real del pulso $\left(f_{\min }, f_{\max }\right)$ calculadas según las siguientes ecuaciones:

$$
\begin{aligned}
& f_{\text {min }}=f_{0}\left(1-\frac{k}{n_{\text {burst }}}\right) \\
& f_{\text {max }}=f_{0}\left(1+\frac{k}{n_{\text {burst }}}\right)
\end{aligned}
$$

Siendo $k$ un valor que depende del ancho de banda del pulso de interrogación y que en nuestro caso tiene un valor de 1.9 (se calcula evaluando una atenuación en el espectro de $40 \mathrm{~dB}$ respecto del máximo, para más detalles sobre su cálculo ver [173]).

Y finalmente $T_{\text {initial }}$ es la duración del pulso de interrogación.

Para nuestro problema se puede efectuar un análisis rápido del orden de magnitud del MRD para saber dónde está el límite de detectabilidad de la técnica SHM utilizada.

$$
T_{\text {initial }} \sim 10^{-5} \mathrm{~s} ; v_{0} \sim \frac{10^{3} \mathrm{~m}}{\mathrm{~s}} ; t \sim 10^{-3} ; l \cdot\left(\frac{1}{v_{\min }}-\frac{1}{v_{\max }}\right) \sim 10^{-5} \mathrm{~s} \rightarrow(M R D \cdot t) \sim 10^{-2} \mathrm{~m}
$$

Típicamente, los daños mínimos detectables están en el orden de $1 \mathrm{~cm}$ para los valores usuales de trabajo en esta tesis. 


\subsection{Efecto de las condiciones ambientales y de operación}

Una vez seleccionada la DSF y la firma del daño en la DSF vamos a comprobar cómo influyen las EOC en la DSF modificando, de forma perniciosa, dicha firma.

La mayoría de las técnicas SHM similares se aplican en términos globales sobre una estructura utilizando también una técnica pitch-catch o transmisor-receptor utilizando una red de sensores [28].

Los datos de las ondas elásticas adquiridas por estos sensores se procesan para determinar si la estructura tiene daño (por comparación con una situación anterior).

Sin embargo las condiciones ambientales y de operación, tales como la temperatura y el estado de carga, en dicha estructura afectan a los datos adquiridos por la red de sensores. Esta interferencia puede modificar las características de la onda causando errores en la determinación de la integridad de dicha estructura[28].

Como se ha comentado anteriormente en esta tesis, la unidad fundamental de trabajo para nosotros es el camino de daño, el camino que recorre la onda entre el transmisor y el receptor, ya las modificaciones que puede sufrir la misma debida a las EOC [160].

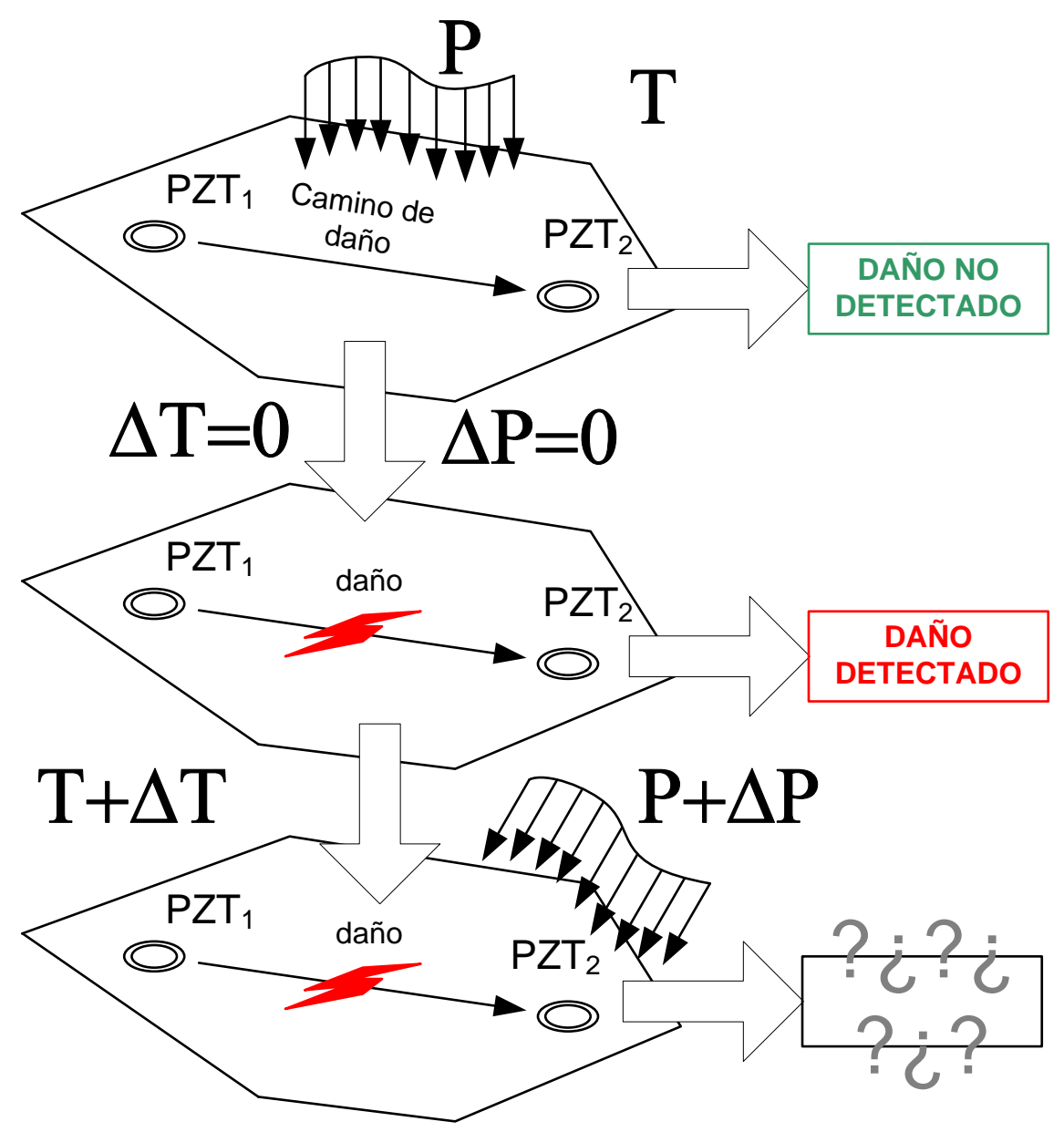

Figura 27 - Efecto de las condiciones ambientales y de operación en el camino de daño. 
Existen diversas maneras para compensar los efectos de la temperatura. Se pueden clasificar en cuatro grupos diferentes:

- Analíticos o FEM.

- Experimentales

- Insensibilidad a las EOC

- Híbridos

Los modelos teóricos pertenecen al primer grupo, en este tipo de modelos se trata de reproducir el efecto que tiene por ejemplo la variación de temperatura sobre la propia onda elástica. La técnica denominada Baseline Signal Stretching (BSS) pertenece a este primer grupo. [160].

En el segundo grupo hay métodos que utilizan únicamente datos experimentales para compensar dichos efectos. Suelen fundamentarse en una gran base de datos experimentales con los que comparar las situaciones de daño, adquiridos para una gran variedad de situaciones ambientales y operacionales. Una técnica de amplio uso perteneciente a este grupo es la selección de señal de referencia óptima o OBS (Optimal Baseline Selection), en la que, en función de las condiciones a las que se tome la medida para comparar con la referencia se selecciona una señal u otra de referencia de entre las disponibles en la base de datos [160].

El tercer grupo utiliza directamente características sensibles al daño que no son sensibles a las EOC. Con técnicas de este tipo la compensación de estos efectos es innecesaria puesto que no modifican la firma del daño en la DSF [168].

El cuarto grupo lo hemos denominado híbrido puesto que utiliza modelos y además datos experimentales. Dentro de este grupo existen modelos físicos cuyos parámetros se ajustan con ensayos [164]. Este tipo de modelos están muy limitados por las hipótesis de comportamiento físico realizadas. Sin embargo esta limitación se puede sortear substituyendo el modelo físicomatemático por un modelo data-driven. El método propuesto en esta tesis pertenece a este grupo. Se utilizan modelos de Inteligencia Artificial, las ANN para generar modelos de compensación de las EOC ajustados con datos experimentales.

El efecto de la temperatura sobre la GLW consiste en una combinación de retrasos y atenuaciones respecto a la GLW de referencia. [161].

Si existiesen más EOC, además de la temperatura la forma de onda se modificaría de un modo similar incluyendo cambios más complejos como puede ser la fase de la onda o la frecuencia de la misma.

Estos efectos deben ser compensados en la GLW adquirida por los sensores para cada combinación particular de EOC en la que tiene lugar la interrogación de la estructura. 
En todos los casos se necesitará medir alguna cantidad que defina dichas EOC para poder ser utilizada como dato de entrada al modelo de compensación.

La principal razón para eliminar el efecto de las EOC es para poder comparar las dos medidas de la estructura, en términos de GLW, intentando que la única variable no controlada del proceso y que por lo tanto se refleje en cambios en la firma sobre la GLW sea el daño presente en el camino de daño.

Esta modificación del camino de daño podría ser por la presencia de un daño o algún cambio en la geometría o las condiciones de contorno del mismo (lo que anteriormente se ha denominado conectividad del sistema.

Nuestro objetivo es extraer la interacción del daño con la GLW, la firma de daño en la DSF, en la señal adquirida en el receptor y para ello habrá que eliminar todos los efectos colaterales que producen las EOC.

Esta situación que aquí describimos es bien conocida en la literatura [162][160]. Y, en el caso de estructura aeronáuticas muy importante si consideramos la variabilidad de EOC que presentan. Por ejemplo, tendremos un rango de variación de temperatura que va desde $\operatorname{los}-70^{\circ} \mathrm{C}$ en vuelo hasta los $60^{\circ} \mathrm{C}$ en tierra. 


\section{Compensación de EOC mediante redes neuronales artificiales}

\subsection{Planteamiento}

Hemos comprobado que existen múltiples aproximaciones para compensar los efectos de las condiciones ambientales (EOC) y de operación en la detección de daño.

Tenemos métodos como la selección de referencia óptima (OBS) que pueden llegar a tener gran precisión en la compensación, sin embargo necesitan generar enormes bases de datos que recorran todas las posibles combinaciones de EOC con las que se va a encontrar la estructura. Esto es una gran desventaja para su utilización en estructuras aeronáuticas reales ya que la cantidad de situaciones con diferentes valores de EOC que se presentan en su utilización real es enorme y muy difícil de definir a priori.

También tenemos otras metodologías como el Baseline Signal Stretching (BSS). Son métodos más o menos sencillos que proporcionan una solución analítica para casos de compensación en estructuras sencillas. Sin embargo obtener estas soluciones para estructuras reales con una precisión aceptable es prácticamente imposible. Habría que acudir a modelos de elementos finitos de la estructura (FEM) que habría que simular en todas las condiciones de operación y ambientales. Se vuelve al problema de la OBS, enormes cantidades de datos, coste computacional elevadísimo y EOC reales difíciles de definir a priori para poder ser simuladas adecuadamente.

Por lo tanto proponemos aquí una metodología híbrida que necesita una cierta cantidad de datos experimentales (pero no enorme como en la OBS) y utiliza modelos de IA como son las ANN que se ajustan con dichos datos. La utilización de datos experimentales nos permite acercarnos a la precisión que tendría una metodología puramente experimental. La selección de un modelo ANN para ser ajustado por dichos datos permite tener la flexibilidad de un modelo analítico en su utilización.

En detalle el método tiene un objetivo muy sencillo. Separar la firma del daño y la firma de las EOC en la DSF. Crear un modelo que relacione la firma de las EOC en la DSF a partir de los parámetros que definen dichas condiciones (temperatura, estado de carga, etc). Aplicarlo a la DSF y así aislar la firma del daño en la misma.

Para esta metodología, además de los modelos de IA, las Redes Neuronales Artificiales, utilizaremos técnicas de procesado de señal como la transformada de Chirplet (CT) para ayudarnos a reducir la cantidad de datos con los que tiene que trabajar el modelo sin disminuir la cantidad de información contenida en los mismos.

Existen tres aspectos destacados y novedosos de la metodología propuesta: 
- Complejidad de la estructura. Siempre para el tipo de estructura considerada, paneles rigidizados de pared delgada, el método de compensación es independiente de dicha complejidad puesto que utiliza directamente para ajustarse los datos experimentales sin efectuar hipótesis adicionales de simplificación. Modelos analíticos o FEM no permiten independencia de la complejidad estructural.

- Propiedades de los materiales. La metodología es prácticamente independiente del material de la estructura. De nuevo al utilizar datos experimentales esa información queda incluida en los mismos. Sólo habrá que tener en cuenta el material a la hora de calcular el campo de velocidades en el mismo para la captura del modo S0 de la GLW.

- Sensores. Aunque la metodología se ha planteado para piezoeléctricos como sensor y actuador, se podría usar con cualquier tipo conjunto de sensores capaz de reproducir un esquema transmisor receptor de GLW. Se efectúa esta comprobación sustituyendo algunos receptores PZT pro FBG en la parte experimental.

- Extracción de las firmas de daño y EOC de la DSF. Se plantea la utilización de la CT para realizar dicha tarea y alimentar los modelos ANN. Se soporta en resultados exitosos previos para el cálculo de las velocidades de dispersión[155] o los análisis de problemas físicamente semejantes en el plano tiempo-frecuencia [107][154][156][157].

- Modelos. La metodología aprovecha la potencia de las ANN para buscar relaciones físicas subyacentes muy complejas de modelar entre la presencia de daño junto con las EOC y los parámetros medibles del sistema.

Dicho esto, la manera de proceder en la realización experimental y construcción del esquema de compensación será la siguiente:

1. Estudio de la influencia de las EOC para un camino de daño. Planteamos una serie de experimentos en los que para una estructura sencilla que podría asimilarse a un camino de daño aislado:

a. Interrogamos la estructura variando alguna EOC, la temperatura.

b. Interrogamos la estructura introduciendo un daño

c. Adquirimos los datos.

d. Evaluamos como la CT resume esa información en una serie de coeficientes con tres objetivos:

i. Coeficientes influenciados por la EOC

ii. Coeficientes influenciados por el daño 
iii. Comprobación de los posibles acoplamientos

e. Ajuste del modelo ANN utilizando como datos los coeficientes de la CT de las señales adquiridas

f. Validación del modelo ANN usando datos diferentes:

i. Comprobación de compensación de la EOC

ii. Evaluación de la presencia del daño.

2. Una vez verificado el esquema más sencillo posible se aplica a una estructura compleja con múltiples caminos de daño. Esta es una situación realista en la que aplicar la solución evaluada en el conjunto de experimentos anterior:

a. Estructura bidimensional, curvada y rigidizada.

b. Variación de temperatura y estado de carga.

c. Introducción de diversos tamaños de daño.

d. Interroga la estructura en el conjunto de situaciones anteriores

e. Procesado de las señales mediante la CT

f. Generación de modelo ANN para esta estructura.

g. Aplicación del esquema completo de compensación para la detección de daño bajo EOC.

El objetivo final es verificar si el esquema propuesto es capaz de compensar las EOC y dejar únicamente la información del daño. 


\subsection{Realización experimental}

El objetivo general de todos los ensayos que se definen en este apartado es conseguir datos de interrogación de diferentes tipos de estructuras en situaciones con y sin presencia de daño bajo la influencia de las condiciones ambientales y de operación (EOC). El conjunto de experimentos se realiza para las siguientes estructuras.

Una estructura sencilla que simula un camino de daño entre transmisor y receptor. Esta estructura consta de dos pletinas idénticas, una utilizada como elemento de referencia y la otra como elemento dañado.

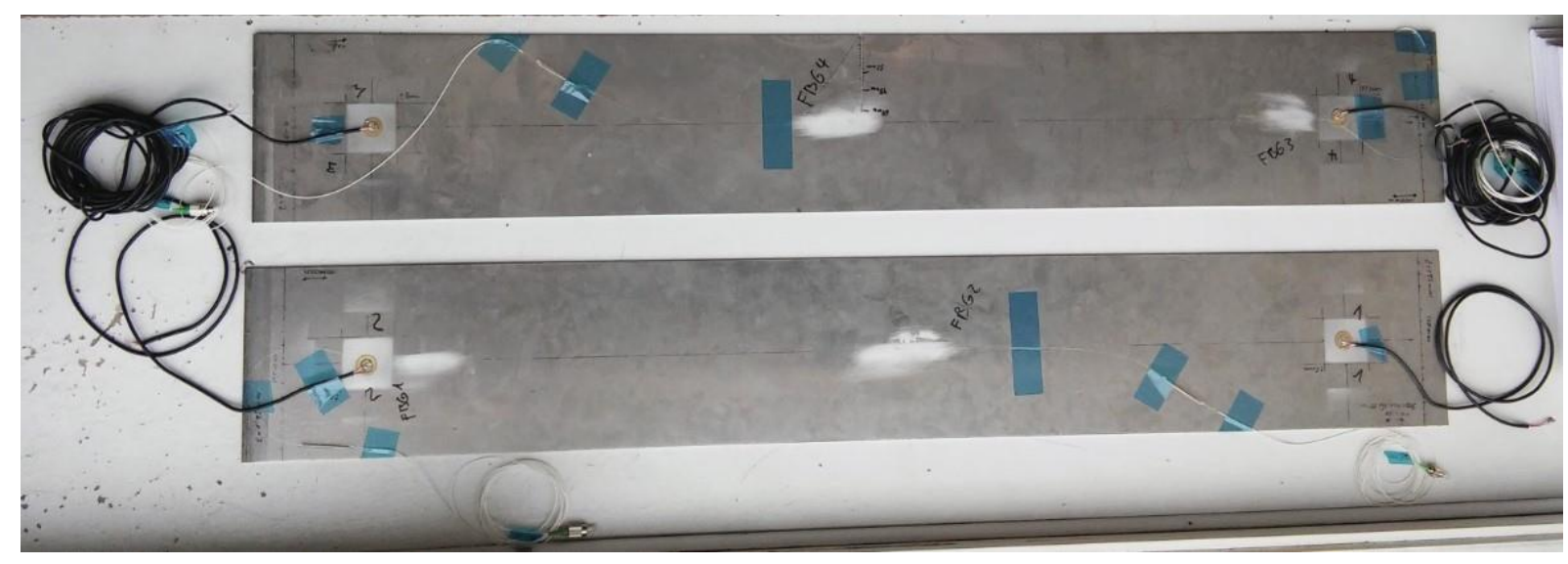

Figura 28 - Pletinas para los experimentos del camino de daño.

La otra estructura disponible es un segmento de fuselaje con cuadernas y rigidizadores.

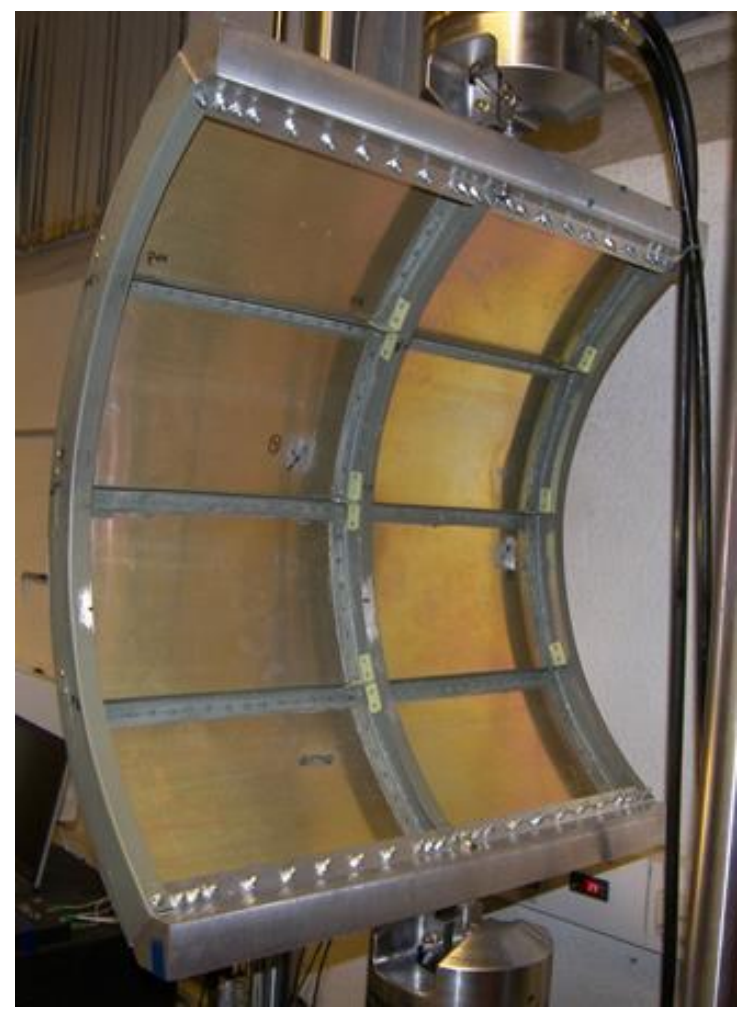

Figura 29 - Estructura tipo fuselaje. 
La realización de cada experimento tiene los siguientes pasos:

- Selección de la estructura. La decisión de la estructura a utilizar y el objetivo se definen en este apartado en las tablas superiores.

- Instalación de los sensores sobre la estructura y el sistema de adquisición de datos.

- Condiciones de ensayo. En particular y para nuestros experimentos serán las siguientes:

- EOC. Variación de temperatura y o de estado de carga.

○ Daño. Introducción y crecimiento.

- Instalación en el laboratorio de ensayo junto con los elementos adicionales necesarios para su realización.

- Cámara climática.

- Máquina de tracción

- Pruebas preliminares y realización.

- Revisión preliminar de los datos adquiridos para evaluar su calidad y corregir errores.

El análisis de resultados para todos los experimentos tiene los siguientes pasos.

El primer paso consiste en un análisis del efecto de la temperatura sobre la GLW y su diferenciación del efecto producido por el daño. Para poder evaluar estas interacciones se ha utilizado la Transformada Chirplet [158][154]. Se busca que coeficientes de esta transformada están relacionados con el cambio de temperatura [155]. El análisis tiene los siguientes objetivos:

- Definir la zona de la señal adquirida (GLW) que se va a analizar para poder detectar el daño.

- Comparar los cambios que induce la temperatura en las señales frente a los cambios que produce el daño para verificar si realmente esta EOC oculta la firma del daño en la DSF.

- Evaluar los coeficientes de la CT que están relacionados con los cambios de temperatura.

- Obtener las relaciones cualitativas entre los coeficientes de la CT y las variaciones de temperatura.

El segundo paso es la generación del esquema o modelo de compensación a partir de los coeficientes de la CT seleccionados y que se van a utilizar para ajustar la ANN [49][163]. Antes de utilizar los datos experimentales directamente, se valorará la factibilidad del modelo utilizando datos teóricos similares a los experimentales. Los objetivos de este segundo paso son: 
- Definición del esquema de compensación, denominaremos a este esquema modelo CTANN o CTANN

- Evaluación teórica del esquema de compensación.

- Evaluación experimental del esquema de compensación

El tercer paso de este conjunto de experimentos es la validación del modelo CT-ANN utilizando datos experimentales que no forman parte de su ajuste (Blind Test). 


\subsection{Estudios unidimensionales en pletinas, camino de daño}

Los ensayos en pletinas consisten básicamente en calentamientos y enfriamientos de las mismas, con y sin presencia de daño. El objetivo es evaluar la influencia de las EOC, en este caso la temperatura, su firma sobre la DSF y su interferencia con la firma del daño en la DSF.

Los ensayos para las pletinas y los objetivos particulares de cada uno de ellos se describen en la Tabla 5.

\begin{tabular}{|l|l|l|}
\hline ENSAYO & DESCRIPCIÓN & OBJETIVO \\
\hline 1 & Térmico Inicial & Variación de temperatura con las pletinas sin daño \\
\hline 2 & Daño Inicial & Daño en una de las pletinas \\
\hline 3 & Térmico 1 & Variación de temperatura en las pletinas con daño 1 en una de ellas \\
\hline 4 & Térmico 2 + FBG & Variación de temperatura en las pletinas con daño 1 usando sensores PZT y FBG \\
\hline 5 & Daño 2 + FBG & Incremento de daño 1 en una de las pletinas PZT y FBG \\
\hline 6 & Térmico 3 & Variación de temperatura pletinas con la presencia de daño 2 en una de ellas \\
\hline
\end{tabular}

Tal y como se comprueba en la tabla superior hay dos ensayos en los que se utiliza un sistema híbrido en los que se trabaja con sensores PZTs y también FBGs. El objetivo de estos ensayos es evaluar la técnica con diferentes tipos de sensores. La solución propuesta es independiente del tipo de sensor que mide la DSF (GLW) por lo que se miden datos con dos esquemas diferentes:

- Sistema PZT transmisor o actuador y PZT receptor o sensor de GLW.

- Sistema PZT transmisor o actuador y FBG receptor o sensor de GLW. 


\subsubsection{Definición de la estructura}

Las estructuras sencillas con las que trabajamos en este experimento son dos placas delgadas y alargadas de aluminio 7075 (la placa numero 1 tiene instalados los sensores PZT 1 y PZT 2, la placa número dos, los sensores PZT 3 y PZT 4).

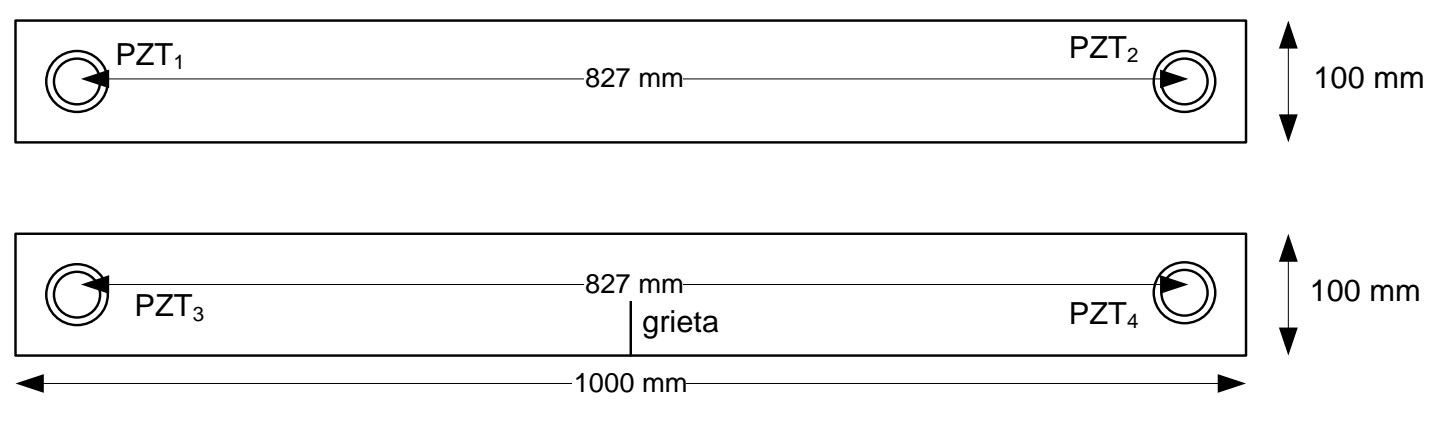

Figura 30 - Dimensiones de las pletinas y sensores piezoeléctricos.

Las propiedades mecánicas del material son las siguientes:

$$
\begin{aligned}
& \lambda=53.6 \mathrm{GPa} \quad \mu=26.5 \mathrm{GPa} \quad \rho=2800 \frac{\mathrm{Kg}}{\mathrm{m}^{3}} \quad c_{t}=3076 \frac{\mathrm{m}}{\mathrm{s}} \quad c_{l}=6208 \frac{\mathrm{m}}{\mathrm{s}} \\
& t=0.002 \mathrm{~m} \quad w=0.1 \mathrm{~m} \quad l=1 \mathrm{~m}
\end{aligned}
$$

En cada una de las placas los sensores PZT están situados en los extremos separados una distancia de $827 \mathrm{~mm}$.

Una de las pletinas no tiene daño y la otra ha sido dañada de modo progresivo en su zona media, donde se indica la grieta.

Esta configuración se ha seleccionado para simular la evolución del daño en un camino de daño.

De modo similar a los piezoeléctricos la pletina 1 tiene instalados los sensores FBG1, próximo al PZT2 y FBG2, en la zona central. La pletina 2 tiene instalado el sensor FBG4 en la zona de la grieta y el sensor FBG3 próximo al PZT4. Todos los sensores FBG se sitúan en la línea media de cada una de las pletinas.

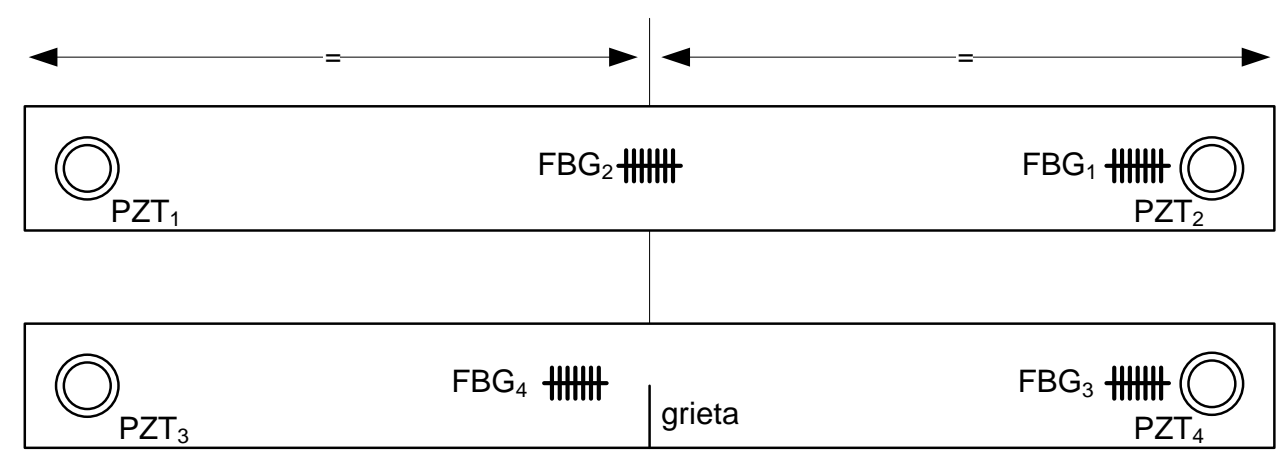

Figura 31 - Posición de los sensores FBG. 


\subsubsection{Instalación de sensores y sistema de adquisición de datos}

Ambos sistemas de adquisición de datos funcionan utilizando un esquema transmisor-receptor (pitch-catch) cuyas configuraciones de interrogación se detallan en la siguiente tabla.

Los sensores se pegan sobre una de las caras de la estructura tal y como se indica en la Figura 30 y se conectan a los diferentes sistemas de adquisición.

Se pueden encontrar más detalles de los sistemas que se indican en la Tabla 6 en el anexo 4, capítulo 11.

\begin{tabular}{|l|l|l|}
\hline $\begin{array}{l}\text { ELEMENTO DE } \\
\text { CONFIGURACIÓN }\end{array}$ & \multicolumn{2}{|l|}{ SISTEMA DE ADQUISICIÓN DE DATOS } \\
\hline & & Sistema National Instruments \\
\hline & & $\begin{array}{l}\text { PZT1-PZT2 } \\
\text { PZT2-PZT1 } \\
\text { PZT3-PZT4 } \\
\text { PZT4-PZT3 }\end{array}$ \\
$\begin{array}{l}\text { Patrón de interrogación actuador- } \\
\text { sensor }\end{array}$ & $\begin{array}{l}\text { PZT1-PZT2 } \\
\text { PZT2-PZT1 }\end{array}$ & $\begin{array}{l}\text { PZT1-FBG2 } \\
\text { PZT1-FBG1 } \\
\text { PZT2-FBG1 } \\
\text { PZT2-FBG2 }\end{array}$ \\
\hline $\begin{array}{l}\text { Peñal de interrogación } \\
\text { Precuencia de la señal de }\end{array}$ & PZT3 & $\begin{array}{l}\text { PZT3-FBG4 } \\
\text { PZT3-FBG3 } \\
\text { PZT4-FBG3 } \\
\text { PZT4-FBG4 }\end{array}$ \\
\hline $\begin{array}{l}\text { Resolución del conversor analógico } \\
\text { digital }\end{array}$ & 12 bit & $\begin{array}{l}\text { Burst de 5 picos modulado por una } \\
\text { ventana tipo Hanning }\end{array}$ \\
\hline $\begin{array}{l}\text { Frecuencia de muestreo de los } \\
\text { canales }\end{array}$ & 48000000 muestras por segundo \\
\hline $\begin{array}{l}\text { Utilización de amplificador de } \\
\text { señales }\end{array}$ & Si & 200 KHz \\
\hline $\begin{array}{l}\text { Promediado efectuado en las } \\
\text { adquisiciones } \\
\text { Sobremuestreo por software de los } \\
\text { datos adquiridos }\end{array}$ & No picos modulado por una & 2000000 muestras por segundo \\
\hline & $200 \mathrm{KHz}$ & No bit \\
\hline & & $\begin{array}{l}\text { Si de 2000000 sps hasta 40000000 } \\
\text { sps }\end{array}$ \\
\hline
\end{tabular}

Tabla 6 - Configuración de los sistemas de adquisición para las pletinas.

Estos sistemas se han utilizado en unos u otros ensayos de un modo indiferentes pues los resultados que proporcionan son exactamente iguales y las diferencias se encuentran en el funcionamiento interno y su rendimiento (más información en el capítulo 11.) 


\subsubsection{Condiciones de ensayo}

Para los ensayos térmicos.

Utilizando la configuración experimental descrita anteriormente se efectúan ensayos variando la temperatura y obteniendo un total de 256 incrementos (y decrementos) de temperatura diferentes adquiridos en total con ambos sistemas de adquisición.

\begin{tabular}{|l|l|l|}
\hline ENSAYO & SISTEMA DE ADQUISICIÓN DE DATOS & VARIACIÓN DE TEMPERATURA $\left(^{\circ} \mathbf{C}\right)$ \\
\hline 1, Térmico Inicial & Acellent ScanGenie & $\begin{array}{l}\text { Desde } 30^{\circ} \mathrm{C} \text { hasta } 66.5^{\circ} \mathrm{C} \text { en } 7 \text { escalones } \\
\text { Desde } 66.5^{\circ} \mathrm{C} \text { hasta } 45^{\circ} \mathrm{C} \text { en } 4 \text { escalones }\end{array}$ \\
\hline 3, Térmico 1 & Acellent ScanGenie & Desde 22.0 hasta 17 en 5 escalones \\
\hline 4, Térmico 2+FBG & National Instruments & $\begin{array}{l}\text { Desde } 17^{\circ} \mathrm{C} \text { hasta } 58.8^{\circ} \mathrm{C} \text { en } 3 \text { escalones } \\
\text { Desde } 26.7^{\circ} \mathrm{C} \text { hasta } 52.9^{\circ} \mathrm{C} \text { en } 3 \text { escalones }\end{array}$ \\
\hline 6, Térmico 3 & National Instruments & Desde 19.5 hasta 52.9 en 4 escalones \\
\hline \multicolumn{2}{|c}{ Tabla 7 - Descripción de los ensayos térmicos para las pletinas }
\end{tabular}

Para los ensayos térmicos con variación del tamaño de daño

En este caso se adquieren datos en ambas pletinas de modo simultáneo para doce tamaños de daño en una de ellas.

\begin{tabular}{|l|l|l|l|}
\hline ENSAYO & SISTEMA DE ADQUISICIÓN & TAMAÑO DE DAÑO (mm) & TEMPERATURA $\left({ }^{\circ} \mathbf{C}\right)$ \\
\hline 2, Daño Inicial & Acellent ScanGenie & $2-4-10-12-16-21-24-28-32$ & Entre 25.6 y 16.7 \\
\hline 5, Daño 2 +FBG & National Instruments & $32-48-64$ & 19.5 \\
\hline
\end{tabular}

Tabla 8 - Descripción de los ensayos de daño para las pletinas 


\subsubsection{Instalación en laboratorio}

Se utilizan dos pletinas para la obtención de dato experimentales. Una de las pletinas está dañada y la otra no tiene daño. Los elementos que forman parte del experimento y su organización pueden verse en la Figura 32. Se muestra la configuración más compleja, la que implica la utilización de la cámara climática, los ensayos de daño se hicieron con una configuración idéntica pero sin la cámara climática.

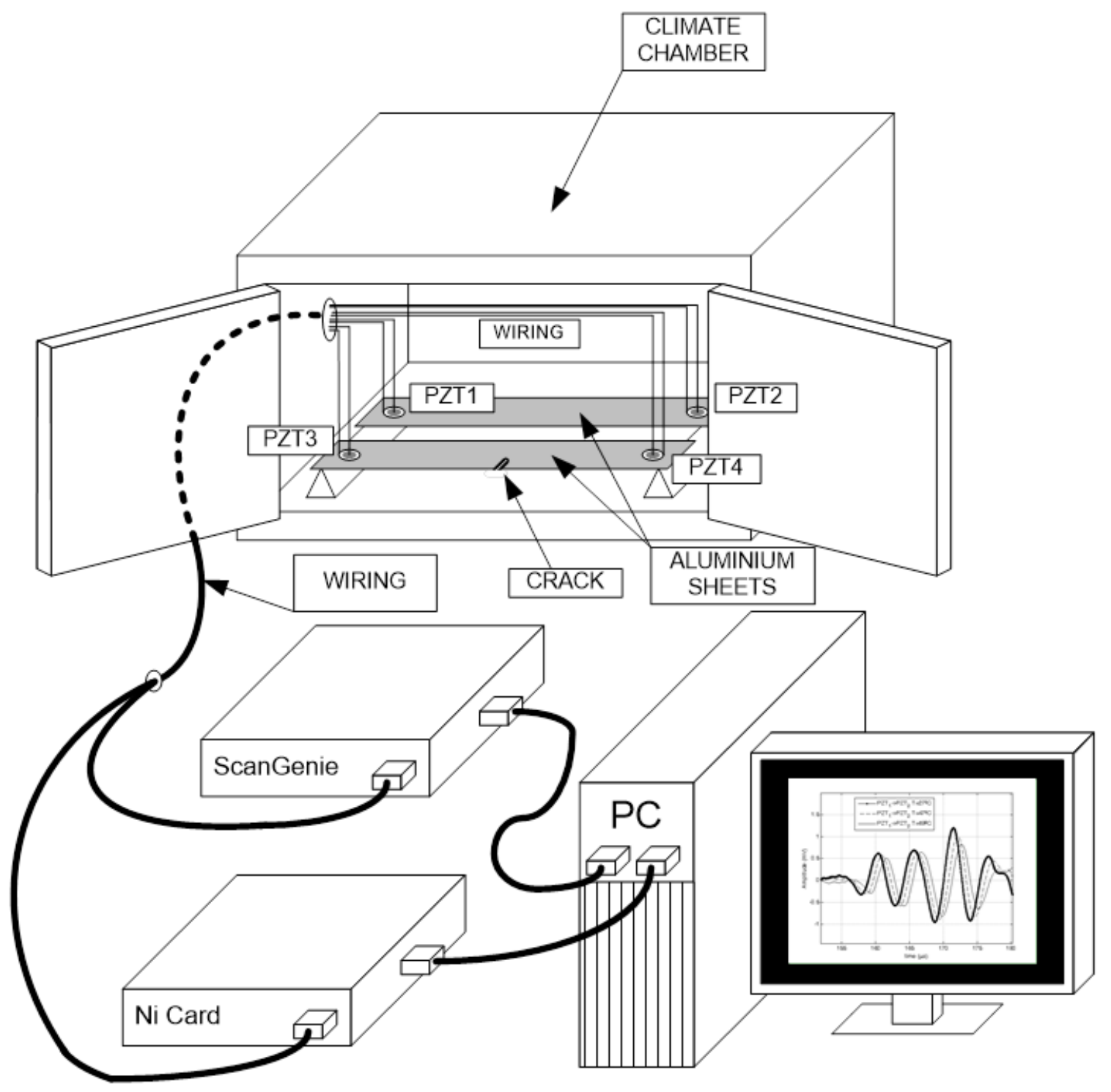

Figura 32 - Esquema completo del experimento con las pletinas.

Se han utilizado dos sistemas de interrogación y adquisición de datos diferentes (aunque no trabajando de manera simultánea, en la figura se indican las dos posibilidades). 
El primero de ellos es comercial, el equipo se denomina Acellent ScanGenie. El segundo es una tarjeta de adquisición de datos estándar de la compañía National Instruments, NI-6366, funcionando con software de adquisición de datos desarrollado internamente en MATLAB.

Ambas pletinas se interrogan de modo activo con los dos sistemas en un rango de temperaturas entre $\operatorname{los} 16.9^{\circ} \mathrm{C}$ y $\operatorname{los} 66.5^{\circ} \mathrm{C}$, con incrementos de temperatura positivos y negativos.

Todos los ensayos se han efectuado en una cámara climática para así obtener el efecto combinado de la presencia de daño y la variación de temperatura.

En la Figura 32 no se muestra la parte del sistema de medición de los sensores FBG por simplicidad, para ver más detalles de este sistema que también está conectado a la tarjeta NI6366 ver Anexo 5, capítulo 12. 


\subsubsection{Realización}

La realización de los ensayos térmicos y de daño tienen una serie de particularidades a tener en cuenta que se resumen a continuación.

Para los ensayos térmicos en la cámara climática es necesario tener en cuenta la inercia de la pieza para calentarse a la temperatura de consigna. Por ello se estableció el siguiente protocolo de actuación:

- Se configuraban los diferentes escalones térmicos tanto ascendentes como descendentes en temperatura. A unos valores ligeramente superiores a los que se deseaba para las pletinas ya que las mismas siempre alcanzaban valores de temperatura inferiores a los de consigna.

- Se esperaba a alcanzar la temperatura del escalón y se añadían unos 10 minutos para la estabilización de la temperatura en el interior de la cámara climática.

- Las medidas de temperatura se realizaban con un termopar instalado sobre las pletinas para obtener el valor real de la temperatura en la pieza. Este valor era normalmente inferior a la temperatura de consigna de la cámara.

- Se realizaba la interrogación de las estructuras, cuya duración solía ser de unos 5 minutos con el equipo de Acellent y de apenas unos segundos con el equipo de National Instruments. En estos ensayos la anotación de temperaturas del termopar era manual y se asignaba posteriormente a cada interrogación efectuada.

- Se efectuaba la revisión preliminar de resultados tal y como se indica en el apartado siguiente y si todo era correcto se pasaba al siguiente escalón de medida.

Para los ensayos de crecimiento de daño la manera de proceder es un poco diferente. El daño se realiza mediante una sierra, por lo tanto la pieza se calienta durante el proceso a una temperatura superior a la del laboratorio en el que se realiza el ensayo. Por esta razón para el crecimiento de daño se procedió del siguiente modo:

- Se toma la medida de temperatura inicial de la pieza y se efectúa la interrogación de las pletinas asegurándose de que no existen gradientes térmicos en el laboratorio. Se efectúa una revisión preliminar de resultados y si todo es correcto se continúa.

- A continuación se daña la pieza con la sierra en la zona indicada y se espera un tiempo a que el desequilibrio térmico introducido por la fricción desaparezca, este tiempo suelen ser unos $15 \mathrm{~min}$. Una vez transcurrido este tiempo se interrogan de nuevo las pletinas y se anota el dato de temperatura. De nuevo se revisan los resultados de modo preliminar y se repite este proceso para todos los tamaños de daño indicados en las tablas. 


\subsubsection{Revisión preliminar de resultados}

En la revisión preliminar de resultados se comprueban los siguientes elementos de calidad en las adquisiciones:

- Comparación cruzada de los caminos de daños. Los datos de los caminos de daño 1-2, 2-1 y para la otra pletina 3-4, 4-3 deben ofrecer medidas similares por la simetría presente en el experimento. Si no ocurre así algunos de los canales de adquisición de los diferentes sistemas podrían estar funcionando mal.

- Circuitos abiertos. Se evalúa que todos los sensores han enviado y adquirido información de manera adecuada sin saturar ni estar desconectados.

- Polaridad de los canales. Todos los canales se han grabado con la polaridad adecuada para evitar que se comparen resultados de señales con polaridad invertida.

- Rango de datos. Se verifica que todos los canales se encuentran dentro de los rangos esperados sin presentar picos ni zonas fuera de rango.

Con todas estas verificaciones realizadas ya se puede pasar al análisis de resultados con la seguridad de que las señales grabadas son correctas. 


\subsubsection{Análisis de resultados}

La base fundamental del análisis a efectuar esta soportada por dos hipótesis básicas[28]:

- Cuando la GLW se propaga del transmisor al receptor se ve modificada por las EOC y el daño.

- Las modificaciones introducidas se reflejan en la onda adquirida por el receptor.

En este estudio se considera la primera llegada de la GLW correspondiente al modo S0, el de tracción-compresión, el más rápido de los dos existentes en el rango de frecuencias de trabajo (ver figura [166]). Al analizar esta primera llegada de la GLW evitamos reflexiones con los bordes de este modo de propagación que incrementarían la complejidad del análisis posterior [164].

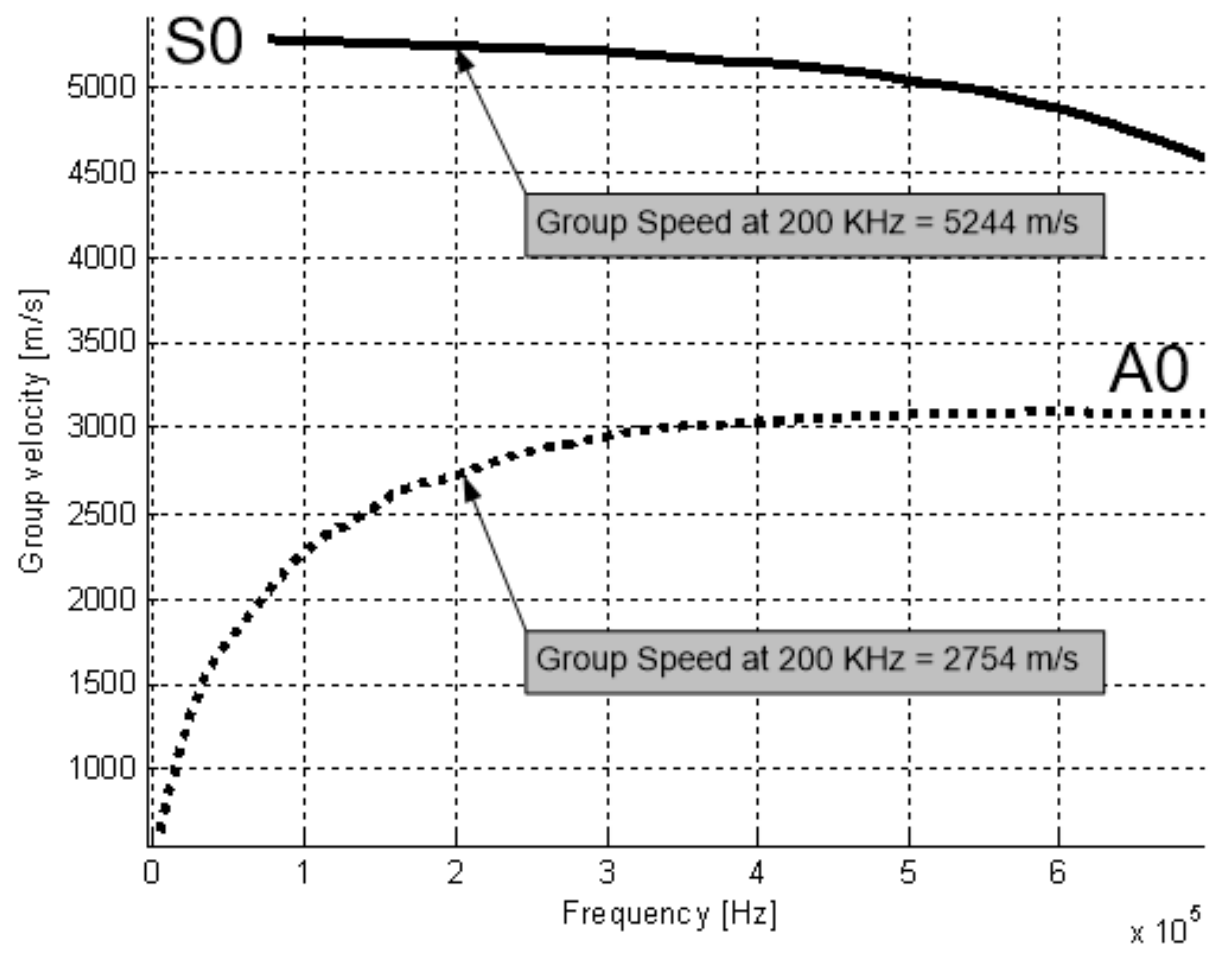

Figura 33 - Curvas de dispersión para las pletinas de aluminio t=2mm obtenidas con mi metodología y validadas con [166]

En el experimento la distancia entre el actuador o transmisor y el receptor es de $0.827 \mathrm{~m}$. Por lo tanto, atendiendo a las curvas de dispersión para este material, el tiempo de llegada para el modo S0 debería ser de 157 microsegundos. La distancia hasta el borde de la pieza son $0.173 \mathrm{~m}$ lo que nos deja unos 33 microsegundos de señal sin interferencias con el borde. Las interferencias con los bordes laterales de la pletina se desprecian. 
Estos tiempos de llegada se verán afectados por las variaciones de temperatura y la amplitud con la que lleguen por la presencia de daño.

En la Figura 34 se puede observar el efecto descrito en la GLW adquirida por el receptor para la variación de temperatura.
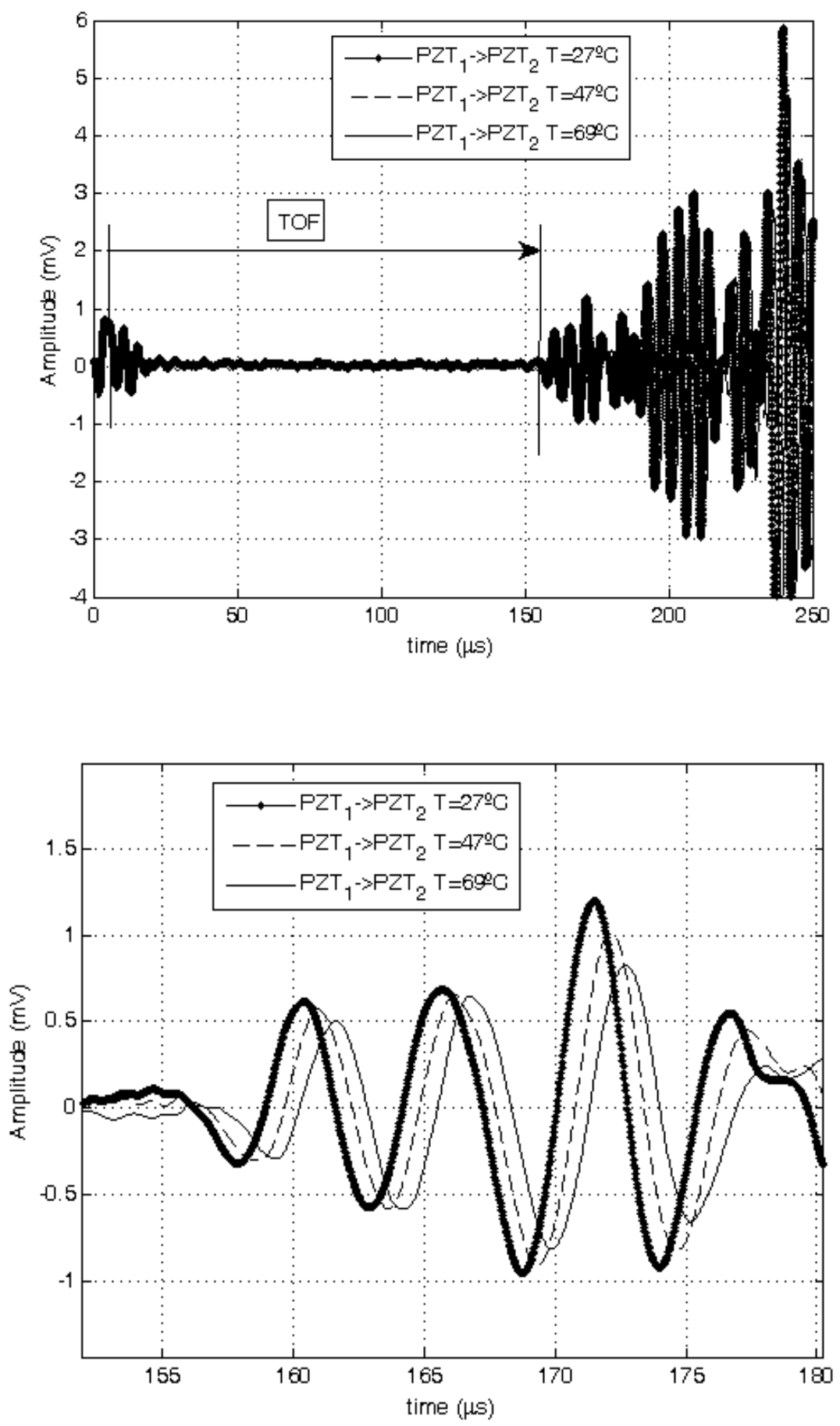

Figura 34 - Efecto de la temperatura en la llegada de la onda al sensor PZT

La Figura 34 indica como las variaciones de temperatura están claramente relacionadas con los retrasos en la llegada del modo S0. 


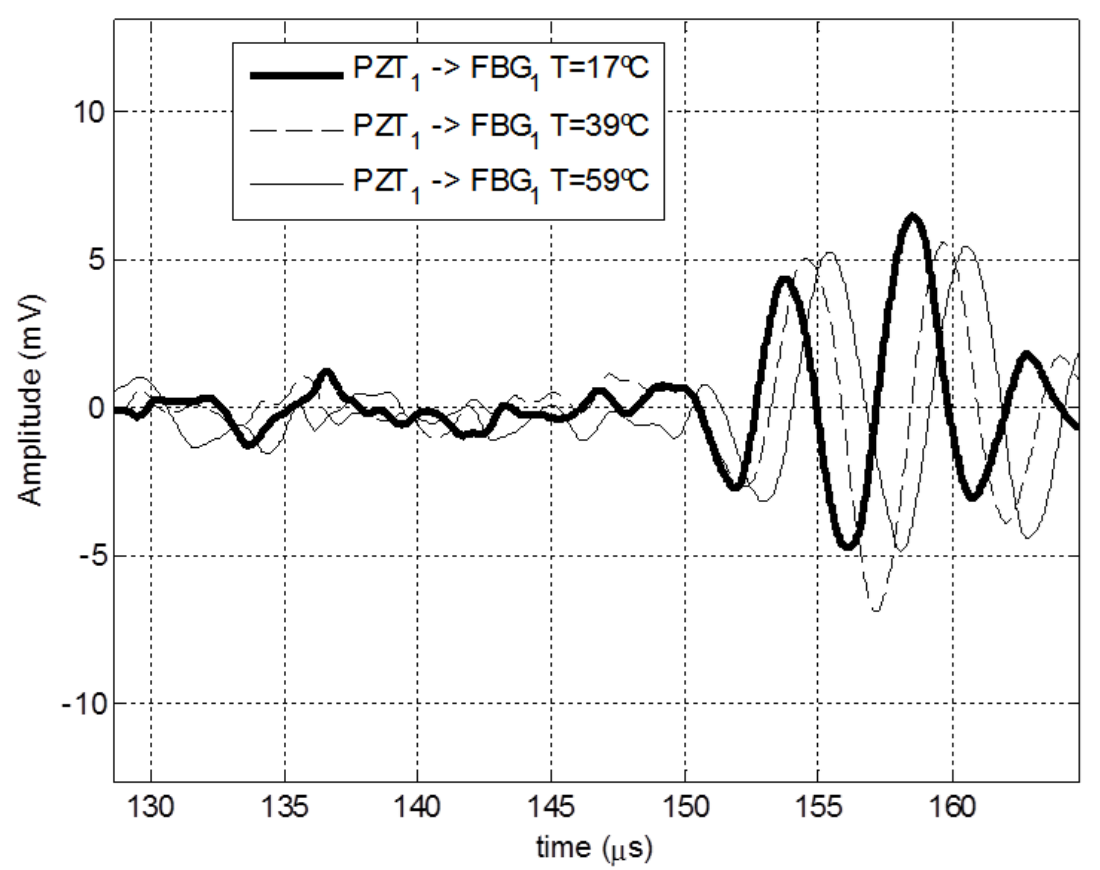

Figura 35 - Efecto de la temperatura en la llegada de la onda al sensor FBG.

La Figura 35 indica que también en el sensor FBG se observan retrasos del mismo tipo aunque el nivel de ruido de fondo es ligeramente mayor y el tiempo de llegada ligeramente inferior ya que la distancia entre el actuador PZT1 y el sensor FBG1 es menor que al PZT2, y los valores de temperatura son menores que en el caso de la interrogación de PZTs. Los valores medidos de amplitud son mayores debido a que el sistema óptico de amplificación ofrece mayor rango de señal, esto carece de importancia ya que todos los cálculos que se realizan son comparativos respecto a una referencia.

En la Tabla 9 se puede comprobar la dispersión introducida en la GLW adquirida por la variación de temperatura (datos de Figura 34 y Figura 35) comparada con la introducida por el daño. Los datos indican que las variaciones de temperatura ocultan claramente las variaciones en la señal producidas por la presencia del daño.

\begin{tabular}{|c|l|l|l|}
\hline$\Delta \mathbf{T}\left({ }^{\circ} \mathbf{C}\right)$ & \multicolumn{1}{|c|}{ VARIACIÓN EN AMPLITUD $(\%)$} & $\begin{array}{c}\text { TAMAÑO DE DAÑO } \\
(\mathbf{m m})\end{array}$ & $\begin{array}{c}\text { VARIACIÓN EN } \\
\text { AMPLITUD }(\%)\end{array}$ \\
\hline $27+20^{\circ} \mathrm{C}$ & $15 \%$ & $32+16 \mathrm{~mm}$ & $4 \%$ \\
\hline $27+42^{\circ} \mathrm{C}$ & $26 \%$ & $32+32 \mathrm{~mm}$ & $9 \%$ \\
\hline $47+22^{\circ} \mathrm{C}$ & $14 \%$ & $48+16 \mathrm{~mm}$ & $6 \%$ \\
\hline
\end{tabular}

Tabla 9 - Comparativa de dispersiones introducidas por la temperatura y por el daño

Si necesitamos aislar la influencia del daño estaremos obligados a compensar el efecto de la temperatura para que este no oculte al anterior.

Este resultado es una mera verificación puesto que está ampliamente descrito en la literatura [162][160]. Sin embargo es necesario reproducirlos para verificar que nuestro proceso de trabajo y sistemas de adquisición funcionan adecuadamente. 
En la Figura 36 se puede ver el efecto de un daño sobre la GLW medida en el receptor (sin interacción de las EOC).
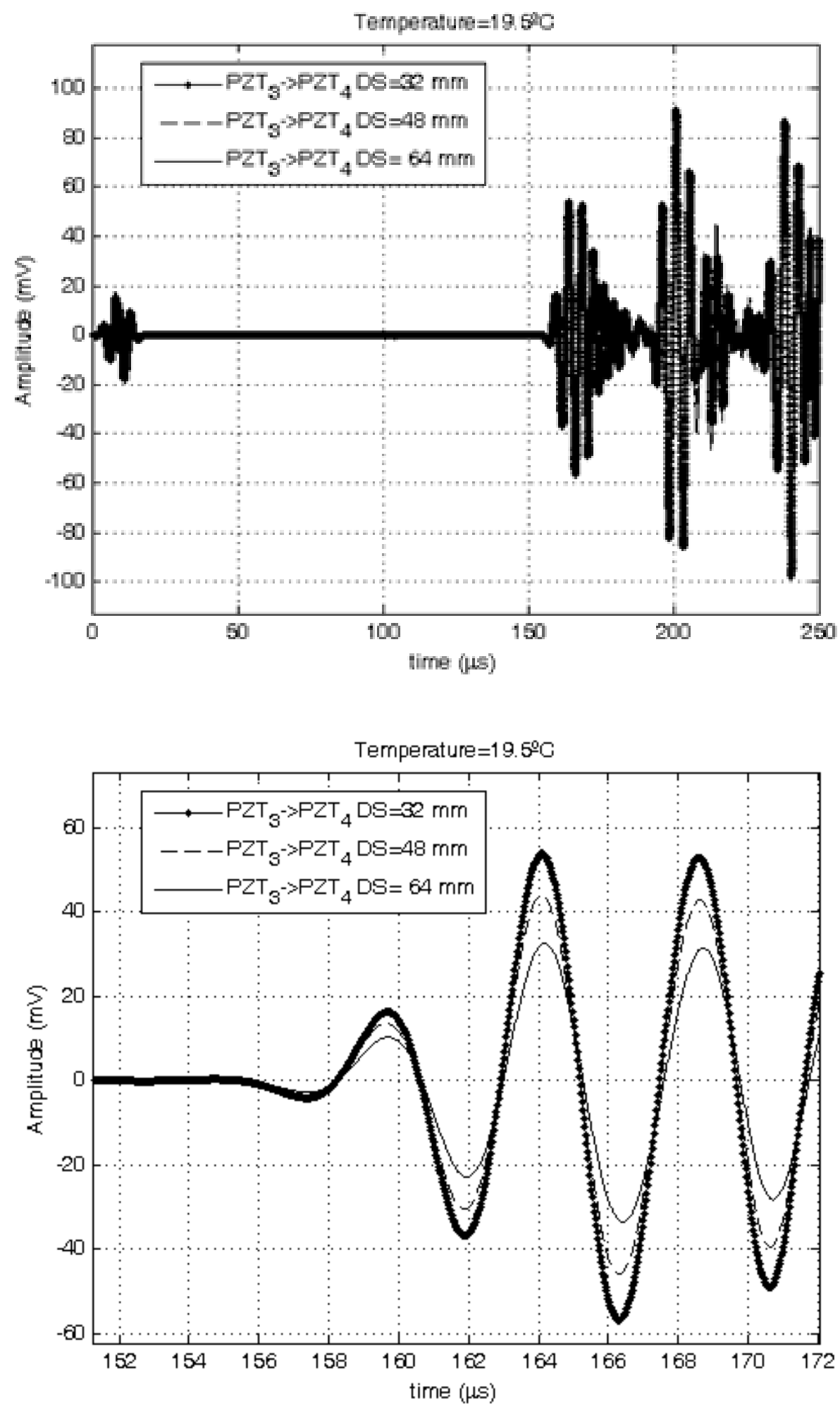

Figura 36 - Efecto de la presencia del daño en la onda elástica medida por PZT4 
La atenuación de la primera llegada del modo S0 aumenta a la vez que el tamaño de daño crece [167]. Esto indica que la firma del daño en la DSF está íntimamente relacionada con la atenuación medida en esta primera llegada.

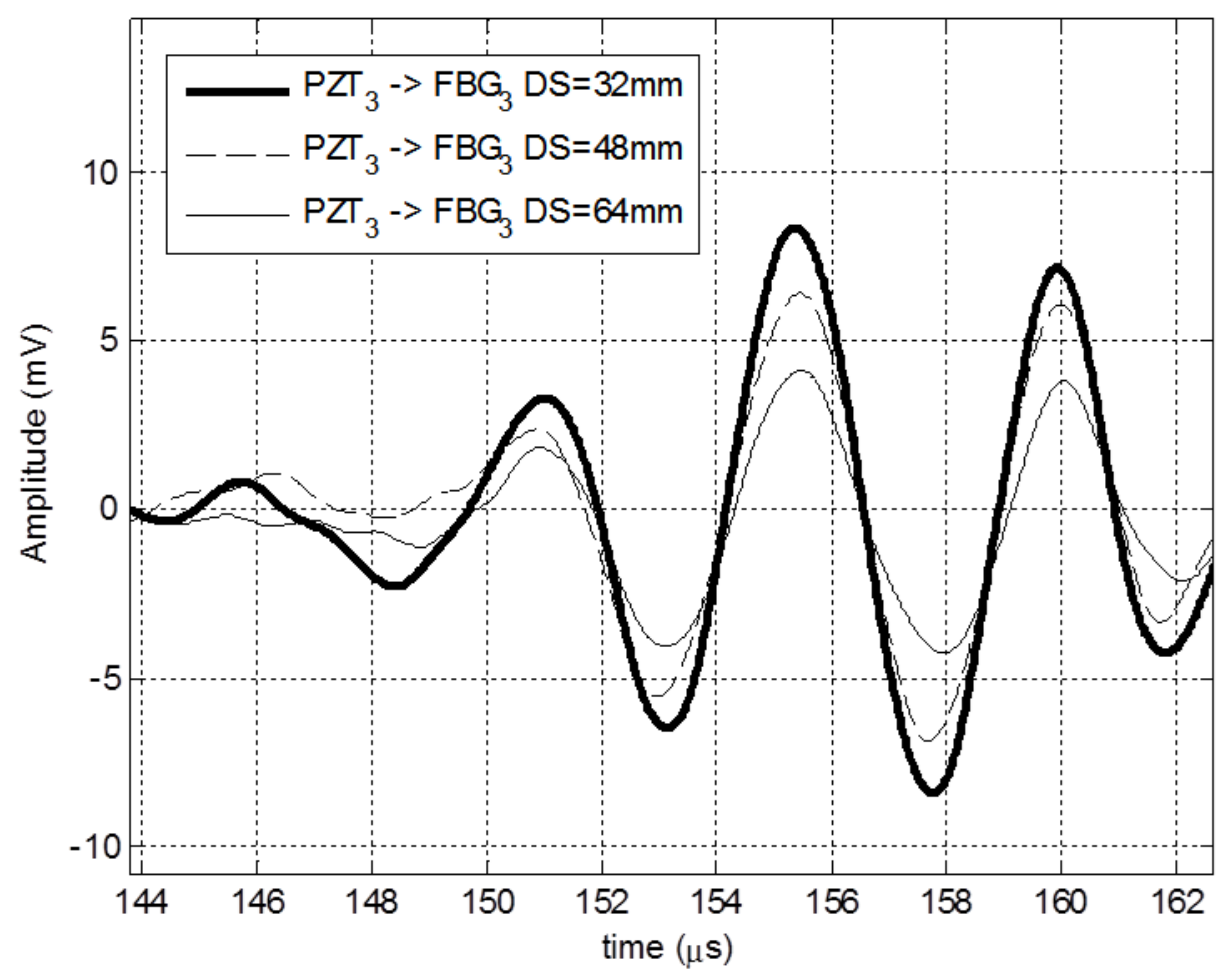

Figura 37 - Efecto de la presencia de daño en la onda elástica medida por FBG3

Se comprueba en la Figura 37 que el comportamiento para los sensores FBG es exactamente el mismo que en los sensores PZT.

En este caso el daño está completamente definido ya que lo hemos producido nosotros mismos y las mediciones se realizaron con EOC invariantes.

Sin embargo esto solo ocurre así en condiciones de laboratorio. En el mundo real un SHM debería medir todos los parámetros relacionados con las EOC para poder compensarlas en la medida de las GLW. Si no se efectúa esta compensación el efecto del daño quedará enmascarado tras la variabilidad introducida en las mediciones de las GLW por las EOC, y no podremos detectarlo.

A continuación evaluaremos los efectos de estos fenómenos sobre los coeficientes de la CT utilizando los datos experimentales.

Aparentemente las EOC, en concreto las variaciones de temperatura parecen estar relacionadas con el retraso en la primera llegada de S0 (coeficiente de Time Shift de la CT).Y, la presencia de daño relacionada con su atenuación (parte real del coeficiente de Scaling de la CT). 


\subsubsection{Efecto de la temperatura}

En la Figura 38 se muestra la gráfica de puntos experimentales de los valores de incremento de temperatura (en grados centígrados, eje horizontal) frente al tiempo de llegada del modo S0 (en nanosegundos, eje vertical)

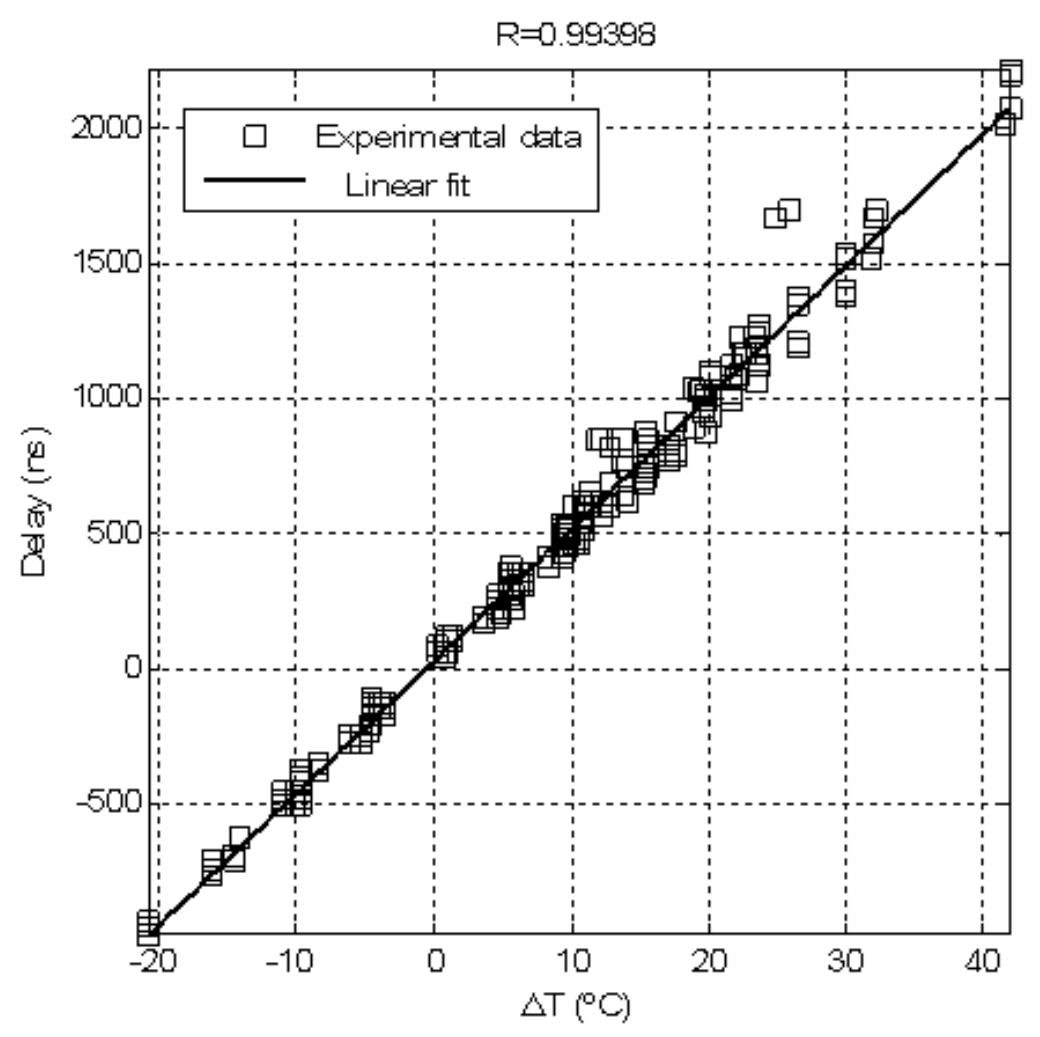

Figura 38 - Valores experimentales del retraso frente al incremento de temperatura. Delay $(\mathrm{ns})=49 \cdot \Delta \mathrm{T}\left({ }^{\circ} \mathrm{C}\right)+29$

La relación entre los retrasos y los incrementos de temperatura puede considerarse lineal en el intervalo de temperaturas estudiado (entre $16.9^{\circ} \mathrm{C}$ y $66.5^{\circ} \mathrm{C}$ )

Los datos experimentales provienen de los dos sistemas de adquisición no observándose diferencias entre los adquiridos por un sistema u otro. Por lo tanto el sistema de adquisición que se utilice no tendrá influencia en la aplicación del esquema de compensación para los datos relativos a los incrementos de temperatura.

La siguiente comprobación consiste en evaluar la relación entre el coeficiente de Time Shift de la CT y el retraso que introduce la variación de temperatura. Para esta tarea se utilizarán los mismos datos experimentales (los 256 incrementos de temperatura diferentes).

Cada señal adquirida se proyectará en la base de coeficientes de la CT para obtener los coeficientes de Time Shift que a continuación se correlacionarán con los retrasos para verificar la relación existente entre ambos conjuntos de datos. Los resultados se muestran en la Figura 39. 


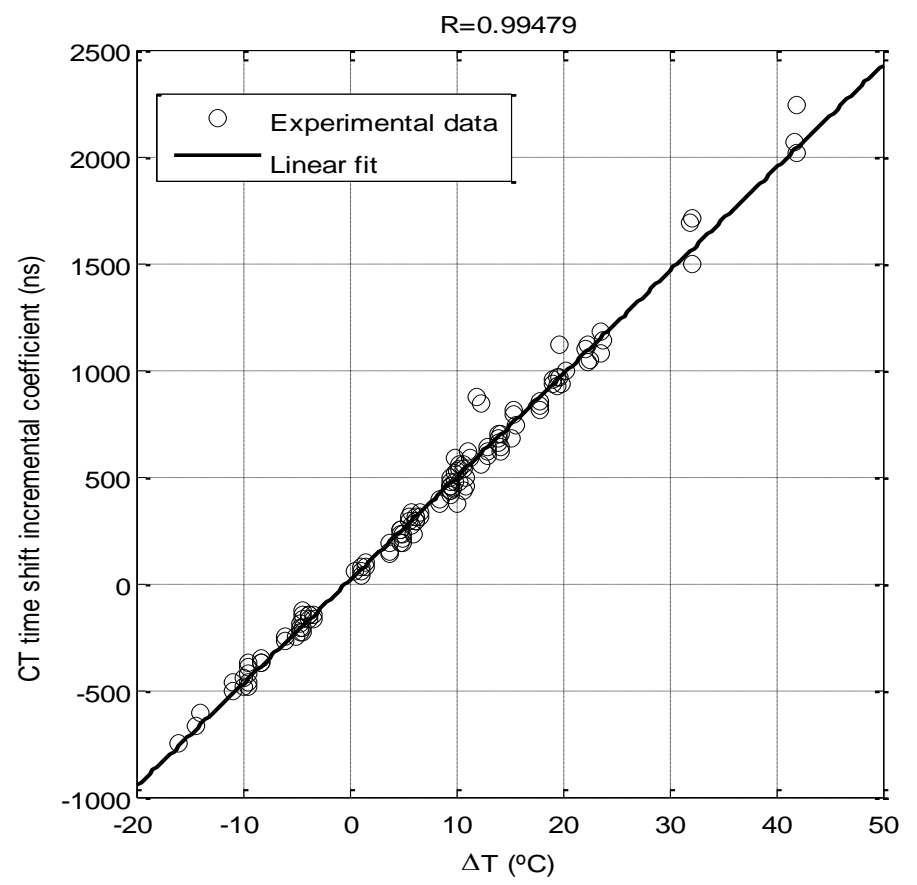

Figura 39 - Coeficiente Time Shift de la CT frente a los incrementos de temperatura. Time-Shift(ns) $=48 \cdot \Delta \mathrm{T}$ $\left({ }^{\circ} \mathrm{C}\right)+22$

La relación que se obtiene entre la variación de temperatura y el Time Shift es lineal, al igual que en el caso anterior.

En la Figura 40 se pinta la relación entre el Time Shift y el retraso en la llegada del modo S0 (la firma de la EOC, la temperatura, en la DSF, la GLW medida), se anticipa que dicha relación será lineal.

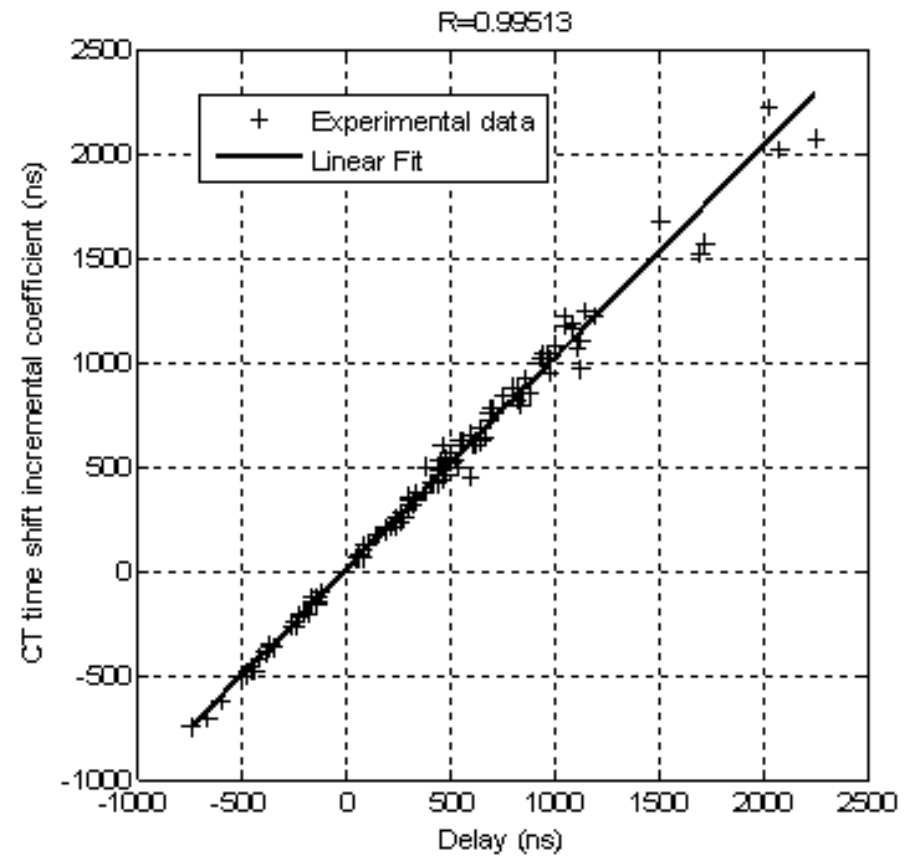

Figura 40 - Relación entre el coeficiente de Time Shift y el retraso del modo S0 de la GLW. 
La Figura 40 muestra una relación directa entre el Time Shift y el retraso, Time Shift $=$ Retraso para el análisis de la primera llegada del modo S0.

Vemos que la última relación es casi 1 a 1 para los sensores PZT y surge la pregunta sobre si el comportamiento será el mismo para los sensores FBG. En este caso los datos disponibles son mucho menores ya que solo se han obtenido con uno de los sistemas de adquisición sin embargo se pueden resumir en una única figura.

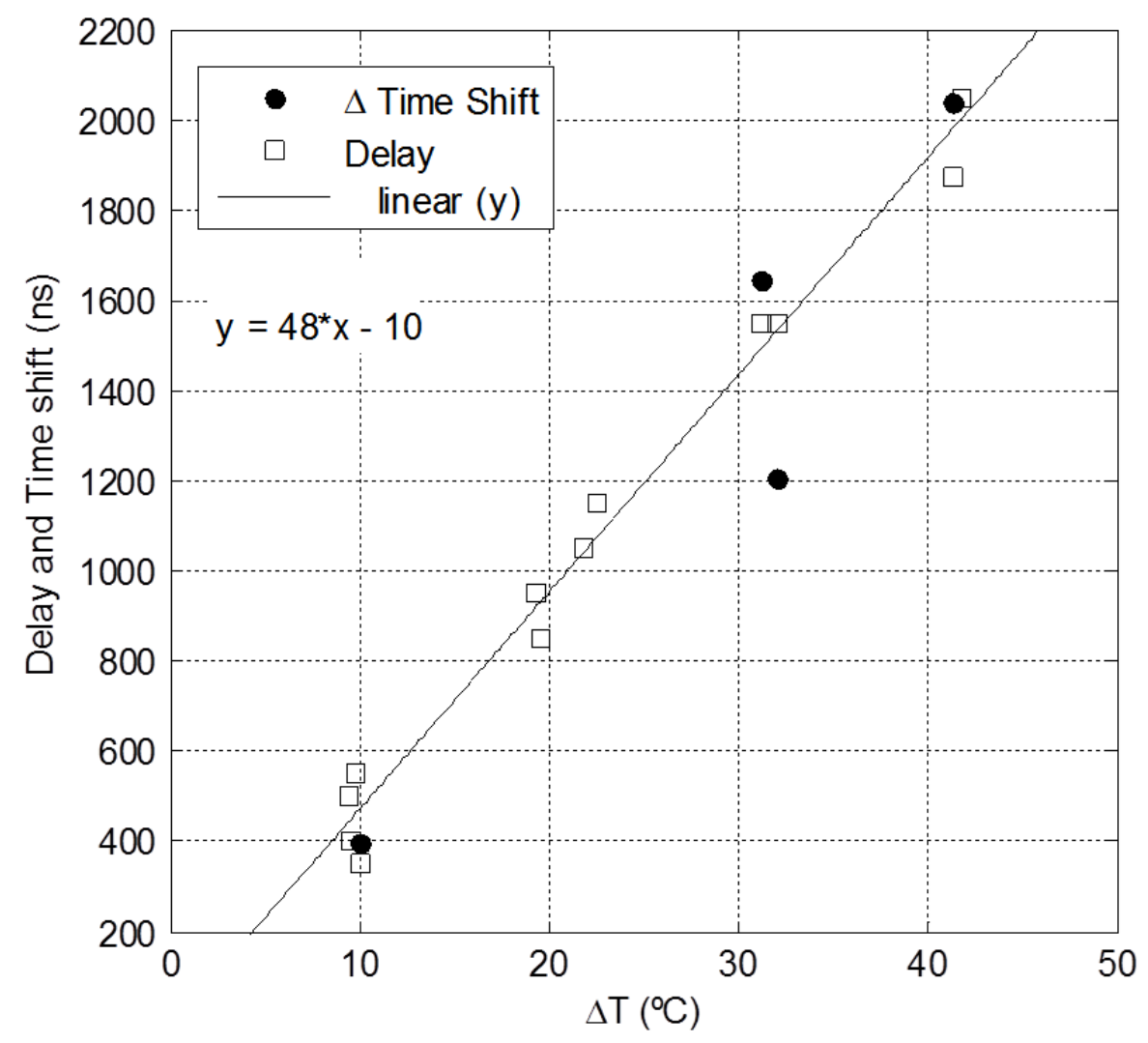

Figura 41 - Delay y Time Shift calculados con sensores FBG

Los resultados de la Figura 41 indican que el coeficiente de Time Shift calculado con sensores PZT o FBG es totalmente equivalente. Esto muestra que la evaluación del efecto térmico propuesta es independiente del tipo de sensor utilizado. Existirán otros efectos particulares del tipo de sensor utilizado pero con claramente de segundo orden comparados con el retraso medido, debido fundamentalmente a la dilatación del camino de daño.

Los resultados obtenidos indican que podemos utilizar el coeficiente de Time Shift de la CT para alimentar un modelo que represente la influencia de la temperatura en nuestra DSF. Adicionalmente no se observan efectos significativos en el resto de coeficientes, especialmente en la parte real del Scaling (aunque sabemos que también existe una pequeña influencia). Estos resultados son coherentes con resultados similares existentes en la literatura [161]. 


\subsubsection{Efecto del daño}

El siguiente efecto que vamos a estudiar es la atenuación inducida en la primera llegada del modo S0 por la presencia de daño. La atenuación se ha calculado directamente a partir de los datos de amplitud de llegada del modo S0. Los resultados experimentales obtenidos se muestran en la Figura 42. La atenuación de referencia se ha tomado para un tamaño de daño intermedio, $32 \mathrm{~mm}$, ya que es el dato que se tomó con ambos sistemas de adquisición. La razón de tomar este dato y no el inicial es porque los sistemas de adquisición de datos producen señales de interrogación diferentes, produciendo llegadas de modos S0 de la GLW que tienen diferentes amplitudes (pero iguales características, simplemente es un factor de escala). Por lo tanto para poder comparar los resultados hay que partir de un punto en común y ese es el daño de $32 \mathrm{~mm}$.

Al igual que en el caso de la temperatura se evaluará el efecto con sensores PZT exclusivamente y a continuación con el esquema híbrido PZT actuador y FBG sensor.

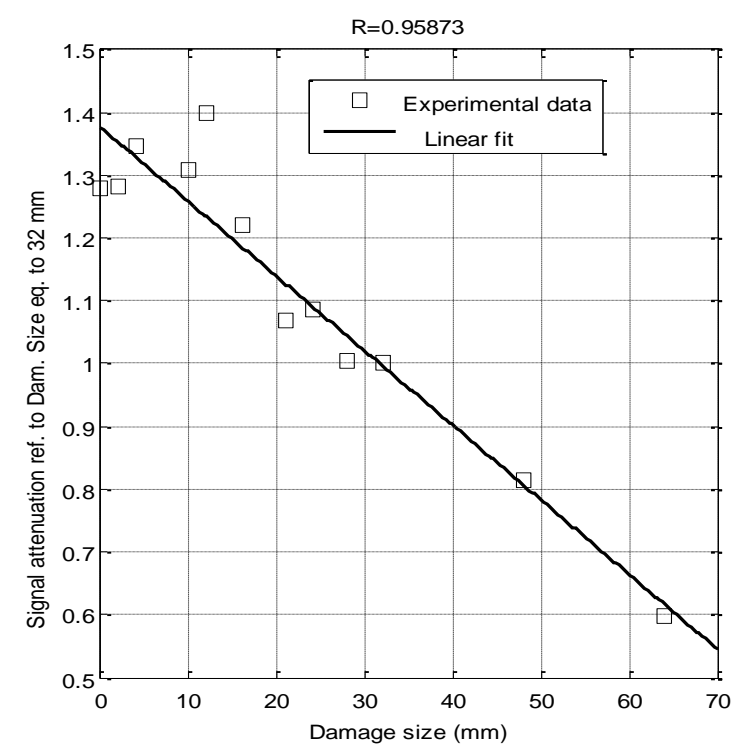

Figura 42 - Atenuación medida en la primera llegada del modo S0 de la GLW para diferentes tamaños de daño. Attenuation=-0.012・DamageSize $(\mathrm{mm})+1.4$

Los datos con atenuación superior a la unidad corresponden al sistema de adquisición Acellent ScanGenie y los datos con atenuación superior a la unidad pertenecen al sistema de adquisición propio. Se observa que la relación es lineal e independiente del sistema de adquisición (siempre que se tome un punto de referencia común que permita ajustar los rangos de trabajo de voltaje, que son diferentes. La dispersión mayor que se observa en la parte superior, para pequeños tamaños de daño, inferiores a $10 \mathrm{~mm}$, son fruto de la resolución de las frecuencias de interrogación utilizadas para la generación de GLW (Minimum Resolvable Distance, MRD·t 0.01m, para nuestro experimento [151]). La evolución que muestra el cálculo del Scaling con los sensores FBG es muy similar a la que se observa en el caso de los PZT aunque 
no exactamente igual. En la Figura 43 se pude comprobar que los valores siguen la tendencia de modo similar a los PZT pero separándose ligeramente.

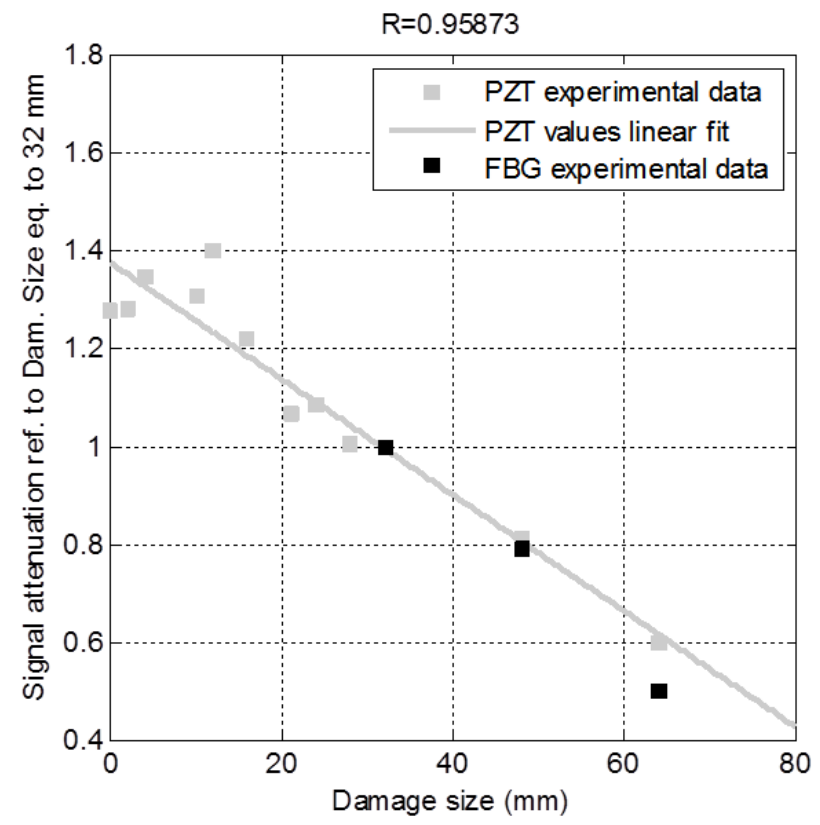

Figura 43 - Atenuación medida mediante sensores FBG para diferentes tamaños de daño.

Seguidamente calculamos la parte real de los coeficientes de Scaling para las señales del experimento. Estos coeficientes deberían estar relacionados con el tamaño del daño y con la atenuación que su presencia genera en el modo S0 de la GLW.

En la Figura 44 se muestra la relación entre la parte real del Scaling y el tamaño del daño.

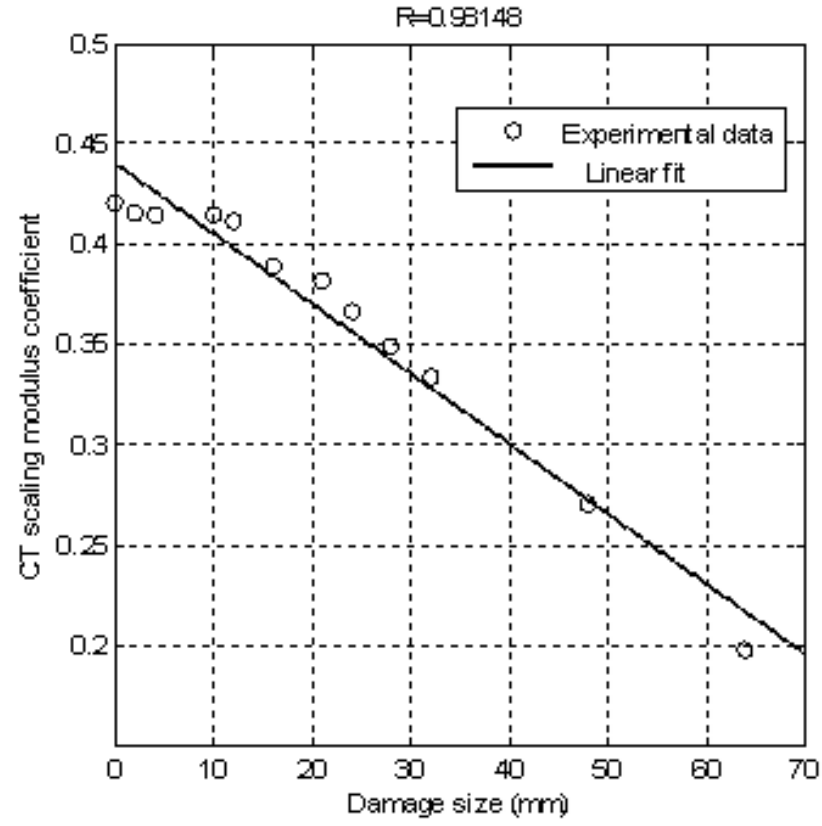

Figura 44 - Parte real del Scaling frente al tamaño del daño, Re(Scaling) $\mid=-0.0035 \cdot$ DamageSize $(\mathrm{mm})+0.44$. 
La relación que se observa en la figura superior es lineal. Además hay que indicar que no se observan efectos con una tendencia definida en la parte imaginaria del coeficiente de Scaling. Tampoco se observa una tendencia que indique una influencia significativa de los valores de temperatura sobre este coeficiente (aunque sabemos que también participa de un modo poco significativo). De nuevo, este resultado está también ampliamente contrastado en la literatura [167] lo que indica que nuestros sistemas de adquisición están funcionando correctamente y el esquema de análisis es correcto. El resultado para sensores FBG es equivalente (Figura 45).

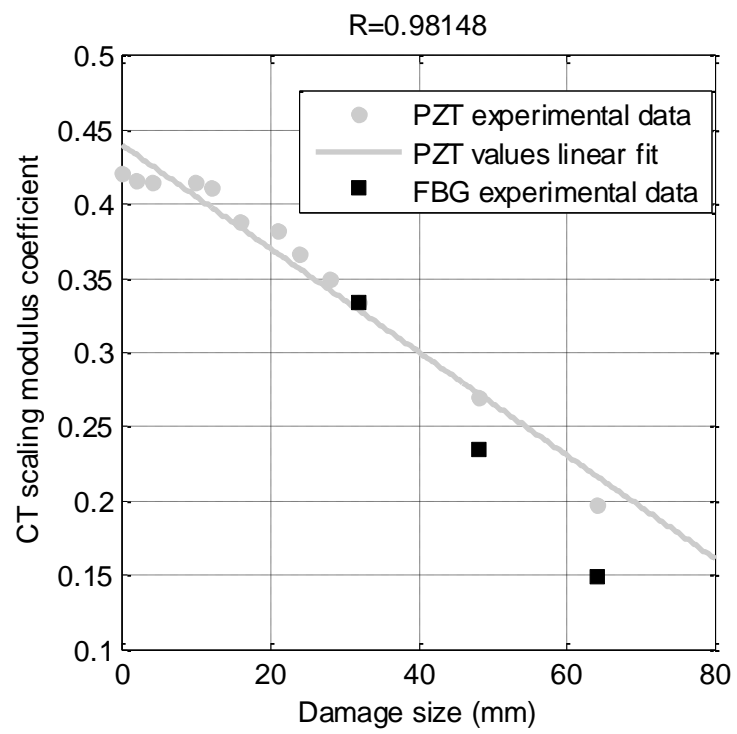

Figura 45 - Parte real del Scaling frente al tamaño del daño para sensores FBG

Finalmente, comprobamos la relación entre la firma del daño en la DSF (la atenuación del modo S0 de la GLW que hemos calculado anteriormente) y el coeficiente de Scaling. Los resultados se indican en la Figura 46.

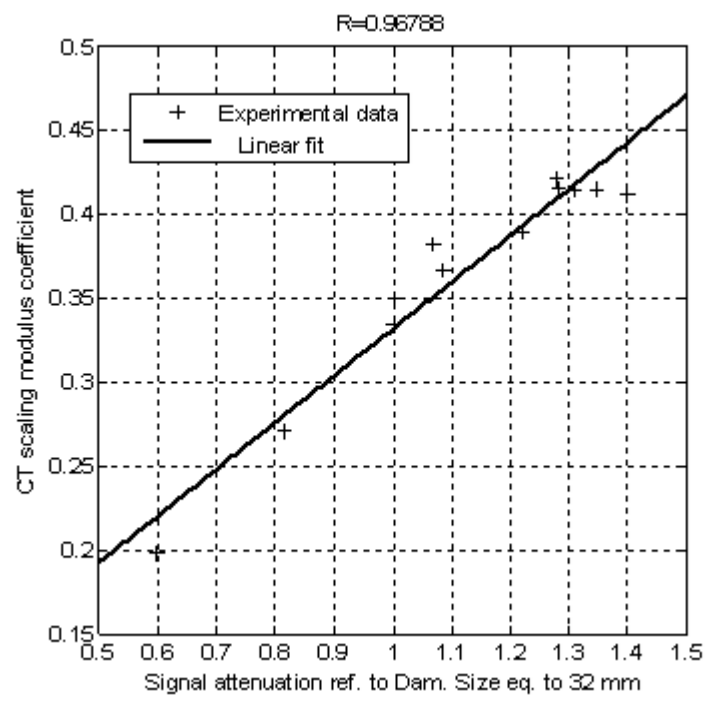

Figura 46 - Relación entre el coeficiente de Scaling y la atenuación del modo S0. $\operatorname{Re}($ Scaling $)=0.28 \cdot$ Attenuation +0.053 
Al igual que en los ensayos de temperatura, existe una relación lineal entre la parte real del Scaling y la atenuación del modo S0. Esto indica que podemos utilizar este coeficiente obtenido mediante la CT a partir del análisis de la primera llegada del modo S0 de la GLW para utilizarlo en el esquema de compensación y poder diagnosticar la presencia de daño.

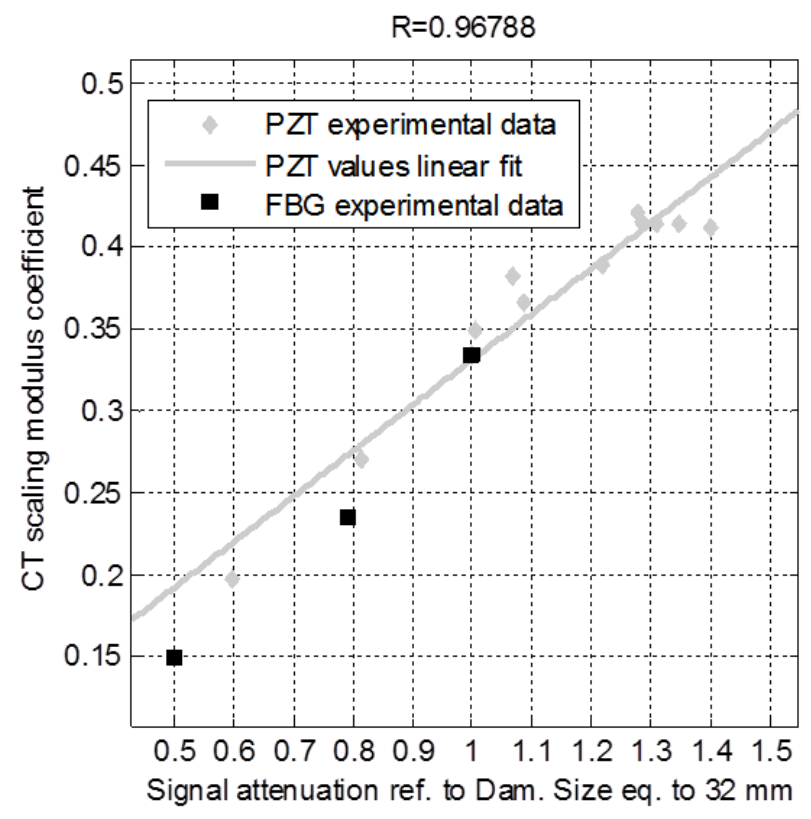

Figura 47 - Relación entre Scaling y la atenuación del modo S0 para sensores FBG.

En la Figura 47 se verifica de nuevo que el comportamiento de los coeficientes es equivalente en sensores FBG y PZT.

Ambos efectos, el cambio en la temperatura y el crecimiento del daño se han relacionado con los coeficientes de Time Shift y $\operatorname{Re}($ Scaling) respectivamente. Estos valores serán utilizados para el modelo de compensación. Sin embargo hemos de tener en cuenta que la temperatura también induce pequeños cambios en la amplitud del modo S0 y no se pueden desacoplar. Será tarea del modelo (la red neuronal), con las entradas seleccionadas adecuadamente, separar dicha influencia. 


\subsubsection{Definición del modelo de compensación}

Una vez que se han definido los parámetros de trabajo del problema:

- Señal de interrogación

- DSF que se va a utilizar. respuesta en el receptor a la primera llegada del modo S0 de la GLW

- Firmas de la EOC y del daño en la DSF:

- Para la EOC el retraso.

- Para el daño la atenuación.

- Procesado de la señal adquirida. Transformada Chirplet, reteniendo los coeficientes relacionados con las firmas en la DSF.

Definiremos el modelo ANN[163] que va a utilizar estos datos dentro del esquema de trabajo para generar la compensación de las EOC y así permitir la diagnosis de daño.

En la Tabla 10 se define el modelo en términos de entradas y salidas del mismo. Una vista esquemática de este modelo se muestra en la Figura 48.

\begin{tabular}{|c|c|c|c|c|}
\hline $\begin{array}{c}\text { GRUPO DE } \\
\text { ENTRADAS } \\
\text { Datos relativos a la } \\
\text { interrogación efectuada } \\
\text { sobre la estructura y las } \\
\text { condiciones en las que se } \\
\text { realiza }\end{array}$ & $\begin{array}{c}\text { ENTRADAS } \\
\text { Parámetros que } \\
\text { representan la } \\
\text { información del grupo } \\
\text { de entradas }\end{array}$ & MODELO & $\begin{array}{c}\text { SALIDAS } \\
\text { Datos relativos a } \\
\text { la respuesta } \\
\text { medida en la } \\
\text { estructura para } \\
\text { las condiciones } \\
\text { definidas en las } \\
\text { entradas }\end{array}$ & $\begin{array}{c}\text { GRUPO } \\
\text { DE } \\
\text { SALIDAS }\end{array}$ \\
\hline Definición de la & BURST TYPE & \multirow{4}{*}{$\begin{array}{l}\text { Modelo ANN. } \\
\text { Modelo gobernado } \\
\text { por los datos que } \\
\text { capturará la relación } \\
\text { entre las } \\
\text { características de } \\
\text { actuación junto con } \\
\text { las EOC de esa } \\
\text { actuación y las } \\
\text { señales adquiridas en } \\
\text { el transmisor en } \\
\text { términos de los } \\
\text { coeficientes de la } \\
\text { CT. }\end{array}$} & $\operatorname{Re}$ (Scaling) & \multirow{4}{*}{$\begin{array}{l}\text { Valores que } \\
\text { tendrían los } \\
\text { coeficientes de la } \\
\text { CT para la señal de } \\
\text { interrogación } \\
\text { definida y las EOC } \\
\text { en las que se } \\
\text { efectuó dicha } \\
\text { interrogación. }\end{array}$} \\
\hline $\begin{array}{l}\text { interrogación. } \\
\text { Características de la señal } \\
\text { de actuación en el } \\
\text { transmisor: } \\
\text { Burst type es el número de } \\
\text { picos en la señal de } \\
\text { interrogación } \\
\text { Amplitud de la } \\
\text { interrogación } \\
\text { Frecuencia de la señal de } \\
\text { interrogación }\end{array}$ & $\begin{array}{l}\text { FRECUENCIA DE } \\
\text { INTERROGACIÓN }\end{array}$ & & $\operatorname{Im}$ (Scaling) & \\
\hline \multirow[b]{2}{*}{$\begin{array}{l}\text { EOC. } \\
\text { Valores para la } \\
\text { temperatura, estado de } \\
\text { carga, etc. Cualquier valor } \\
\text { que potencialmente pueda } \\
\text { modificar las } \\
\text { características de la señal } \\
\text { de interrogación en su } \\
\text { viaje por el camino de } \\
\text { daño y no sea el propio } \\
\text { daño. }\end{array}$} & TEMPERATURA & & Frequency shift & \\
\hline & CARGA & & Frequency shear & \\
\hline
\end{tabular}

Tabla 10 - Estructura del modelo de compensación 


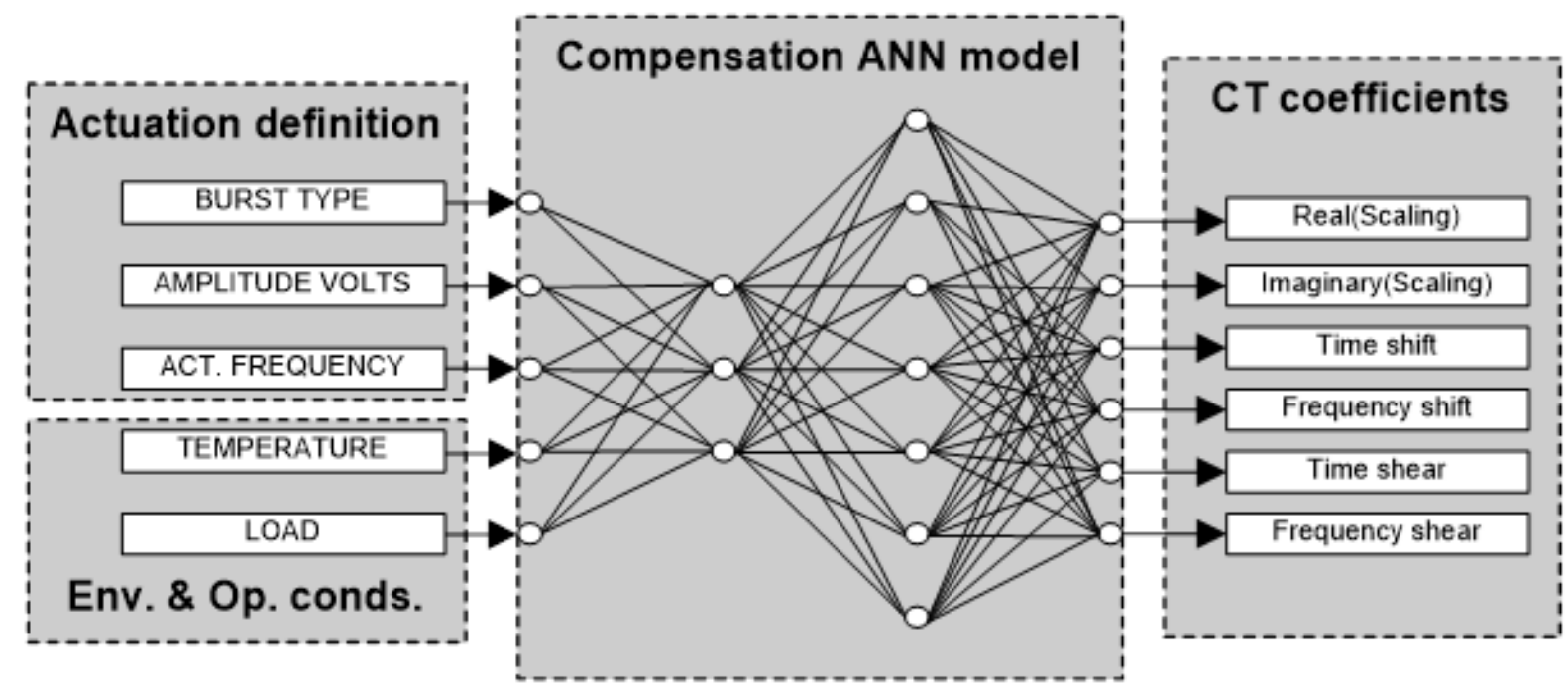

Figura 48 - Definición del modelo de compensación

Este modelo se entrenará con condiciones libres de daño en múltiples situaciones con diferentes valores de las EOC de modo que capture los datos relativos a las situaciones de referencia. De este modo el modelo ANN será un modelo de situaciones de referencia cuyos parámetros de entrada son la definición de la interrogación que se efectúa a la estructura y los parámetros medibles relacionados con las diferentes EOC en las que se realiza dicha interrogación.

\subsubsection{Factibilidad teórica del modelo de compensación}

Para comprobar la factibilidad de esta propuesta de modelo se efectúan una serie de pruebas con datos teóricos previamente al ajuste mediante datos experimentales (de modo semejante a como se realiza para comprender el comportamiento de la CT en el Anexo 3, capítulo 10).

En esta prueba teórica se ajustará el modelo con datos semejantes a los que obtenemos de los ensayos y comprobaremos si es capaz de capturar las relaciones existentes entre entradas y salidas.

Las características particulares de la red neuronal utilizada se indican en la Tabla 11. Los datos de entrada y salida con los que se ajustará este modelo se definen en la Tabla 12.

\begin{tabular}{|c|c|}
\hline PARÁMETRO DE DEFINICIÓN & VALOR \\
\hline Tipo de Red Neuronal & Feedforward Backpropagation \\
\hline Número de entradas & 5 \\
\hline Número de capas & 3 \\
\hline Número de neuronas por capa & $\begin{array}{l}7 \\
10 \\
2\end{array}$ \\
\hline Función de transferencia neuronal en cada capa & $\begin{array}{l}\text { Tangente sigmoidea } \\
\text { Tangente sigmoidea } \\
\text { Tangente sigmoidea }\end{array}$ \\
\hline Número de salidas & 2 \\
\hline Algoritmo de entrenamiento & Levenberg-Marquardt con regularización bayesiana \\
\hline
\end{tabular}




\begin{tabular}{|l|l|}
\hline \multicolumn{1}{|c|}{ ENTRADA } & \multicolumn{1}{c|}{ VALORES } \\
\hline Burst type (no dimensional) & {$[3,5,7,10]$} \\
\hline Amplitud (voltios) & {$[10,20,30,40]$} \\
\hline Frecuencia de interrogación $(\mathrm{KHz})$ & {$[100,150,200,250,300]$} \\
\hline Temperatura $\left({ }^{\circ} \mathrm{C}\right)$ & {$[$ de 2550 con $\Delta \mathrm{T}=1$ y de 50 a 25 con $\Delta \mathrm{T}=-1]$} \\
\hline Carga (adimensional) & {$[50$ valores modulados por una ventana tipo Hanning $]$} \\
\hline
\end{tabular}

Las entradas definidas en la Tabla 12 se generan una serie de llegadas teóricas modificadas según las condiciones de operación (retrasos y atenuaciones). A estas llegadas teóricas del modo S0 se aplica la CT obteniendo los coefientes $\operatorname{Re}($ Scaling) y Time Shift que serán utilizados como salidas del modelo.

Las diferentes combinaciones de valores de entrada producen un total de 4000 interrogaciones teóricas. Con todos estos datos se entrena la ANN y se comprueba su funcionamiento.

Los resultados de entrenamiento de una de las variables de salida simulada frente a la objetivo se indican en la Figura 49.

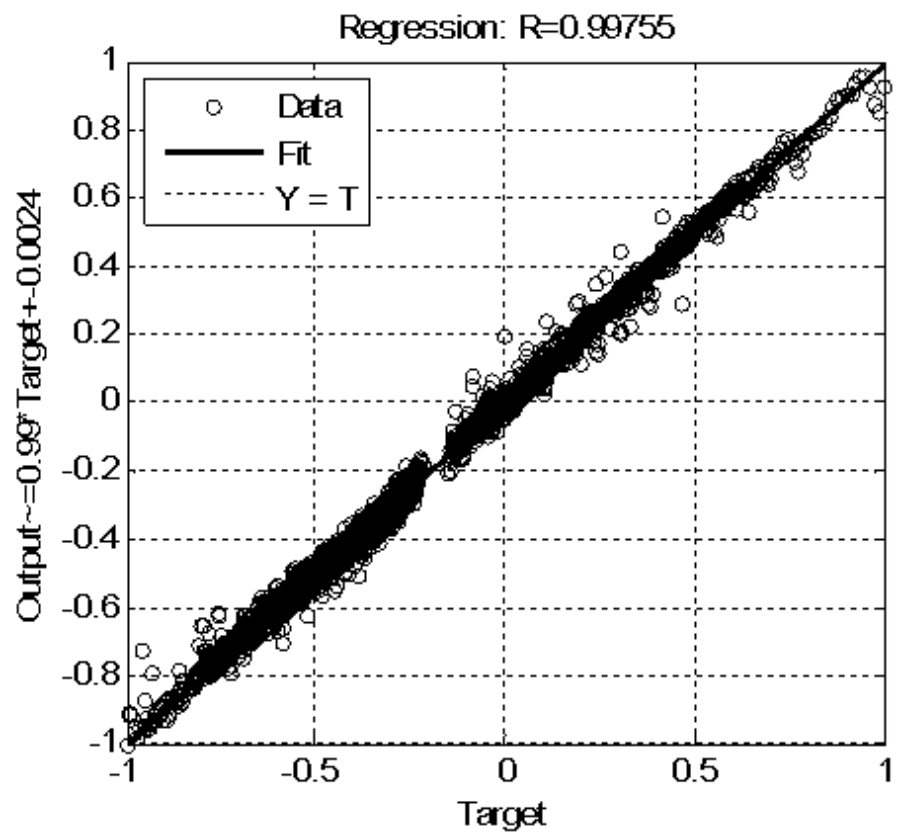

Figura 49 - Valores objetivo frente a los simulados por el modelo ANN para su entrenamiento (Time Shift)

Los resultados de la figura anterior indican que las salidas deseadas se aproximan bastante a las objetivo para el entrenamiento de la ANN. Esto muestra que, en teoría, el modelo CT-ANN debe funcionar. A continuación se procede a su entrenamiento y validación con datos reales. 


\subsubsection{Ajuste del modelo de compensación con datos experimentales}

El esquema de trabajo para la compensación de las EOC incluye el modelo ANN definido anteriormente y una serie de tareas periféricas. Antes de indicar como se realiza el entrenamiento del modelo ANN se muestra el diagrama de flujo del esquema de compensación en la Figura 50.

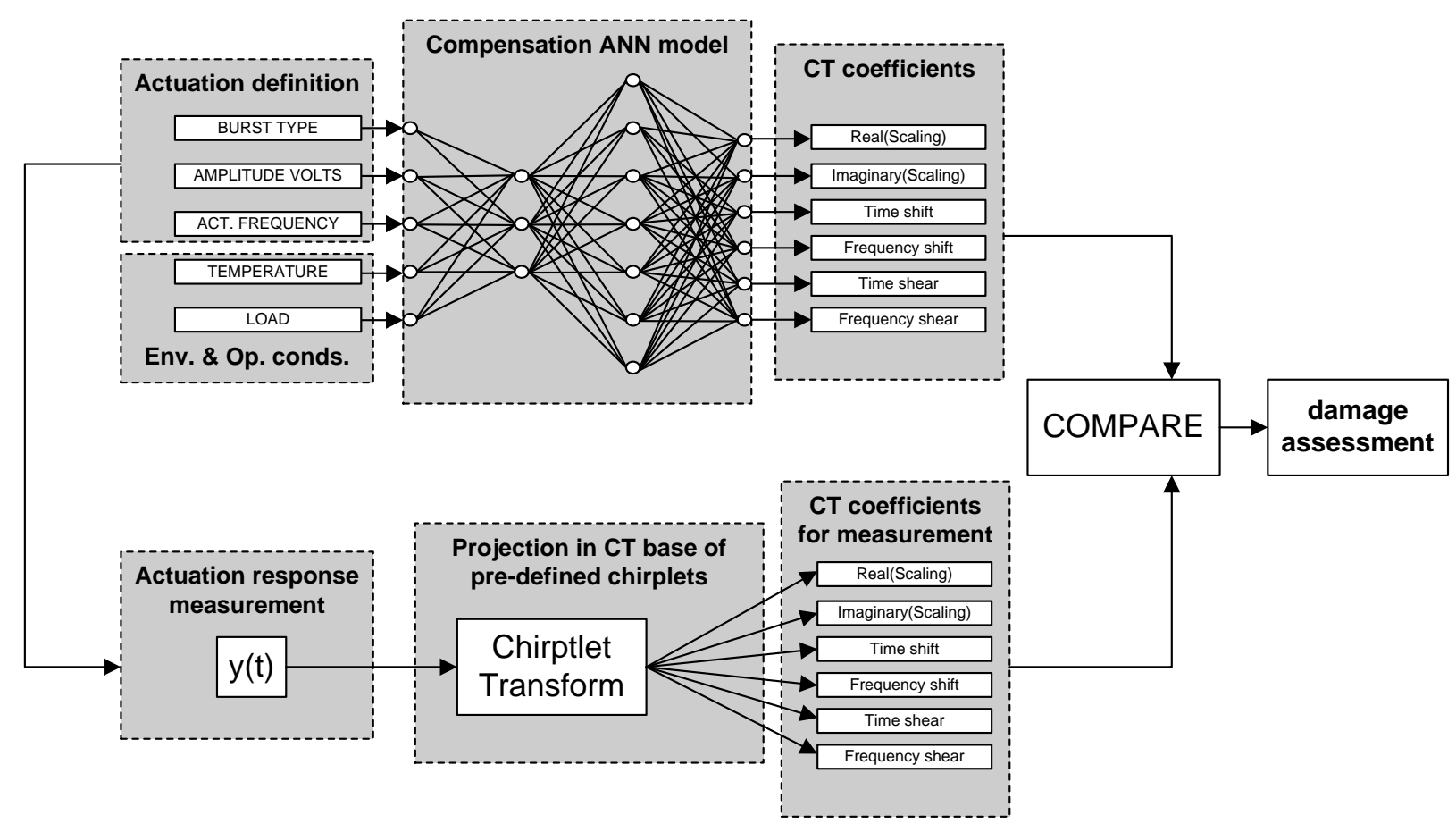

Figura 50 - Diagrama de flujo para la utilización del modelo

Se parte de una definición de la interrogación que van a efectuar los transmisores y las EOC en las que se realiza dicha interrogación:

- Burst type

- Amplitud

- Frecuencia de actuación

- Temperatura

- Carga

Estos datos alimentan el modelo de compensación basado en ANN, produciendo los coeficientes de la CT correspondientes a la situación de referencia según las entradas.

Por otra parte se mide la respuesta de la estructura en el receptor y se aplica la CT del modo que se ha indicado en apartados previos. Con esto obtenemos los coeficientes de la CT, reales, correspondientes a la interrogación efectuada. 
Finalmente se comparan los coeficientes obtenidos por la simulación del modelo ANN y los reales. Dicha comparación dará como resultado diferencias en aquellos coeficientes que no están relacionados con los parámetros de entrada al modelo. Los coeficientes relacionados con las EOC y las características de la actuación deberían mantenerse iguales y los que están relacionados con el daño, cambiar, si este existe. El resultado final sería la diagnosis de daño con compensación de EOC.

Los ensayos realizados no contienen tantas variables como las que participan en la definición anterior. En este caso se utilizará una versión simplificada del mismo:

- El Burst type es fijo, 5 picos, se elimina de las entradas.

- La frecuencia es fija, $200 \mathrm{KHz}$, se elimina de las entradas.

- La amplitud cambia como ya hemos comentado anteriormente en función de la interrogación y del sistema de adquisición utilizado. Mantenemos esta entrada

- La temperatura será la única EOC considerada. Mantenemos esta entrada pero de forma incremental respecto a una referencia.

Esta simplificación se puede ver en la Figura 51, Tabla 13.

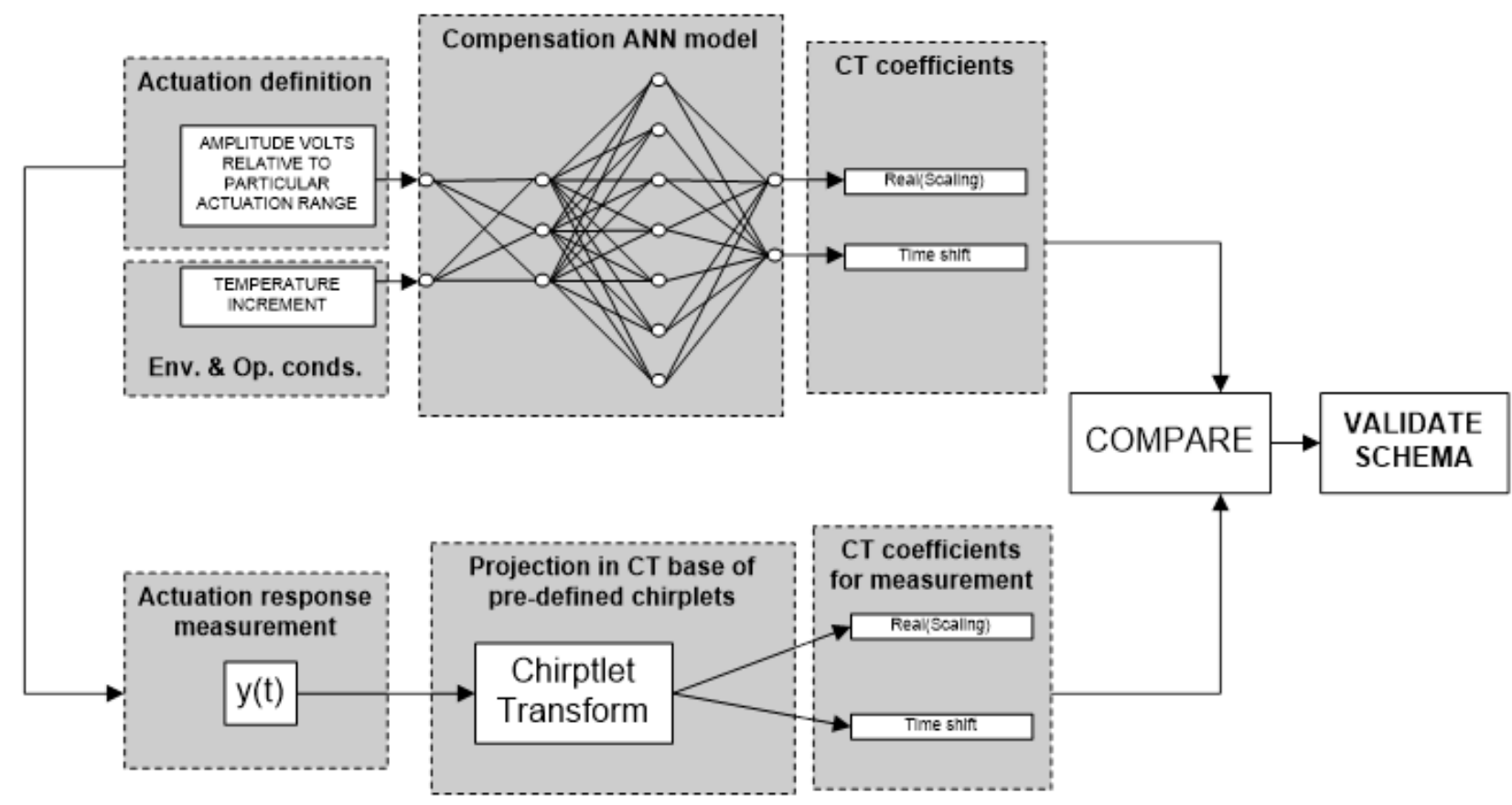

Figura 51 - Aplicación del modelo de compensación simplificado 


\begin{tabular}{|c|c|}
\hline PARÁMETRO DE DEFINICIÓN & VALOR \\
\hline Tipo de Red Neuronal & Feedforward Backpropagation \\
\hline Número de entradas & 2 Amplitud e incremento de temperatura \\
\hline Número de capas & 3 \\
\hline Número de neuronas por capa & $\begin{array}{l}7 \\
23 \\
2 \\
\end{array}$ \\
\hline Función de transferencia neuronal en cada capa & $\begin{array}{l}\text { Tangente sigmoidea } \\
\text { Tangente sigmoidea } \\
\text { Lineal }\end{array}$ \\
\hline Número de salidas & 2 Re(Scaling) y Time Shift incremental \\
\hline Algoritmo de entrenamiento & Levenberg-Marquardt con regularización bayesiana \\
\hline
\end{tabular}

Tabla 13 - Parámetros de definición del modelo de compensación.

Para el entrenamiento y validación de la ANN se utilizarán datos experimentales con variaciones de temperatura y en condiciones sin daño. Para el blind test del modelo ANN se usarán datos experimentales con variación de temperatura y del tamaño de daño. Se comprobará si el coeficiente de la CT, salida de la ANN, Re(Scaling) muestra un comportamiento similar a los observados en el apartado de análisis de los datos experimentales. Y también si el comportamiento del Time Shift es el adecuado para las variaciones de temperatura simuladas.

Las pasos para entrenar, validar y comprobar mediante blind test el esquema de compensación CT-ANN son los siguientes:

1. Calcular los coeficientes de la CT para cada llegada del modo S0 (Re(Scaling) y Time Shift) esto nos proporciona los datos de salida objetivo de la ANN.

2. Calcular y ajustar la amplitud de llegada y el incremento de temperatura para cada interrogación. Así obtenemos los parámetros de entrada para el modelo ANN.

3. Dividir los datos en dos grupos:

a. Conjunto de datos de entrenamiento, $80 \%$ del total.

b. Conjunto de datos de validación, $20 \%$ del total.

4. Entrenar la ANN usando los dos conjuntos de datos anteriores (el conjunto de datos de validación sirve como control para el proceso de ajuste que se efectúa únicamente con el conjunto de datos de entrenamiento). Entrenamiento y validación es un proceso simultáneo.

5. Comprobar el modelo ANN entrenado mediante un blind test con datos adicionales no utilizados para el entrenamiento o para la validación. Estos datos se procesan del siguiente modo

a. Calcular los coeficientes de la CT. Re(Scaling) y Time Shift. Datos objetivo de referencia. 
b. Recuperar los datos de amplitud e incremento de temperatura para estas interrogaciones.

c. Simular la ANN con esos datos, obteniendo los valores de Re(Scaling) y Time Shift simulados.

d. Comparar los coeficientes obtenidos en (a) y en (c)

\subsubsection{Validación del esquema de compensación con datos experimentales}

Los resultados de entrenamiento y validación se muestran en la Figura 52 y Figura 53 respectivamente.

Los errores de aproximación obtenidos para los coeficientes simulados de la CT son los siguientes:

- $\quad$ Entrenamiento RMSE $=6.6 \%$ para el rango de variación de cada salida.

- Validación RMSE = 14 \% para el rango de variación de cada salida.
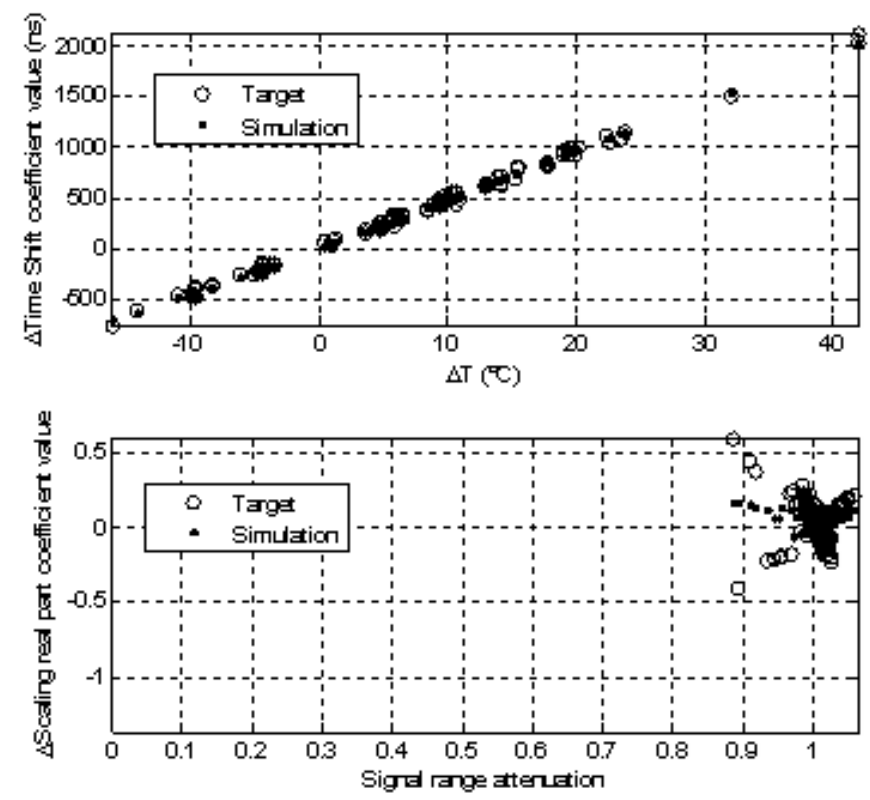

Figura 52 - Resultados de entrenamiento del modelo ANN 

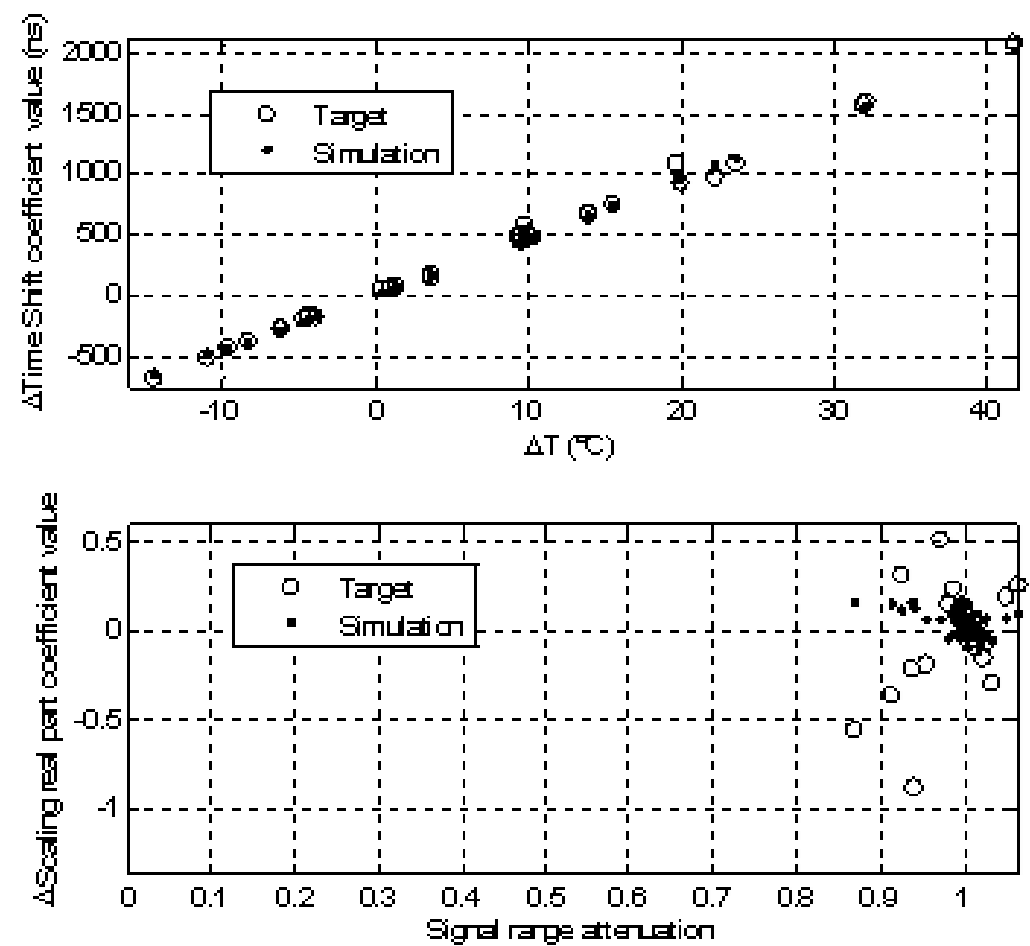

Figura 53 - Resultados de validación del modelo ANN

Los resultados de entrenamiento con datos reales revelan que el modelo ANN se puede aplicar para modelar las relaciones existentes entre los coeficientes de la CT y los parámetros de interrogación junto con las EOC de dicha interrogación.

Los resultados de validación indican que este modelo ANN es capaz de interpolar correctamente para valores de los parámetros de entrada dentro de los rangos utilizados en el entrenamiento. Así pues se puede usar como modelo para los valores de referencia de la situación sin daño utilizando un rango de variación de las EOC suficientemente amplio pero sin la necesidad de un gran número de situaciones diferentes. Simulando esta referencia y calculando los valores equivalentes para una interrogación efectuada en una combinación de EOC nuevas se podrían comparar ambos conjuntos de datos para realizar la diagnosis de daño con cierta fiabilidad.

Tal y como se ha comentado antes el modelo ANN únicamente se ha entrenado con datos de situaciones sin daño (baselines con diferentes EOC). Si, a continuación, simulamos este modelo en condiciones en las que también exista daño, la comparación de los diferentes grupos de coeficientes de la CT (los obtenidos por simulación del modelo ANN y los reales) debería sacar a la luz la firma del daño sobre la DSF, variaciones en el coeficiente $\operatorname{Re}(\operatorname{Scaling})$. Este comportamiento se ha simulado en la comprobación mediante blind test, definida anteriormente y se han obtenido los resultados de la Figura 54. 

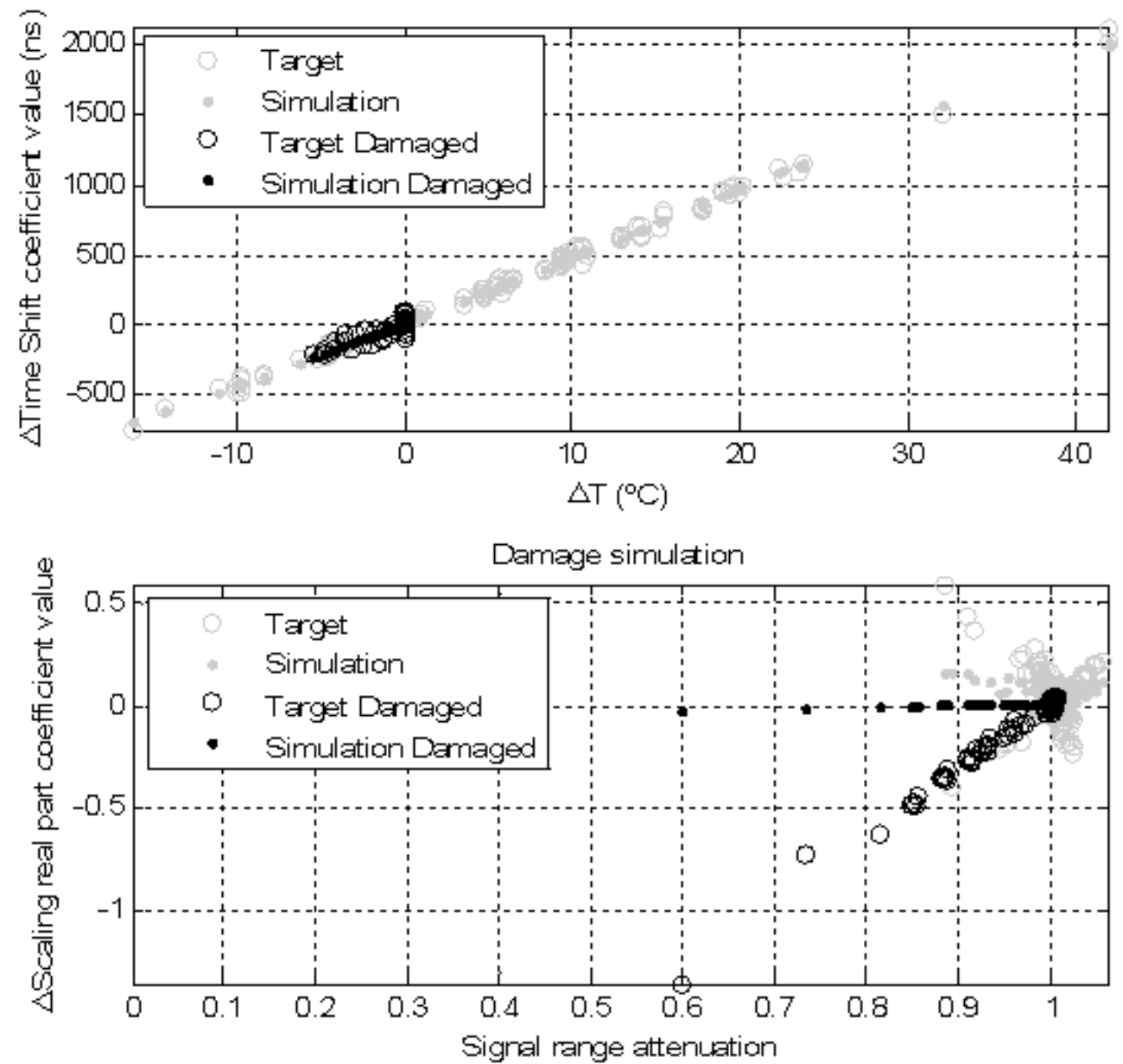

Figura 54 -Blind test del modelo con datos de daño bajo condiciones variables de temperatura

Observamos en la Figura 54, gráfica superior, que el coeficiente de Time Shift sigue perfectamente las variaciones previstas por el modelo para los incrementos de temperatura a los que se han efectuado estas interrogaciones. Sin embargo, en la misma figura, gráfica inferior, comprobamos que el coeficiente $\operatorname{Re}($ Scaling) simulado y real (objetivo) se separan de modo lineal debido a la presencia de daño, del mismo modo que se comprobó anteriormente (ver Figura 46). Con lo cual se confirma que el modelo CT-ANN permite sacar a la luz la presencia del daño bajo la influencia de EOC, cosa que no se podría obtener directamente debido a que las EOC ocultan la firma del daño en la DSF (ver Tabla 9). 


\subsection{Estudios bidimensionales en fuselaje, múltiples caminos de daño}

El objetivo general de los ensayos en el fuselaje es evaluar la metodología comprobada en los ensayos anteriores, pero en una estructura real y con condiciones lo más realistas posibles.

Los ensayos para el fuselaje y los objetivos particulares de cada uno de ellos se describen en la Tabla 14

\begin{tabular}{|l|l|l|}
\hline ENSAYO & \multicolumn{1}{|c|}{ DESCRIPCIÓN } & \multicolumn{1}{|c|}{ OBJETIVO } \\
\hline 1 & Variación de carga & $\begin{array}{l}\text { Situación de referencia sin daño con diferentes } \\
\text { valores de carga aplicada }\end{array}$ \\
\hline 2 & $\begin{array}{l}\text { Variación de carga y daño 1 } \\
\text { aplicados con daño 1 para diferentes casos de carga }\end{array}$ \\
\hline 3 & $\begin{array}{l}\text { Variación de carga y temperatura con daño 1 } \\
\text { presente }\end{array}$ & $\begin{array}{l}\text { Situación con daño 1 para diferentes casos de carga y } \\
\text { térmicos }\end{array}$ \\
\hline 4 & $\begin{array}{l}\text { Variación de carga y daño 1 } \\
\text { aplicados }\end{array}$ \\
\hline 5 & $\begin{array}{l}\text { Variación de carga y temperatura con daño 2 - } \\
\text { tamaño 1 presente }\end{array}$ & $\begin{array}{l}\text { Situación con daño 2, tamaño 1, para diferentes casos } \\
\text { de carga y temperatura }\end{array}$ \\
\hline 6 & $\begin{array}{l}\text { Variación de carga y temperatura con daño 2 - } \\
\text { tamaño 2 presente }\end{array}$ & $\begin{array}{l}\text { Situación con daño 2, tamaño 2, para diferentes casos } \\
\text { de carga y temperatura }\end{array}$ \\
\hline
\end{tabular}

Tabla 14 - Ensayos realizados para el fuselaje. 


\subsubsection{Definición de la estructura}

La estructura seleccionada para las pruebas reales es una sección de fuselaje de pared delgada con rigidizadores transversales, cuadernas en C, y longitudinales, larguerillos en L. El material, de nuevo, es aluminio 7075 .
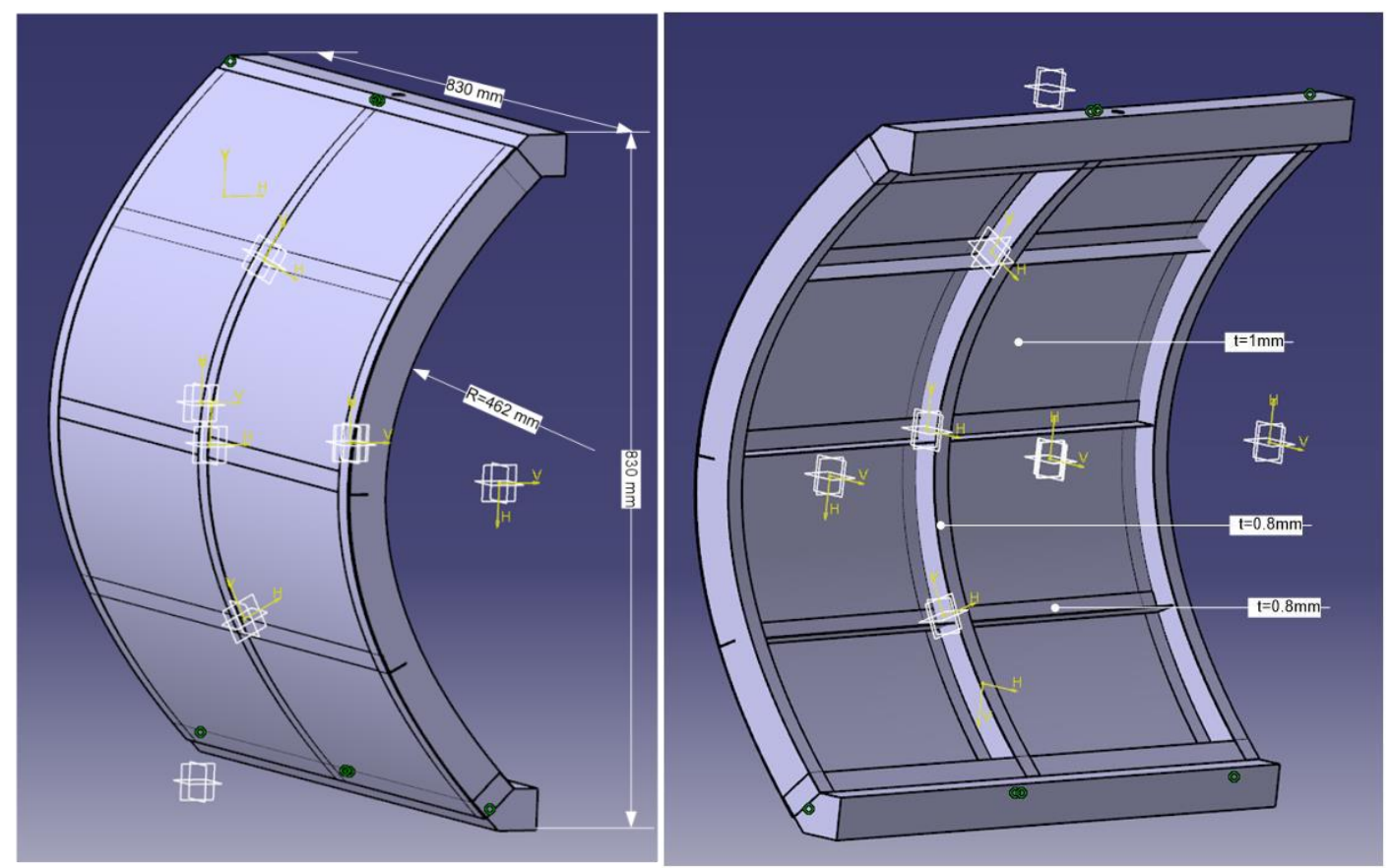

Figura 55 - Dimensiones principales del segmento de fuselaje

Las propiedades mecánicas del material son las siguientes (y en particular del revestimiento que es por donde principalmente viajarán las ondas elásticas):

$$
\lambda=53.6 \mathrm{GPa} \quad \mu=26.5 \mathrm{GPa} \quad \rho=2800 \frac{\mathrm{Kg}}{\mathrm{m}^{3}} \quad c_{t}=3076 \frac{\mathrm{m}}{\mathrm{s}} \quad c_{l}=6208 \frac{\mathrm{m}}{\mathrm{s}}
$$

Esta configuración se ha seleccionado para simular una estructura lo más realista posible la evolución del daño en un camino de daño. 


\subsubsection{Instalación de sensores y sistema de adquisición de datos}

Para la instalación de los sensores se han seleccionado dos de las bahías de la pieza tal y como se define en la Figura 56, cubriendo un área de unos 415 x $415 \mathrm{~mm} \cdot \mathrm{mm}$ aproximadamente.

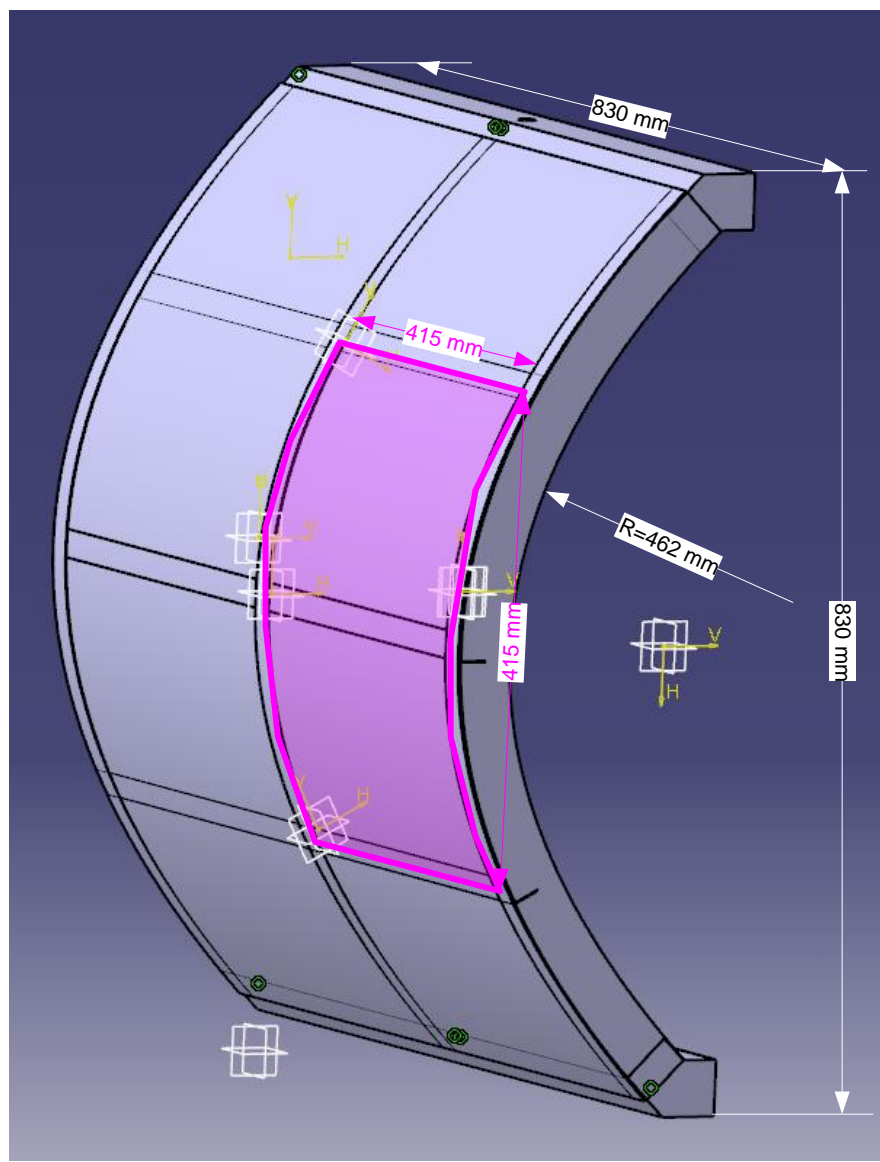

Figura 56 - Instalación de los sensores

En la Figura 57 se puede comprobar la instalación de los sensores en la pieza real.
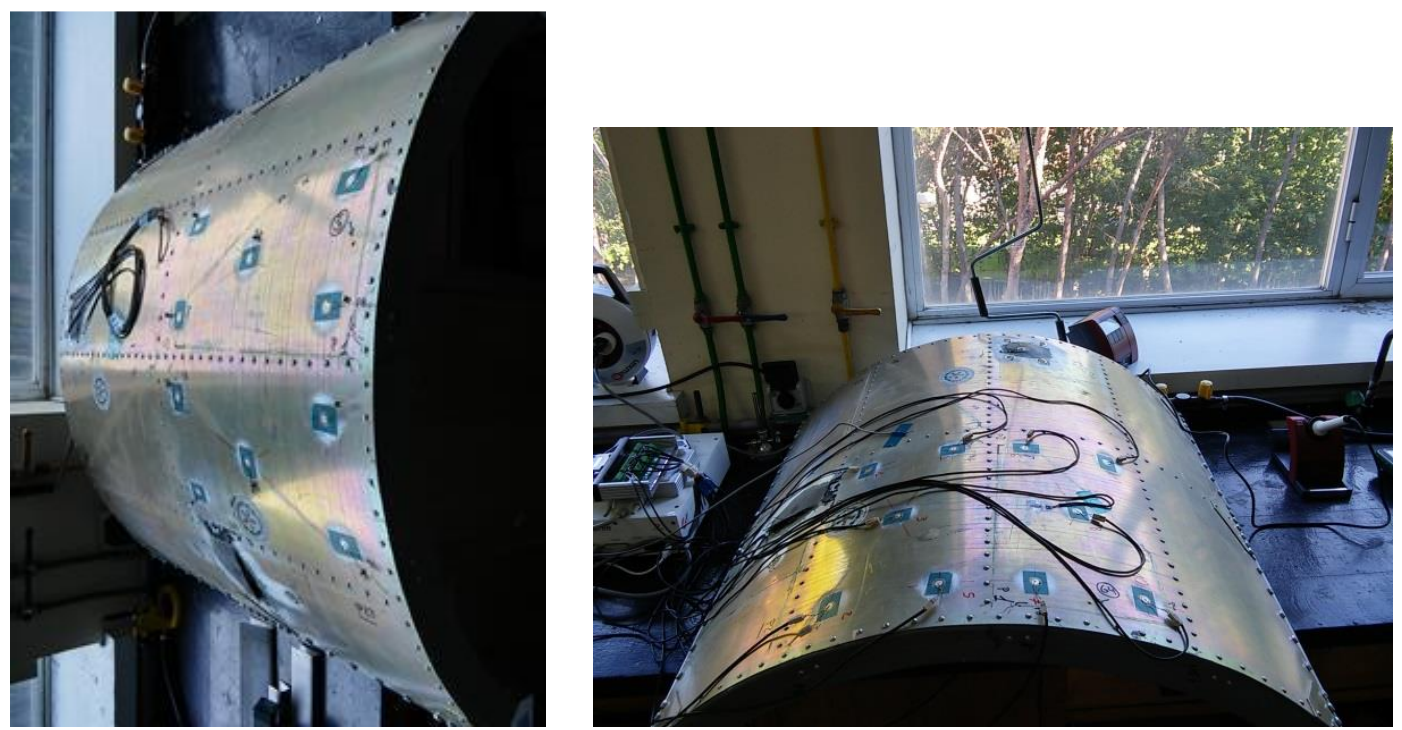

Figura 57 - Instalación de los sensores en la zona seleccionada del fuselaje 
Los sensores piezoeléctricos se instalan sobre la zona seleccionada de la pieza con la siguiente configuración y posicionamiento respecto al sistema de coordenadas local de los sensores ((x,y) en magenta en la Figura 58 ).

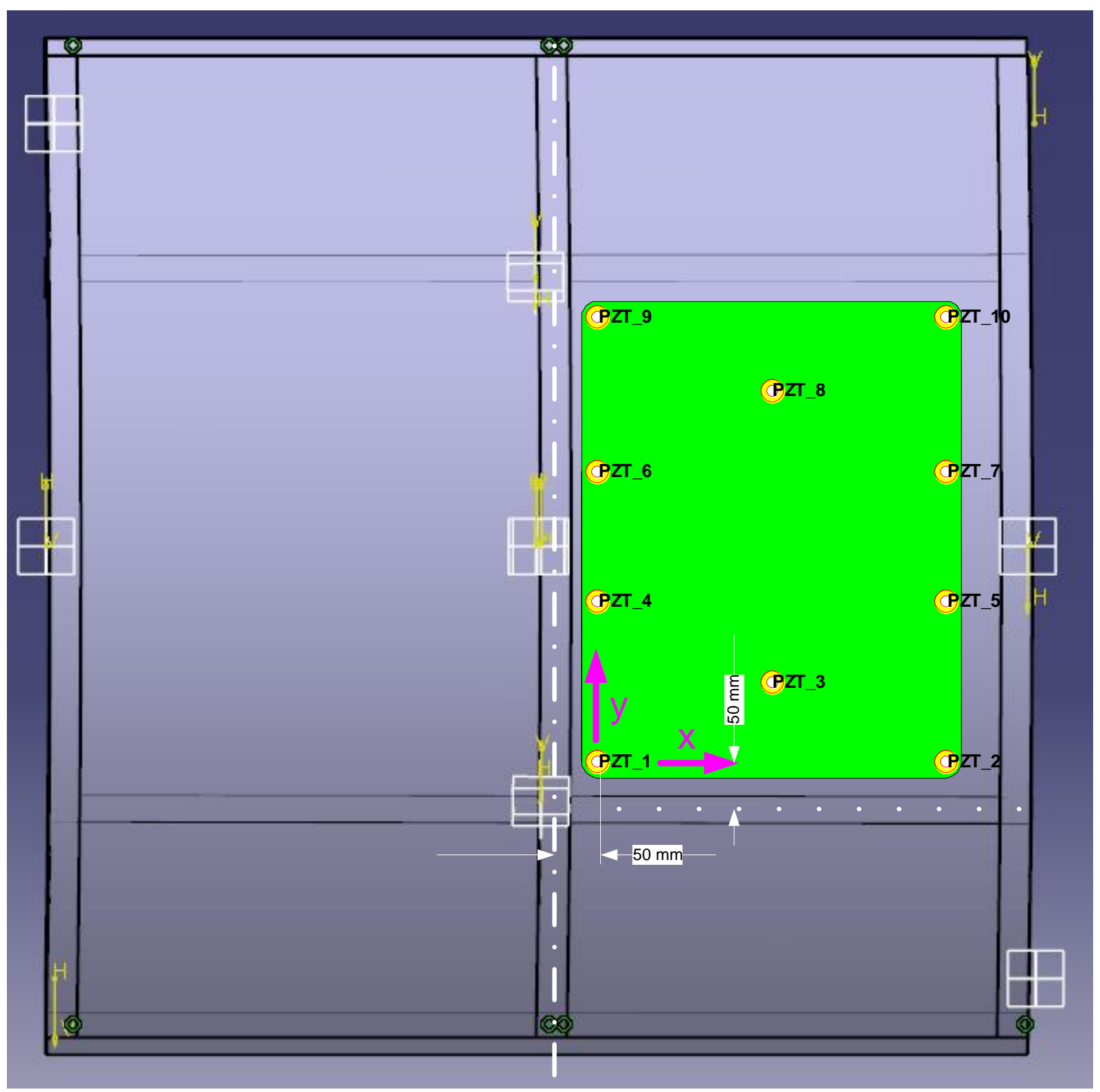

Figura 58 - Posicionamiento de sensores en la pieza de fuselaje.

Las posiciones respecto al sistema de coordenadas indicado de cada uno de los sensores se define en la Tabla 15. 


\begin{tabular}{|l|c|c|}
\hline SENSOR & $\mathbf{x}(\mathbf{m m})$ & $\mathbf{y}(\mathbf{m m})$ \\
\hline PZT 1 & 0 & 0 \\
\hline PZT 2 & 280 & 0 \\
\hline PZT 3 & 140 & 65 \\
\hline PZT 4 & 0 & 130 \\
\hline PZT 5 & 280 & 130 \\
\hline PZT 6 & 0 & 235 \\
\hline PZT 7 & 280 & 235 \\
\hline PZT 8 & 140 & 300 \\
\hline PZT 9 & 0 & 360 \\
\hline PZT 10 & 280 & 360 \\
\hline
\end{tabular}

Tabla 15 - Posicionamiento de los sensores en el fuselaje.

Los caminos de daño que tenemos con esta configuración suman un total de 90 y se indican en la Figura 59en blanco. Estos caminos de daño se asimilarán al camino de daño estudiado en las pruebas en las pletinas para poder efectuar los cálculos.

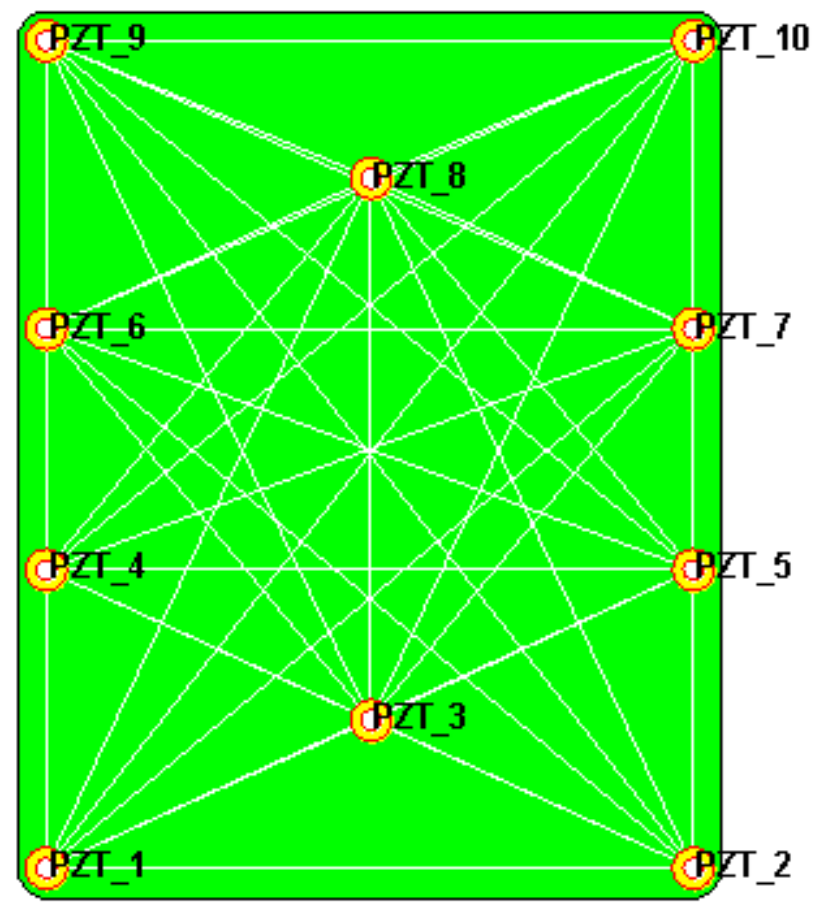

Figura 59 - Caminos de daño para la configuración de sensores instalada en la pieza de fuselaje.

Para esta estructura, no solo se han instalado sensores de tipo piezoeléctrico sino que también se ha instalado extensometría y un termopar para poder medir el estado de carga y la temperatura en la zona central de la pieza.

En la Figura 60 se puede comprobar el posicionamiento de los extensímetros en la línea de unión entre los sensores piezoeléctricos 8 y tres. Los extensímetros están instalados en ambas caras de la pieza, back to back, y con sentidos opuestos para compensar de modo automático las variaciones de temperatura en la pieza. El termopar se sitúa en la zona central, ligado a la pieza, 
y por la parte interior de la misma. La posición del termopar es móvil y según interese se colocará en un lugar u otro dependiendo de la configuración del ensayo pero siempre ligado a la pieza para tomar su temperatura.

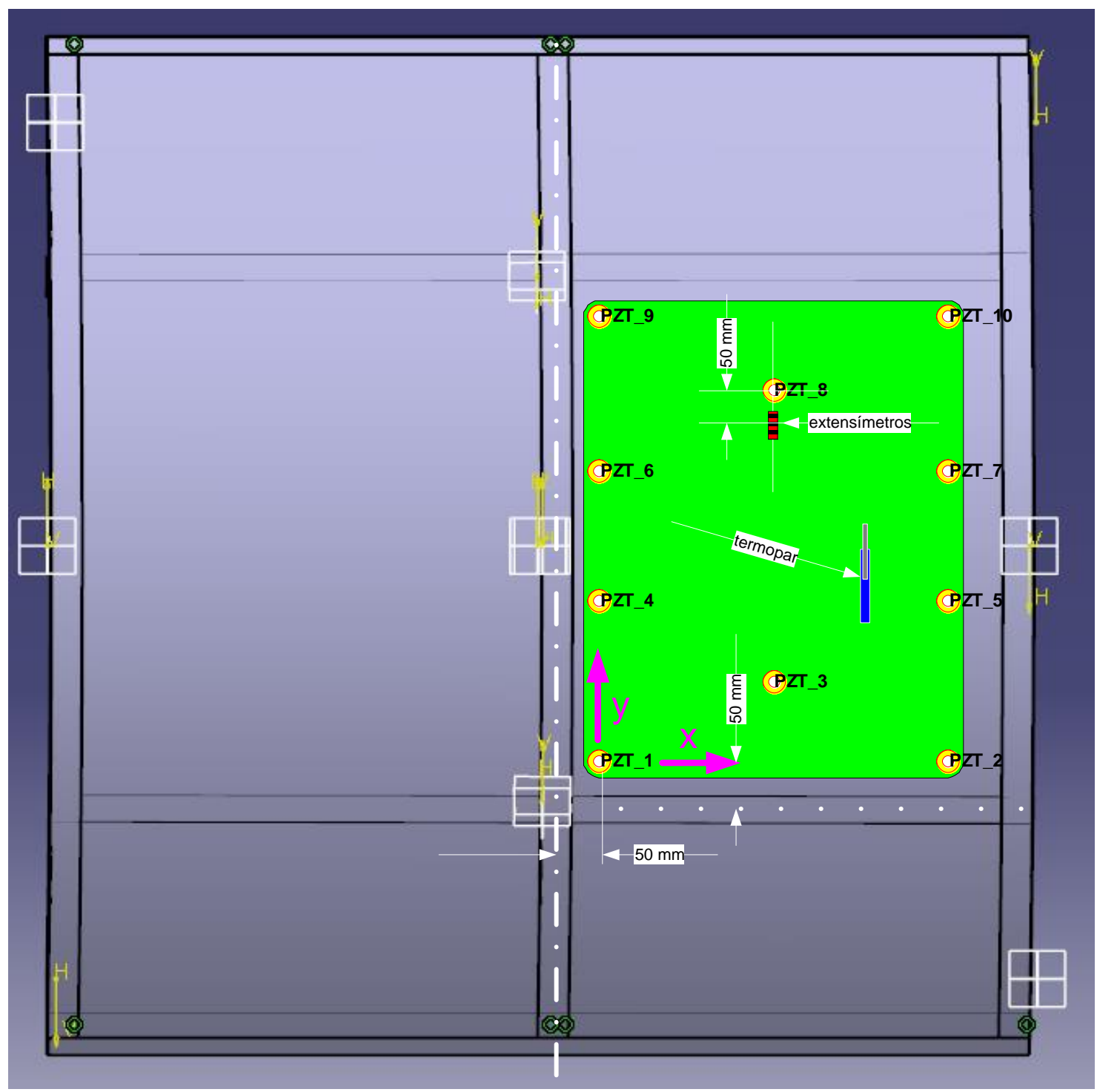

Figura 60 - Posicionamiento de los extensímetros y del termopar.

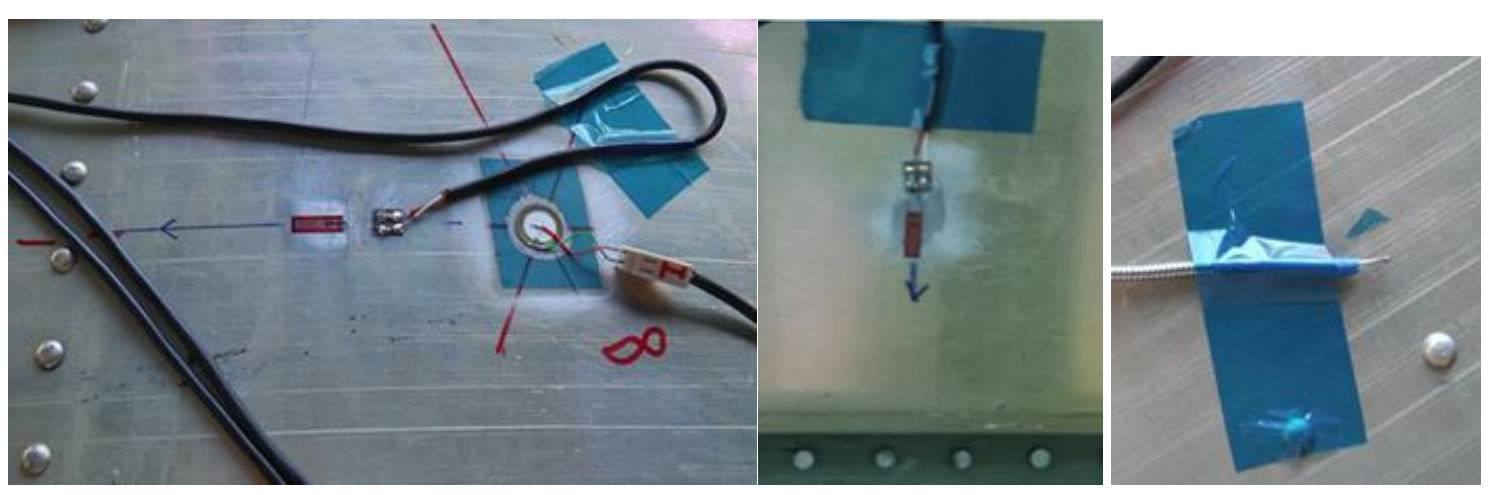

Figura 61 -Extensímetros situados en ambas caras de la pieza y termopar. 
Los sistemas de adquisición de datos utilizados para estos ensayos se pueden comprobar en la Figura 62 y una visión de conjunto de las pruebas preliminares en la Figura 63.

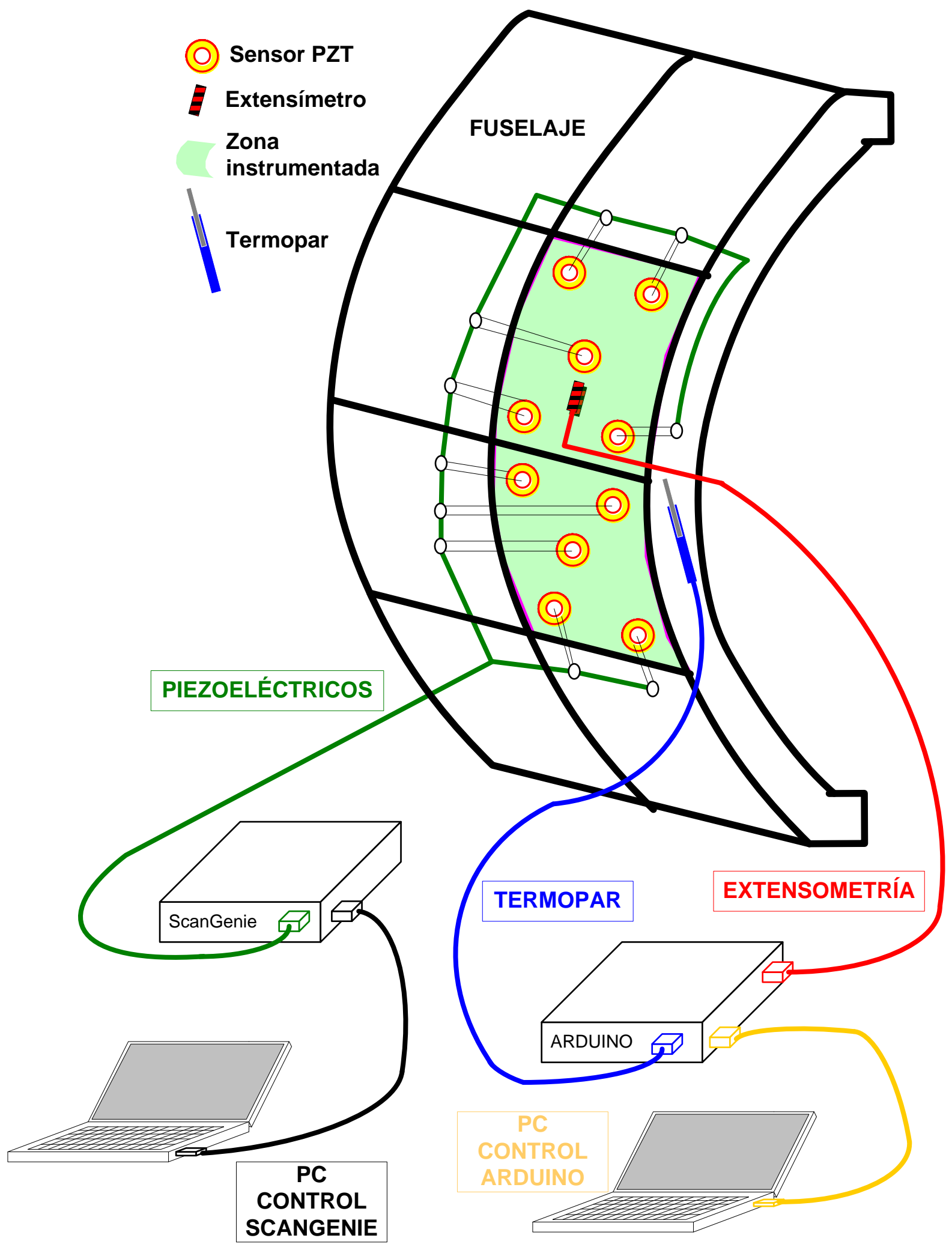

Figura 62 - Esquema de los sistemas de adquisición de datos utilizados. 


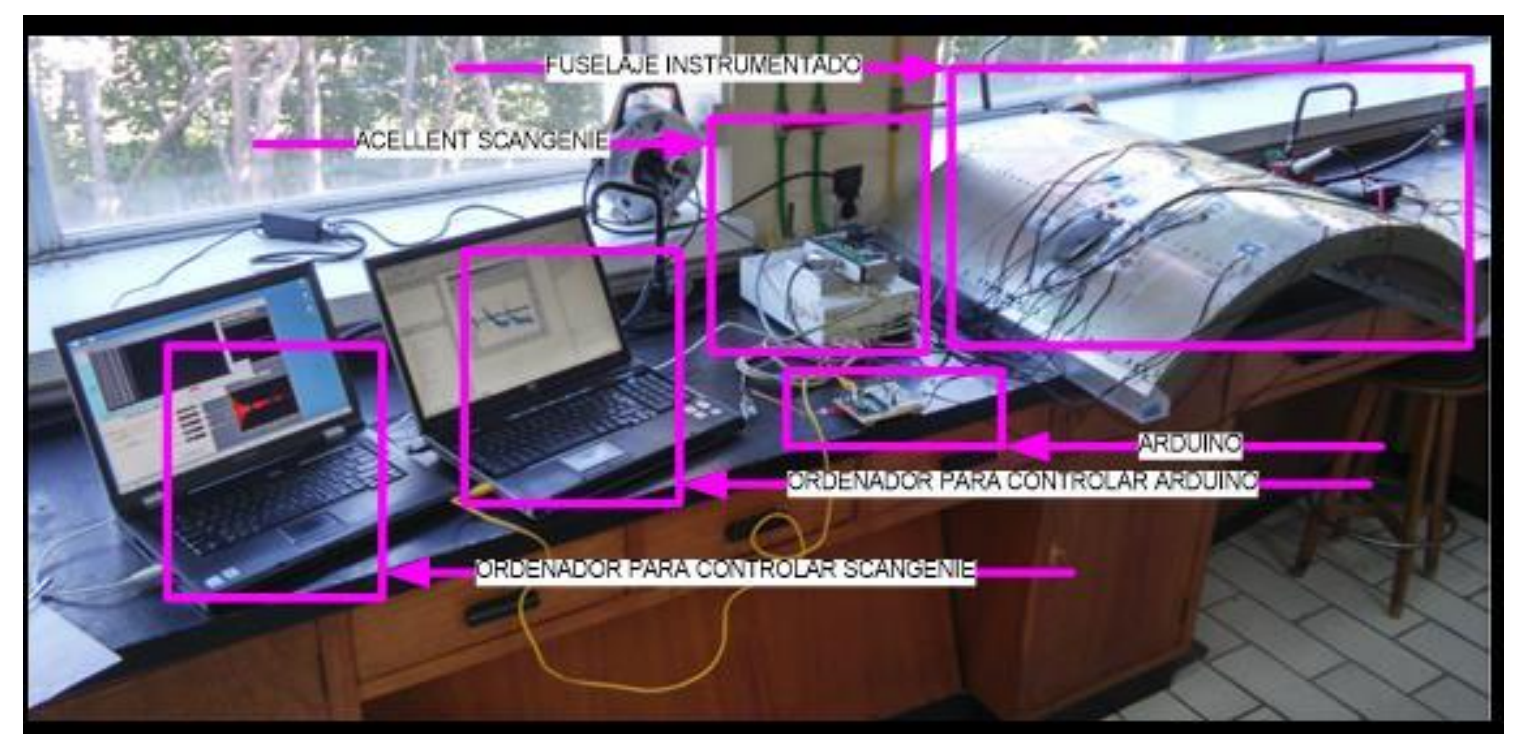

Figura 63 - Sistemas de adquisición de datos conectados para las pruebas preliminares.

En este caso se ha utilizado un único sistema de adquisición (Acellent ScanGenie, debido a la limitación de canales y capacidades de conmutación limitadas de la tarjeta de National Instruments) de datos para los sensores PZT y otro, simultáneo, para la temperatura y la extensometría. El sistema de los PZT sigue un esquema transmisor-receptor (pitch-catch) cuyas configuraciones de interrogación se detallan en la siguiente tabla.

\begin{tabular}{|c|c|c|}
\hline \multirow{2}{*}{$\begin{array}{l}\text { ELEMENTO DE } \\
\text { CONFIGURACIÓN }\end{array}$} & \multicolumn{2}{|c|}{ SISTEMA DE ADQUISICIÓN DE DATOS } \\
\hline & Acellent ScanGenie & Sistema Arduino \\
\hline $\begin{array}{l}\text { Patrón de interrogación actuador- } \\
\text { sensor }\end{array}$ & $\begin{array}{l}\text { PZT1-PZT2, PZT3... PZT10 } \\
\text { PZT2-PZT1, PZT3... PZT10 } \\
\ldots \\
\text { PZT9-PZT1, PZT2... PZT10 } \\
\text { PZT10-PZT1, PZT2.... PZT9 }\end{array}$ & $\begin{array}{l}\text { Adquisición continua de los } 2 \\
\text { canales de extensometría y del canal } \\
\text { de temperatura del termopar de } \\
\text { modo sincronizado }\end{array}$ \\
\hline Señal de interrogación & $\begin{array}{l}\text { Burst de } 5 \text { picos modulado por una } \\
\text { ventana tipo Hanning }\end{array}$ & No aplica \\
\hline $\begin{array}{l}\text { Frecuencia de la señal de } \\
\text { interrogación }\end{array}$ & $\begin{array}{l}200 \mathrm{KHz} \\
250 \mathrm{KHz} \\
300 \mathrm{KHz}\end{array}$ & No aplica \\
\hline $\begin{array}{l}\text { Resolución del conversor analógico } \\
\text { digital }\end{array}$ & 16 bit & 12 bit \\
\hline $\begin{array}{l}\text { Frecuencia de muestreo de los } \\
\text { canales }\end{array}$ & 48000000 muestras por segundo & 1 muestra por segundo \\
\hline $\begin{array}{l}\text { Utilización de amplificador de } \\
\text { señales }\end{array}$ & $\mathrm{Si}$ & $\begin{array}{l}\text { Si, amplificación particular con } \\
\text { placa dedicada para los } \\
\text { extensímetros y el termopar }\end{array}$ \\
\hline $\begin{array}{l}\text { Promediado efectuado en las } \\
\text { adquisiciones }\end{array}$ & 10 & 100 \\
\hline $\begin{array}{l}\text { Sobremuestreo por software de los } \\
\text { datos adquiridos }\end{array}$ & 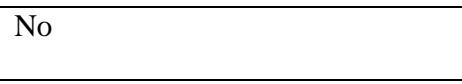 & 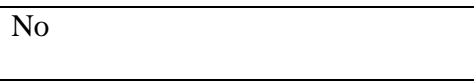 \\
\hline Sincronización & $\begin{array}{l}\text { Semiautomática por nombre de } \\
\text { fichero }\end{array}$ & $\begin{array}{l}\text { Automática, señal de tiempo grabada } \\
\text { de modo síncrono con los datos }\end{array}$ \\
\hline
\end{tabular}

Tabla 16 - Configuración de los sistemas de adquisición para las pletinas.

Se pueden encontrar más detalles de los sistemas que se indican en la Tabla 16en el anexo 4, capítulo 11. 


\subsubsection{Condiciones de ensayo}

Como ya se ha comentado anteriormente las condiciones del ensayo son con variación del estado de carga y de la temperatura de la pieza de fuselaje. Las condiciones de ensayo para el fuselaje y los objetivos detallados de cada uno de ellos se describen en la Tabla 17.

\begin{tabular}{|c|c|c|c|c|c|}
\hline ENSAYO & DESCRIPCIÓN & TEMPERATURA & $\begin{array}{c}\text { SECUENCIA } \\
\text { DE } \\
\text { CARGA } \\
\text { APLICADA }\end{array}$ & $\begin{array}{c}\text { DAÑO } \\
\text { INTRODUCIDO }\end{array}$ & OBJETIVO \\
\hline 1 & Variación de carga & $\begin{array}{l}\text { Ambiente, sin } \\
\text { controlar entre } \\
26^{\circ} \mathrm{C} \text { y } 28^{\circ} \mathrm{C}\end{array}$ & $\begin{array}{l}0 \mathrm{kN} \\
1 \mathrm{kN} \\
2 \mathrm{kN} \\
3 \mathrm{kN} \\
4 \mathrm{kN} \\
0 \mathrm{kN} \\
-1 \mathrm{kN} \\
-2 \mathrm{kN} \\
-3 \mathrm{kN}\end{array}$ & Sin daño & $\begin{array}{l}\text { Obtener } \\
\text { situaciones de } \\
\text { referencia para } \\
\text { diferentes } \\
\text { estados de carga } \\
\text { a una } \\
\text { temperatura dada }\end{array}$ \\
\hline 2 & $\begin{array}{l}\text { Variación de carga } \\
\text { y daño } 1\end{array}$ & $\begin{array}{l}\text { Ambiente sin } \\
\text { controlar entre } \\
28^{\circ} \mathrm{C} \text { y } 29^{\circ} \mathrm{C}\end{array}$ & $\begin{array}{l}0 \mathrm{kN} \\
1 \mathrm{kN} \\
2 \mathrm{kN} \\
3 \mathrm{kN} \\
4 \mathrm{kN} \\
0 \mathrm{kN} \\
-1 \mathrm{kN} \\
-2 \mathrm{kN} \\
-3 \mathrm{kN}\end{array}$ & $\begin{array}{l}\text { Daño número } 1 \text {, } \\
40 \text { mm en zona } \\
\text { central }\end{array}$ & $\begin{array}{l}\text { Obtener } \\
\text { situaciones } \\
\text { dañadas para } \\
\text { diferentes } \\
\text { estados de carga } \\
\text { y a una } \\
\text { temperatura } \\
\text { diferente de la } \\
\text { anterior }\end{array}$ \\
\hline 3 & $\begin{array}{l}\text { Variación de carga } \\
\text { y temperatura con } \\
\text { daño } 1 \text { presente }\end{array}$ & $\begin{array}{l}\text { Ambiente sin } \\
\text { controlar a } 24^{\circ} \mathrm{C}\end{array}$ & $\begin{array}{l}0 \mathrm{kN} \\
2 \mathrm{kN} \\
-2 \mathrm{kN}\end{array}$ & $\begin{array}{l}\text { Daño número 1, } \\
40 \text { mm en zona } \\
\text { central }\end{array}$ & $\begin{array}{l}\text { Obtener } \\
\text { situaciones } \\
\text { dañadas para } \\
\text { diferentes } \\
\text { estados de carga } \\
\text { y a una tercera } \\
\text { temperatura }\end{array}$ \\
\hline 4 & $\begin{array}{l}\text { Variación de carga } \\
\text { y daño } 1\end{array}$ & $\begin{array}{l}\text { Controlada } \mathrm{T} 1= \\
\text { Con manta térmica } \\
\text { Controlada } \mathrm{T} 2= \\
\text { Con manta térmica }\end{array}$ & $\begin{array}{l}0 \mathrm{kN} \\
2 \mathrm{kN} \\
-2 \mathrm{kN} \\
0 \mathrm{kN} \\
2 \mathrm{kN} \\
-2 \mathrm{kN}\end{array}$ & $\begin{array}{l}\text { Daño número } 1, \\
40 \text { mm en zona } \\
\text { central }\end{array}$ & $\begin{array}{l}\text { Obtener } \\
\text { situaciones } \\
\text { dañadas para } \\
\text { diferentes } \\
\text { estados de carga } \\
\text { con mayores } \\
\text { incrementos de } \\
\text { temperatura }\end{array}$ \\
\hline 5 & $\begin{array}{l}\text { Variación de carga } \\
\text { y temperatura con } \\
\text { daño } 2 \text { - tamaño } 1 \\
\text { presente }\end{array}$ & $\begin{array}{l}\text { Ambiente } \mathrm{T} 0= \\
\text { Sin manta térmica } \\
\text { Controlada } \mathrm{T} 2= \\
\text { Con manta térmica }\end{array}$ & $\begin{array}{l}0 \mathrm{kN} \\
2 \mathrm{kN} \\
-2 \mathrm{kN} \\
0 \mathrm{kN} \\
2 \mathrm{kN} \\
-2 \mathrm{kN}\end{array}$ & $\begin{array}{l}\text { Daño número } 2, \\
10 \text { mm en zona } \\
\text { superior }\end{array}$ & $\begin{array}{l}\text { Obtener } \\
\text { situaciones con } \\
\text { daño para } \\
\text { diferentes cargas } \\
\text { y temperaturas } \\
\text { en el límite de } \\
\text { sensibilidad de la } \\
\text { técnica SHM }\end{array}$ \\
\hline 6 & $\begin{array}{l}\text { Variación de carga } \\
\text { y temperatura con } \\
\text { daño } 2 \text { - tamaño } 2 \\
\text { presente }\end{array}$ & $\begin{array}{l}\text { Ambiente } \mathrm{T} 0= \\
\text { Sin manta térmica } \\
\text { Controlada } \mathrm{T} 2= \\
\text { Con manta térmica }\end{array}$ & $\begin{array}{l}0 \mathrm{kN} \\
2 \mathrm{kN} \\
-2 \mathrm{kN} \\
0 \mathrm{kN} \\
2 \mathrm{kN} \\
-2 \mathrm{kN}\end{array}$ & $\begin{array}{l}\text { Daño número 2, } \\
20 \text { mm en zona } \\
\text { superior }\end{array}$ & $\begin{array}{l}\text { Obtener } \\
\text { situaciones con } \\
\text { daño para } \\
\text { diferentes cargas } \\
\text { y temperaturas } \\
\text { ligeramente por } \\
\text { encima del límite } \\
\text { de la técnica } \\
\text { SHM }\end{array}$ \\
\hline
\end{tabular}

Tabla 17 - Ensayos realizados para el fuselaje. 


\begin{tabular}{|c|c|c|c|c|c|c|}
\hline ENSAYO & $\begin{array}{c}\text { CAMINOS } \\
\text { DE } \\
\text { CARGA }\end{array}$ & $\begin{array}{c}\text { FRECUENCIAS } \\
\text { DEE } \\
\text { INTERROGACIÓN }\end{array}$ & $\begin{array}{c}\text { ESCALONES } \\
\text { DE CARGA }\end{array}$ & TEMPERATURAS & DAÑOS & $\begin{array}{c}\text { NÚMERO } \\
\text { TOTAL } \\
\text { DE } \\
\text { SENALES }\end{array}$ \\
\hline 1 & 90 & 3 & 9 & 1 & No & 2430 \\
\hline 2 & 90 & 3 & 9 & 1 & SI & 2430 \\
\hline 3 & 90 & 3 & 3 & 2 & SI & 810 \\
\hline 4 & 90 & 3 & 3 & 2 & SI & 1620 \\
\hline 5 & 90 & 3 & 3 & 2 & SI & 1620 \\
\hline 6 & 90 & 3 & 3 & & SI & 1620 \\
\hline & & & & & TOTAL & 10530 \\
\hline
\end{tabular}

Tabla 18 - Número de adquisiciones realizadas en cada ensayo del fuselaje

En la Tabla 18 se puede comprobar la cantidad de información generada en el conjunto de ensayos realizados para la pieza de fuselaje. La cantidad de información es notable y ello exige una automatización de todos los procesos de datos para poder extraer información útil de todo el conjunto de datos.

\subsubsection{Instalación en laboratorio}

Para realizar los experimentos indicados en el apartado anterior se necesita una gran cantidad de elementos trabajando simultáneamente:

- Fuselaje instrumentado con:

- Sensores PZT.

- Termopar de medición continua y termopar de control.

- Extensometría para medir el estado de carga.

- Máquina de tracción para la introducción de cargas en la pieza de fuselaje.

- Manta térmica para la variación de temperatura en la pieza de fuselaje.

- Sistema de control térmico para la introducción de los diferentes escalones térmicos en la pieza.

- Sistema de aislamiento de la zona de la mata térmica para evitar la pérdida de calor por convección natural.

- Sistemas de adquisición de datos:

- Acellent Scangenie para la interrogación activa de la estructura.

- Sistema Arduino para la adquisición de datos de extensometría y termopar de medida continua.

- Ordenadores para el control de los equipos de adquisición de datos:

- Computador de control del Acellent Scangenie.

○ Computador de control del Arduino. 
El esquema de conexionado de todos estos elementos se puede comprobar en la Figura 64 y los detalles reales de la instalación finalmente realizada en las figuras siguientes.

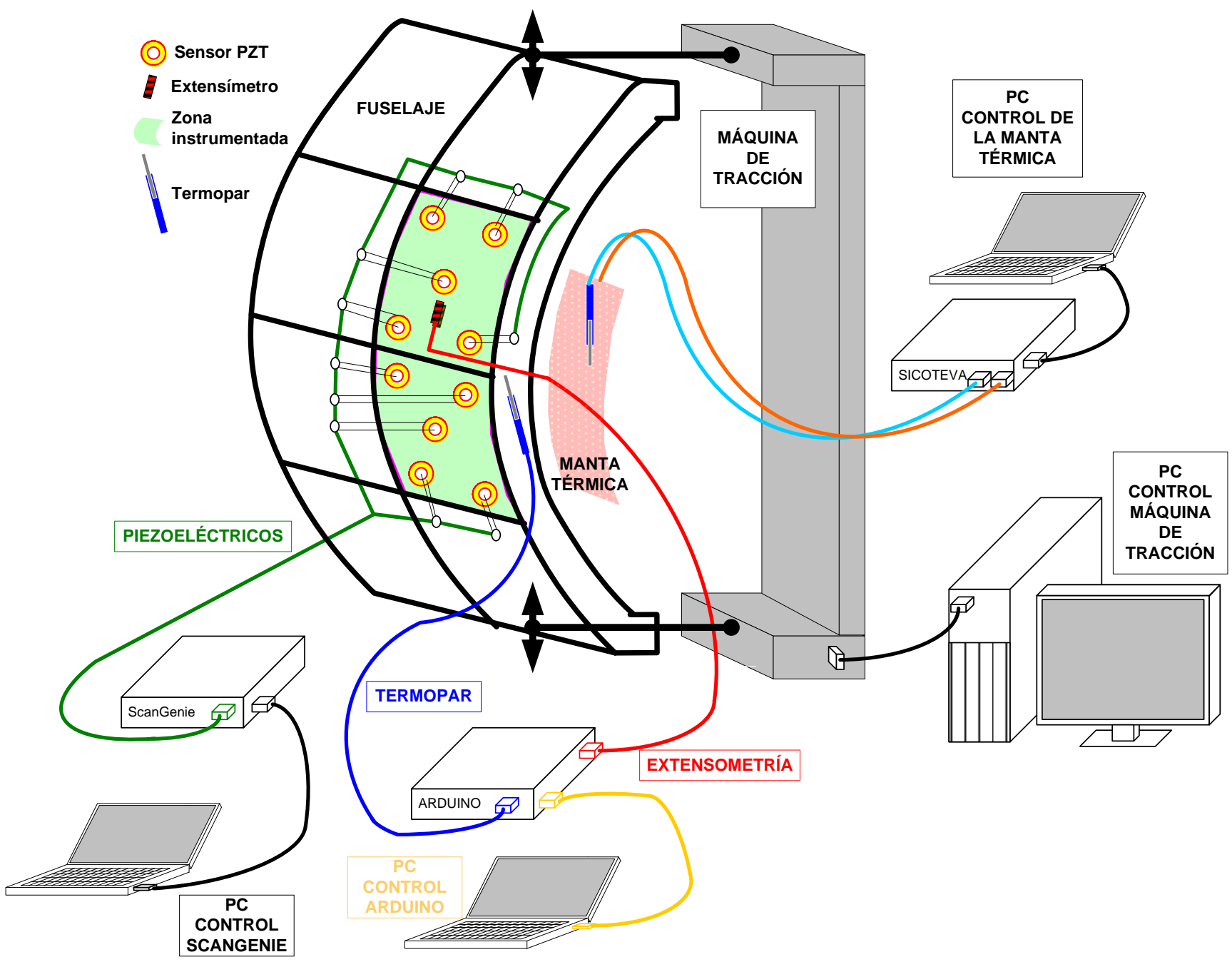

Figura 64 - Elementos del ensayo del fuselaje 


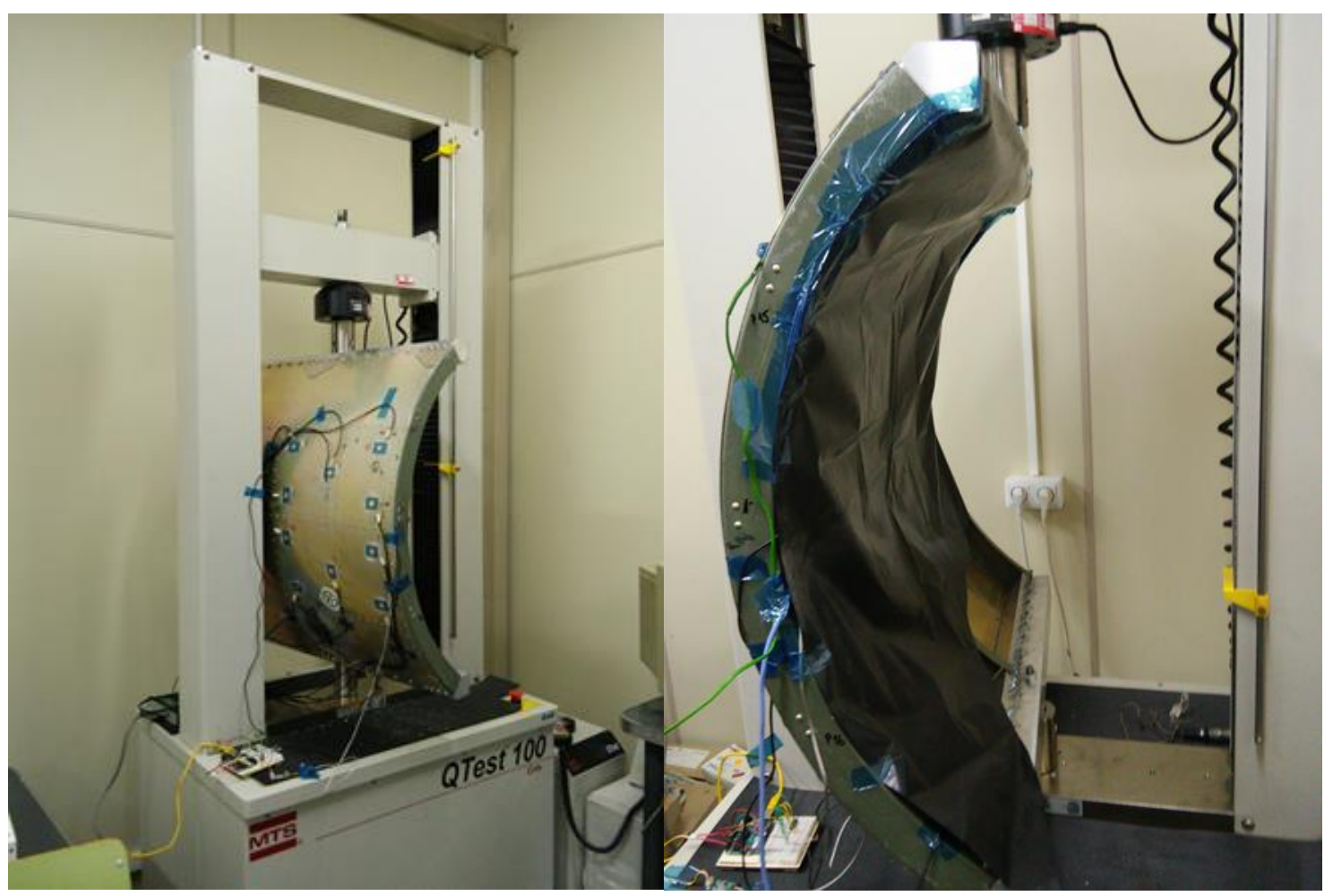

Figura 65 - Pieza de fuselaje instalada en la máquina de tracción (izquierda) y zona de instalación de la manta térmica (derecha).

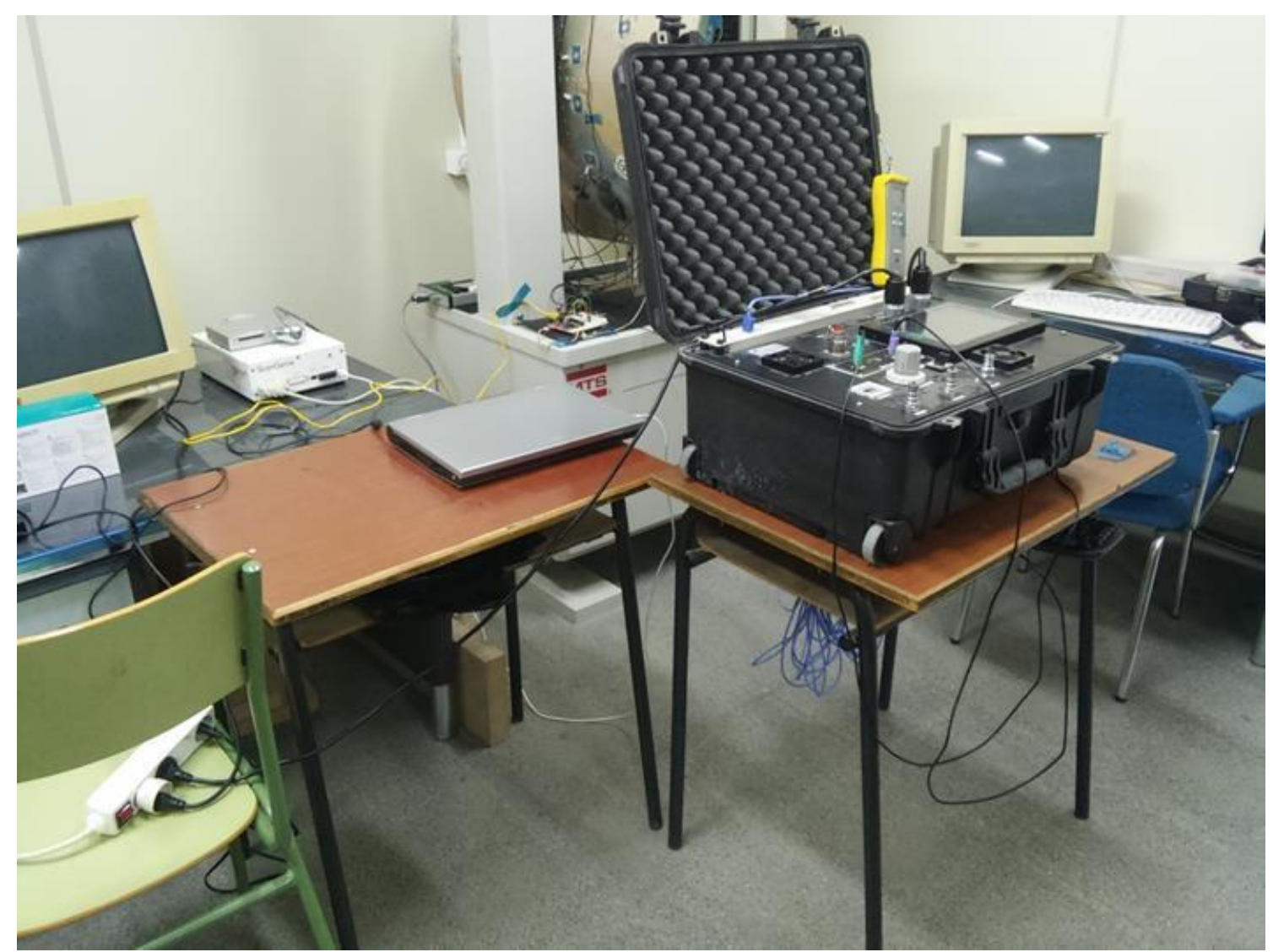

Figura 66 - Sistema de control de la manta térmica en primer plano. Instalación del fuselaje, equipo de control y máquina de tracción en segundo plano. 


\subsubsection{Realización}

La complejidad de los ensayos en el fuselaje es un poco mayor que los de las pletinas.

Debido al tamaño de la estructura no se ha podido introducir en una cámara climática y se ha tenido que aprovechar las variaciones de temperatura ambiente y las introducidas por una manta térmica en la estructura. Además se ha tenido que tener en cuenta los diferentes escalones de carga a introducir mediante la máquina de tracción. Todo esto sincronizando los diferentes sistemas de adquisición y controlando los tiempos para la estabilización tanto térmica como la relativa al estado de carga. El protocolo seguido ha sido el siguiente:

- Previamente al ensayo se instalaron todos los dispositivos salvo la manta térmica y la máquina de tracción para comprobar que los sistemas de adquisición de datos funcionaban correctamente y podían ser sincronizados.

- Seguidamente se instaló la pieza de fuselaje en la máquina de tracción y se tomaron referencias para diferentes escalones de carga a diferentes temperaturas ambientes e introduciendo un daño de tamaño considerable.

- Una vez verificado que el sistema junto con la máquina de tracción funcionaba adecuadamente se introdujo la manta térmica y se efectuaron pruebas con diferentes temperaturas de consigna en la manta térmica. Se comprobó que la configuración óptima de ensayo era efectuar una primera adquisición a temperatura ambiente y una segunda a una temperatura de consigna de $80^{\circ} \mathrm{C}$ en la manta, con lo que se conseguía elevar la temperatura de la pieza hasta $\operatorname{los} 40^{\circ} \mathrm{C}$ aproximadamente. La dificultad del control térmico con la manta fue notablemente más elevada que con la cámara climática.

- Una vez establecidos los criterios para los escalones térmicos se procede a ensayar combinando diversos estados de carga y los escalones térmicos descritos anteriormente para varios tamaños de daño en el límite de sensibilidad de la técnica SHM para evaluar la capacidad de detección en el caso más desfavorable de influencia de las EOC. Cuando la firma de daño en la DSF es muy pequeña y la variación de las EOC notable.

- De nuevo hubo que esperar cierto tiempo hasta que la temperatura de la pieza se estabilizase, en este caso unos 40 min para cada escalón térmico.

- Para el caso de la estabilización del estado de cargas, en apenas un par de minutos la señal de la extensometría se estabilizaba.

- En este caso los crecimientos de daño se ensayaron para todas las variaciones de carga y temperatura definidas. En este caso tres casos de carga y dos temperaturas .superiores a 


\subsubsection{Revisión preliminar de resultados}

Siguiendo los mismos criterios indicados en el apartado 5.3.6 se revisan las señales adquiridas en las diferentes interrogaciones se muestran las señales y se analizan. En este caso el análisis se muestra de manera explícita para uno de los casos de ensayo. Sin embargo al existir multitud de situaciones, unas 2000 señales por ensayo, se ha realizado de manera automática y se muestra a modo de conclusiones de la revisión preliminar.

Seleccionamos el siguiente caso para indicar el proceso de análisis de resultados preliminar:

- $\quad$ Experimento $\rightarrow$ Número 3

- Frecuencia $\rightarrow 200 \mathrm{KHz}$

- $\quad$ Temperatura $\rightarrow$ Ambiente $24^{\circ} \mathrm{C}$

- Caminos de daño seleccionados $\rightarrow$ Todos 90

- Carga aplicada $\rightarrow 0 \mathrm{kN}$

El resultado de pintar todas las señales para los diferentes caminos de daño se muestra en la Figura 67, Figura 68 y Figura 69.

De la revisión visual de las diferentes gráficas se deduce lo siguiente, para este ensayo:

- Se observa una primera perturbación, anterior a los 50 microsegundos en todas las señales debido al crosstalk de la electrónica, esta zona debe eliminarse en los análisis.

- A continuación aparecen las primeras llegadas del modo S0 de la GLW. Se comprueban varias cosas relativas a esta primera llegada:

- Algunos sensores están demasiado próximos y la primera llegada se mezcla con el crosstalk. Los caminos de daño en los que esto ocurra no deben ser utilizados.

- En algunos caminos de daño no se observa llegada del primer modo S0. Ello indica que la adquisición ha fallado y únicamente se observa la presencia de crosstalk. Estos caminos tampoco deben participar en posteriores análisis. Para el caso concreto de este ensayo los caminos que involucren al PZT 6 tanto como actuador como sensor no funcionan y no deben usarse

Como se puede comprobar la cantidad de información es enorme y ello hace necesario el procesado automático de la misma ya que la revisión o el manejo manual de la misma es imposible. Se ha indicado aquí el proceso de modo visual, aunque en realidad su implementación es automática por razones obvias. 


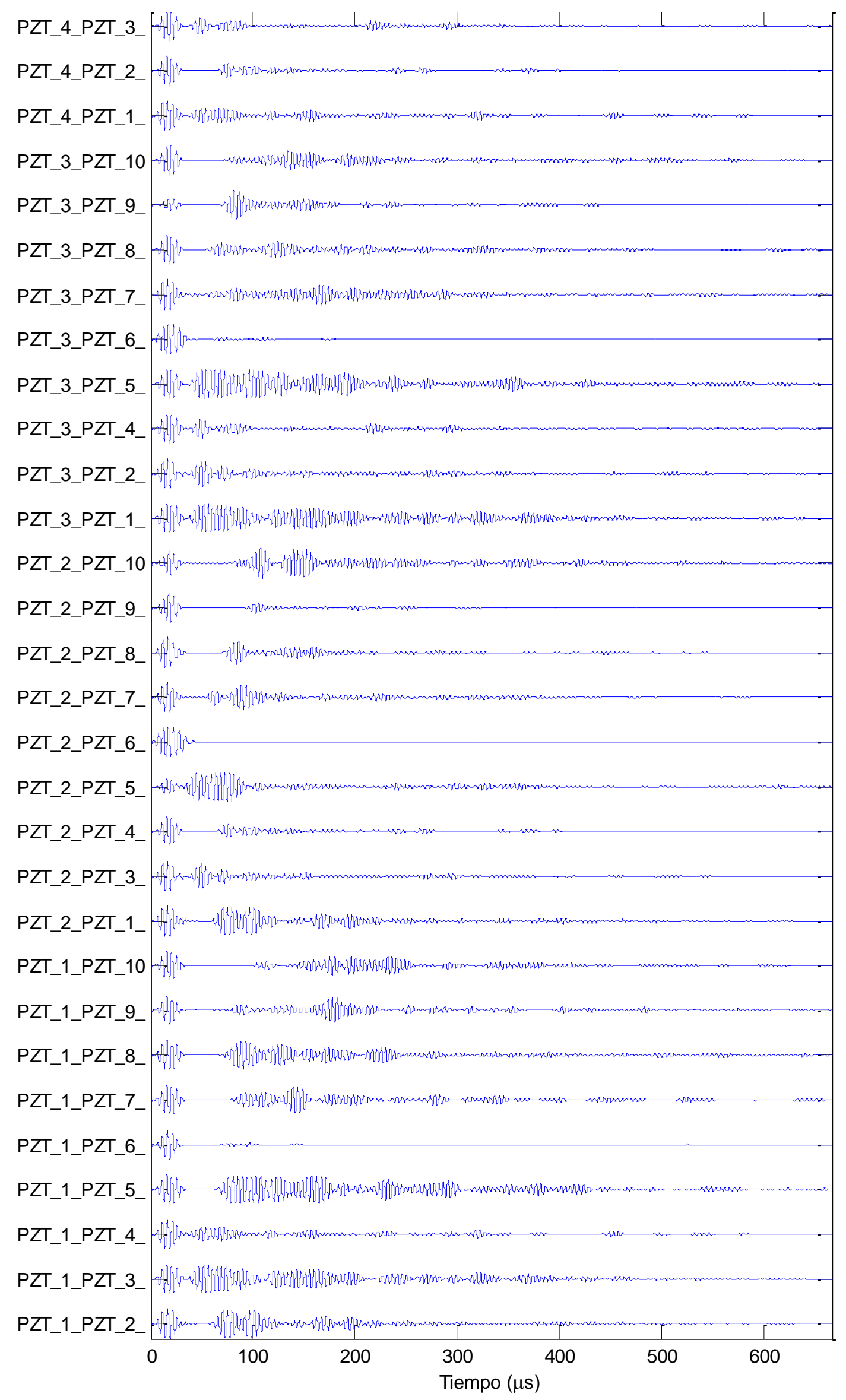

Figura 67 - Análisis preliminar de los datos de fuselaje, caso de muestra, caminos 1 a 30. 


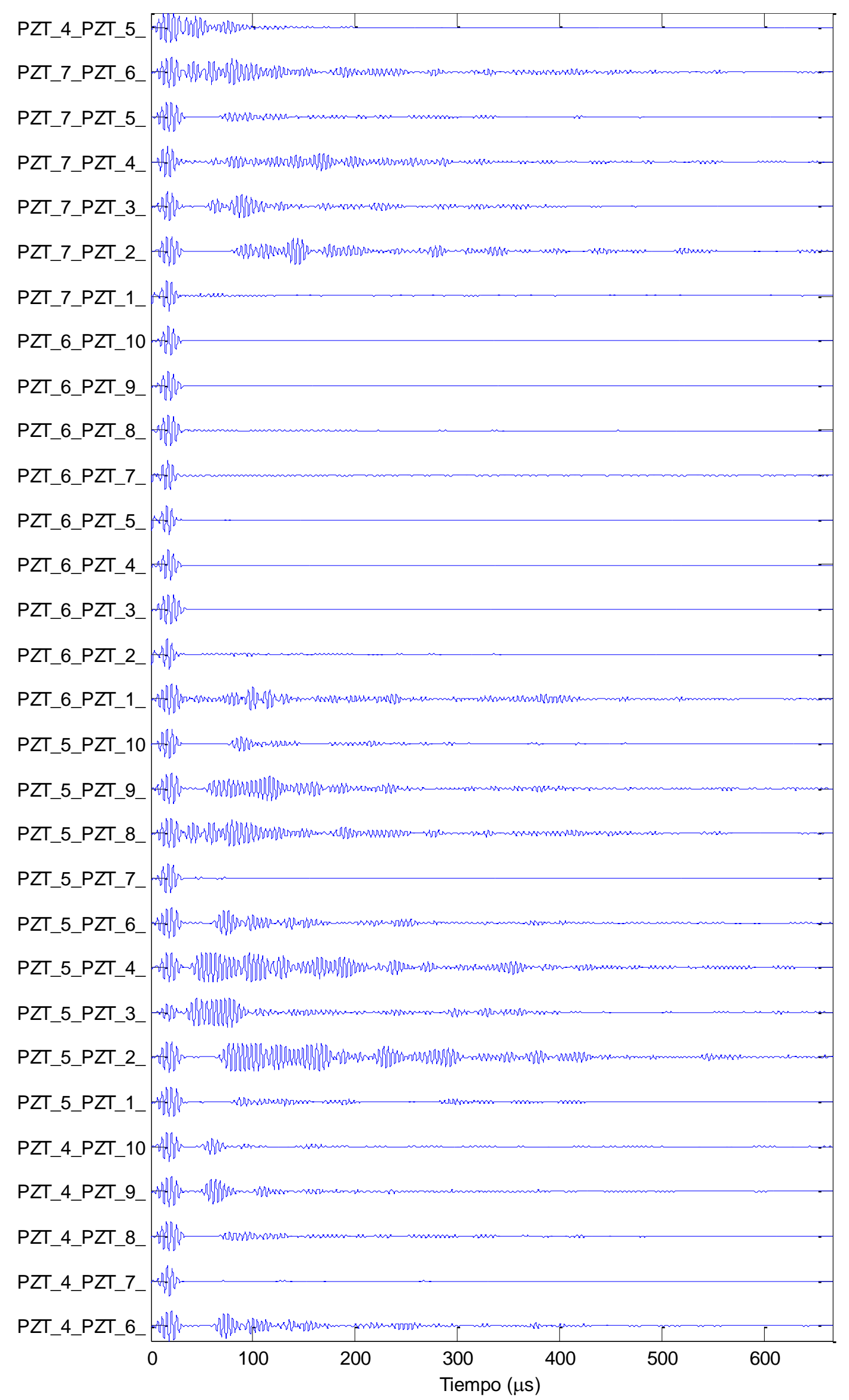

Figura 68 - Análisis preliminar de los datos de fuselaje, caso de muestra, caminos 31 a 60. 


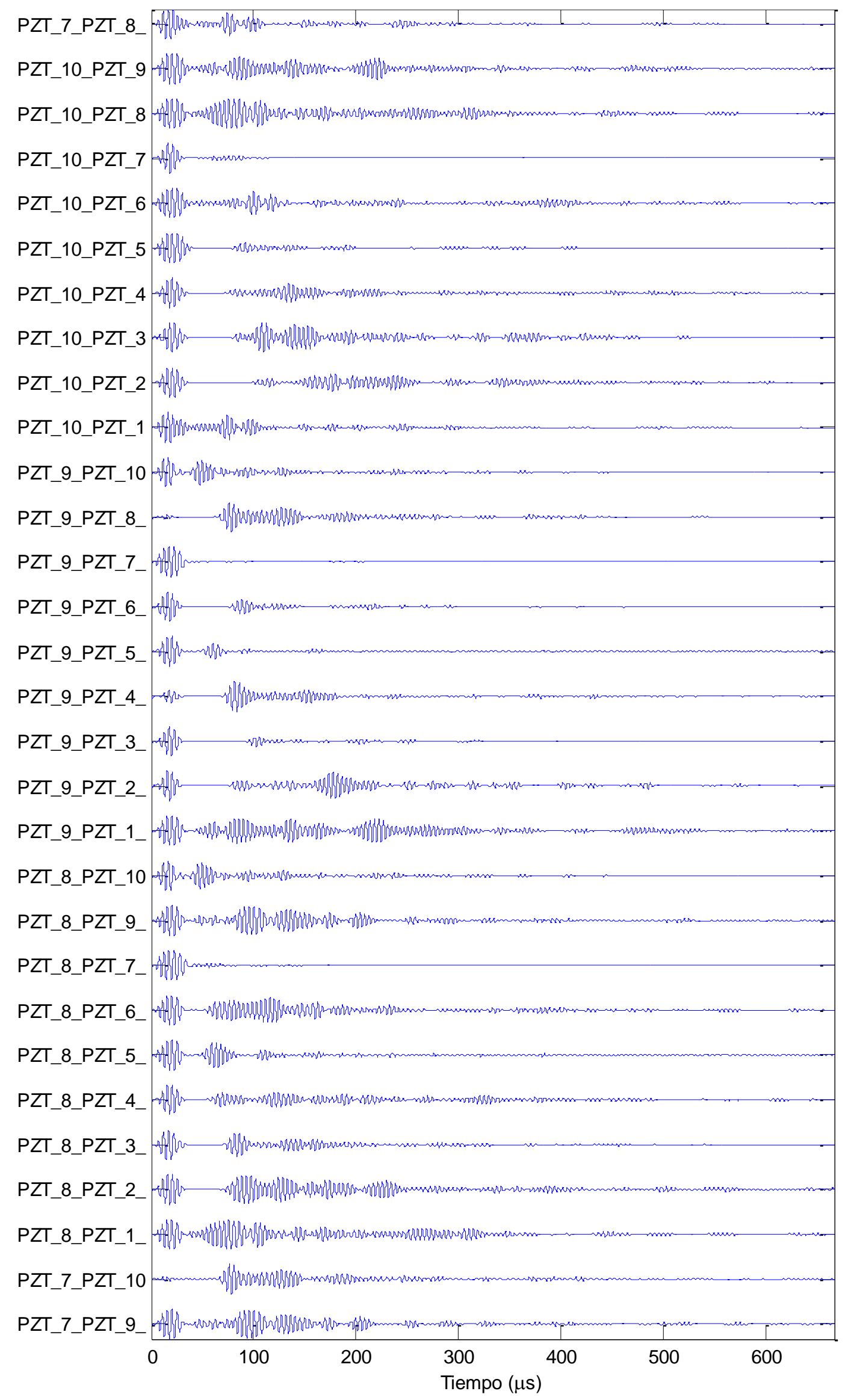

Figura 69 - Análisis preliminar de los datos de fuselaje, caso de muestra, caminos 61 a 90. 
Este mismo análisis se realiza también para los diferentes casos de carga aplicados (señales de extensometría) y temperaturas alcanzadas (señales de temopar). La evolución temporal durante el ensayo 3 se puede apreciar en la Figura 70.

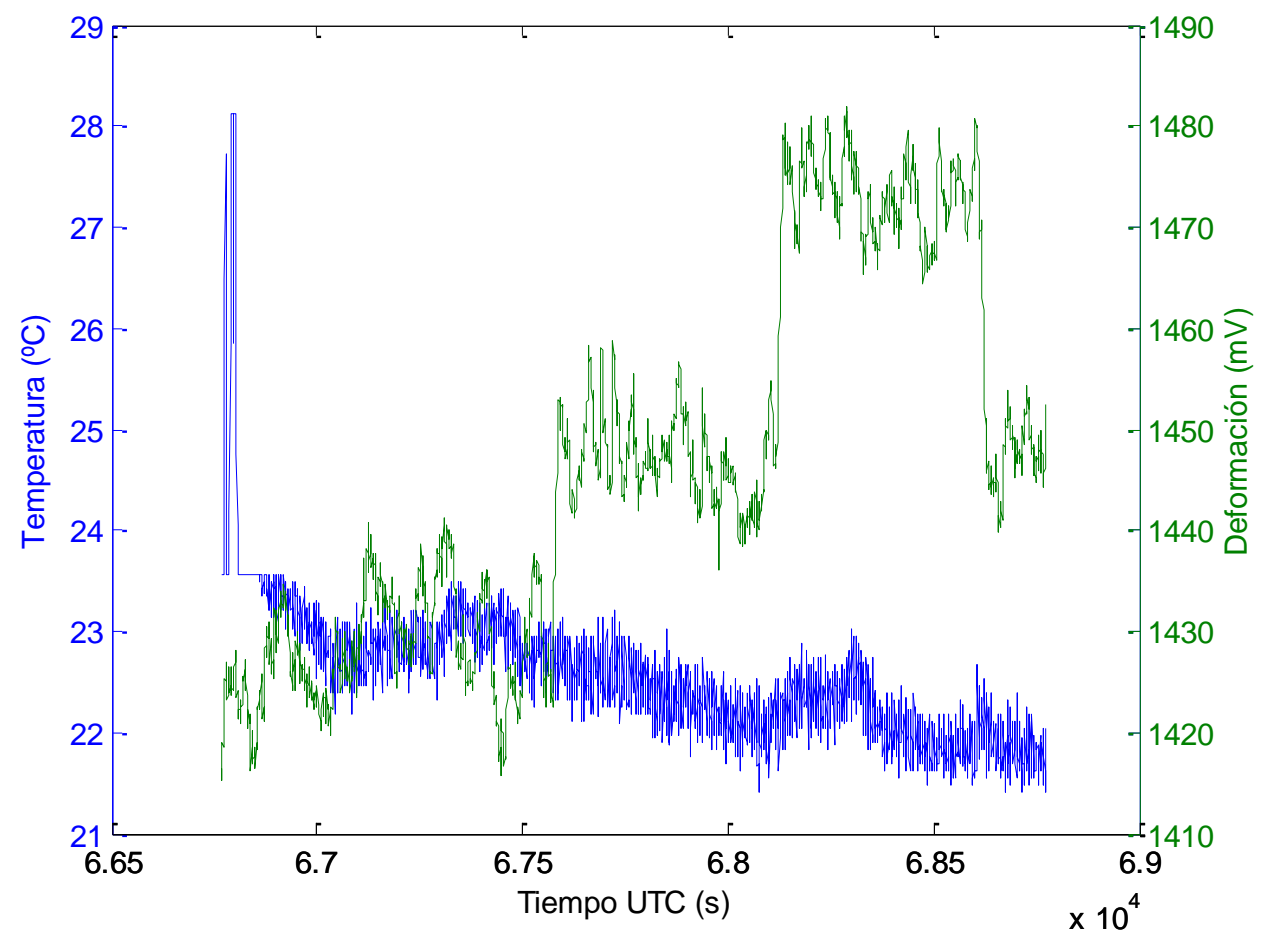

Figura 70 - Evolución de la temperatura y la deformación para el experimento 3.

De nuevo se observa que en la temperatura se tienen unos valores erróneos, y que las señales tienen mucho ruido. Estos datos se filtran y corrigen para el momento en el que se realiza cada una de las adquisiciones del ensayo obteniéndose los escalones de temperatura y carga aplicados, ver figura.

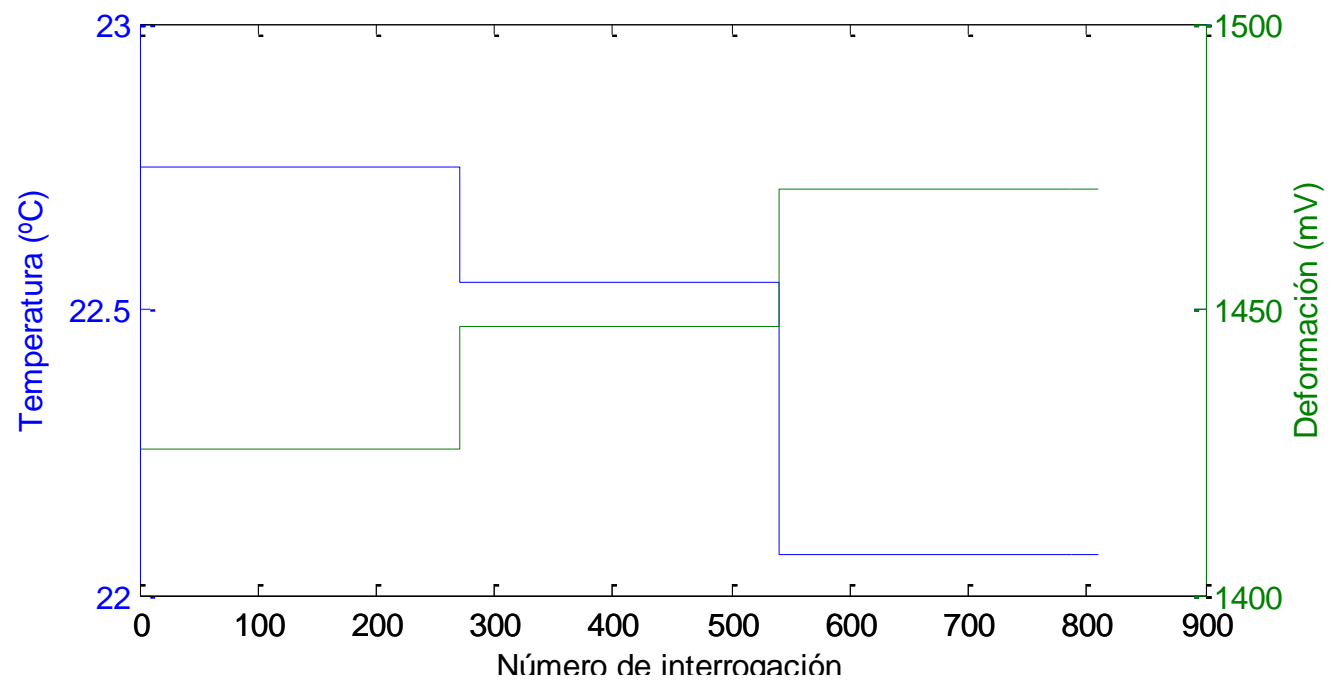

Figura 71 - Datos de temperatura y carga corregidos y filtrados. 
En la Figura 72 se pueden comprobar los datos de temperatura y estado de carga para cada interrogación realizada.

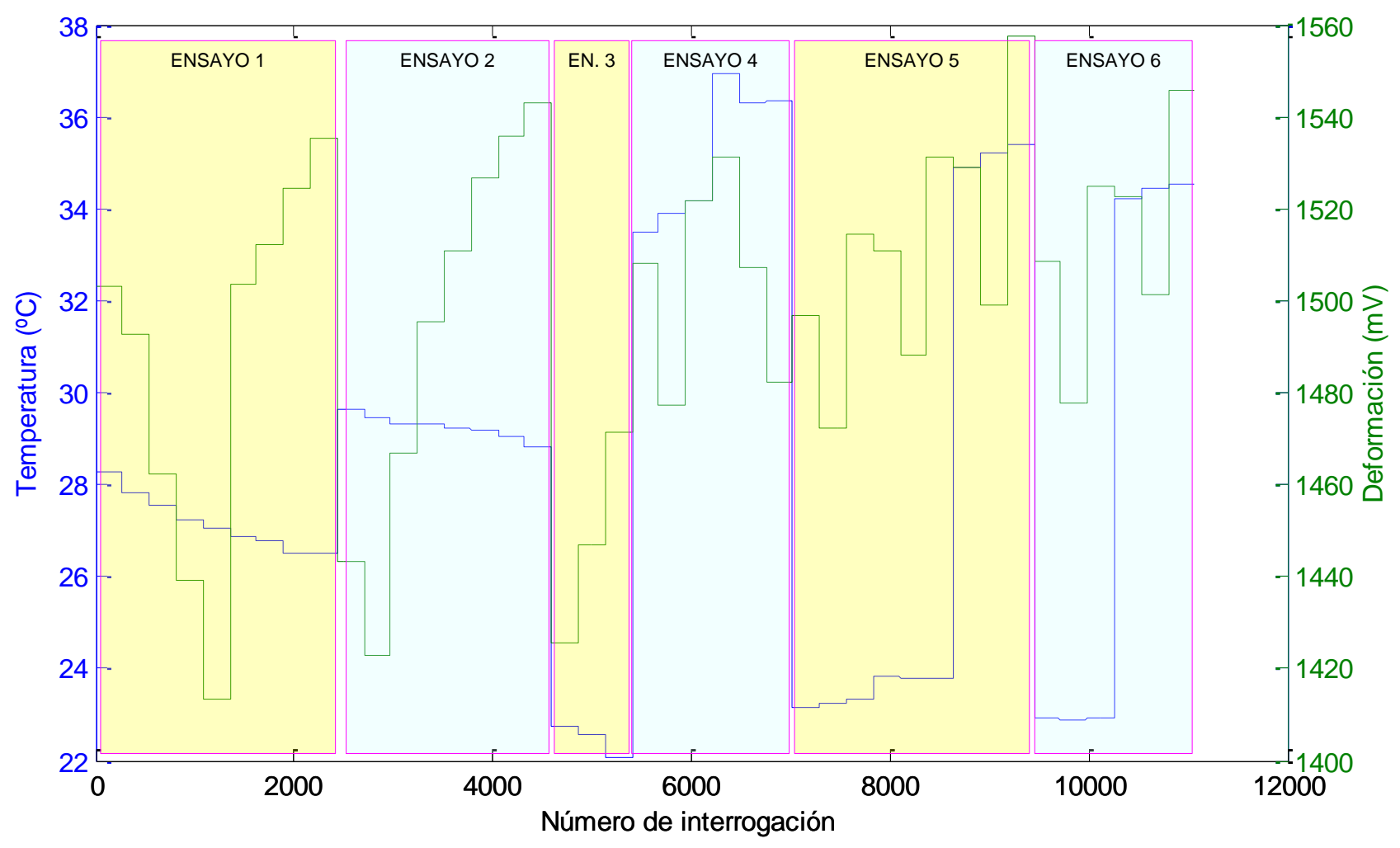

Figura 72 - Temperatura y estado de carga para cada una de las interrogaciones

Se evalúa también la situación de daño de cada una de las adquisiciones en la Figura 73.

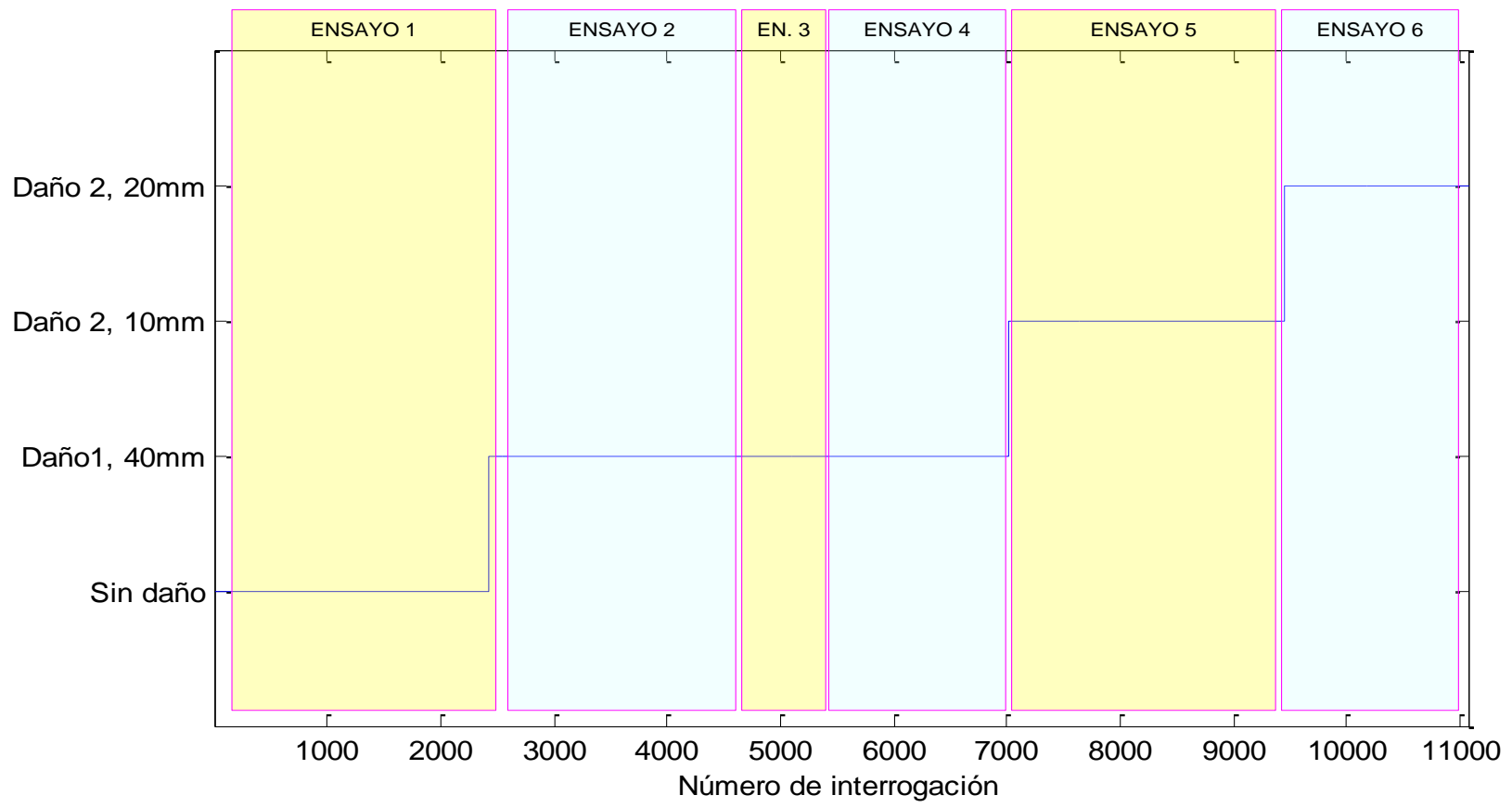

Figura 73 - Situación de daño para cada una de las interrogaciones. 
En Figura 72 y Figura 73 se puede comprobar un número mayor de adquisiciones que las indicadas en la Tabla 18. Esto se debe a que para el experimento 5 se tuvieron que repetir los tres estados de carga debido a un funcionamiento erróneo de la adquisición de temperaturas. Esto se puede comprobar en la Figura 72 en el salto que se produce en el entorno de la adquisición número 8000.

Además el sensor PZT 6 estuvo estropeado en algunas de las adquisiciones. Esto implica que no envía pulsos y además no recibe pulsos correctamente. Por esta razón se elimina de los cálculos para no tener que hacer el análisis detallado de los experimentos dependiente del camino de daño con el que se está trabajando

Se comprueba también que aunque se ha intentado que la medición de carga en la estructura mediante extensometría sea independiente de la temperatura, colocando los extensímetros en oposición en ambas caras de la pieza, no se ha conseguido eliminar totalmente. Esto se debe fundamentalmente al gradiente térmico entre ambas caras. El efecto será pequeño a temperatura ambiente pero mayor al calentar la pieza por una de las caras. Sin embargo al introducir toda la información en los modelos de manera simultánea se compensará automáticamente sin necesidad de un procesado adicional de la extensometría. 


\subsubsection{Análisis de resultados}

Al igual que en los ensayos para las pletinas, en este estudio se considera la primera llegada de la GLW correspondiente al modo S0, el de tracción-compresión. Este modo es el más rápido de los dos existentes en el rango de frecuencias de trabajo. El análisis de esta primera llegada es ligeramente más complejo.

Ya se ha indicado anteriormente que al estar trabajando en estructura bidimensional y a varias frecuencias la definición de la zona de análisis depende de la longitud de los caminos de daño considerados en cada caso y de la frecuencia de interrogación:

- La velocidad de grupo del modo S0 se ha evaluado directamente de manera experimental en la pieza de fuselaje. Al ser una estructura rigidizada de pared curva las curvas de dispersión de Lamb únicamente son orientativas y es necesario calcular dicha velocidad de modo experimental. Para poder definir las zonas de análisis se ha comprobado que dicha velocidad se encuentra en el entorno de $\operatorname{los} 4500 \mathrm{~m} / \mathrm{s}$. Esta velocidad definirá el inicio de la zona de análisis según la longitud de cada camino de daño.

- Tamaño de crosstalk. Esta zona de la señal, caracterizada por la interferencia del pulso de salida de la interrogación tiene una longitud de aproximadamente 1.5 veces la longitud del pulso, así que para cada frecuencia de interrogación y considerando que el burst de interrogación tiene 5 picos ( 5 periodos) las longitudes de crosstalk para cada frecuencia será la siguiente:

○ $200 \mathrm{kHz} \rightarrow$ Pulso=25 microsegundos $\mathrm{x} 1.5$ veces $\rightarrow 37.5$ microsegundos

○ $250 \mathrm{kHz} \rightarrow \mathrm{Pulso}=20$ microsegundos $\mathrm{x} 1.5$ veces $\rightarrow 30$ microsegundos

○ $300 \mathrm{kHz} \rightarrow$ Pulso $=16.7$ microsegundos $\mathrm{x} 1.5$ veces $\rightarrow 25$ microsegundos

Estas zonas iniciales deben eliminarse del análisis.

- Interferencia entre el crosstalk y la primera llegada. En algunos casos el PZT actuador y el PZT sensor están demasiado cerca, lo que implica que la zona de crosstalk y la primera llegada del modo S0 de la GLW se solapan e impide el análisis. Teniendo en cuenta la velocidad de grupo típica evaluada para esta estructura y los diferentes tiempos de crosstalk, se ha establecido una distancia mínima entre PZTs para el análisis de $180 \mathrm{~mm}$ (este es el tamaño mínimo de camino de daño que se considera analizable).

De nuevo todos estos criterios se implementan en el análisis automático de las señales y se presenta aquí un ejemplo para uno de los ensayos, en el que se indican las diferentes zonas de las señales. La zona de análisis de las señales será la longitud del pulso. 


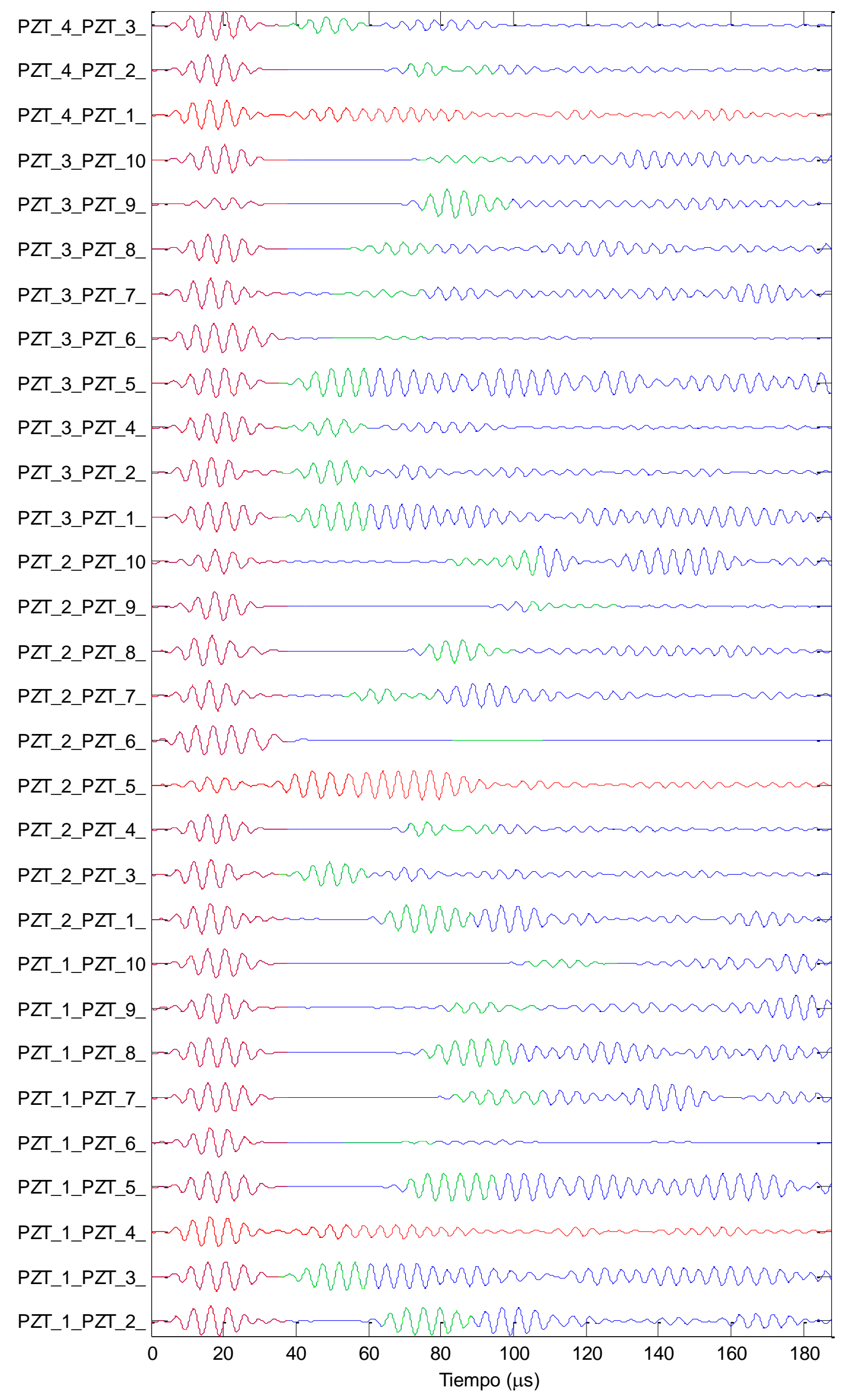

Figura 74 - Definición de las zonas de análisis y descarte, caminos de daño 1 a 30. 


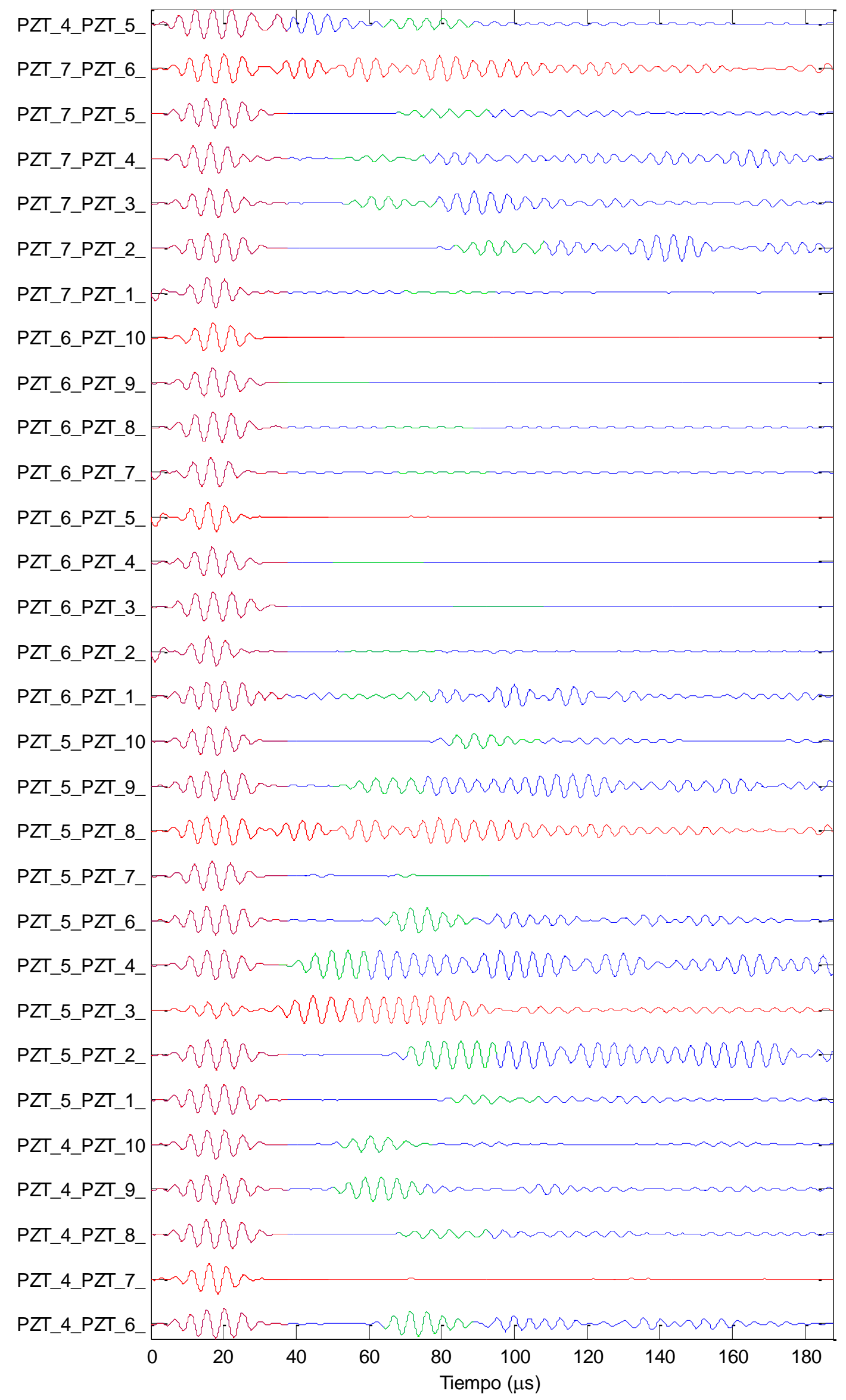

Figura 75 - Definición de las zonas de análisis y descarte, caminos de daño 31 a 60. 


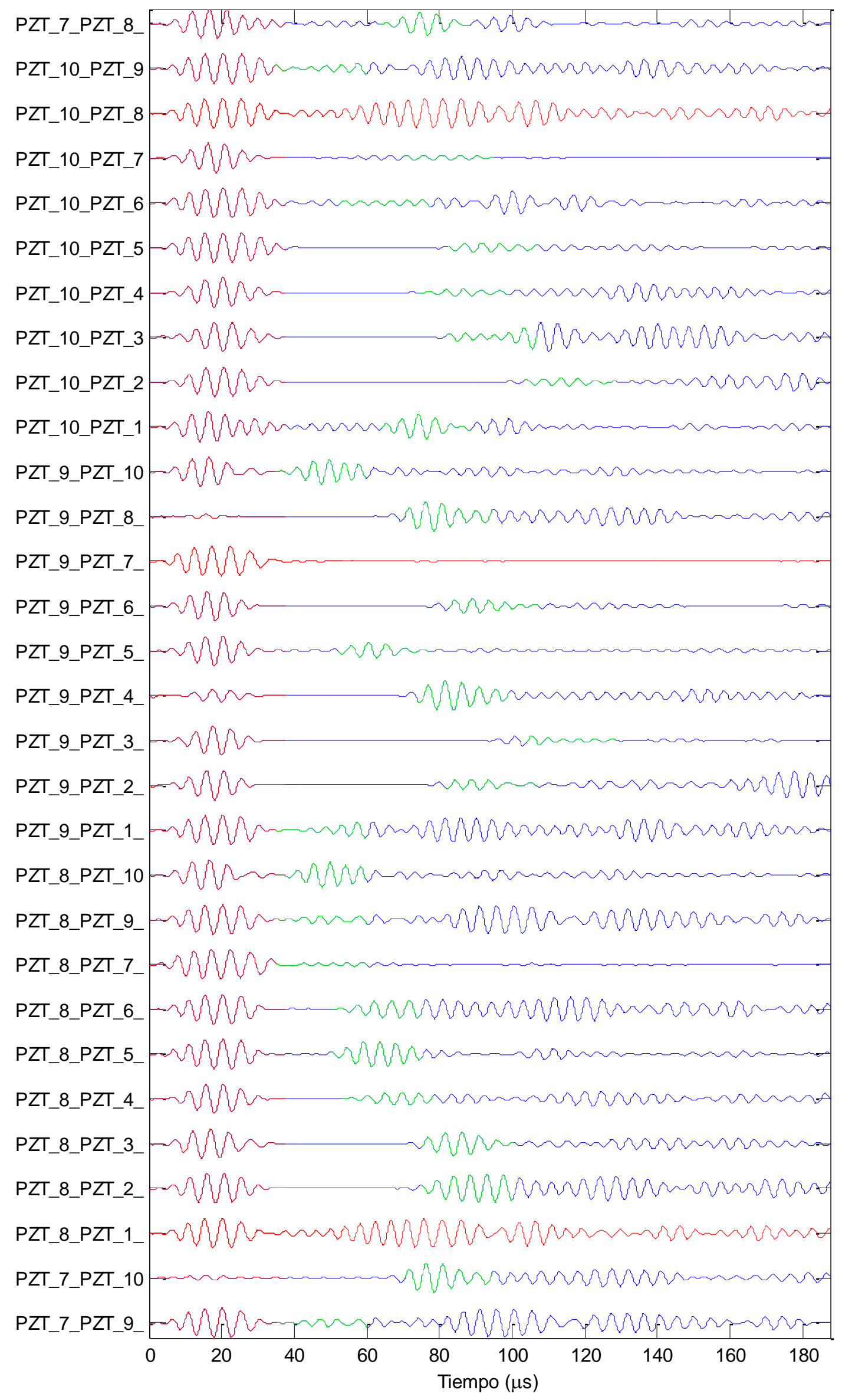

Figura 76 - Definición de las zonas de análisis y descarte, caminos de daño 61 a 90. 
En las figuras anteriores se indican las diferentes zonas a tener en cuenta para camino de daño:

- En azul, se presenta la señal completa.

- En rojo la señal completa si se descarta por interferencia con el crosstalk y el propio crosstalk de las señales.

- En verde la zona de análisis, la primera llegada al sensor del modo S0 de la GLW.

Las zonas indicadas en verde para las diferentes señales, serán las que se utilizarán para el análisis en cada uno de los ensayos realizados. En este caso únicamente se muestra a modo de ejemplo el resultado de la selección de las zonas de análisis para el ensayo número 3 , sin embargo este proceso de definición de la zona de análisis se realiza para todos los ensayos.

A continuación se describe el proceso de captura de la primera llegada del modo S0 de la GLW. Siendo el proceso una generalización bidimensional del utilizado para las pletinas. Para esto se necesitan los siguientes elementos:

- Tamaño del pulso enviado, que depende la frecuencia de actuación. Cuyos valores ya se han indicado en los párrafos anteriores y la metodología de cálculo en 4.2.

- Posiciones del PZT actuador y del PZT sensor.

- Velocidad de grupo del modo S0 entre el actuador y el sensor.

Matemáticamente definiremos el camino de daño y su análisis del siguiente modo:

$$
\begin{gathered}
\text { PZT actuador } \rightarrow \text { PZT }, \text { posición } x_{i}, y_{i} \text { PZT sensor } \rightarrow \text { PZT } T_{j} \text {, posición } x_{j}, y_{j} \\
d_{i j}=\sqrt{\left(x_{j}-x_{i}\right)^{2}+\left(y_{j}-y_{i}\right)^{2}}
\end{gathered}
$$

Con esta información se calculan las distancias de los diferentes caminos de daño. En estos caminos de daño se descartan aquellos menores de $0.165 \mathrm{~m}$ debido a la interferencia con el

\begin{tabular}{|c|c|c|c|c|c|c|c|c|c|c|c|}
\hline \multirow{2}{*}{\multicolumn{2}{|c|}{$d_{i j}$}} & \multicolumn{10}{|c|}{ PZT Sensor } \\
\hline & & 1 & 2 & 3 & 4 & 5 & 6 & 7 & 8 & 9 & 10 \\
\hline \multirow{6}{*}{ 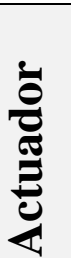 } & 1 & & 0.280 & 0.154 & 0.130 & 0.308 & 0.235 & 0.365 & 0.331 & 0.360 & 0.456 \\
\hline & 2 & & & 0.154 & 0.308 & 0.130 & 0.365 & 0.235 & 0.331 & 0.456 & 0.360 \\
\hline & 3 & & & & 0.154 & 0.154 & 0.220 & 0.220 & 0.235 & 0.326 & 0.326 \\
\hline & 4 & & & & & 0.280 & 0.105 & 0.299 & 0.220 & 0.230 & 0.362 \\
\hline & 5 & & & & & & 0.299 & 0.105 & 0.220 & 0.362 & 0.230 \\
\hline & 6 & & & & & & & 0.280 & 0.154 & 0.125 & 0.306 \\
\hline \multirow{4}{*}{$\underline{N}$} & 7 & & & & & & & & 0.154 & 0.306 & 0.125 \\
\hline & 8 & & & & & & & & & 0.152 & 0.152 \\
\hline & 9 & & & & & & & & & & 0.280 \\
\hline & 10 & & & & & & & & & & \\
\hline
\end{tabular}
crosstalk de la señal enviada por el PZT actuador. Se muestran en la Tabla 19.

Tabla 19 - Longitudes de los diferentes caminos de daño. 
En la Tabla 19 se marcan en ámbar los caminos de daño cuya longitud implica que la llegada del modo S0 de la GLW interfiera con el crosstalk. También se marcan en rojo los caminos relacionados con el sensor 6 , que en algunos experimentos falló.

Para cada uno de los caminos de daño se ha medido experimentalmente la velocidad de grupo de las ondas introducidas por el actuador. Para esta tarea se ha empleado un análisis en el plano tiempo-frecuencia, denominado Reduced Interference Diagram o RID [107](es un diagrama tipo espectrograma). Usando este diagrama se captura experimentalmente la primera llegada del modo S0 de la GLW para el cálculo de la velocidad a diferentes frecuencias. Veamos un ejemplo para el camino de daño PZT1-PZT10.

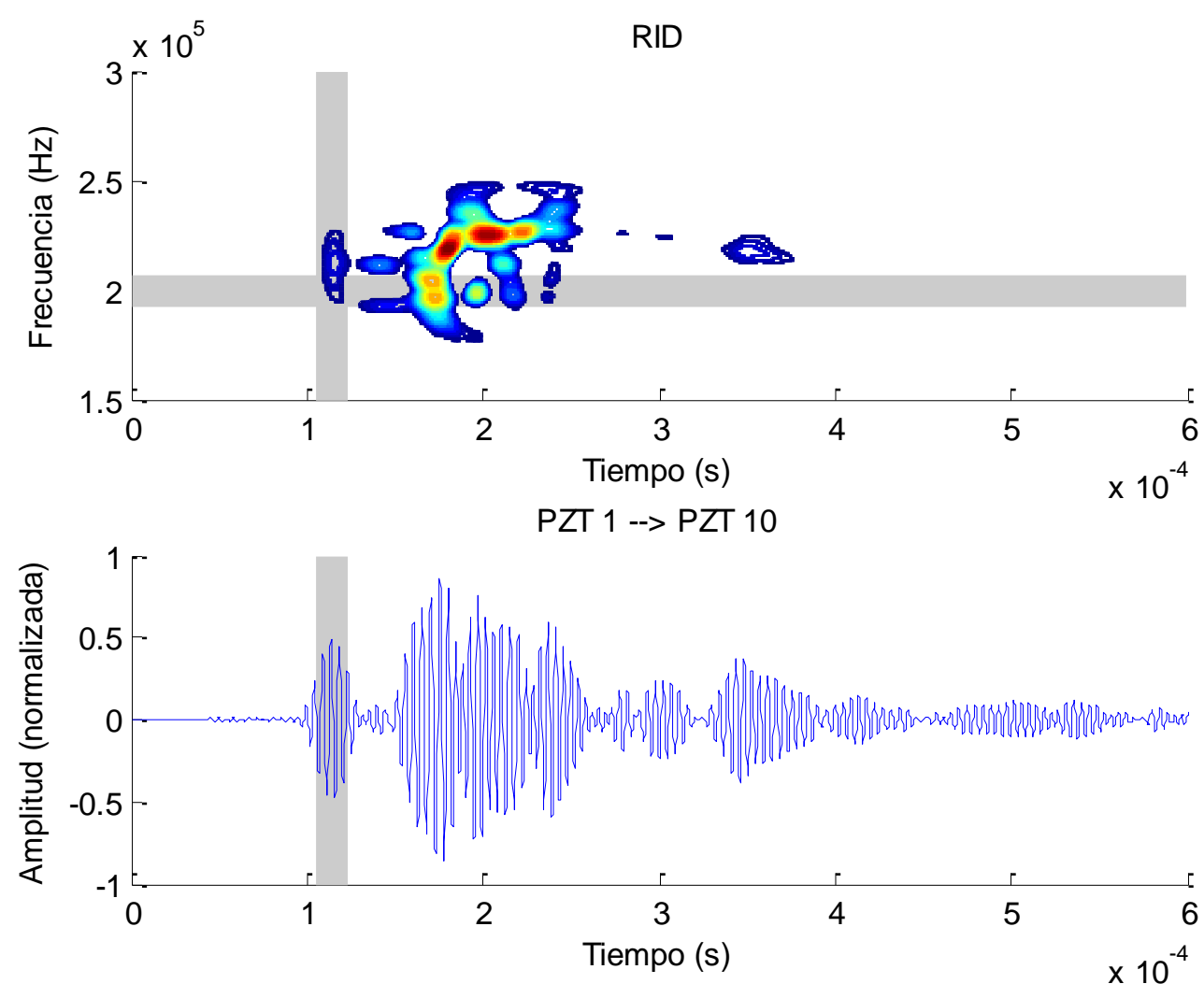

Figura 77 - RID del camino de daño 1-10 y la serie temporal asociada (crosstalk inicial eliminado, interrogación a $200 \mathrm{kHz})$

En la Figura 77 se comprueba la presencia de la primera llegada del modo S0 de la GLW a 200 $\mathrm{kHz}$ en un tiempo de unos 0.115 milisegundos. Teniendo en cuenta la longitud del camino de daño, podemos calcular la velocidad en esta dirección:

$$
v_{\text {grupo }_{i j}}=\frac{d_{i j}}{t_{i j}}
$$

Esta operación se realiza para cada uno de los caminos de daño con el objetivo de calcular dichas velocidades de modo experimental. 
Pintando las velocidades obtenidas para cada camino de daño en función del ángulo de dicho camino de daño se puede evaluar el nivel de anisotropía en la zona de la estructura analizada.

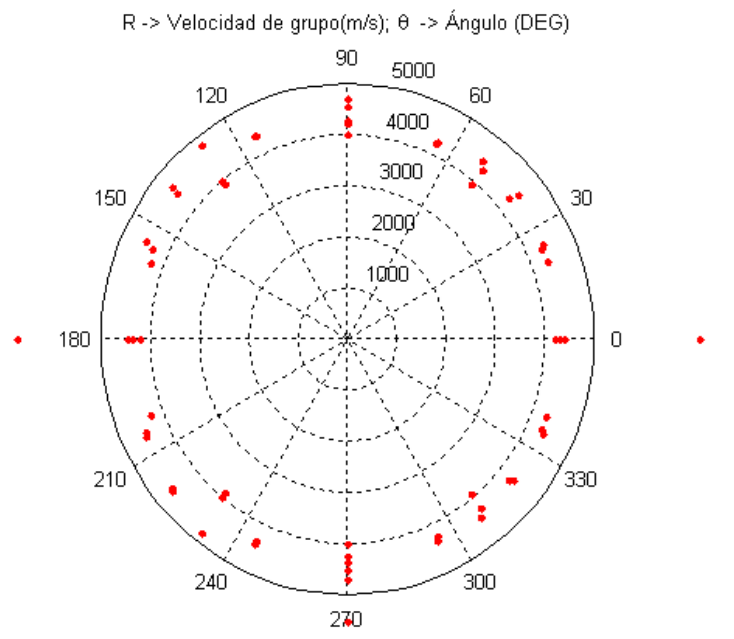

Figura 78 - Velocidades de grupo para los diferentes caminos de daño para $200 \mathrm{kHz}$.

En la Figura 78 se comprueba que la anisotropía no es muy acusada puesto que la mayoría de valores se encuentra entre 4000 y $5000 \mathrm{~m} / \mathrm{s}$. Por ello se puede utilizar un valor medio de velocidad de grupo para todos los caminos de daño (añadiendo la correspondiente dispersión a la zona de análisis posteriormente). Calculamos los valores medios y la dispersión para cada una de las frecuencias de interrogación.

\begin{tabular}{|c|c|c|c|}
\hline $\begin{array}{c}\text { FRECUENCIA DE } \\
\text { INTERROGACIÓN } \\
(\mathbf{k H z})\end{array}$ & $\begin{array}{c}\text { VELOCIDAD DE } \\
\text { GRUPO MEDIA (m/s) }\end{array}$ & $\begin{array}{c}\text { DESVIACIÓN } \\
\text { ESTÁNDAR DE DICHA } \\
\text { VELOCIDAD (m/s) }\end{array}$ & $\begin{array}{c}\text { DISPERSIÓN MÁXIMA } \\
\text { ADICIONAL PARA EL } \\
\text { ANÁLISIS }\end{array}$ \\
\hline 200 & 4456 & 555 & 25 microsegundos \\
\hline 250 & 4322 & 588 & 25 microsegundos \\
\hline 300 & 4231 & 498 & 25 microsegundos \\
\hline
\end{tabular}

Tabla 20 - Velocidades de grupo medias para las diferentes interrogaciones

En la Tabla 20 se indican las velocidades de grupo que se utilizarán para capturar la primera llegada del modo S0 de la GLW a diferentes frecuencias de interrogación. También se indica la dispersión máxima adicional calculada usando las velocidades máxima y mínima de la tabla $\left(v_{\text {grupo }_{\text {media }}} \pm\right.$ desviación estandar) en microsegundos que se añadirá al tiempo del pulso para definir la zona de análisis.

Simplificando se tomarán unos $4400 \mathrm{~m} / \mathrm{s}$ como velocidad de grupo.

Además de la anisotropía del panel debida a los elementos rigidizadores, existe el efecto de curvatura del panel. Este efecto de la curvatura en las velocidades de grupo es despreciable para el radio de curvatura que presenta el panel [173]. 


\subsubsection{Efecto de la temperatura y del estado de carga}

En el apartado anterior se ha indicado la zona de análisis de las señales. En este se calcularán los coeficientes de la CT para las zonas definidas.

Además de la recepción del modo indicada en los apartados anteriores también se retienen datos relativos a la señal de interrogación. En esta señal la zona de análisis es la longitud del pulso. Y también se retienen los valores de las EOC, temperatura y estado de carga, junto con la situación de daño de cada ensayo.

El proceso es el siguiente:

- Definición de la zona de análisis. Primera llegada del modo S0 de la GLW para cada camino de daño con una duración equivalente al pulso enviado según la frecuencia de interrogación.

- Cálculo de la CT para cada zona. Se guardan los siguientes coeficientes:

- Parte real del Scaling tanto para la señal de actuación como para la recepción.

- Time Shift de la interrogación y de la recepción. Relativos a los valores iniciales de referencia para cada ensayo y promediados según la longitud del camino de daño.

- Asignación de los valores que definen las EOC del ensayo. Temperatura y estado de carga para cada interrogación. A diferencia del ensayo de las pletinas en este caso se tomarán valores absolutos en vez de incrementales. Las correlaciones se mantienen iguales para ambos conjuntos de parámetros, absolutos o incrementales.

- Asignación de la situación de daño. Referencia, daño 1, daño 2 tamaño 1 y daño 2 tamaño 2.

El proceso de representación de los datos es más complejo que en el caso de camino de daño único de las pletinas. Para el fuselaje se mostrarán relaciones generales con el objetivo de comprobar que las tendencias son similares al caso de las pletinas. Las relaciones no serán tan claras como en el caso del camino de carga único aunque las tendencias nos indicarán si la influencia es similar. 


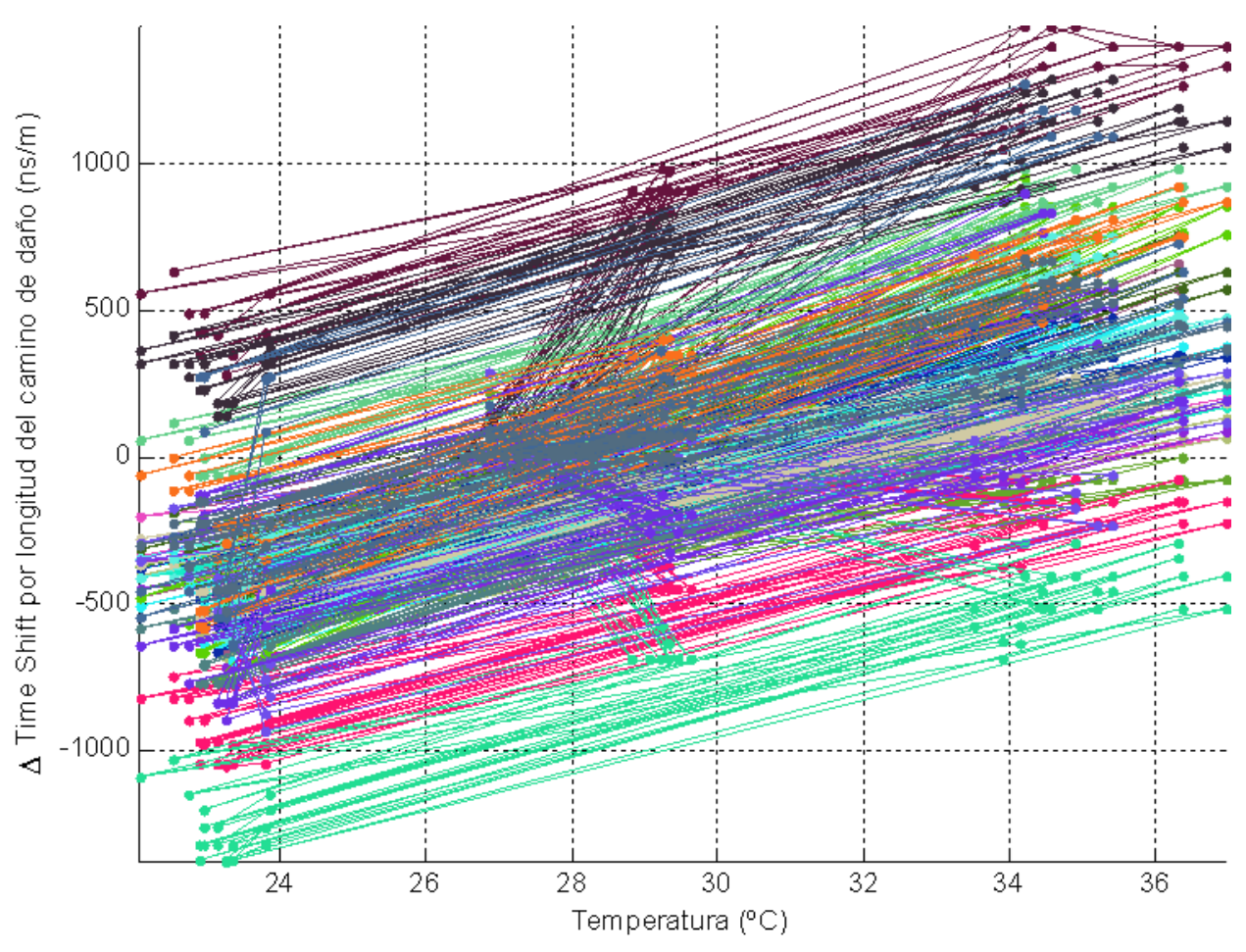

Figura 79 - Variación del coeficiente de Time Shift con la temperatura para todos los caminos de daño.

En la Figura 79 se comprueba que las relaciones son lineales para cada camino de daño pero existe un factor de variabilidad adicional que las desplaza en el eje vertical, el estado de carga que está acoplado con la variación térmica. Por sencillez se presentarán análisis de tendencia para cada camino de daño en vez de todos los puntos, líneas rojas en la Figura 80.

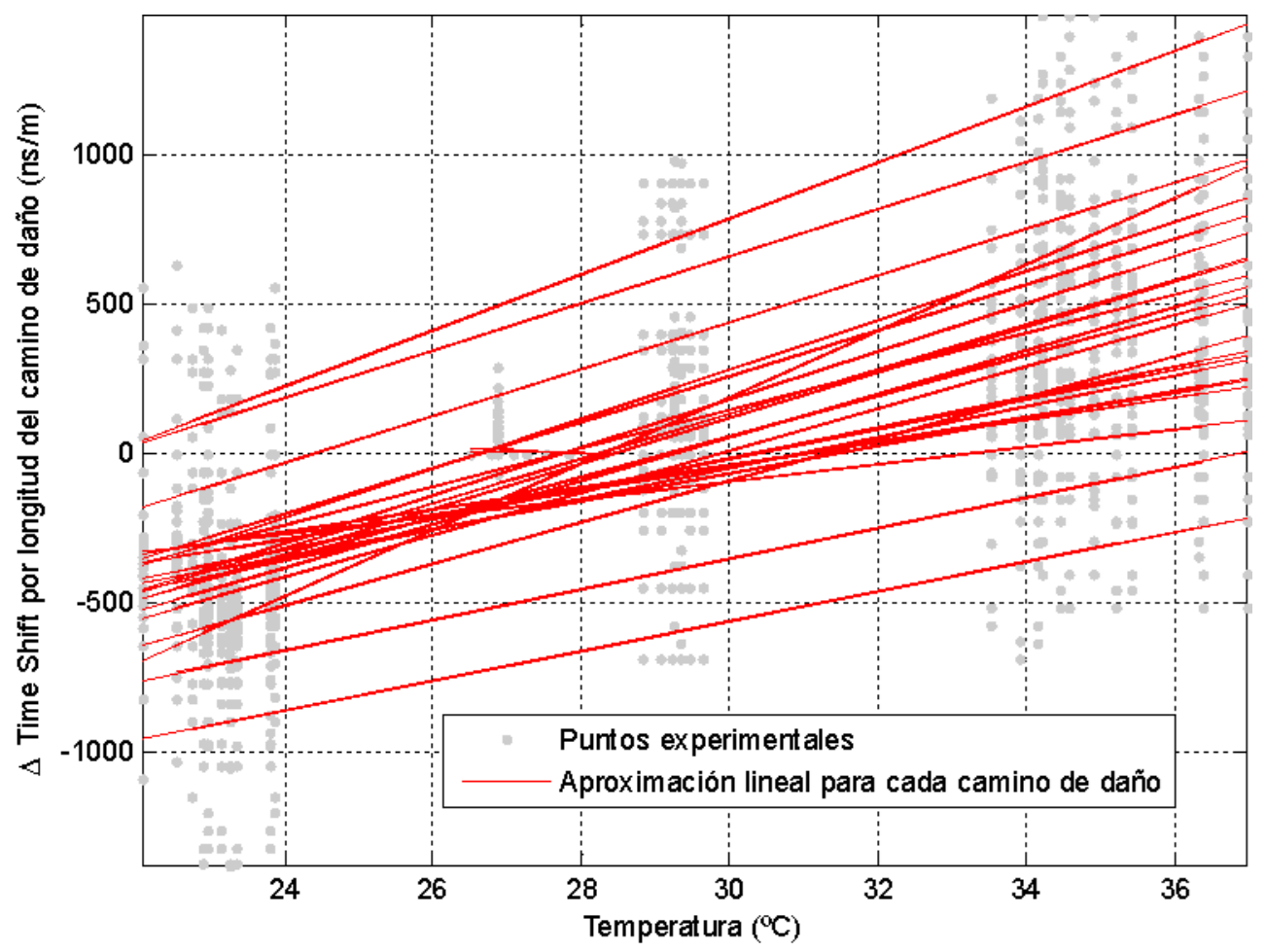

Figura 80 - Variación del CT-TS con la temperatura, aproximaciones lineales para cada camino de daño. 
La influencia del estado de carga se puede comprobar claramente pintando el retraso obtenido para la llegada de S0 de la GLW frente al CT-TS. Esta relación es prácticamente lineal por lo que el haz de rectas que se produce en la Figura 80 se debe a dicha influencia.

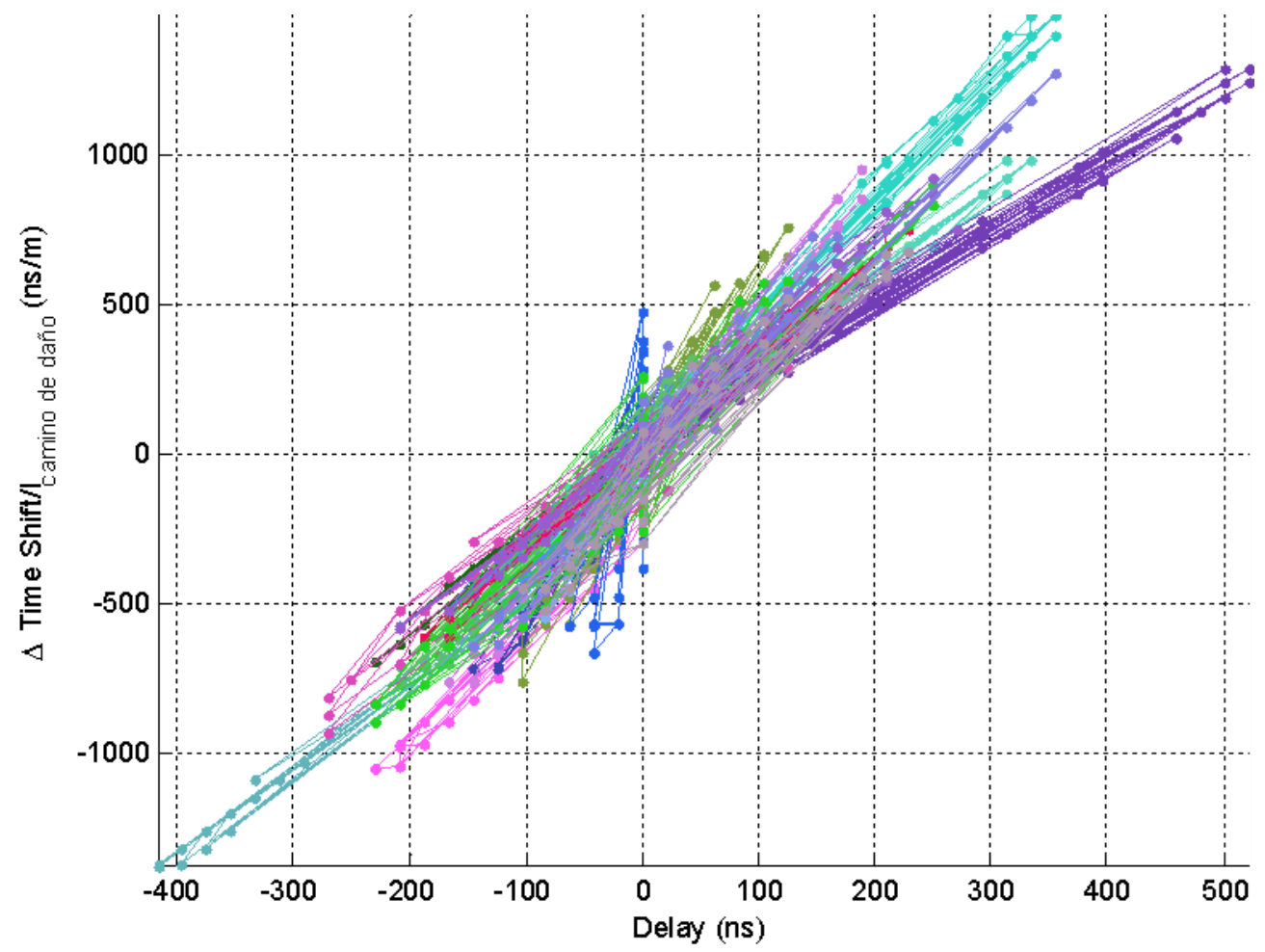

Figura 81 - Variación de CT-TS frente al retraso de la llegada del modo S0 de la GLW.

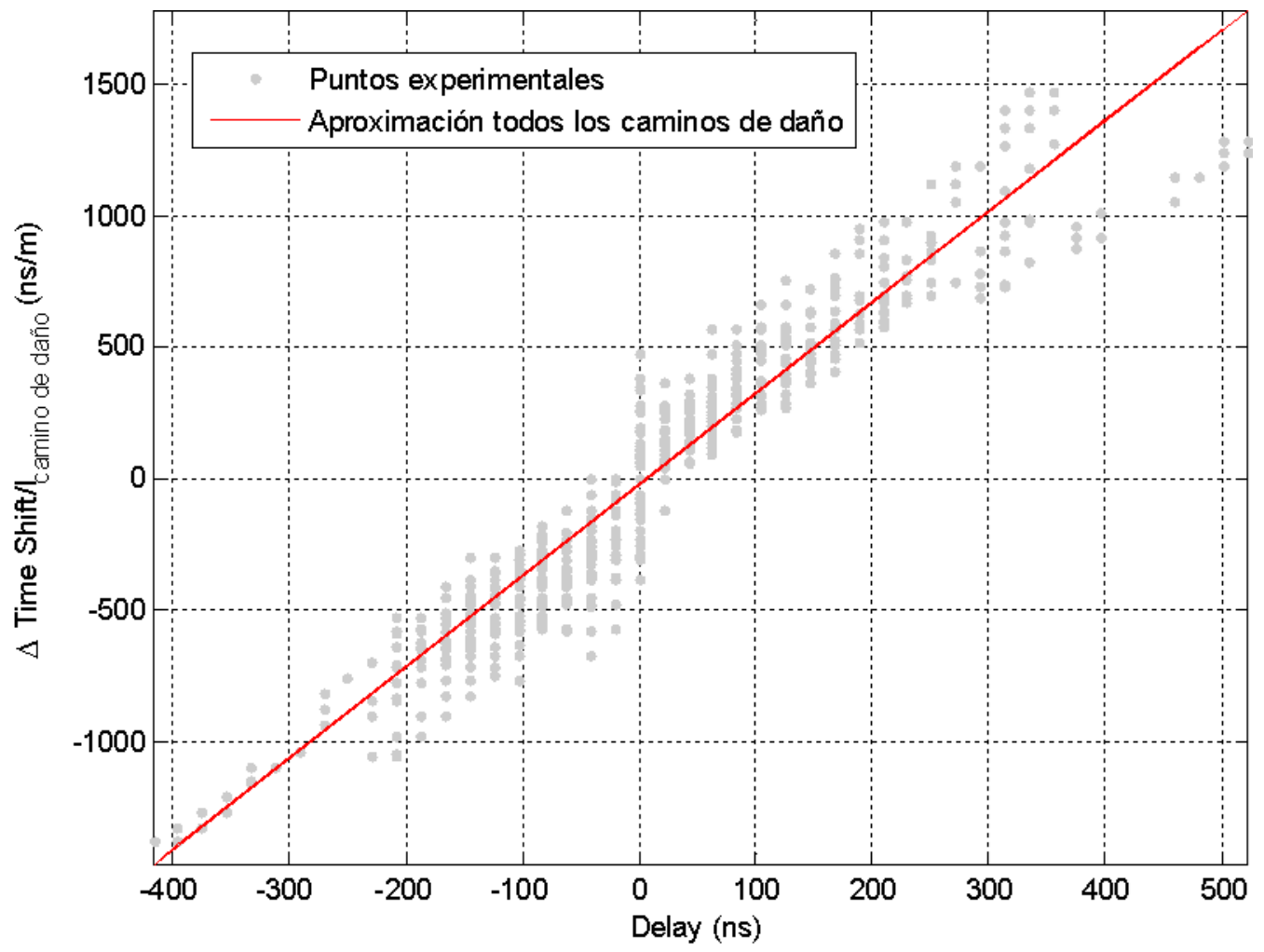

Figura 82 - Aproximación lineal entre el retraso y CT-TS para todos los caminos de daño 
En las figuras (Figura 81 y Figura 82) se comprueba como el CT-TS refleja perfectamente el retraso del modo S0 de la GLW pero en ese retraso participa además de la variación de temperatura, la variación del estado de carga. Los efectos están acoplados y no son sencillos de mostrar debido a la complejidad de la estructura.

Se muestra la relación entre el CT-TS y el estado de carga.

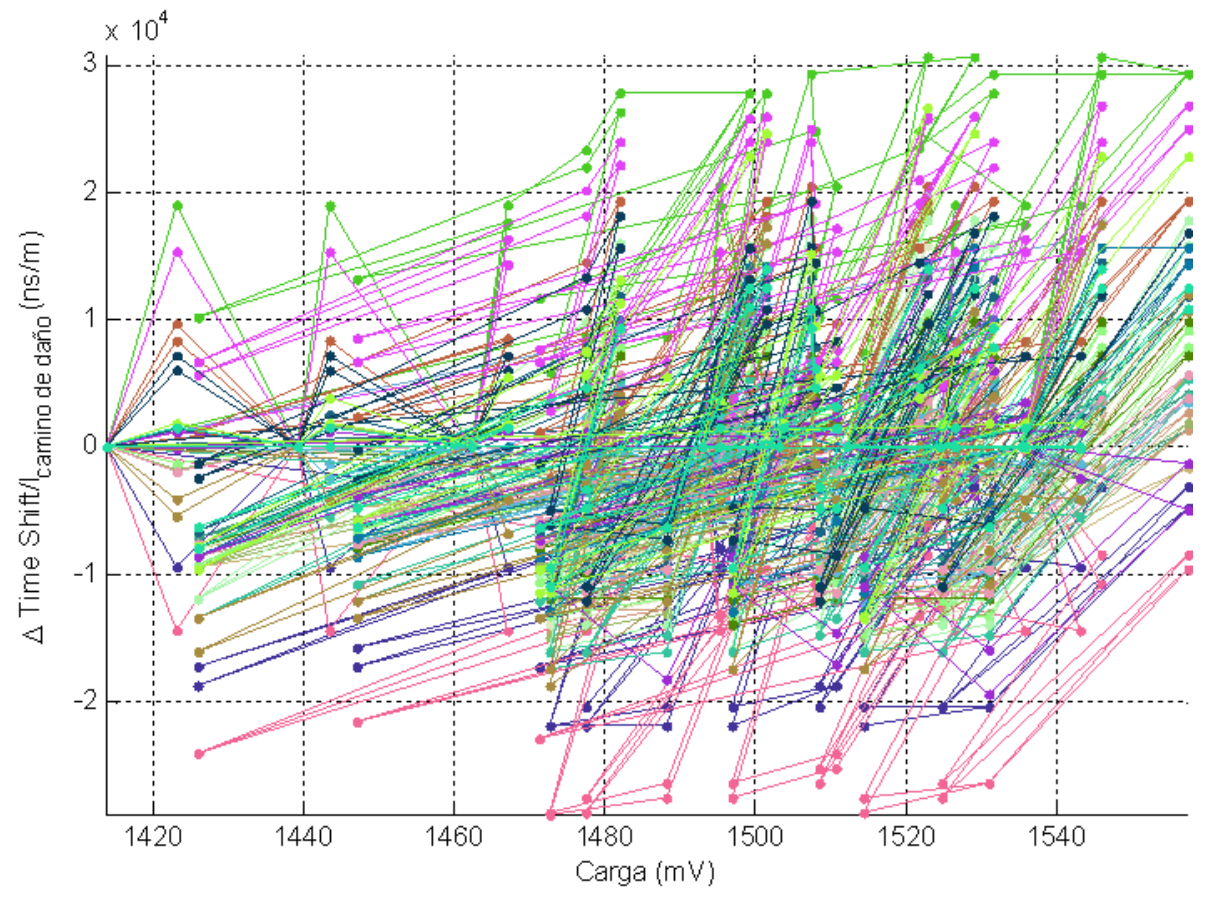

Figura 83 - Relación entre CT-TS y estado de carga.

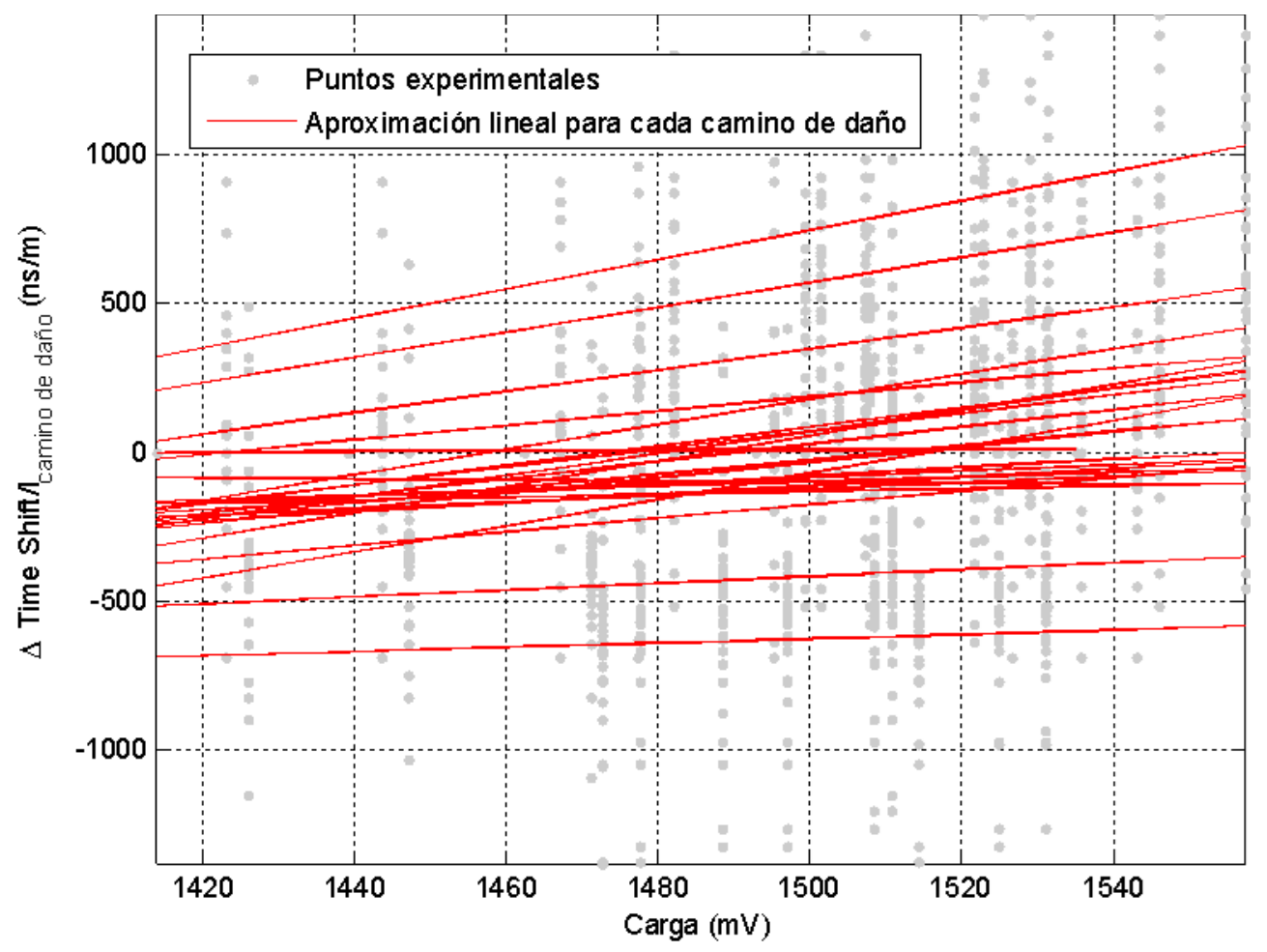

Figura 84 - Relación CT-TS/estado de carga, aproximación lineal para cada camino de daño. 
A la vista de las figuras anteriores se observa que la influencia del estado de carga también participa en el cambio del coeficiente de Time Shift.

Para los coeficientes de Scaling solo se producen pequeños cambios relacionados con las EOC que debido a su magnitud y la complejidad de los datos experimentales apenas se pueden observar y por lo tanto no se muestran.

En conclusión, la influencia que se observa es similar a la que se vio para las pletinas. La complejidad subyacente en los datos experimentales es mucho mayor. Para simplificar se han mostrado aproximaciones lineales para cada camino de daño pero las relaciones que hay detrás son mucho mayores.

Será el esquema de compensación propuesto CT-ANN el que se encargará de captar dichas relaciones. 


\subsubsection{Efecto del daño}

Antes de pasar a la generación del modelo de compensación se va a comprobar que el efecto de la presencia de daño produce variaciones en la parte real del coeficiente Scaling de la CT.

Si estas variaciones son de una naturaleza similar a la observada en las pletinas se podrá utilizar el esquema de compensación CT-ANN (con la salvedad de los múltiples caminos de daño que presenta el fuselaje)

En primer lugar se presentan los resultados de los valores de este coeficiente para todos los caminos de daño, para tener una visión general de conjunto de lo que ocurre. Se graficarán los coeficientes obtenidos frente a las diferentes situaciones de daño.

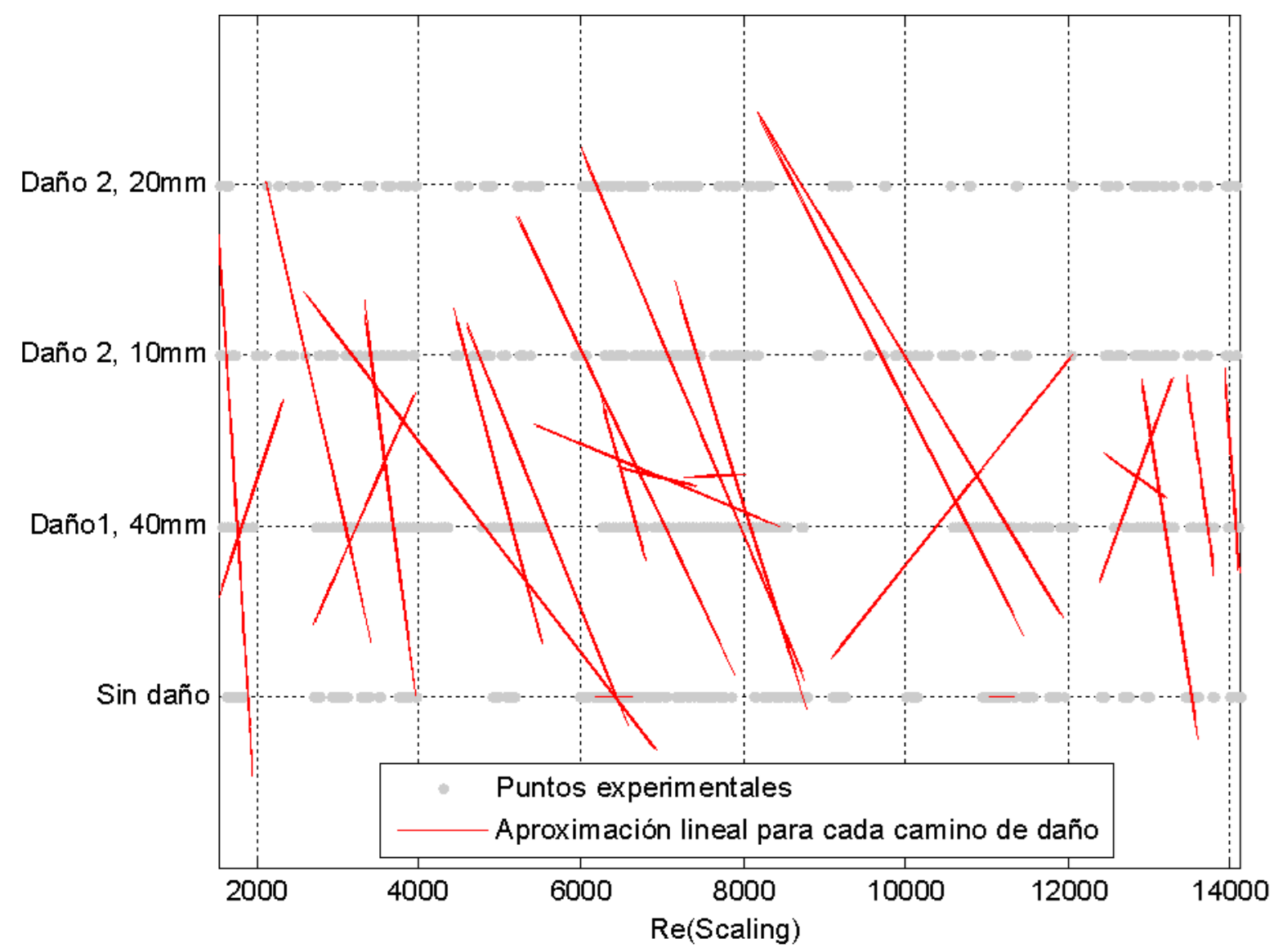

Figura 85 - Efecto de la presencia de daño para los diferentes caminos de daño sobre el coeficiente de la CT, $\operatorname{Re}($ Scaling)

En la Figura 85 se comprueba que las relaciones del coeficiente Re(Scaling) es muy compleja para cada uno de los caminos de daño. Por esta razón se va a evaluar uno de los caminos de daño que intersecta los dos daños producidos en la estructura para verificar dicha variación.

Toda la complejidad anterior será tenida en cuenta por el modelo CT-ANN para poder dilucidar la presencia del daño. 
Seleccionamos el camino de daño PZT1-PZT10 para comprobar la influencia sobre Re(Scaling) de la presencia de daño.

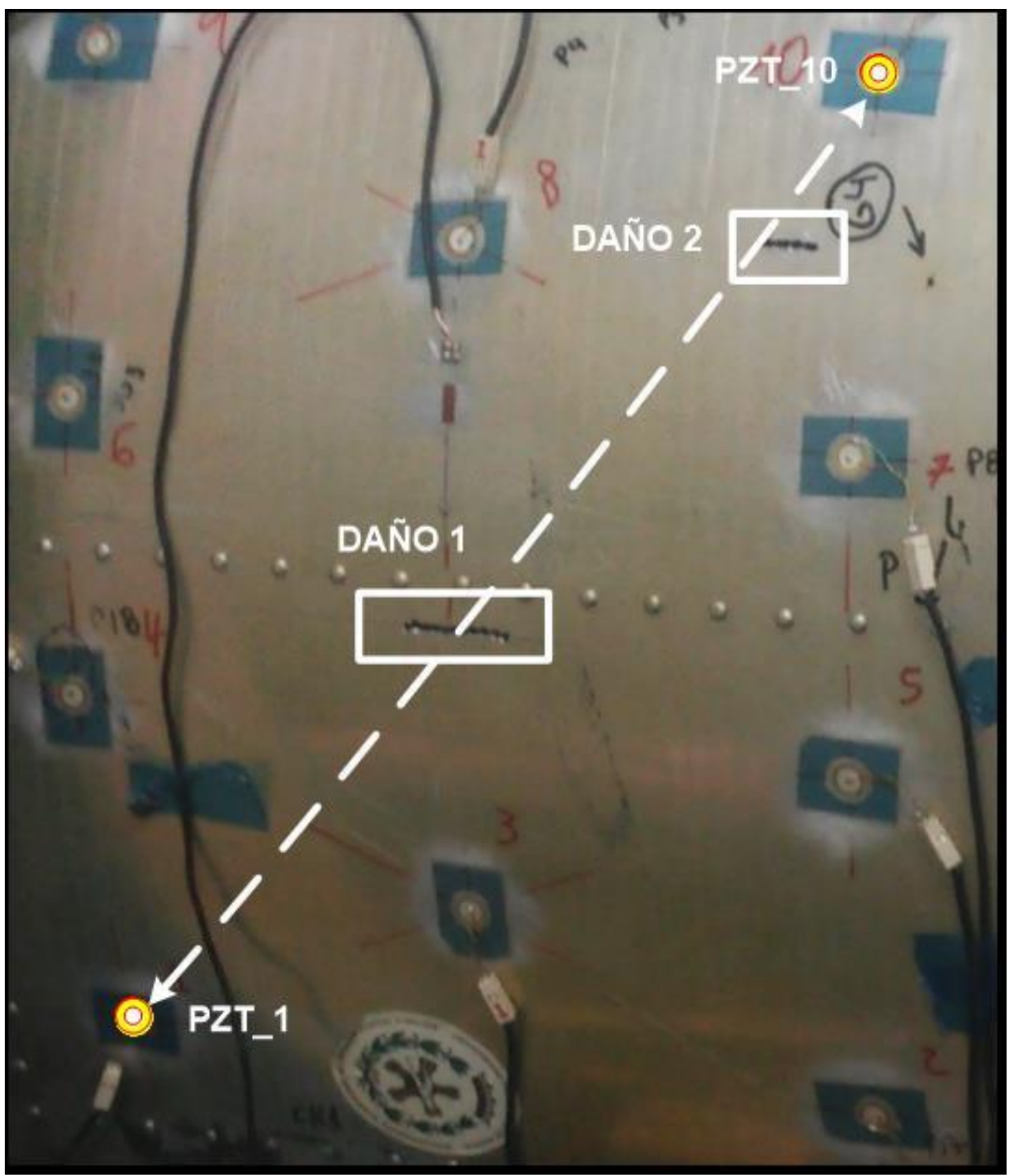

Figura 86 - Camino de daño PZT-1 $\rightarrow$ PZT-10 junto con los dos daños efectuados en la pieza.

Para este camino de daño se muestra la variación del coeficiente de la CT $\operatorname{Re}($ Scaling) en la figura obteniéndose las variaciones indicadas para cada una de las situaciones de daño. 


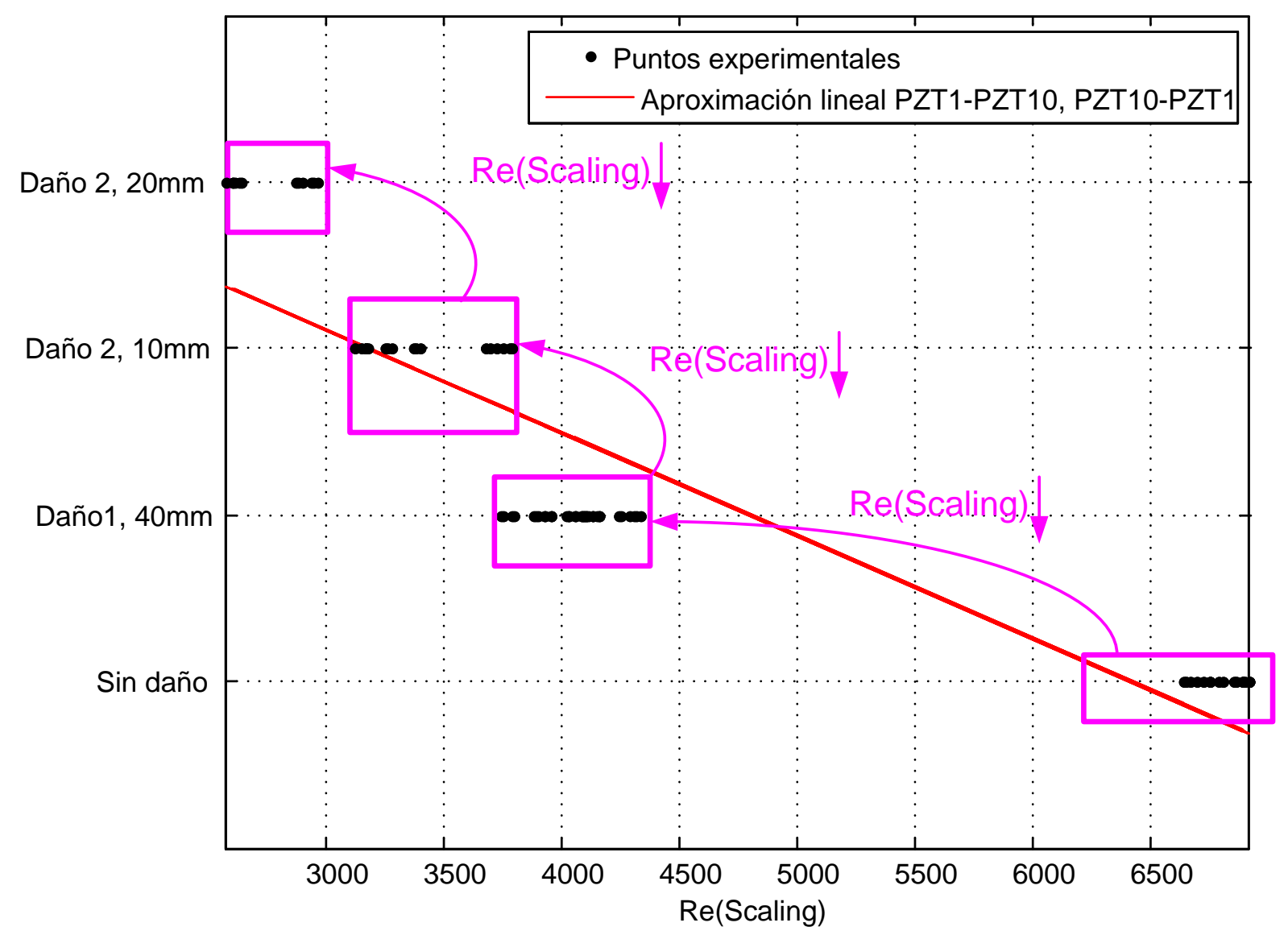

Figura 87 - Variación de Re(Scaling) para el camino de daño PZT1/10-PZT10/1

Los resultados gráficos indican que la variación del tamaño de daño queda claramente reflejada en el camino de daño. Además la variación es proporcional en cierto modo al tamaño del daño introducido, en el daño 1 que es mayor que los otros dos el salto en el coeficiente es notablemente mayor.

Para poder tener una idea comparativa en el resto de caminos de daño se muestra la comparativa entre los resultados para el camino 1-10, que intersecta los daños, y el camino 1-9 que no intersecta ningún daño (como se puede comprobar en la Figura 86).

Los resultados comparativos se pintan en la Figura 88. Se observa que la diferencia de variación de $\operatorname{Re}($ Scaling) es casi un orden de magnitud menor en el caso del camino de daño sin daño. 

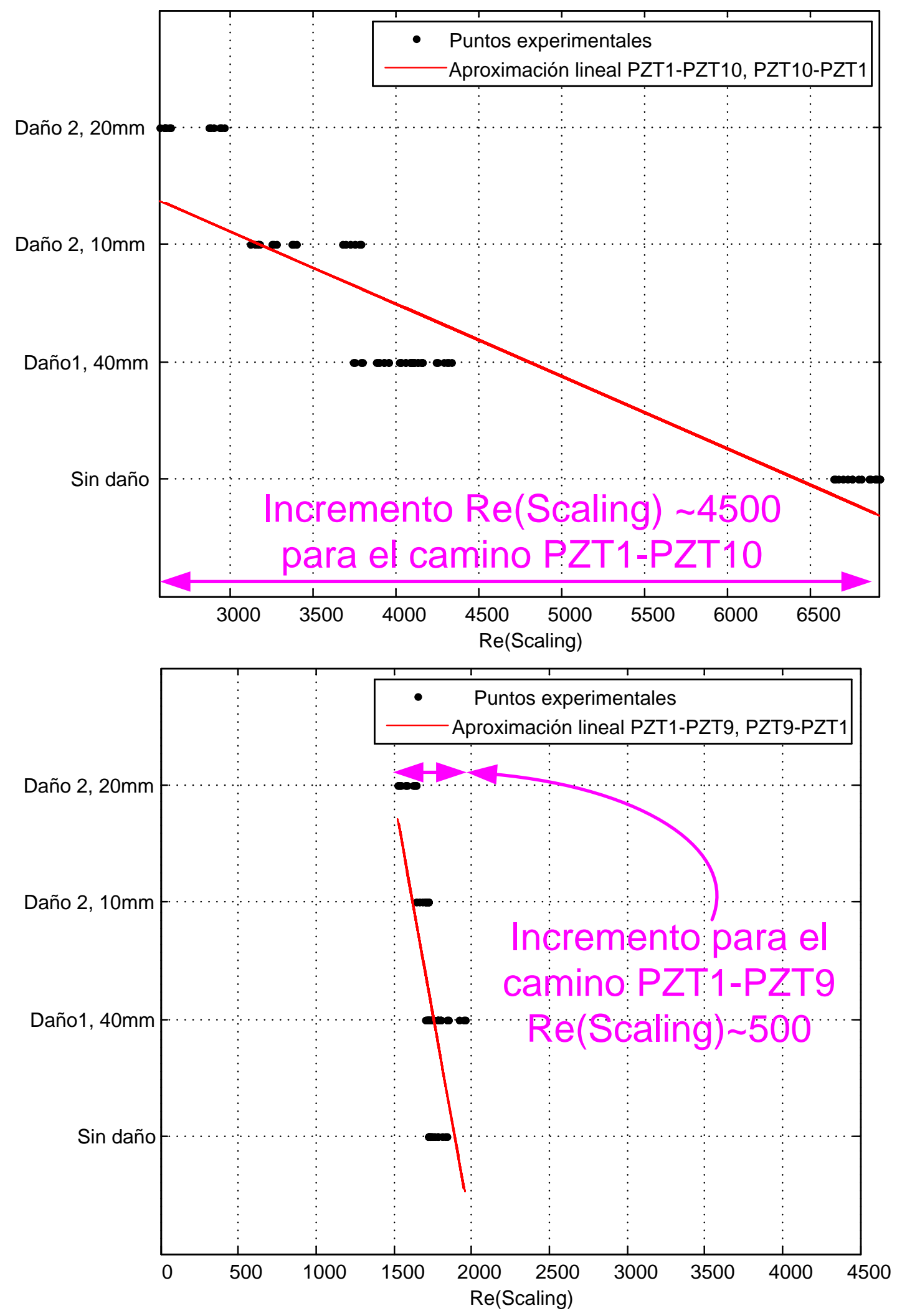

Figura 88 - Comparativa de variación de Re(Scaling) para los caminos PZT1-PZT10 y PZT1-PZT9. 
En conclusión, el efecto es muy similar al que se observó en el caso de las pletinas, aunque más complejo. Por lo tanto se procede a generar el modelo de compensación a partir de los datos experimentales.

\subsubsection{Definición del modelo de compensación con datos experimentales}

El modelo de compensación a aplicar es de la misma naturaleza al descrito en el apartado 5.3.7.3. Las diferencias que aquí se indican son relativas a la bidimensionalidad del fuselaje, ya que el modelo ANN de compensación será único para todos los caminos de daño.

El modelo ANN es una simplificación del indicado en la Tabla 10, al igual que en el caso de las pletinas. Las entradas y salidas del modelo se definen en la siguiente tabla.

\begin{tabular}{|c|c|c|c|c|}
\hline $\begin{array}{l}\text { GRUPO DE } \\
\text { ENTRADAS }\end{array}$ & ENTRADAS & MODELO & SALIDAS & $\begin{array}{c}\text { GRUPO } \\
\text { DE } \\
\text { SALIDAS }\end{array}$ \\
\hline \multirow{4}{*}{$\begin{array}{l}\text { Definición de la } \\
\text { interrogación. } \\
\text { Características de la señal } \\
\text { de interrogación }\end{array}$} & $\begin{array}{l}\text { Time shift de la señal } \\
\text { de interrogación } \\
\text { frecuencia de } \\
\text { interrogación }\end{array}$ & \multirow{6}{*}{$\begin{array}{l}\text { Modelo ANN. } \\
\text { Modelo gobernado } \\
\text { por los datos que } \\
\text { capturará la relación } \\
\text { entre las } \\
\text { características de } \\
\text { actuación junto con } \\
\text { las EOC de esa } \\
\text { actuación y las } \\
\text { señales adquiridas en } \\
\text { el transmisor en } \\
\text { términos de los } \\
\text { coeficientes de la } \\
\text { CT. }\end{array}$} & \multirow{2}{*}{$\begin{array}{l}\text { Re (Scaling) de la } \\
\text { señal adquirida en } \\
\text { la interrogación } \\
\sim \text { atenuaciones } \\
\text { introducidas por el } \\
\text { daño + otros } \\
\text { efectos } \\
\sim \text { firma del daño en } \\
\text { la DSF }\end{array}$} & \multirow{6}{*}{$\begin{array}{l}\text { Valores que } \\
\text { tendrían los } \\
\text { coeficientes de la } \\
\text { CT para la señal de } \\
\text { interrogación } \\
\text { definida y las EOC } \\
\text { en las que se } \\
\text { efectuó dicha } \\
\text { interrogación. }\end{array}$} \\
\hline & $\begin{array}{l}\text { Re(Scaling) de la señal } \\
\text { de interrogación } \\
\sim \text { amplitud de la señal de } \\
\text { interrogación }\end{array}$ & & & \\
\hline & $\begin{array}{l}\text { Identificador del PZT } \\
\text { Actuador } \\
\text { bidimensionalidad } \\
\end{array}$ & & $\begin{array}{l}\text { Time Shift de la } \\
\text { señal adquirida en } \\
\text { la interrogación }\end{array}$ & \\
\hline & $\begin{array}{l}\text { Identificador del PZT } \\
\text { Sensor } \\
\text { bidimensionalidad }\end{array}$ & & $\begin{array}{l}\sim \text { retrasos } \\
\text { introducidos por } \\
\text { las EOC+otros }\end{array}$ & \\
\hline \multirow{2}{*}{$\begin{array}{l}\text { EOC. } \\
\text { Condiciones ambientales y } \\
\text { de operación }\end{array}$} & Temperatura & & efectos & \\
\hline & Carga & & sobre la DSF & \\
\hline
\end{tabular}

Tabla 21 - Modelo de compensación para el fuselaje

El diagrama de flujo del modelo se muestra en la Figura 89.

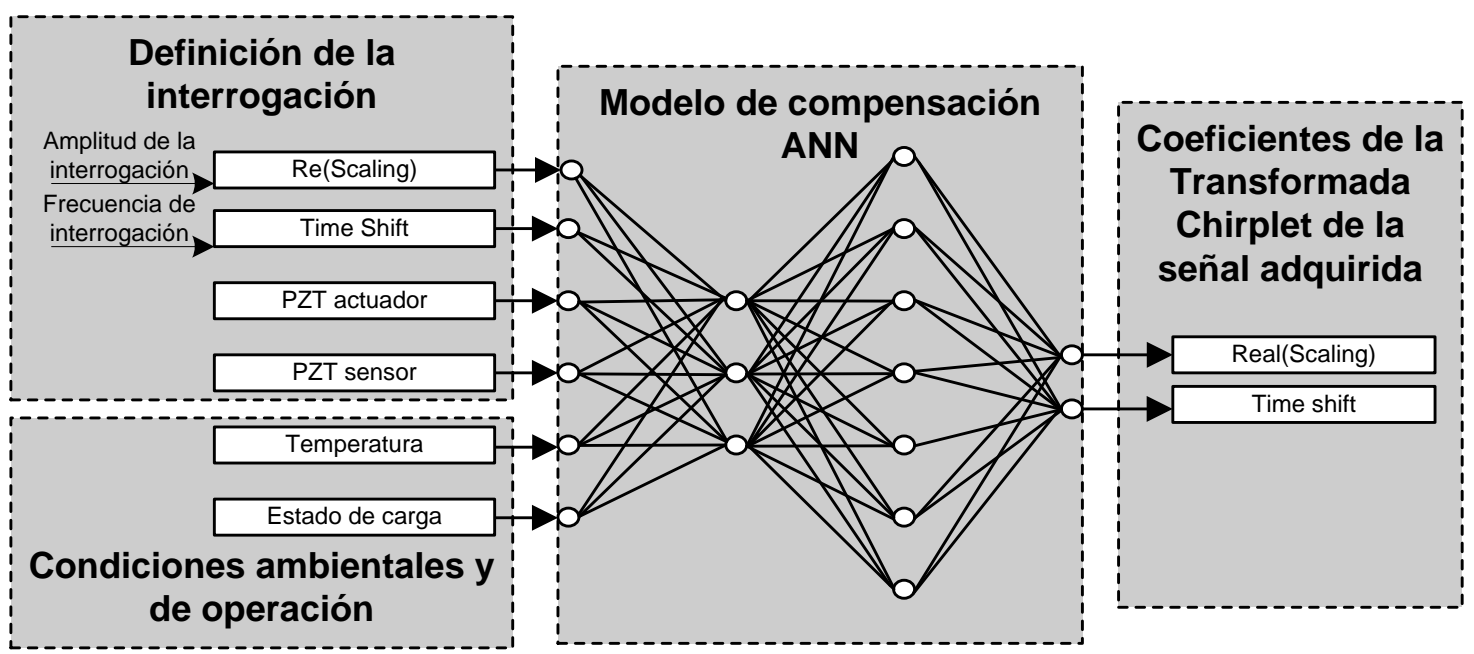

Figura 89 - Diagrama del modelo de compensación ANN. 


\subsubsection{Ajuste del modelo de compensación con datos experimentales}

En la Figura 90 se indica el diagrama de flujo de trabajo del esquema de compensación en el que participa el modelo ANN y la transformada chirplet.

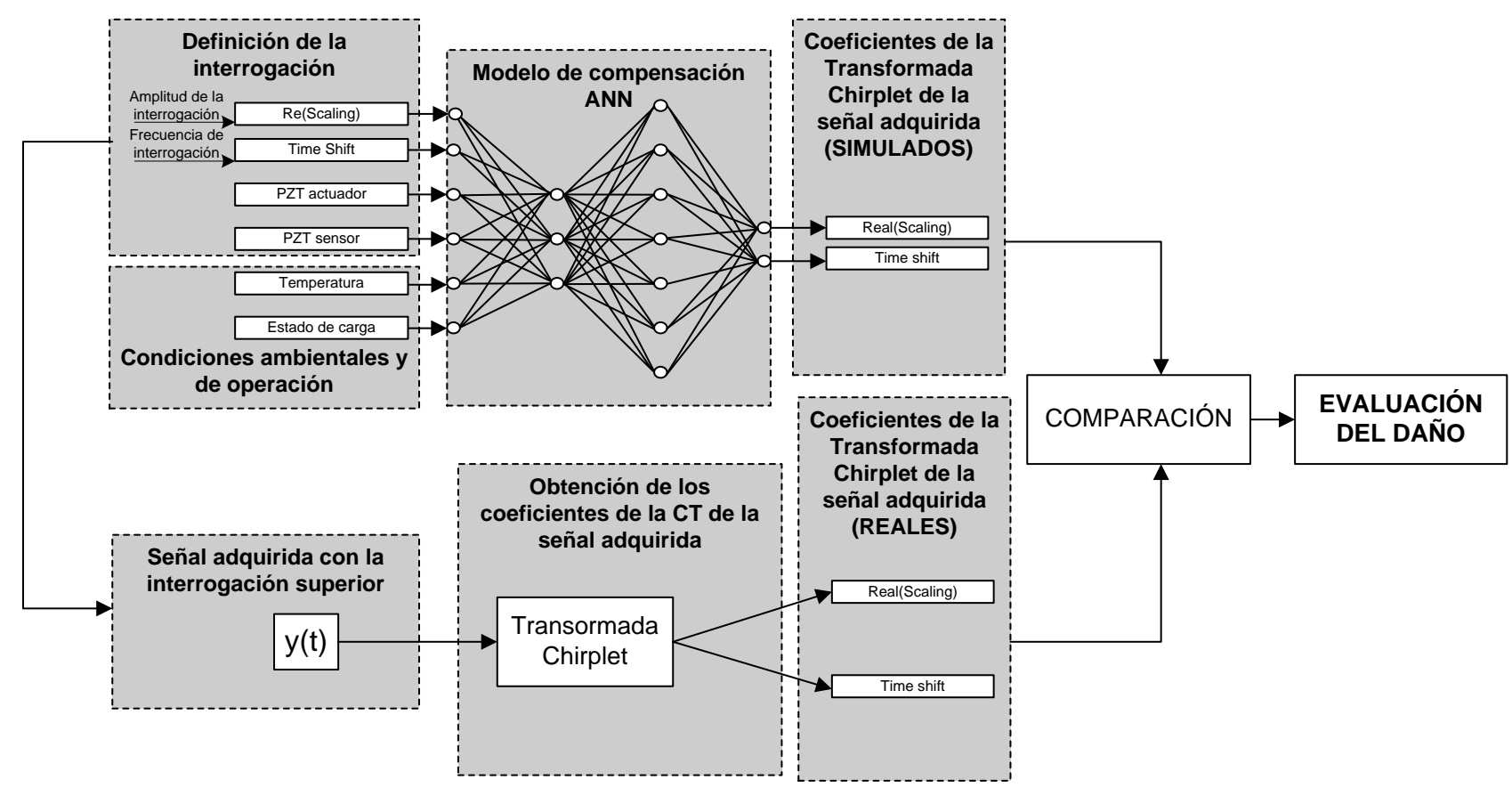

Figura 90 - Aplicación del modelo de compensación para el fuselaje.

La definición en detalle del modelo ANN se describe en la Tabla 22.

\begin{tabular}{|l|l|}
\hline \multicolumn{1}{|c|}{ PARÁMETRO DE DEFINICIÓN } & \multicolumn{1}{c|}{ VALOR } \\
\hline Tipo de Red Neuronal & Feedforward Backpropagation \\
\hline Número de entradas & 6 \\
& Re(Scaling) de la señal de actuación \\
& Time Shift incremental de la señal de actuación \\
& Número de PZT transmisor \\
& Número de PZT receptor \\
& Temperatura \\
& Estado de carga \\
\hline Número de capas & 3 \\
\hline Número de neuronas por capa & 15 \\
& 41 \\
\hline Función de transferencia neuronal en cada capa & 2 \\
\hline Número de salidas & Tangente sigmoidea \\
& Tangente sigmoidea \\
& Lineal \\
\hline \multicolumn{2}{|c|}{ Tabla 22 - Parámetros de definición del modelo de compensación } \\
\hline \multicolumn{2}{|l}{} \\
\hline
\end{tabular}

El esquema de entrenamiento, validación y blind test es el mismo al indicado en el apartado 5.3.7.5. Los datos particulares en los tres procesos cambian. 
Para el entrenamiento y como situación de referencia se ha utilizado la situación con el daño número 1. El esquema propuesto no obliga a que la referencia sea una situación sin daño, puede ser cualquier situación. Al ser un método comparativo veremos las diferencias con la situación sin daño del mismo modo que si ajustásemos con esa como referencia y luego evaluásemos la de daño 1. Al utilizar esta situación intermedia se podrá diferenciar la situación sin daño y las correspondientes al daño 2. Además, es en esta situación donde más información se ha tomado lo que la hace óptima para establecer la referencia. Las dos situaciones adicionales se utilizarán para validación y blind test, siendo en este caso pruebas equivalentes. Este pequeño ajuste de trabajo se indica en la tabla.

\begin{tabular}{|l|l|l|}
\hline ENSAYO & \multicolumn{1}{|c|}{ DESCRIPCIÓN } & \multicolumn{1}{|c|}{ UTILIZACIÓN } \\
\hline 1 & Variación de carga sin daño & VALIDACIÓN DE LA ANN \\
\hline 2 & Variación de carga y daño 1 & \multirow{2}{*}{ ENTRENAMIENTO DE LA ANN } \\
\hline 3 & Variación de carga y temperatura con daño 1 presente & \\
\hline 4 & Variación de carga y daño 1 & \multirow{2}{*}{ BLIND TEST DE LA ANN } \\
\hline 5 & Variación de carga y temperatura con daño 2 - tamaño 1 presente \\
\hline 6 & Variación de carga y temperatura con daño 2 - tamaño 2 presente & \\
\hline
\end{tabular}

Tabla 23 - Segmentación de los datos experimentales para entrenamiento del modelo ANN en el fuselaje.

Los pasos para entrenar, validar y comprobar mediante blind test el esquema de compensación CT-ANN, en el caso del fuselaje son los siguientes:

1. Calcular los coeficientes de la CT para cada llegada del modo S0 (Re(Scaling) y Time Shift) esto nos proporciona los datos de salida objetivo de la ANN.

2. Calcular los datos de entrada:

a. $\operatorname{Re}($ Scaling) de la señal de interrogación. Parámetro relacionado con la amplitud de actuación utilizada en el modelo ANN de las pletinas.

b. Time Shift de la señal de interrogación. Parámetro relacionado con la frecuencia de actuación.

c. Temperatura a la que se realiza la actuación.

d. Estado de carga en el que se realiza la interrogación.

3. Dividir los datos en tres grupos:

a. Conjunto de datos de entrenamiento. Los correspondientes a los ensayos 2, 3 y 4.

b. Conjunto de datos de validación. Los del primer ensayo.

c. Conjunto de datos de blind test. Ensayos 5 y 6 .

4. Entrenar la ANN usando los dos conjuntos de datos de entrenamiento, en este caso separamos entrenamiento y validación al ser un caso más complejo (debido a la bidimensionalidad del problema). 
5. Validar la ANN con los datos de validación.

6. Verificar y validar el comportamiento de la ANN mediante los datos de blind test y validación. Estos datos se procesan del siguiente modo

a. Recuperar datos de validación y blind test.

b. Simular la ANN con esos datos, obteniendo los valores de Re(Scaling) y Time Shift simulados.

c. Comparar los coeficientes de la interrogación real recuperados en (a), ya calculados en los pasos 1 y 2 .

Los resultados de entrenamiento para cada una de las frecuencias de interrogación utilizadas son los siguientes.

\begin{tabular}{|c|c|}
\hline $\begin{array}{c}\text { FRECUENCIA DE } \\
\text { INTERROGACIÓN }\end{array}$ & $\begin{array}{c}\text { ERROR DE ENTRENAMIENTO } \\
(\boldsymbol{\%})\end{array}$ \\
\hline $200 \mathrm{kHz}$ & 1.78 \\
\hline $250 \mathrm{kHz}$ & 2.06 \\
\hline $300 \mathrm{kHz}$ & 1.72 \\
\hline
\end{tabular}

Figura 91 - Errores de entrenamiento de los modelos ANN de compensación del fuselaje para diferentes frecuencias.

Si pintamos los resultados de entrenamiento de las salidas esperadas de los modelos ANN frente a las obtenidas el resultado se grafica en la figuras siguientes.

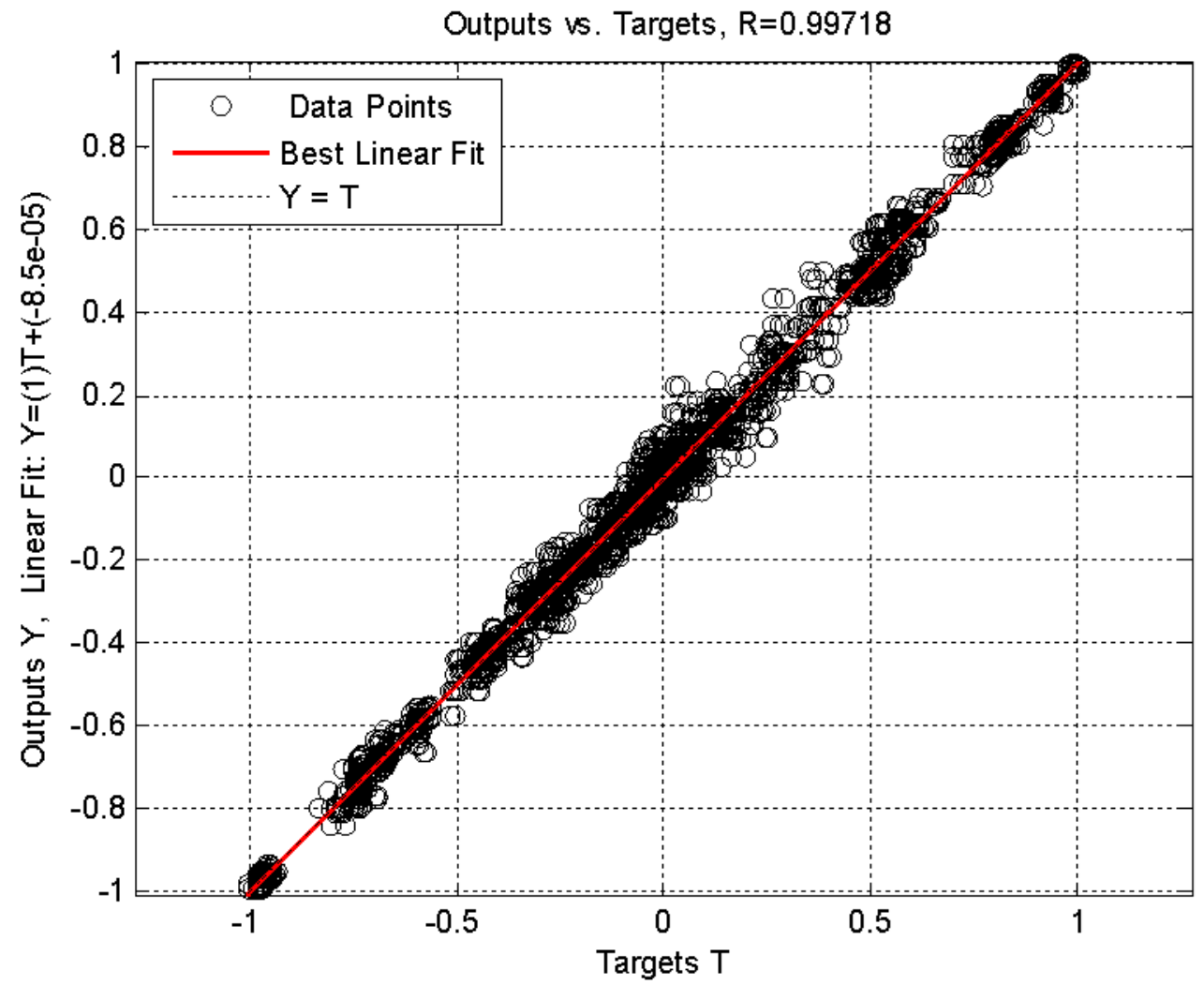

Figura 92 - Comparación entre salidas obtenidas y deseadas para el modelo ANN a $200 \mathrm{kHz}$. 
Outputs vs. Targets, $\mathrm{R}=0.99637$

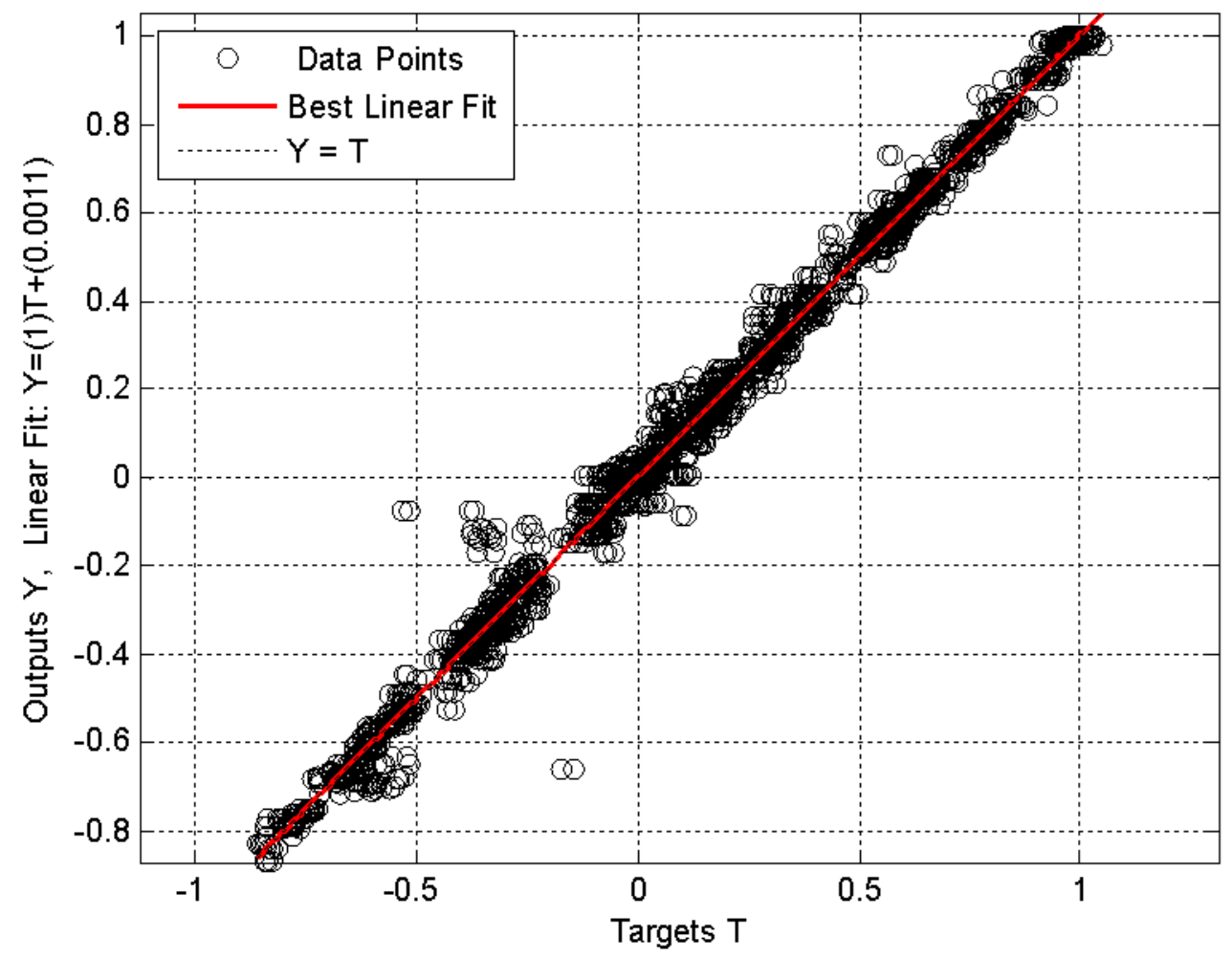

Figura 93 - Comparación entre salidas obtenidas y deseadas para el modelo ANN a $250 \mathrm{kHz}$.

Outputs vs. Targets, $\mathrm{R}=0.99763$

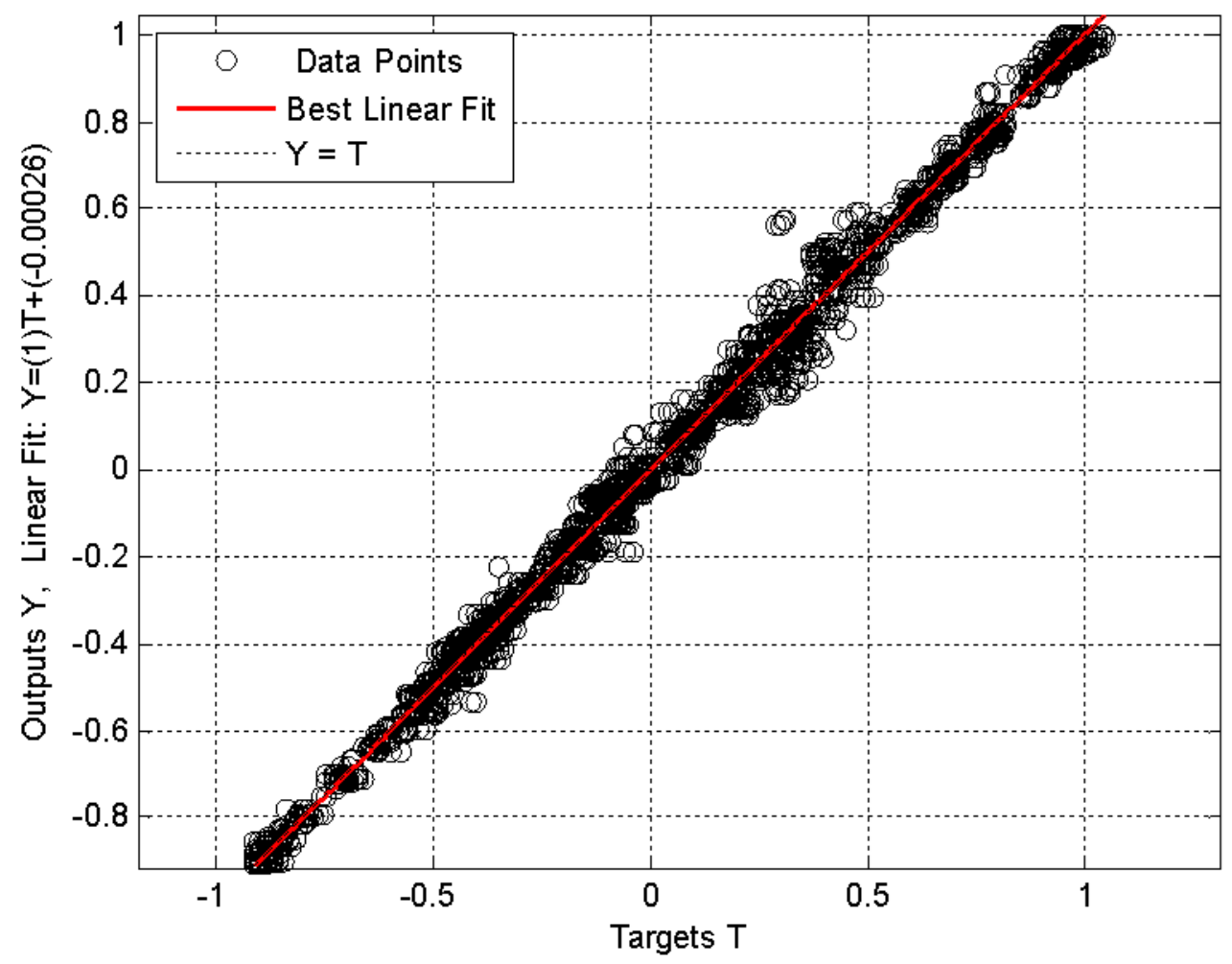

Figura 94 - Comparación entre salidas obtenidas y deseadas para el modelo ANN a $300 \mathrm{kHz}$. 
Se observa que el coeficiente de correlación obtenido en los tres casos es superior a 0.99 , con lo que la aproximación efectuada es adecuada.

Se puede también echar un vistazo a la aproximación obtenida para cada situación de entrenamiento (para cada una de las interrogaciones utilizadas).
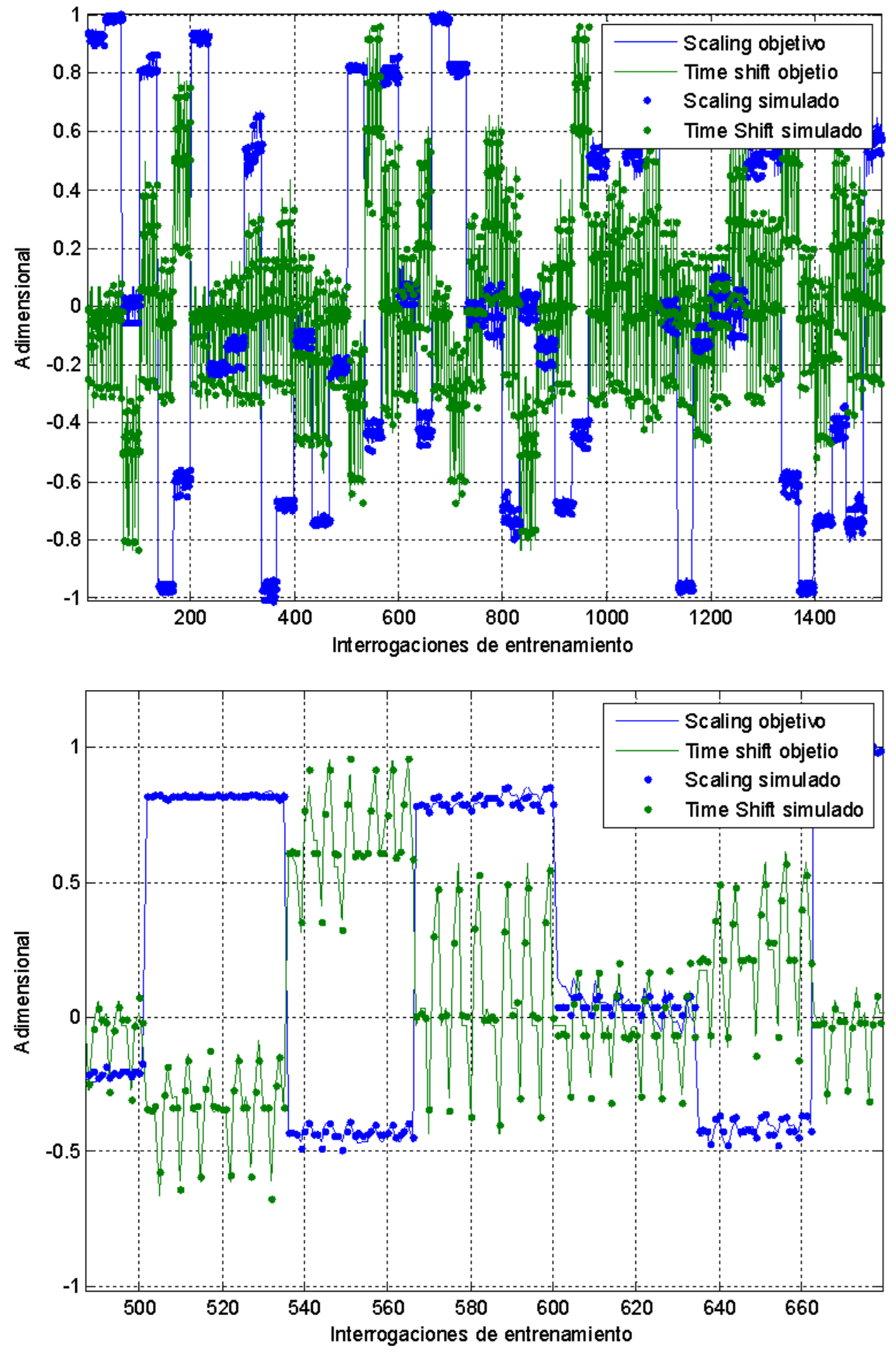

Figura 95 - Resultados de entrenamiento para Re(Scaling) y Time Shift a 200kHz. 


\subsubsection{Validación \blind test del modelo de compensación con datos experimentales}

Ya se ha comprobado que los modelos se han podido entrenar adecuadamente. El siguiente paso consiste en aplicar el esquema de compensación y evaluar si el modelo ANN cumple su función adecuadamente.

Para ello se utilizarán los siguientes grupos de datos:

- Datos de referencia sin daño. Por comparación con la situación de daño 1 debería sacar a relucir el daño1.

- Datos de daño 2, con dos tamaños. Al incluir esta segunda situación también el daño 1 por comparativa sólo deberían ocurrir dos cosas:

- No aparecer el daño 1.

- Aparecer el daño 2.

El proceso consiste en simular los diferentes modelos ANN con las interrogaciones correspondientes a las situaciones indicadas.

Así obtendríamos los coeficientes Re(Scaling) y Time Shift correspondientes a la situación de daño 1 (nuestra situación de referencia) en las condiciones de interrogación (temperatura y estado de carga). Estos los denominamos coeficientes simulados de referencia.

Por otro lado tenemos los mismos coeficientes calculados para esas situaciones directamente a partir de las mediciones realizadas. Estos otros coeficientes los llamamos coeficientes reales.

El resultado esperado es diferente para cada coeficiente.

Para el Time Shift debería obtenerse el coeficiente correspondiente para ese camino de daño correspondiente al estado de carga y temperatura de la interrogación. Es decir, los reales deberían ser iguales a los simulados.

Para $\operatorname{Re}$ (Scaling) deberían ser también iguales siempre que no haya daño. Sin embargo entre las situaciones que vamos a comparar existen diferencias en cuanto a la presencia de daño. Comparando los valores para cada uno de los caminos de daño deberían cambiar aquellos que intersecten los daños.

Presentamos los resultados obtenidos con una escala de color en la que se compara directamente los coeficientes $\operatorname{Re}($ Scaling) de la situación de referencia frente a los $\operatorname{Re}($ Scaling) de la situación a comparar (para cada uno de los caminos entre sensores). Así se crea el denominado mapa de daño que muestra una mayor atenuación en las zonas donde se sitúa el daño. 


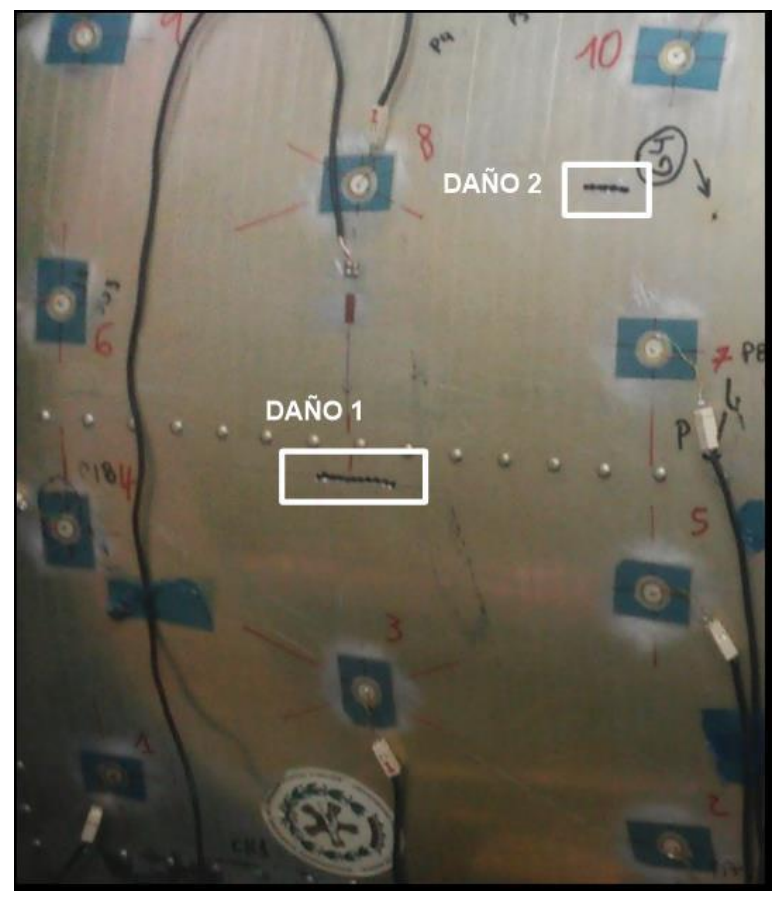

Figura 96 - Daños introducidos en el fuselaje.

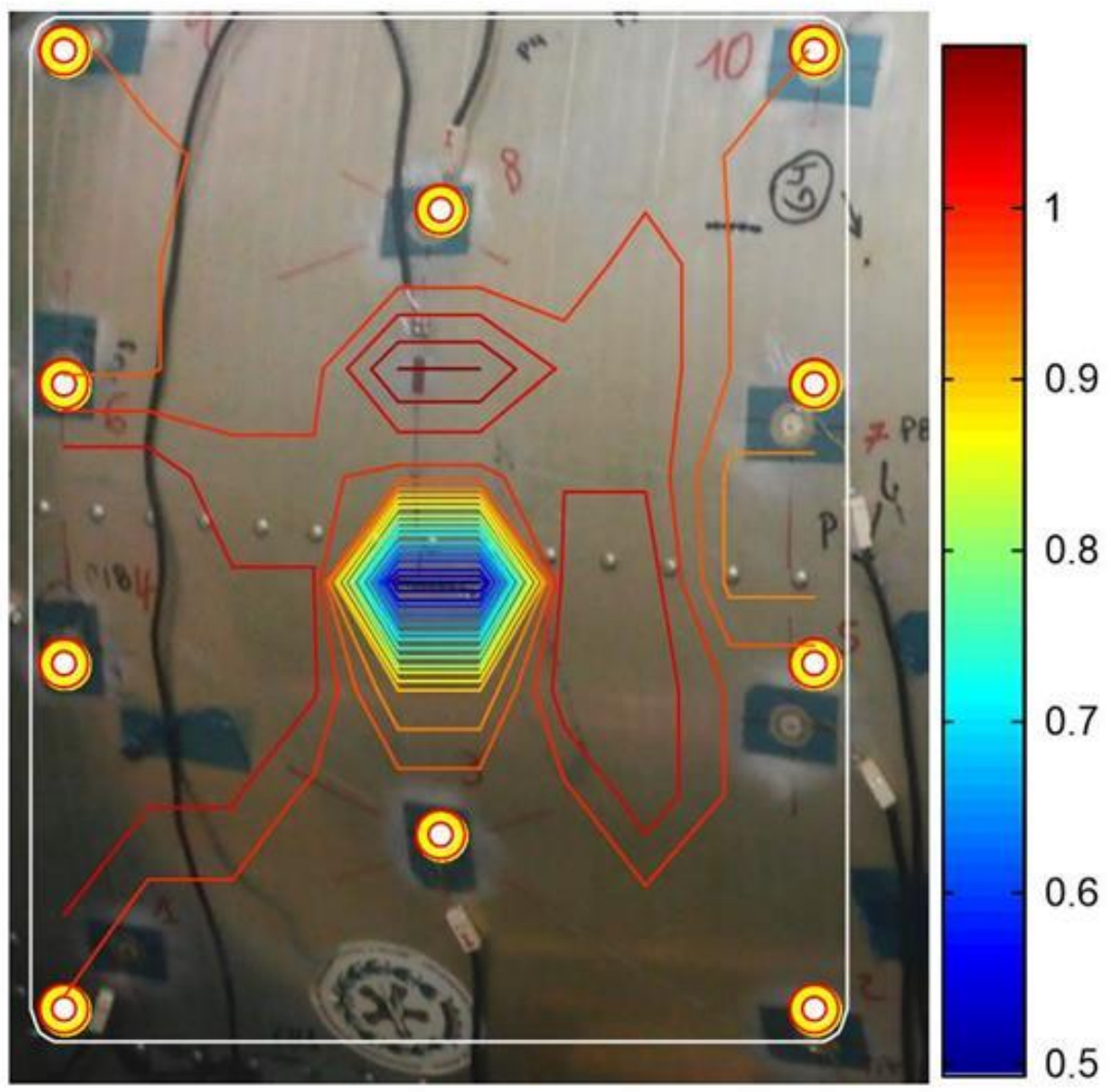

Figura 97 - Comparativa de $\operatorname{Re}($ Scaling), escala de color, para el daño 1, $40 \mathrm{~mm}$. 


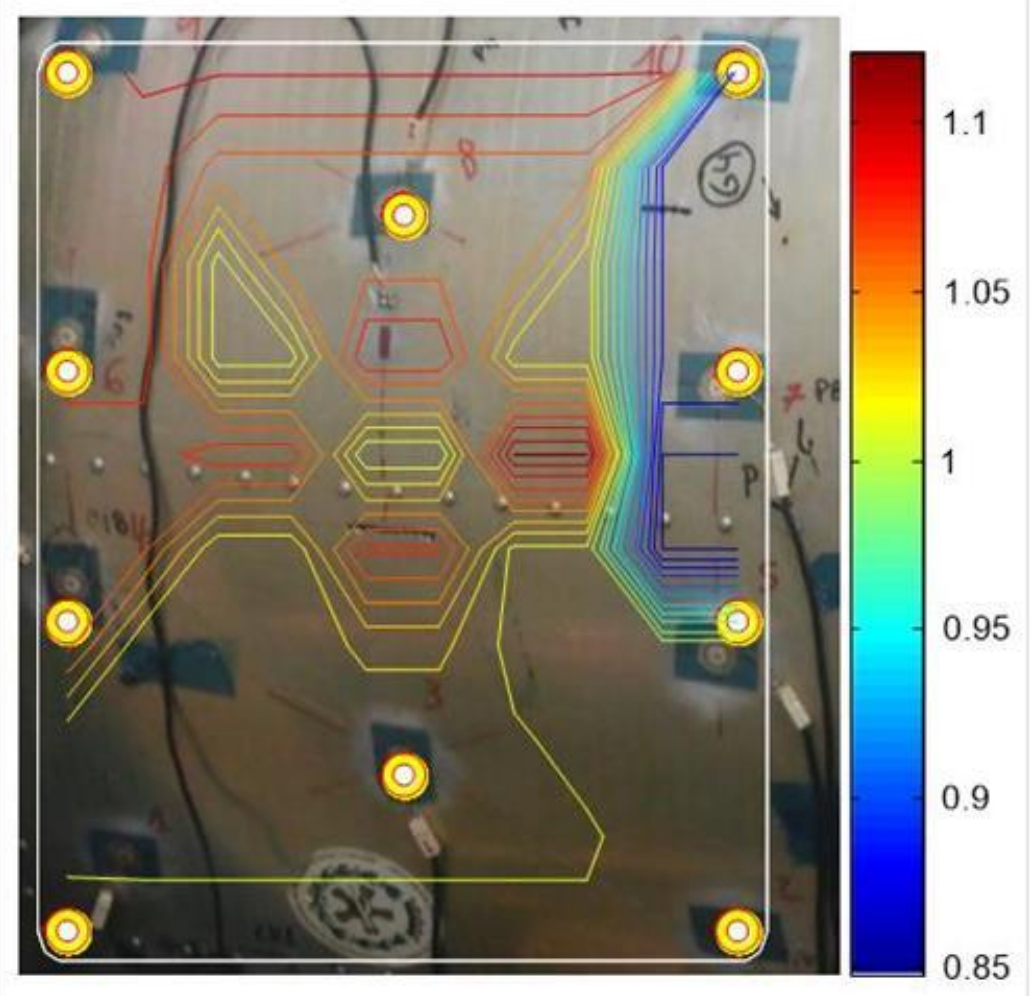

Figura 98 - Comparativa de Re(Scaling), escala de color, para el daño 2, $10 \mathrm{~mm}$.

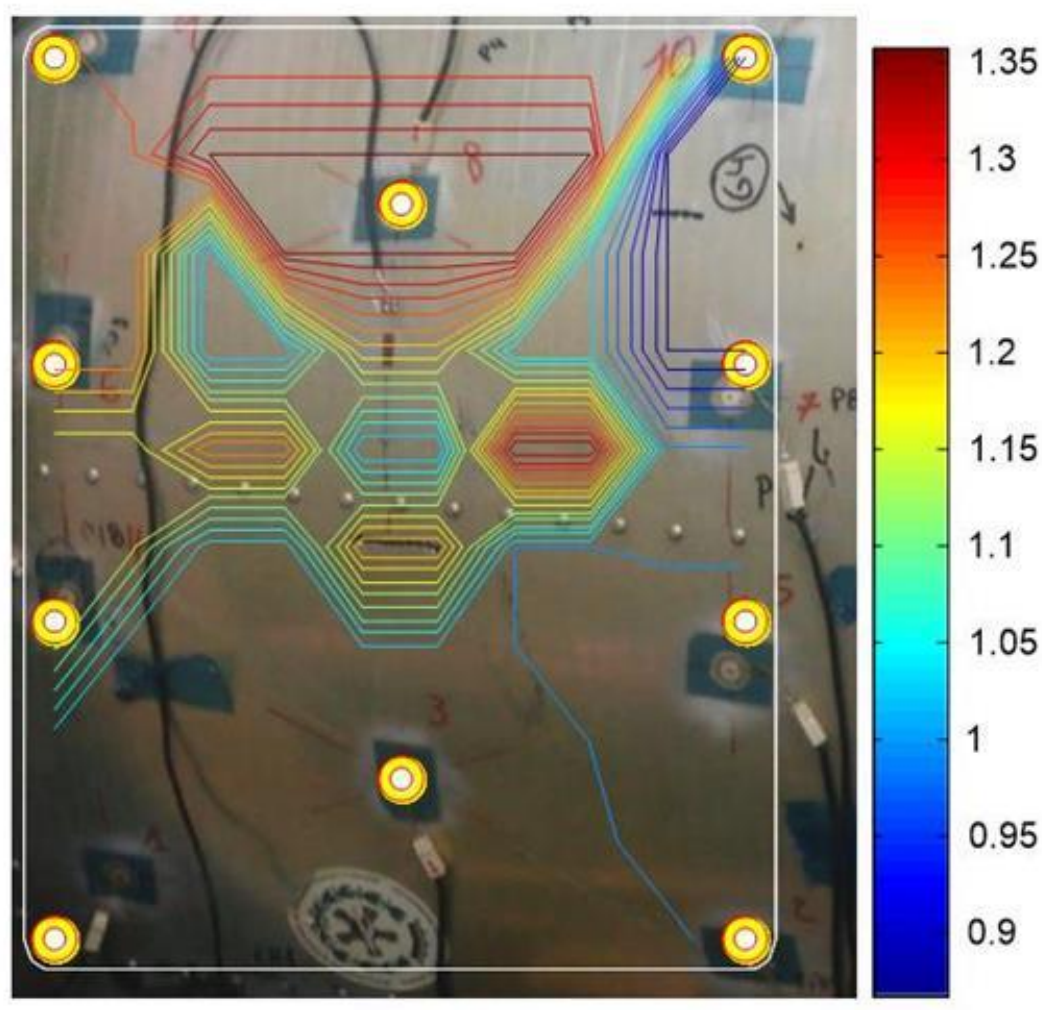

Figura 99 - Comparativa de $\operatorname{Re}($ Scaling), escala de color, para el daño 2, 20 mm. 
En la Figura 97 se observa como el esquema de compensación permite la detección del daño 1 en la pieza de fuselaje. Este es un daño de gran tamaño efectuado para hacer una comprobación de que el método efectivamente funciona a grandes rasgos.

En el caso de la Figura 98 y Figura 99, se comprueba como también la metodología permite detectar daños en el límite de sensibilidad de la técnica SHM (daño 2), aunque con menor precisión que en caso del daño 1 .

También se comprueba que la metodología incremental funciona. En este caso se ha tomado como referencia la situación de daño 1 y se han efectuado las siguientes comparaciones:

- Con la situación inicial sin daño. La única diferencia entre ambos estados de la estructura, aparte de las EOC cambiantes, es el propio daño, tal y como muestra el mapa de daño.

- Con las situaciones de daño 2, en dos tamaños. También los detecta sin problemas, mejorando la precisión según aumenta el tamaño de daño. Acercándose la zona de máxima atenuación más a la posición real en la Figura 99 que en la Figura 98. 


\section{Conclusiones y trabajos futuros}

En este apartado se resumen las principales conclusiones derivadas de los trabajos realizados y una serie de aportaciones originales que han ido surgiendo en el desarrollo de la tesis. Seguidamente se indican una serie de líneas de trabajo para el futuro.

Conclusiones y aportaciones:

- Se ha reducido el problema de detección de daño mediante ondas elásticas guiadas a su componente más simple, el camino de daño. Sobre este camino de daño se han efectuado una serie de ensayos para comprobar la influencia de las EOC en dichas ondas elásticas. Posteriormente se ha generalizado a un caso bidimensional con elementos rigidizadores obteniéndose resultados equivalentes. Esto supone una aproximación novedosa al problema de la compensación de estos efectos. En los estudios habituales de esta técnica SHM se efectúa una aproximación global para todos los sensores en conjunto, que impide el estudio en detalle de la influencia de las EOC en las ondas elásticas guiadas para dicho camino de daño. Los estudios unidimensionales para el camino de daño permiten entender la complejidad del problema y la necesidad de potentes modelos para la compensación de los mismos.

- Para el camino de daño se ha evaluado cuantitativamente que las EOC ocultan la presencia de daño para la técnica SHM basada en ondas elásticas guiadas. Para un camino de daño formado exclusivamente por sensores PZT y también para combinaciones PZT-FBG.

- Se ha utilizado una transformada novedosa, la Transformada Chirplet, como elemento de procesado y análisis de las señales obtenidas en la técnica SHM seleccionada. Es una transformada con una potencia de análisis y de sintetización de la información contenida en las señales muy superior a otras transformadas utilizadas habitualmente (como por ejemplo la transformada Wavelet).

- Se han asociado los coeficientes de la Transformada Chirplet, Scaling y Time Shift, con la atenuación y retraso de la GLW respectivamente. Esto se ha realizado para los estudios unidimensionales y se ha generalizado en el caso bidimensional del fuselaje. La asociación de estos coeficientes permite la automatización del análisis de la onda elástica y la modelización de las firmas de daño y EOC sobre la DSF. Además, puesto que las relaciones son directas (sobre todo en el caso unidimensional) permite utilizar parámetros con un significado físicamente claro y no hace necesario acudir a complicadas estadísticas para explicar la influencia del daño y las EOC sobre los parámetros medibles. 
- Se ha utilizado la CT para el procesado de señales provenientes de PZT y FBG. En el caso de las FBGs no existe información previa en la literatura. Con estos datos se ha ajustado una Red Neuronal Artificial que actúa como generador de estados de referencia para cualquier valor de las condiciones EOC que se necesiten (siempre que estén dentro de los valores de entrenamiento utilizados) comportándose como un "interpolador de estados de referencia".

- Se ha definido y validado un esquema de compensación de EOC en el que participa un modelo "data-driven", Redes Neuronales Artificiales, utilizando datos experimentales procesados mediante la Transformada Chirplet. Este tipo de esquema es independiente de la complejidad estructural dependiendo únicamente de la red de sensores utilizada y de las propiedades de los materiales.

- El esquema de compensación se ha aplicado usando temperatura y estado de carga. Se ha comprobado su funcionamiento en casos unidimensionales con diversos tipos de sensores y se ha generalizado al caso bidimensional. Comprobando que funcionaba del mismo modo en todos los casos. Esto se debe a que la definición planteada es generalista y permite la utilización de cualquier conjunto de condiciones ambientales y de operación para cualquier tipo de estructura (en la que la técnica SHM sea aplicable). De hecho cuantas más condiciones existan y más compleja sea su influencia mejor se aprovechará la potencia del modelo de Redes Neuronales Artificiales.

- Se ha comprobado el no confinamiento de las GLW entre los elementos rigidizadores de una estructura aeronáutica. El modelo desarrollado no discrimina si el camino de daño atraviesa un elemento rigidizador o no. Este resultado contradice los resultados existentes hasta la fecha, si bien la señal medida experimentalmente sufre una importante atenuación, que unida a la influencia de los EOC habría impedido hasta ahora ser empleada. Se ha validado experimentalmente que la señal atenuada permite detectar la aparición de daños.

- Se ha desarrollado un sistema de adquisición optimizado con funcionalidades similares a los equipos comerciales disponibles. Mejorando dichos sistemas en aspectos de tiempos de adquisición y velocidad de proceso. Además permite usar redes heterogéneas de sensores para GLW como por ejemplo PZT y FBG. Este sistema de adquisición también utiliza metodologías de interrogación novedosas de la estructura. En vez de efectuar interrogaciones discretas y luego efectuar un promediado, si procede, trabaja con un tren de pulsos generado de manera adecuada. Esto hace que las interrogaciones sean mucho más rápidas. Lo que a su vez permite promediar mucho más las interrogaciones. Cuya consecuencia es que no sea imprescindible un 
amplificador de piezoeléctricos para este tipo de sistema de adquisición. Abaratando notablemente su coste y permitiendo usar hardware estándar para este tipo de ensayos.

Líneas futuras de trabajo:

- En primer lugar, y por ser un resultado que contradice aparentemente lo publicado hasta la fecha. Es imprescindible profundizar en el comportamiento de las ondas elásticas guiadas al atravesar elementos rigidizadores. Se ha comprobado que no quedan confinadas entre estos elementos y esto abre un mundo de posibilidades en cuando a la aplicación de este tipo de técnicas SHM en estructuras reales. Sobre todo simplificando notablemente dicha aplicación.

- En segundo lugar estaría la generalización de la metodología expuesta a las estructuras de material compuesto o híbridas (metal+compuesto). Tal y como está planteada no debería haber demasiados problemas en su aplicación salvo la anisotropía en la propagación de las ondas. Problema que ya se ha tenido en cuenta en el caso del fuselaje analizado. Desarrollando una metodología de captura de las primeras llegadas a cada sensor de la GLW mediante el análisis del diagrama RID (en el planto tiempofrecuencia).

- En tercer lugar profundizar en el desarrollo de sistemas híbridos PZT-FBG. Pues este tipo de sistemas aprovecharían las ventajas de los PZT como emisores de GLW y las ventajas de los FBG como sensores de GLW, principalmente la direccionalidad y el pequeño tamaño de los mismos.

- Finalmente y como paso natural, el objetivo final sería introducir el sistema en una aeronave en operación para evaluar el funcionamiento del esquema propuesto. En este caso se medirían las EOC reales que afectan a la detección del daño y se eliminaría la incertidumbre que tiene el ensayo de las mismas. Es bien conocido que es mucho más complicado simular las condiciones reales de operación de una estructura que medirlas directamente sobre la propia estructura en operación. 


\section{Bibliografía}

[1] Speckmann, H. and Daniel J.P. Structural Health Monitoring for Airliner, from research to user requirements, a European view. Published by American Institute of Aeronautics and Astronautics 2004-6742, Conference on Micro-Nano-Technologies 1-5 November 2004, Monterrey, California. Airbus SAS.

[2] J. M. Menéndez. Structures with integrated sensors: smart structures basics. ETSIA-UPM 2005.

[3] M. C.Y. Niu. Airframe structural design. Honk Kong ConMilit Press Ltd, 1995.

[4] G. Anderson. Providing best value IVHM solutions for aging aircraft. Boeing Phantom Works, 9th Joint FAA/DoD/NASA Conference on Aging Aircraft, Atlanta-Georgia, 6-9 March 2006.

[5] C. Farrar and N. A. J. Lieven. Damage prognosis: the future of Structural Health Monitoring. Phil. Trans. R. Soc. A (2007) 365, 623-632. DOI: 10.1098/rsta.2006.1927

[6] C. Boller et al. Optimisation and simulation approach for the determination of SHM potentials on commercial aircraft. $4^{\text {th }}$ European Workshop on SHM, Krakow, Poland, 2008.

[7] R. J. H. Wanhill. Milestone case histories in Aircraft Structural Integrity. NLR-TP-2002521.

[8] D. Roach and K. Rackow. Health Monitoring of aircraft structures using distributed sensors systems". Sandia National Labs., FAA Airworthiness Assurance Center, 9th Joint FAA / DoD / NASA Conference on Aging Aircraft, Atlanta-Georgia, 6-9 March 2006.

[9] C. Farrar et al. Structural Health Monitoring using statistical pattern recognition. $3^{\text {rd }}$ European Workshop on SHM, Granada, Spain, 2006.

[10] M. Wallace. The load and damage tolerance of a fleet \& usage management system (FUMS). Smith Aerospace, $9^{\text {th }}$ Joint FAA / DoD / NASA Conference on Aging Aircraft, Atlanta, Georgia, 6-9 March 2006.

[11] J. Gomez-Escalonilla, J. García, J. Cabrejas and J. I. Armijo. A full scale parametric-based Fatigue Monitoring System using Neural Networks". EADS-CASA, Proc. 24th symposium of the ICAF, Naples, Italy, 2007.

[12] L. Molent. A unified approach to fatigue usage monitoring of fighter aircraft based on F/A-18 experience. ICAS, Melbourne, Australia, 13-18 Sept. 1998.

[13] C. Boller and M. Burderath. Fatigue in aerostructures-where Structural Health Monitoring can contribute to a complex subject. Phil. Trans. R. Soc. A (2007) 365, 561-587. DOI: 10.1098/rsta.2006.1924

[14] C. R. Farrar and K. Worden. An introduction to Structural Health Monitoring. Phil.Trans. R. Soc. A (2007) 365, 303-315. DOI: 10.1098/rsta.2006.1928

[15] J. M. Menéndez, A. Fernández and Alfredo Güemes. Structural Health Monitoring with embedded fibre bragg gratings and piezoelectric devices. $6^{\text {th }}$ European Workshop on SHM, Dresden, Germany, 2012.

[16] L. Ranson. MRO Special Report: Down on downtime. Flight International, pp.16-22, Sept. 2008. 
[17] N. O'Keeffe. MRO Special Report: Diggin for gold. Flight International, pp.16-22, Sept. 2008.

[18] A. Turner. MRO Special Report: Healthy obsession. Flight International, pp.16-22, Sept. 2008.

[19] P. Richfield. MRO Special Report: Warning signs. Flight International, pp.16-22, Sept. 2008.

[20] L. V. Fausett. Fundamentals of Neural Networks, Architectures, Algorithms and Applications. Pearson Education, 1993.

[21] D. Dumas, F. Lani, T. Monnier and M. Lallart. Simulation of Lamb wave propagation to predict damage detection in thin plate structures. $4^{\text {th }}$ European Workshop on SHM, Krakow, Poland, 2008.

[22] J. García. Monitorización de la integridad estructural: identificación de daño por reconocimiento de patrones. Trabajo de investigación, programa de doctorado ETSIA-UPMCTIA, 2008.

[23] J. Cronkhite, B. Dickson, W. Martin and G Collingwood. Operational evaluation of a Health and Usage Monitoring System (HUMS). NASA Lewis Research Center, NASA/CR1998-207409, 1998.

[24] C. McColl and S. Bradfield. The effects of extreme weather environments/severe flight load spectra on the aging fleet of NOAA's WB-D Hurricane Hunter Aircraft. Tech. Data Analysis, 9th Joint FAA/DoD/NASA Conference on Aging Aircraft, Atlanta-Georgia, 6-9 March 2006.

[25] D. Tipps. UDRI/FAA Operational Loads Monitoring program. Univ. of Dayton, 9th Joint FAA/DoD/NASA Conference on Aging Aircraft, Atlanta-Georgia, 6-9 March 2006.

[26] J. Nelson. US Forrest service Operational Loads Monitoring program. US Forrest Service, 11th Joint FAA/DoD/NASA Conference on Aging Aircraft, Phoenix-Arizona, April 2008.

[27] K. V. Jata, J. S. Knopp, J. C. Aldrin, E. A. Medina and E. A. Lindgren. Transitioning from NDE inspection to online structural health monitoring - Issues and challenges. $3^{\text {rd }}$ European Workshop on SHM, Granada-Spain, 2006.

[28] Jeong-Beom Ihn and Fu-Kuo Chang. Ultrasonic Nondestructive Evaluation: Engineering and Biological Material characterization, chapter 9, "Ultrasonic nondestructive evaluation for Structural health Monitoring: Built-In Diagnostics for Hot-Spot Monitoring in Metallic and Composite Structures, CRC Press 2004, ISBN -13: 978-0-203-50196-2

[29] B. Petitjean, D. Simonet and S. Rolet. SHM developments at EADS. $21^{\text {st }}$ AAAF Colloquium, , Materials for Aerospace Applications, Paris/France, November 22-23, 2005

[30] G. Gautschi. Piezoelectrics sensorics. Springer-Verlag, 2002.

[31] James F. Doyle. Wave propagation in structures. Spectral analysis using fast discrete fourier transform. Springer, 1997.

[32] J. Wiig. Optimization of fault diagnosis in helicopter HUMS. ENSAM, 2006.

[33] J. L. Blackshire, S. Martin \& A. Cooney. Evaluation of crack and corrosion detection sensitivity using piezoelectric sensor arrays. $3^{\text {rd }}$ European Workshop on SHM, Granada, Spain, 2006. 
[34] B. I. Epurenau and K. D'Souza. Nonlinear model updating based on system augmentation for nonlinear damage detection. $3^{\text {rd }}$ European Workshop on SHM, Granada, Spain, 2006.

[35] L. Mujica. A hybrid approach of knowledge-based reasoning for structural assessment. Doctoral Thesis, Univ. Girona, 2006.

[36] G. Manson and K. Worden. Feature selection for a Neural Network Damage diagnostic using a genetic algorithm. $3^{\text {rd }}$ European Workshop on SHM, Granada, Spain, 2006.

[37] G. M. Kamath et al. A neural network based health monitoring methodology for cocured/co-bonded composite aircraft structures. $3^{\text {rd }}$ European Workshop on SHM, Granada, Spain, 2006.

[38] I. Herszberg et al. Application of SHM systems to a composite aircraft structures. $4^{\text {th }}$ European Workshop on SHM, Krakow, Poland, 2008.

[39] O. R. de Lautour and P. Omenzetter. Classification of damage using time series analysis and statistical pattern recognition. $4^{\text {th }}$ European Workshop on SHM, Krakow, Poland, 2008.

[40] L. E. Mújica, J. Rodellar, A. Güemes \& J. López Díez.PCA Based measures: Q Statistics and T Statistics for assessing damages in structures. $4^{\text {th }}$ European Workshop on SHM, KrakowPoland, 2008.

[41] C. C. Olson, L. A. Overbey and M. D. Todd. Applying evolutionary algorithms to optimize active sensing for structural health monitoring applications. $4^{\text {th }}$ European Workshop on SHM, Krakow, Poland, 2008.

[42] J. L. Blackshire, S. Martin and A. Cooney. Characterization and medeling of bonded piezoelectric sensor performance and durability in simulated aircraft environments. $3^{\text {rd }}$ European Workshop on SHM, Granada, Spain, 2006.

[43] R. J. Barthorpe, K. Worden and G. Manson. An investigation into the necessary model fidelity for SHM feature selection. $4^{\text {th }}$ European Workshop on SHM, Krakow, Poland, 2008.

[44] H. Hytti. Efficient signal reconstruction and analysis for integrated SHM system. $4^{\text {th }}$ European Workshop on SHM, Krakow, Poland, 2008.

[45] H. Baier. Potential limits of using structural modal data for health monitoring. TU München, $20^{\text {th }}$ Aircraft Integrated Monitoring Systems, Garmisch-Partenkirchen, May 2000.

[46] A. L. Gyekenyesi et al. Damage Assessment of aerospace structural components by impedance-based Structural Health Monitoring. NASA Glenn Research Center, NASA/TM2005-213579, 2005.

[47] H. Speckmann. SHM: History and Future. $6^{\text {th }}$ International Workshop on SHM, Stanford, 11-13 September 2007.

[48] C. Boller. Impact of SHM on aircraft materials and structures performance. $21^{\text {st }}$ AAAF Colloquium, 2005.

[49] Madam M. Gupta, Liang Jin, Noriyasu Homma and Lofti A. Zadeh. Static and Dynamic Neural Networks, from fundamentals to advanced theory. IEEE Press, Wiley-Interscienc, John Wiley \& Sons, 2003. DOI: 10.1002/0471427950.

[50] S. S. Kessler. Piezoelectric-based in-situ damage detection of composite materials for SHM. MIT, 2002. 
[51] L. Mújica, J. Vehí, W. Staszewski and K. Worden. Multivariate statistics process control for dimensionality reduction on structural health monitoring. $3^{\text {rd }}$ European Workshop on SHM, Granada, Spain, 2006.

[52] A. Iwasaki, K. Hoshino, Y. Shimamura and A. Todoroki. Method for the reduction of the reference data for the damage detection via the unsupervised damage diagnostic method. $4^{\text {th }}$ European Workshop on SHM, Krakow, Poland, 2008.

[53] H. Demuth, M. Beale and M. Hagan. Matlab Neural Networks Toolbox 6 user's guide. The Mathworks. Martin T. Hagan, Howard B. Demuth, Mark H. Beale. Neural Network Design. PWS Publishing. Instructors transparency masters for teaching, 1996.

[54] Steve Lawrence, C. Lee Giles, Ah Chung Tsoi. What Size Neural Network Gives Optimal Generalization? Convergence properties of backpropagation. Technical Report UMIACS-TR96-22 and CS-TR-3617, Institute for Advanced Computer Studies, University of Maryland, 1996.

[55] B. J. Taylor. Methods \& Procedeures for the verification and validation of Artificial Neural Networks. Springer, 2006.

[56] H. Lamb. On Waves in an Elastic Plate. Proceedings of the Royal Society, 1917.

[57] V. Giurgiutiu. Structural Health Monitoring with piezoelectric wafer active sensors. Elsevier, 2008.

[58] J. Cardona, P. Tabuenca and A. Samartín. A numerical solution of the dispersion equation of the guided wave propagation in N-layered media. 2008.

[59] D. Royer, E. Dieulesaint. Elastic Waves in Solids I: Free and guided propagation. Springer-Verlag, 2000.

[60] H. Kolsky. Stress Waves in solids. DOVER, 1963.

[61] H. Goldstein. Mecánica clásica. Ed. Reverté, S.A., 2000.

[62] S.Timoshenko and J. N. Goodier. Theory of elasticity. Mc Graw-Hill Book company Inc., 1951

[63] J.M. W. Brownjohn. Structural Health Monitoring of civil infrastructure. Phil. Trans. R. Soc A 2007 365, 589-622, 2007.

[64] www.rae.es

[65] M. M. Derriso, M. P. Desimio, C. D. McCurry, C. M. S. Kabban and S. E. Olson. Industrial Aged NDE to Information Age SHM. $9^{\text {th }}$ International Workshop on SHM, 2013.

[66] Balagueas, Fritzen and Güemes. Structural Health Monitoring. Wiley, 2010.

[67] J. B. Ihn. Structural Health Monitoring. Overview \& Aerospace Applications. Lecture series for ME/MSE 568: Active and sensing materials and their devices. Univ. of Washington and Boeing Research \& Technology, 2013.

[68] SAE Aerospace Recommended Practice ARP6461. Guidelines for implementation of Structural Health Monitoring on Fixed wind Aircraft. SAE International, 2013.

[69] SAE Aerospace Recommended Practice ARP6245. Guidance on the evolution and integration of Structural Health Monitoring systems for military aircraft. SAE International. Work in progresss. 
[70] A. Abdelrazq. Validating the Structural Behavior and Respnse of Burj Khalifa: Synopsis of the Fusll Scale Structural Health Monitoring Programs. Highrise \& Complex Building, Samsung C \& T, Seoul, Korea, 2010.

[71] A. Rytter. Vibrational based inspection of civil engineering structures. PhD. Thesis, Dep. of Building Technology and Structural Engineering, Univ. of Aalborg, Denmark, 1993.

[72] S. kim, M. Torbol and P. H. Chou. Remote Structural Health Monitoring Systems for Next Generation SCADA. Univ. of California, Irvine. Nationl Tsing Hua University, Hsinchu, Taiwan, 2013.

[73] U.S.NRC. Backgrounder on the Three Mile Island Accident. 2013

[74] International Nuclear Safety Advisory Group. INSAG-7 the Chernobyl Accident: updating of INSAG-1. International Atomic Energy Agency, Vienna, 1992.

[75] IAEA. IAEA International fact finding expert mission of the Fukushima DAI-ICHI NPP accident following the great east Japan Earthquake and Tsunami. International Atomic Energy Agency, 2011.

[76] A. Cusano et al. Applications of Modern FOS Techniques in High Energy Article Physics Detectors for the LHC at CERN. $5^{\text {th }}$ European Workshop on SHM, Sorrento, Naples, Italy, 2010.

[77] K. Hashemi. High precisión optical instrumentation for large structure position monigoring: the BCAM system applied to the CMS Magnet. International Workshop on Accelerator Alignment, SLAC, Stanford, 2006.

[78] M. Pieraccini. Monitoring of Civil Infrastructures by interferometric RADAR: A Review. Hindawi Publishing Corporation, The Scientific World Journal, 2013.

[79] S. Lancini, M. Lazzari, A. Masera, P. Salvaneschi. The KALEIDOS system for structural monitoring of monuments. Proc. Of the 10th International Conference on the Applications of Artificial Intelligence in Engineering, 1995.

[80] M. Hong, Q. Wang, Z. Su, L. Cheng and Y. Ni. In-Situ Guided-Wave-Based Health Monitoring for Train Bogie Structures: Technique Development and Application to BeijingShanghai High-Speed Railway. $9^{\text {th }}$ International Workshop on SHM, 2013, Stanford, California, USA.

[81] J. Castellano and S. Wander. Derailed. NASA System Failure Case Studies, Vol. I Issue 5, 2007.

[82] T. Tamutus. Structural Health Monitoring Case Studies from In-Service Structures. MISTRAS Group, Princeton NJ, 5th CANDU NDT in service inspection workshop, 2014.

[83] P. Hess III. ONR Ship Structural Reliability Program. Office of Naval Research 331.

[84] M. Collette, J. P. Lynch. Lifecycle Support for Naval Ships base on Structural Health Monitoring: Data to Decisions Strategies. Dept. of Naval Architecture and Marine Engineering, Dept. of Civil and Environmental Engineering, University of Michigan.

[85] L. Murawski et al. Investigations of Marine Safety Improvements by Structural health Monitoring Systems. International Journal on Marine Navigation and Safety of Sea Transportation, vol. 6, num. 2, June 2012. 
[86] I. Perez, M. DiUlio, S. Maley, N. Phan. Structural Health Management in the Navy. Structural Health Monitoring, vol. 9 (3), 2010.

[87] H. Sohn et al. A Review of Structural Health Monitoring Literature: 1996-2001. Los Alamos National Laboratory, LA-13976-MS, February 2004.

[88] A. Liu, C. Cheung, M. Martinez. Use of Artificial Neural Networks for Helicopter Load Monitoring. Structures and Materials Performance Laboratory, Institute for Aerospace Research, national Research Council Canada. AIAC14 Fourteenth Australian International Aerospace Congress HUMS, 2011.

[89] L. Molent, B. Aktepe. Review of fatigue monitoring of agile military aircraft. Blackwell Science Ltd. Fatigue Fract Enfnf Mater Struct 23, 767-785, 2000. DSTO.

[90] L. Molent, J. Agius. Structural Health Monitoring of agile military aircraft. Encyclopaedia of SHM, 1999-2014. DOI: 10.1002/9780470061626.shm137

[91] P. F. Licthenwlaner et al. Active damage interrogation method for structural health monitoring. United States Patent number 6006163, Dec. 21, 1999. McDonnell Douglas Corporation.

[92] V. Giurgiutiu. In-situ Structural Health Monitoring, diagnostic utilizing thin piezoelectric sensors. United States Patent Application number US 2003/000930 A1, Jan. 9, 2003.

[93] J. Dunne, J-B. Ihn. Methods and systems for structural health monitoring. United States Patent Application number US 2012/0029877 A1, Feb. 2, 2012.

[94] N. Brigman. Structural Health Monitoring in Commercial Aviation. Master of engineering in civil and environmental engineering, MIT, 2012.

[95] C. Sbarufatti, A. Manes, M. Giglio. Diagnostic System Validation for Damage Monitoring of Helicopter Fuselage. $6^{\text {th }}$ European Workshop on SHM , Dresden, Germany, 2012.

[96] S.C. Reed, D. M. Holford. Guidance for Aircraft Operational Loads measurement Programmes. Airworthines and Structural Integrity Group, Qinetiq Farnborough, 2007. MASAAG paper 109.

[97] R. A. Osegueda, C. M. Ferregut. Research and educational activities at the FAST center for structural integrity of aerospace systems. Univ. of El Paso, Texas. US Air Force Office of Scientific Research, 2002.

[98] NASA-HDBK-7005. Dynamic environmental criteria.2001.

[99] M. W. Hawman et al. Framework for a Space Shuttle Main Engine Health Monitoring System. NASA Lewis Research Center, Contract NAS 3-25626. May 1990.

[100] W. Lance Richards et al. NASA Applications of Structural Health Monitoring Technology. NASA. $9^{\text {th }}$ International Workshop on SHM, Stanford, Sept. 2013.

[101] Columbia accident investigation board report volume I. NASA, August 2003. http://www.nasa.gov/columbia/home/CAIB Vol1.html

[102] J. Miller, J. Patterson and R. Garbos. Wireless Power and Data System for Integrated System health Management of systems Operating in the Harsh Environment of Deep Space. NASA Marshall Space Flight Center, ISHM Engineering and AMI Research and Development, LLc. Annual Conference of the Prognostics and Health Management Society 2013. 
[103] S. Gopalakrishnan, M. Ruzzene, S. Hanagud. Computational Techniques for Structural Health Monitoring. Springer Series in Reliability Engineering, Springer-Verlag London Limited 2011.

[104] M. A. Kamizi, G. R. C. Possetti, M. Muller, J. L. Fabris. Fiber Bragg grating sensors probed by artificial intelligence to detect and localize impacts on structures. Journal of Microwaves, Optoelectronics and Electromagnetic Applications, Vol. 14, SI-1, July 2015.

[105] A. Ahmed, J. G. Bakuckas Jr, J. Awerbuch, A. C. Lau and T-M Tan. Fatigue Testing of a Stiffened Lap Joint Curved Fuselage Structure. $46^{\text {th }}$ AIAA/ASME/ASCE/AHS/ASC Structures, Structural Dynamics \& Materials Conference, April 2005, Austin, Texas.

[106] A. Galvagni and P. Cawley. Guided Wave Permanently Installed Pipeline Monitoring System. Imperial College London with the support of BP, RCNDE and EPSRC, 2011.

[107] S. C. Bradford V. Time-frequency analysis of Systems with Changing Dynamic Properties. PhD Theis, CALTECH, Pasadena, California, July 2006.

[108] V. Julio, C. Catherine, W. Weichao. Evolutionary Computation Methods for Helicopter Loads Estimation. National Research Council, Canada, 2011.

[109] M. M. Ratwani. Effect of Damage on Strength and Durability. R-Tec, NATO, RTO-ENAVT-156. 2010.

[110] F. B. Cegla. 'Piping Hot' Ultrasonic thickness monitoring at high temperatures [up to $\left.600^{\circ} \mathrm{C}\right]$. Dynamics and NDE Group, Imperial College, London, 2011.

[111] T. Ganev, F. Ymazaki, H. Ishizaki and M. Kitazawa. Response Analysis of the HigashiKobe gridge and surrounding soil in the 1995 Hyyogoken-Nanbu earthquake. Earthquake engieneering and structural Dynamics 27, 557-576, 1998.

[112] A. Tuck and V. Kekoc. KC-30A Structural Health Monitoring System Verification and Validation. AIAC14, $7^{\text {th }}$ DSTO International Conference on Health \& Usage Monitoring, 2011.

[113] J. Gómez-Escalonilla, J. García, M. M. Andrés and J. I. Armijo. Strain predictions using Artificial Neural Networks for a full-scale fatigue monitoring system. AIAC13, 6th DSTO International Conference on Health \& Usage Monitoring, 2009.

[114] Los Alamos Dynamics. Concluding Remarks on Structural health Monitoring Using Statistical Pattern Recognition. $7^{\text {th }}$ European Workshop on SHM, Nantes, France, 2014.

[115] C. K. Grimes. Studies on the propagation of elastic waves in solid media. PhD Thesis, CALTECH, Pasadena, California, 1964.

[116] S. Han. Finite Element Analysis of lamb waves acting within a thin aluminium plate. Thesis, Air Force Institute of Technology, Wright-Patterson AFB, Ohio, 2007.

[117] H. GravenKamp. Numerical methods for the simulation of ultrasonic guided waves. Dissertation, BAM Bundesanstalt für Materialsforschung und prüfung, 2014.

[118] W. H. Prosser et al. Structural health management for future aerospace vehicles. NASA Langley, CSIRO Industrial Physics and Lockheed Martin Aeronautics, 2004.

[119] E. C. Lundgren. Design and Maintainability considerations Regarding the Effects of Suborbital Flights on Composite Constructed Vehicles. DTRT57-05-D-30103, Task 27B, 2010. 
[120] M. Scheerer. SHM of Composite Structures using Acoustic Emission Methods. Austrian Research Centers GmbH - ARC, European Ground Testing Instrumentation Aerospace Testing Expo, Munich, April 2008.

[121] C. Boller. Structural Health Management of Ageing Aircraft and Other Infrastructure. Monograph on Structural Health Monitoring, Inst. of Smart Structures and Systems, Bangalore / India, 2008.

[122] K. Worden, C. R. Farrar, G. Manson and G. Park. The fundamental axioms of structural health monitoring. Proceedings of the Royal Society, A(2007) 463, 1639-1664.

[123] A. Lewis. Structural Health Management / Monitoring. The Boeing company, EASA presentation, 2008,

[124] G. Bartelds. Aircraft structural health monitoring, prospects for smart solutions from a European viewpoint. NLR TP 97489, 1997.

[125] H. Speckmann. Structural Health Monitoring (SHM). IMRBPB Meeting, EASA, Cologne, April 2007.

[126] T. E. Munns, C. B. Gause, A. Ray, et al. Health Monitoring for Airframe Structural Characterization. ARINC Inc, Luna Innovations and Pennsylvania State University. NASA / CR-2002-211428

[127] José María Gutiérrez, Rafael Cano, Antonio S. Cofiño, Carmen M. Sordo (2004). Redes probabilísticas y neuronales en las ciencias atmosféricas. Universidad de Cantabria, Instituto Nacional de Meteorología. 2004. ISBN: 84-8320-281-6

[128] J. García. Obtención de funciones de transferencia para un sistema de monitorización de fatiga. Proyecto fin de carrera, ETSIA-UPM, 2006.

[129] S. J. Russell and P. Norvig. Artificial Intelligence A Modern Approach. Prentice Hall, 1995.

[130] N. J. Nilsson. The quest for artificial intelligence a history of ideas and achievements. Stanford University. Published by Cambridge University Press, 2010.

[131] B. G. Buchanan. A (Very) Brief History of Artificial Intelligence. AI Magazine Volume 26 Number 4, AAAI, 2005.

[132] R. Miikkulainen. Artificial Intelligence.University of Texas course CS343, 2015. http://www.cs.utexas.edu/users/risto/cs343/

[133] C. Smith, B. McGuire, C. Smith, T. Huang, G. Yang. The history of artificial intelligence. University of Washington, History of Computing Course CSEP 590A, 2006. https://www.cs.washington.edu/node/160

[134] T. Lozano-Pérez and L. Kaelbling. 6.825 Techniques in Artificial Intelligence. Massachusetts Institute of Technology: MIT OpenCourseWare, 2002. http://ocw.mit.edu/courses/electrical-engineering-and-computer-science/6-825-techniques-inartificial-intelligence-sma-5504-fall-2002/index.htm

[135] L. A. Zadeh. Fuzzy sets. Information and Control 8, 338-353, 1965.

[136] J. I. Armijo Torres, J. Gomez-Escalonilla Martín, J. García Alonso. Method and system for monitoring a structure. United States Patent No. : US8855852B2, Oct. 7, 2014. 
[137] H. Sohn, K. Worden, C. R. Farrar. Statistical Damage Classification under Changing Environmental and Operational Conditions. Journal of Intelligent Materials and Structures, LAUR-02-1992.

[138] P. H. Kirkegaard and A. Rytter. Vibration based damage assessment of civil engineering structures using Neural Networks. Fracture \& Dynamics paper No. 53, April 1994.

[139] Z. Dworakowski et al. Application of artificial neural networks for damage indices classification with the use of Lamb waves for the aerospace structures. Key Engineering Materials Vol. 588 (2014) pp. 12-21.

[140] Z. Su and L. Ye. Lamb Wave Propagation-based Damage Identification for Quasiisotropic CF/EP Composite Laminates Using Artificial Neural Algorithm: Part II Implementation and Validation. Journal of Intelligent Materials and Structures, 2005; 16;113; DOI:10.1177/1045389X05047600.

[141] C. Sbarufatti, A. Manes, M. Giglio. Performance optimization of a diagnostic system based upon a simulated strain field for fatigue damage characterization. Mechanical Systems and Signal Processing 40 (2013) 667-690. DOI: http://dx.doi.org/10.1016/j.ymssp.2013.06.003

[142] D. A. Tibaduiza, M. A. Torres-Arredondo, L. E. Mujica, J. Rodellar, C. P. Fritzen. A study of two unsupervised data driven statistical methodologies for detecting and classifying damages in structural health monitoring. Mechanical Systems and Signal Processing 41 (2013) 467-484. DOI: http://dx.doi.org/10.1016/j.ymssp.2013.05.020

[143] S. Liu, C. Du, J. Mou, L. Martua, J. Zhang, F. L. Lewis. Diagnosis of structural cracks using wavelet transforma dn neural networks. NDT\&E International 54 (2013) 9-18. DOI: http://dx.doi.org/10.1016/j.ndteint.2012.11.004

[144] M. A. Torres-Arredondo, D. A. Tibaduiza, M. McGugan, H. Toftegaard, K. K. Borum , L. E. Mjica, J. Rodellar, C. P. Fritzen. Multivariate data-driven modelling and pattern recognition for damage detection and identification for acoustic emission and acousto-ultrasonics. Smart Materials and Structures 22 (2013) DOI: http://dx.doi.org/10.1088/0964-1726/22/10/105023

[145] A. G. Haig, P. Stavrou. Defect detection for aircraft components: An approach using ultrasonic guided waves and neural networks. European Community's Seventh Framework Programme managed by REA-Research Executive Agency http://ec.europa.eu/research/rea ([FP7- SME-2008-1] under grant agreement no [232212].

[146] V. Lopes Jr, G. Park, H. H. Cudney, D. J. Inman. Structural integrity identification based on smart materials and neural networks. IMAC-XVIII Conference, San Antonio, Texas, 2000.

[147] D. A. Sofge. Structural Health Monitoring Using Neural Network Based Vibrational System Identification. Proceedings of the Australia and New Zealand Conference on Intelligent Information Systems, 1994.

[148] K. Worden and G. Manson. The application of machine learning to structural health monitoring. Philosophical transactions of The Royal Society A. 2007 365, 515-537. DOI:10.1098/rsta.2006.1938.

[149] M. Schawabacher and KL Goebel. A Survey of Artificial Intelligence for Prognostics. NASA Ames Research Center.

[150] G. R. Kirikera. An Artificial Neural System with Distributed Parallel Processing for StructuralHealth Monitoring. Thesis, University of Cincinnati, 2003. 
[151] Z. Su, L. Ye, Y. Lu. Guided Lamb waves for identification of damage in composite structures: A review. Journal of Sound and Vibration 295 (2006) 753-780. DOI:10.1016/j.jsv.2006.01.020

[152] MIT OpenCourseWare 12.510. Introduction to Seismology. Spring 2008.

[153] H. Sohn. Effects of environmental and operational variability on structural health monitoring, Philosophical transactions of the Royal Society A 2007 365, 539-560. DOI: 10.1098/rsta.2006.1935.

[154] O. Karpenko. Signal analysis in guided wave structural health monitoring. Thesis. Michigan State University, 2013. http://etd.lib.msu.edu/islandora/object/etd\%3A167/datastream/OBJ/view

[155] F. Kerber. Dispersive Wave Analysis using the Chirplet Transform. Thesis. Georgia Institute of Technology, 2006. DOI: 10.1063/1.2718031.

[156] B. Xu, V. Giurgiutiu, L. Yu. Lamb Waves Decomposition and Mode identification using Matching Pursuit Method. University of South Carolina, 2009. DOI: 10.1117/12.816087.

[157] A. Raghavan and C. E. S. Cesnik. Guided-wave signal processing using chirplet matching pursuits and mode correlation for structural health monitoring. University of Michigan. Smart Materials and Structures 16 (2007) 355-366. DOI: 10.1117/12.657404.

[158] S. Mann and S. Haykin. The Chirplet Transform: A Generalization of Gabor's Logon Transform. McMaster University. Vision Interface 1991. http://citeseerx.ist.psu.edu/viewdoc/download?doi=10.1.1.18.5028\&rep=rep1\&type=pdf.

[159] S. Mann and S. Haykin. The Chirplet Transform: Physical Considerations. IEEE Trans. on signal processing, vol. 43, no. 11, November 1995. DOI: 10.1109/78.482123.

[160] A. J. Croxford, J. Moll, P. D. Wilcox, J. E. Michaels. Efficient temperature compensation strategies for guided wave structural health monitoring. Ultrasonics 50 (2010) 517-528. DOI: 10.1016/j.ultras.2009.11.002.

[161] Y. Lu, J. E. Michaels. A methodology for structural health monitoring with diffuse ultrasonic waves in the presence of temperature variations. Ultrasonics 43 (2005) 717-731. DOI: 10.1016/j.ultras.2005.05.001.

[162] P. Kijanka, R. Radecki, P. Packo, W. J. Staszewski and T. Uhi. GPU-based local interaction simulation approach for simplified temperature effect modelling in Lamb wave propagation used for damage detection. Smart materials and structures 22 (2013). DOI: 10.1088/0964-1726/22/3/035014.

[163] S. Haykin. Neural Networks. A comprehensive Foundation. McMaster University. Prentice Hall 1994. ISBN-13: 9780132733502.

[164] S. Roy, P. Ladpli, K. Lonkar and F. K. Chang. Structural Damage Detection Using Ultrasonic Guided Waves under varying ambient temperature and loading environments. 9 $^{\text {th }}$ International Workshop on SHM, 2013.

[165] Matlab Discrete TFDs GNU collection, Copyright (C) 1997-2013 Jeffrey C. O'Neill et al.

[166] The LAMB Matlab toolbox 1st release Beta version 0.1 (GPL), José Luis Prego Borges. Universitat Politecnica de Catalunya. 2010. 
[167] O. Diligent. Interaction between fundamental lamb modes and defects in plates. $\mathrm{PhD}$ Thesis, London Imperial College, 2003. http://www3.imperial.ac.uk/pls/portallive/docs/1/50535698.PDF.

[168] E. J. Cross, G. Manson, K. Worden and S. G. Pierce. Features for damage detection with insensitivity to environmental and operational variations. Proc. of the Royal Society, November 2012. DOI: $10.1098 /$ rspa.2012.0031.

[169] A. Fernández López: Detección de daño en estructuras aeronáuticas mediante sensors piezoeléctricos y de fibra óptica. Tesis Doctoral, ETSIA-UPM, Madrid 2009.

[170] M. Culpepper and S-G. Kim. 2.76 Multi-Scale System Design, Fall 2004. (Massachusetts Institute of Technology: MIT OpenCourseWare), http://ocw.mit.edu. License: Creative Commons BY-NC-SA.

[171] V. V. Vasiliev and E. V. Morozov. Mechanics and analysis of composite materials. ELSEVIER, ISBN: 0-08-042702-2, 2001.

[172] R. P. Dalton.: The Propagation of Lamb Waves through metallic aircraft structure. PhD. Thesis, Dpt. Of Mechanical Engineering, Imperial College of Science and Technology, London 2000.

[173] P. D. Wilcox. Lamb Wave inspection of large structures using permanently attached transducers. PhD., Dpt. of Mechanical Engineering, Imperial College of Science, Technology and Medicine, London, 1998.

[174] Acellent Technologies. Acess 2.0 user's manual. 2007

[175] Acellent Technologies. Scangenie setup and operation guide. 2007

[176] National Instruments 6366 acquisition card specifications http://sine.ni.com/nips/cds/view/p/lang/es/nid/209076

[177] B. Hernández, J. García, A. Fernández López, A. Güemes: Detección de daño en materiales compuestos por medio de sistemas híbridos PZT-FBG. MATCOMP, 2013.

[178] www.arduino.cc/en/Main/ArduinoBoardUno

[179] www.tml.jp

[180] UK DEF-STAN 00-970 Part 1, Section 3, Leaflets 38-41-42.

[181] Boeing Commercial Airplanes. Statistical Summary of Commercial Jet Airplanes Accidents. Worldwide Operations 1959-2014. August 2015. http://www.boeing.com/resources/boeingdotcom/company/about_bca/pdf/statsum.pdf 


\section{Anexo1: Obtención de las curvas de dispersión.}

Se incluye aquí la revisión de las ecuaciones que gobiernan la propagación de ondas elásticas a partir de los estudios de Lamb [56]. Aunque este tipo de discusiones se han indicado en multitud de estudios desde la publicación inicial de Lamb, es interesante incluirlo debido a la importancia de conocer las simplificaciones que se realizan en dichos estudios y dónde tienen lugar para que, en caso de que interese no realizarlas saber qué tipo de ecuaciones utilizar. Una discusión mucho más detallada para multitud de casos se puede encontrar en [57]. En este apartado sólo se obtendrán las ecuaciones que se utilizan para las estructuras estudiadas y se indica el método de cálculo de las velocidades de dispersión de las ondas elásticas.

En primer lugar se plantea el dominio en el que se va a trabajar.

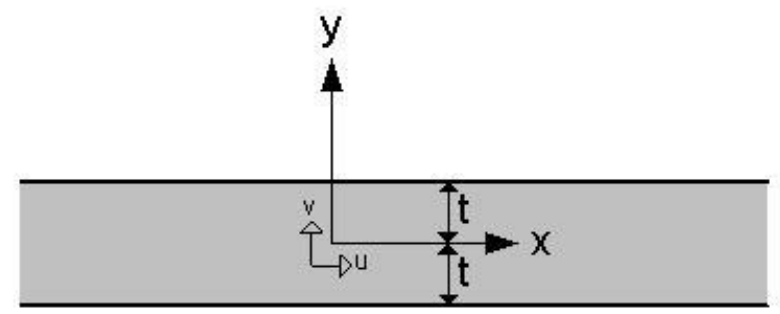

Figura 100 - Dominio de cálculo para las ondas elásticas

Considerando el teorema de conservación de la cantidad de movimiento (segunda ley de Newton), el balance de todas las fuerzas internas más las externas es igual a la variación de la cantidad de movimiento [61]:

$$
\bar{F}_{\mathrm{i}}+\bar{F}_{e x t}=\frac{d \bar{P}}{d t}
$$

Reescribiendo esta ecuación en términos de esfuerzos se obtiene la ecuación de ondas elástodinámica[60]:

$$
\sigma_{j i, j}+F_{i}^{e x t}=\rho \partial_{t t} u_{i}
$$

Para un material elástico lineal e isotrópico las ecuaciones de esfuerzos-deformaciones son las siguientes [62]:

$$
\begin{array}{ll}
\sigma_{x x}=\lambda \cdot\left(u_{x}+v_{y}\right)+2 \cdot \mu \cdot u_{x} & \Rightarrow \sigma_{x x, x}=\lambda \cdot\left(u_{x x}+v_{y x}\right)+2 \cdot \mu \cdot u_{x x} \\
\sigma_{x y}=\lambda \cdot\left(u_{y}+v_{x}\right) & \Rightarrow \sigma_{x y, x}=\lambda \cdot\left(u_{y x}+v_{x x}\right) \Rightarrow \sigma_{x y, y}=\lambda \cdot\left(u_{y y}+v_{x y}\right) \\
\sigma_{y y}=\lambda \cdot\left(u_{x}+v_{y}\right)+2 \cdot \mu \cdot v_{y} & \Rightarrow \sigma_{y y, y}=\lambda \cdot\left(u_{x y}+v_{y y}\right)+2 \cdot \mu \cdot v_{y y}
\end{array}
$$


Los desplazamientos según la teoría de ondas pueden ser derivados de los siguientes potenciales [58][59]:

$\bar{U}=(u, v, w)=\nabla \phi+\nabla \wedge \bar{\psi}=\left(\phi_{x}, \phi_{y}, \phi_{z}\right)+\nabla \wedge\left(\psi^{1}, \psi^{2}, \psi^{3}\right)=\left(\phi_{x}+\psi_{y}^{3}{ }_{y}-\psi_{z}^{2}, \phi_{y}+\psi_{z}^{1}-\psi_{y}^{3}, \phi_{z}+\psi_{x}^{2}-\psi_{y}^{1}\right)$

Atendiendo a la geometría del problema:

$$
\begin{aligned}
& \phi=\phi(x, y) \Rightarrow \phi_{z}=0 \\
& \bar{\psi}=\bar{\psi}(x, y) \Rightarrow \psi_{z}^{2}=0 ; \psi_{z}{ }_{z}=0
\end{aligned}
$$

Y teniendo en cuenta sólo los desplazamientos en el plano $(\mathrm{x}, \mathrm{y})$, se considera únicamente la tercera componente del vector potencial, de aquí en adelante:

$$
\psi^{3}=\psi
$$

Obtenemos así la solución de ondas viajeras que propone Lamb [56]:

$$
\begin{aligned}
& u=\phi_{x}+\psi_{y} \\
& v=\phi_{y}-\psi_{x}
\end{aligned}
$$

Si se substituyen los desplazamientos en la ecuación elástodinámica se obtienen sendas ecuaciones de ondas para los potenciales:

$$
\begin{aligned}
& \rho \cdot \phi_{t t}=(\lambda+2 \cdot \mu) \nabla^{2} \phi \\
& \rho \cdot \psi_{t t}=\mu \nabla^{2} \psi
\end{aligned}
$$

En primer lugar se supone periodicidad en el tiempo:

$$
\begin{aligned}
& \phi=\phi(x, y) e^{i \tau t} \Rightarrow \phi_{t t}=-\tau^{2} \phi(x, y) e^{i \tau t} \\
& \psi=\psi(x, y) e^{i \tau t} \Rightarrow \psi_{t t}=-\tau^{2} \psi(x, y) e^{i \tau t}
\end{aligned}
$$

Y se substituye en las ecuaciones de ondas:

$$
\begin{aligned}
& \nabla^{2} \phi+\frac{\rho \tau^{2}}{\lambda+2 \mu} \phi=0 \Rightarrow h^{2}=\frac{\rho \tau^{2}}{\lambda+2 \mu} \Rightarrow \nabla^{2} \phi+h^{2} \phi=0 \Rightarrow\left(\nabla^{2}+h^{2}\right) \phi=0 \\
& \nabla^{2} \psi+\frac{\rho \tau^{2}}{\mu} \psi=0 \Rightarrow k^{2}=\frac{\rho \tau^{2}}{\mu} \Rightarrow \nabla^{2} \psi+k^{2} \psi=0 \Rightarrow\left(\nabla^{2}+k^{2}\right) \psi=0
\end{aligned}
$$

En segundo lugar, se supone también que la solución también es periódica en x:

$$
\begin{aligned}
& \phi=\phi(y) e^{i \xi x} \Rightarrow \nabla^{2} \phi=-\xi^{2} \phi e^{i \xi x}+\phi_{y y} e^{i \xi x} \\
& \psi=\psi(y) e^{i \xi x} \Rightarrow \nabla^{2} \psi=-\xi^{2} \psi e^{i \xi x}+\psi_{y y} e^{i \xi x}
\end{aligned}
$$

Substituyendo en la ecuación de ondas de nuevo: 


$$
\begin{aligned}
& \phi_{y y}+\left(h^{2}-\xi^{2}\right) \phi \Rightarrow \alpha^{2}=\xi^{2}-h^{2} \Rightarrow \phi_{y y}=\alpha^{2} \phi \\
& \psi_{y y}+\left(k^{2}-\xi^{2}\right) \psi \Rightarrow \beta^{2}=\xi^{2}-k^{2} \Rightarrow \psi_{y y}=\beta^{2} \psi
\end{aligned}
$$

Ahora se retoma la ecuación de esfuerzos-deformaciones y se substituyen las soluciones obtenidas a partir de la ecuación de ondas:

$$
\begin{gathered}
u=\phi_{x}+\psi_{y} \Rightarrow u_{x}=\phi_{x x}+\psi_{y x} ; u_{y}=\phi_{x y}+\psi_{y y} \\
v=\phi_{y}-\psi_{x} \Rightarrow v_{x}=\phi_{y x}-\psi_{x x} ; v_{y}=\phi_{y y}-\psi_{x y} \\
\sigma_{x y}=\lambda\left(\phi_{x y}+\psi_{y y}+\phi_{y x}-\psi_{x x}\right) \Rightarrow \sigma_{x y}=2 \mu i \xi \phi_{y}+\mu \xi^{2} \psi+\mu \beta^{2} \psi \Rightarrow \frac{\sigma_{x y}}{\mu}=\left(\xi^{2}+\beta^{2}\right) \psi+2 i \xi \phi_{y} \\
\sigma_{y y}=\lambda\left(\phi_{x x}+\phi_{y y}\right)+2 \mu\left(\phi_{y y}-\psi_{x y}\right) \Rightarrow \sigma_{y y}=-\lambda h^{2} \phi+2 \mu \alpha^{2} \phi-2 \mu i \xi \psi_{y} \Rightarrow \frac{\sigma_{y y}}{\mu}=\left(\xi^{2}+\beta^{2}\right) \phi-2 i \xi \psi_{y}
\end{gathered}
$$

En estas últimas ecuaciones se buscarán soluciones simétricas y antisimétricas.

En primer lugar las simétricas

$$
\begin{aligned}
& \phi=A \cosh (\alpha y) e^{i \xi x} \\
& \psi=A \sinh (\alpha y) e^{i \xi x}
\end{aligned}
$$

Con la condición de contorno de borde libre en la superficie del dominio:

$$
y= \pm t \Rightarrow \sigma_{y y}=0 ; \sigma_{x y}=0
$$

Se imponen las condiciones de contorno en las ecuaciones en esfuerzos:

$$
\begin{aligned}
& \frac{\sigma_{x y}}{\mu}=\left(\xi^{2}+\beta^{2}\right) \psi+2 i \xi \phi_{y}=\left.0\right|_{y= \pm t} \Rightarrow\left(\xi^{2}+\beta^{2}\right) A \sinh (\alpha t)=-2 i A \alpha \xi \sinh (\alpha t) \\
& \frac{\sigma_{y y}}{\mu}=\left(\xi^{2}+\beta^{2}\right) \phi-2 i \xi \psi_{y}=\left.0\right|_{y= \pm t} \Rightarrow\left(\xi^{2}+\beta^{2}\right) A \cosh (\alpha t)=2 i \beta B \xi \cosh (\beta t)
\end{aligned}
$$

Si se dividen ambas ecuaciones obteniendo la solución simétrica de Lamb:

$$
\frac{\tanh (\beta t)}{\tanh (\alpha t)}=\frac{4 \xi^{2} \alpha \beta}{\left(\xi^{2}+\beta^{2}\right)^{2}}
$$

A continuación se repite el proceso para las soluciones antisimétricas:

$$
\begin{aligned}
& \phi=A \sinh (\alpha y) e^{i \xi x} \\
& \psi=A \cosh (\alpha y) e^{i \xi x}
\end{aligned}
$$

Con la condición de contorno de borde libre en la superficie del dominio: 


$$
y= \pm t \Rightarrow \sigma_{y y}=0 ; \sigma_{x y}=0
$$

Se imponen las condiciones de contorno en las ecuaciones en esfuerzos:

$$
\begin{aligned}
& \frac{\sigma_{x y}}{\mu}=\left(\xi^{2}+\beta^{2}\right) \psi+2 i \xi \phi_{y}=\left.0\right|_{y= \pm t} \Rightarrow\left(\xi^{2}+\beta^{2}\right) B \cosh (\beta t)=-2 i A \alpha \xi \cosh (\alpha t) \\
& \frac{\sigma_{y y}}{\mu}=\left(\xi^{2}+\beta^{2}\right) \phi-2 i \xi \psi_{y}=\left.0\right|_{y= \pm t} \Rightarrow\left(\xi^{2}+\beta^{2}\right) A \sinh (\alpha t)=2 i \beta B \xi \sinh (\beta t)
\end{aligned}
$$

Si se dividen ambas ecuaciones obteniendo la solución antisimétrica de Lamb:

$$
\frac{\tanh (\beta t)}{\tanh (\alpha t)}=\frac{\left(\xi^{2}+\beta^{2}\right)^{2}}{4 \xi^{2} \alpha \beta}
$$

Es importante establecer un método eficiente para el cálculo de las relaciones de dispersión que definen las velocidades de estas ondas elásticas. En concreto las velocidades de fase y de grupo:

- Velocidad de fase. Velocidad a la que cambia la forma de la onda.

- Velocidad de grupo. Velocidad a la que se transmite la energía de la onda [57].

En nuestro caso será de gran utilidad la velocidad de grupo puesto que definirá la llegada de la onda al sensor, y define el punto inicial a partir del cual se analiza la forma de dicha onda.

1. Para calcular estas velocidades se propone el siguiente método:

2. Discretización del dominio de velocidades de fase-frecuencias.

3. Cálculo de los funcionales de Lamb para las soluciones simétricas y antisimétricas:

$$
\begin{gathered}
F L_{\text {simétrico }}=\frac{\tanh (\beta t)}{\tanh (\alpha t)}-\frac{4 \xi^{2} \alpha \beta}{\left(\xi^{2}+\beta^{2}\right)^{2}} \\
F L_{\text {antisimétrico }}=\frac{\tanh (\beta t)}{\tanh (\alpha t)}-\frac{\left(\xi^{2}+\beta^{2}\right)^{2}}{4 \xi^{2} \alpha \beta}
\end{gathered}
$$

4. Búsqueda de los mínimos de los funcionales.

5. Asociación y suavizado de curvas para las velocidades de fase

6. Aproximación de las velocidades de fase y cálculo de las de grupo

Los valores obtenidos se pueden verificar mediante simulaciones de ondas elásticas utilizando resultados disponibles en la literatura [116] [117]. 


\section{Anexo 2: Generación/medición de GLW mediante sensores PZT.}

Para la técnica SHM que hemos seleccionado, GLW, se utilizarán sensores piezoeléctricos de tipo PZT trabajando en modo pitch-catch o transmisor-receptor. Esto implica que los utilizaremos tanto para generar ondas elásticas guiadas de Lamb como para medirlas.

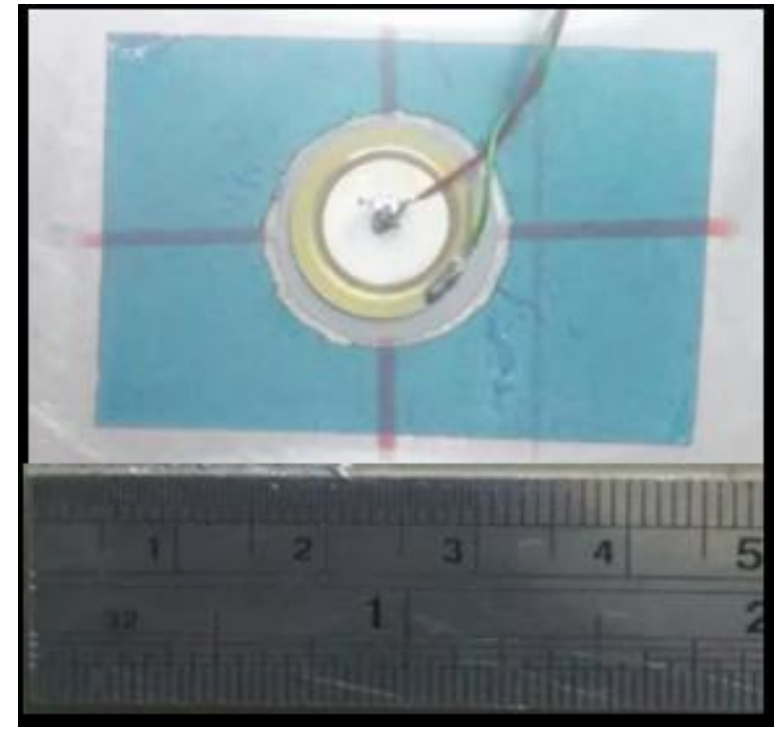

Figura 101 - Sensor PZT en forma de disco pegado sobre la estructura

Aquí se ofrece una breve discusión sobre los aspectos prácticos que se han utilizado en el cuerpo de la tesis, se puede encontrar un estudio mucho más profundo en trabajos publicados previamente[169], así como una caracterización completa de su comportamiento.

Este tipo de sensores se fundamentan en el efecto piezoeléctrico [30] según el cual una deformación en el material provoca una diferencia de potencial en el material.

Nosotros utilizaremos estos transductores de dos maneras:

- Como actuadores, aprovechando el efecto piezoeléctrico inverso. A partir de una diferencia de potencial controlada y aplicada al PZT generamos una onda elástica en la estructura.

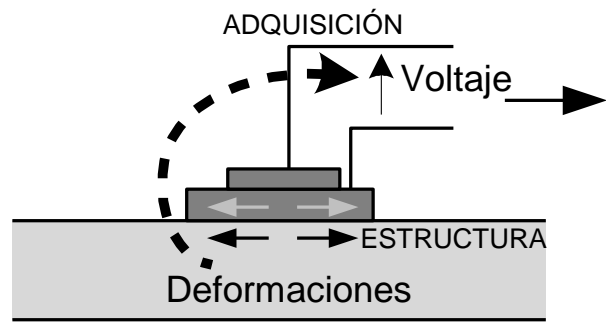

Figura 102 - Efecto piezoeléctrico inverso, PZT como sensor, medición de GLW. 
- Como sensores, en este caso, aprovechando el efecto piezoeléctrico directo. La deformación de la onda elástica, al pasar por el piezoeléctrico lo deforma y genera una diferencia de potencial.

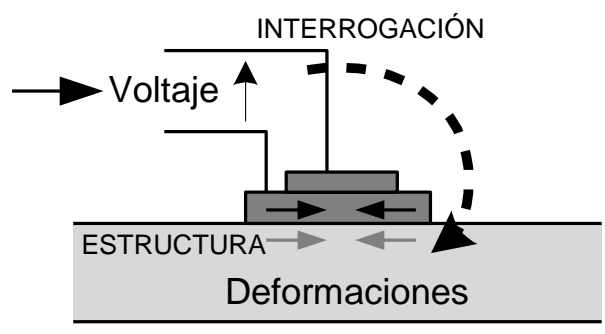

Figura 103 - Efecto piezoeléctrico directo, PZT como actuador generación de GLW.

La capacidad de funcionar tanto como actuador como sensor es una de las razones fundamentales para su selección para la técnica SHM que estamos aplicando pero existen otras [169]:

- Presenta una gran sensibilidad. Se puede encontrar en la literatura, comparativas en cuanto a sensibilidad, voltaje que produce el PZT ante una cantidad determinada de deformación llegando a ser de hasta 5 voltios por microdeformación [30]. Comparativamente podemos decir que es aproximadamente 1 millón de veces más sensible a la deformación que un extensímetro clásico.

- Tiene un rango de frecuencias de trabajo muy amplio. Esto permite efectuar interrogaciones a muy alta frecuencia, en el rango del $\mathrm{KHz}$ al $\mathrm{MHz}$. Así se puede trabajar con ondas elásticas guiadas de Lamb y aun así estar lejos de la frecuencia de resonancia del sensor. Que suele estar por encima del MHz [30].

- Se pueden montar fácilmente sobre la estructura. Teniendo en cuenta el tipo de piezoeléctricos que utilizamos con una configuración de disco de pequeño espesor (ver Figura 101) y el tipo de estructura de trabajo que nos ocupa (paneles rigidizados de pequeño espesor) resultan sencillos de instalar. Y además permiten un acoplamiento óptimo entre estructura y sensor debido a su gran rigidez.

- En el rango de frecuencias de trabajo presentan una relación lineal entre esfuerzos y deformaciones. Aunque nuestro objetivo no es evaluar los valores concretos de esfuerzo o deformación inducidos por el sensor esta relación es de gran importancia puesto que asegura que el uso como sensor o como actuador es equivalente en ambos sentidos. Transforma de un modo muy similar los voltajes en ondas elásticas y viceversa.

- Los PZT son muy baratos y fáciles de conseguir. Ello facilita la realización de experimentos. 
Sin embargo también tienen una serie de desventajas que habrá que tener en cuenta a la hora de utilizarlos[169]:

- El tipo seleccionado, PZT, no permite realizar medidas estáticas. Esto es una desventaja puesto que si fuese capaz no habría más que filtrar la medida del mismo para obtener el estado de carga estático de la estructura, información necesaria a la hora de compensar las EOC.

- Se degradan con el tiempo. El efecto piezoeléctrico se va perdiendo según el material va envejeciendo.

- Presentan una temperatura máxima de trabajo, la temperatura de Curie[30], que se sitúa entre los $250^{\circ} \mathrm{C}$ y $330^{\circ} \mathrm{C}$, a partir de la cual pierde la polarización. Esto limita las zonas de trabajo de este tipo de sensores aunque para el tipo de estructuras que evaluamos no es crítico.

- Sus propiedades cambian con la temperatura de trabajo aun sin alcanzar la temperatura de Curie. Esto implica que es un factor adicional a considerar en la compensación de las EOC afectando de modo indirecto a las interrogaciones.

- Son sensores integradores con un tamaño finito lo que implica que existirá una interacción entre la longitud de onda de la GLW y el tamaño del sensor. Para evitar acoplamientos indeseados siempre se trabajará con longitudes de onda mayores que el tamaño del sensor para asegurar una correcta adquisición de la misma. Trabajos previos indican que la longitud de onda del pulso de interrogación debe ser al menos cinco veces mayor que el diámetro del disco del PZT. Esto deberá ser tenido en cuenta a la hora de efectuar la definición de las señales de interrogación de la estructura para el tipo de sensores PZT que se utilicen.

Otro aspecto muy importante es la manera en la que se transmite la deformación del sensor a la estructura y como la deformación de la estructura se transmite al sensor.

En cuanto a un PZT en forma de disco pegado a una placa delgada, trabajando como actuador, podríamos considerarlo como un generador de ondas en el contorno del mismo [169].

Sin embargo el mismo disco PZT trabajando como sensor, pegado sobre una placa delgada, está funcionando como un sensor que integra superficialmente las deformaciones que las ondas elásticas producen bajo el mismo al atravesarlo en su viaje [169].

Estas dos últimas consideraciones pueden ser de gran utilidad a la hora de entender cómo se generan las GLW en la estructura y como se miden. 
Seguidamente echaremos un vistazo a las ecuaciones que gobiernan tanto el efecto piezoeléctrico directo como el inverso y que permiten la conversión de voltajes en GLW y viceversa [170].

El comportamiento del PZT es la combinación de la ley de Hooke[171] que relaciona esfuerzos y deformaciones (elasticidad lineal):

$$
\sigma_{i j}=c_{i j k l} \epsilon_{k l} \quad \epsilon_{i j}=s_{i j k l} \sigma_{k l} \quad \text { siendo } \quad s=c^{-1}
$$

Y de los desplazamientos dieléctricos que relaciona los desplazamientos en el piezoeléctrico y el campo eléctrico aplicado (piezoelectricidad lineal):

$$
D_{i}=\mathrm{E}_{i j} E_{j}
$$

Siendo E la constante dieléctrica o permitividad (un escalar o un tensor en función del material utilizado) y E el campo eléctrico aplicado. La constante dieléctrica cuantifica la tendencia del piezoeléctrico a polarizarse cuando aplicamos un campo eléctrico.

Combinando ambas ecuaciones obtenemos las relaciones para:

- Efecto piezoeléctrico directo (PZT sensor): $D_{i}=d_{i j k} \sigma_{j k}+\mathrm{E}_{j i} E_{j}$

- Efecto piezoeléctrico inverso (PZT actuador): $\epsilon_{i j}=s_{i j k l} \sigma_{k l}+d_{k i j} E_{k}$

Con los siguientes coeficientes:

- La constante piezoeléctrica, d. Que puede considerarse como la variación de las deformaciones con el campo eléctrico aplicado para esfuerzos constantes o la variación del desplazamiento dieléctrico con el esfuerzo para un campo eléctrico constante.

- El tensor de deformación elástica en ausencia de campo eléctrico, s.

Lo que debemos considerar en el ámbito de esta tesis y relacionado con las ecuaciones anteriores es únicamente lo siguiente. Se puede encontrar ejemplos prácticos de aplicación de las ecuaciones en [170].

El proceso general simplificado de interrogación de la estructura se esquematiza en la Figura 104.

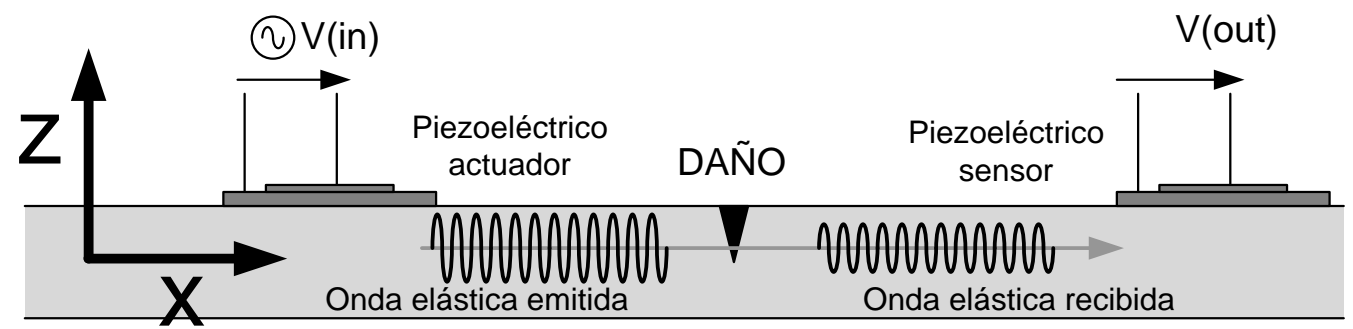

Figura 104 - Generación y medición de GLW en la estructura con sensores PZT. 
Los pasos (con ecuaciones simplificadas y para el modo de tracción compresión) que tiene el proceso son los siguientes:

- Aplicamos un voltaje en el PZT actuador: $\quad V_{\text {in }}(t)$

- Esta diferencia de potencial genera un campo eléctrico: $E_{z}(t)=-\nabla V_{i n}(t)$

- El campo eléctrico genera unas deformaciones longitudinales (consideramos ausencia de otro tipo de esfuerzos): $\quad \epsilon_{x x}(t)=d_{x z} E_{z}(t)$

- Las deformaciones longitudinales se propagan por la estructura sufriendo modificaciones debido a la presencia de daño y las EOC: $\quad \epsilon_{x x}(t) \rightarrow \widetilde{\epsilon}_{x x}(t)$

- Estas deformaciones llegan al piezoeléctrico generando deformaciones dieléctricas (en ausencia de un campo eléctrico externo): $D_{z}(t) \sim d_{x z} \tilde{\epsilon}_{x x}(t)$

- Que generan un campo eléctrico: $\quad E_{z}(t) \sim D_{z}(t) / \mathrm{E}$

- Produciendo un voltaje de salida en el PZT sensor: $\quad E_{z}(t) \rightarrow V_{\text {out }}(t)$

Este voltaje de salida será el que medimos y su serie temporal será la forma de onda que representa la GLW que ha viajado por la estructura. 


\section{Anexo 3: La Transformada Chirplet (CT)}

La Transformada Chirplet (CT) se ha utilizado anteriormente para el análisis de GLW con el objetivo de caracterizar los modos de propagación [155]. También es ampliamente utilizada para el análisis dispersivo de estas mismas tipo de ondas elásticas [154][155][156].

Nosotros pretendemos utilizar la CT para convertir la representación de las señales en forma de series temporales en un espacio penta-dimensional cuyas coordenadas son los coeficientes de esta transformada. Y tratar de relacionar las variaciones en dichos coeficientes con variaciones inducidas por las EOC o el daño.

La definición de esta transformada es como sigue[158][159]:

$C^{c t}\left(t_{0}, \omega_{0}, s, q, p\right)=\int_{-\infty}^{\infty} x(t) g_{t_{0}, \omega_{0}, s, q, p}^{*}(t) d t=\frac{1}{2 \cdot \pi} \int_{-\infty}^{\infty} X(\omega) G_{t_{0}, \omega_{0}, s, q, p}^{*}(\omega) d \omega$

En la siguiente figura se puede comprobar la representación en el plano tiempo-frecuencia de un chirp.

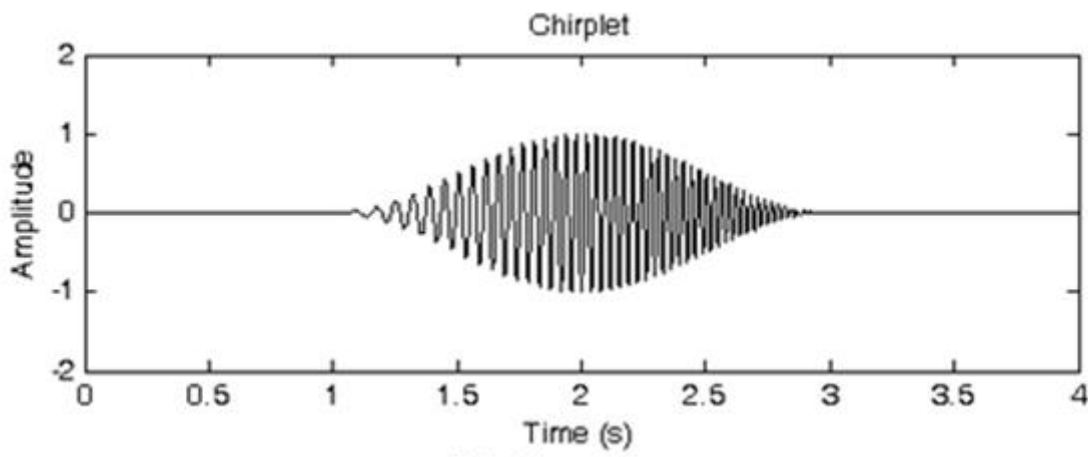

Chirplet spectrogram

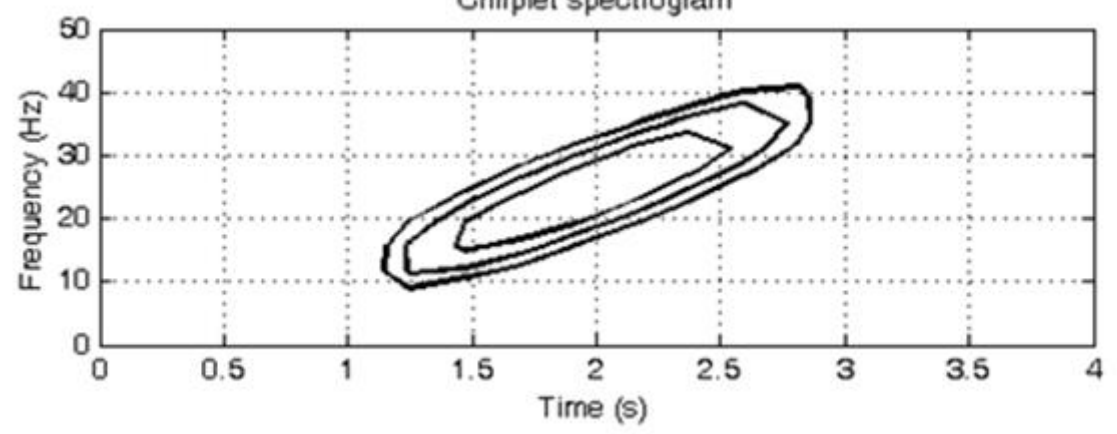

Figura 105 - Representación en el plano tiempo-frecuencia de la CT de un chirp [158][159]

En la transformada Chirplet la señal x o X se proyecta en un sub-espacio de cinco dimensiones utilizando como funciones base de ese sub-espacio, $g$ o G[158][159].

$g_{t_{0}, \omega_{0}, s, q, p}(t)=T_{t_{0}} F_{\omega_{0}} S_{S} Q_{q} P_{p} h(t)$

$G_{t_{0}, \omega_{0}, s, q, p}(\omega)=T_{t_{0}} F_{\omega_{0}} S_{s} Q_{q} P_{p} H(\omega)$ 
Cada uno de los coeficientes (T, F, S, Q and P) indica un operador con un cierto significado físico[158][159].

\section{Time shift:}

$$
\begin{gathered}
T_{t_{0}} h(t)=h\left(t-t_{0}\right) \\
T_{t_{0}} H(\omega)=e^{-i \omega t_{0}} H(\omega)
\end{gathered}
$$

Frequency shift:

$$
\begin{gathered}
F_{\omega_{0}} h(t)=e^{i \omega_{0} t} h(t) \\
F_{\omega_{0}} H(\omega)=H\left(\omega-\omega_{0}\right)
\end{gathered}
$$

Scaling:

$$
\begin{gathered}
S_{s} h(t)=\frac{1}{\sqrt{s}} h\left(\frac{t}{s}\right) \\
S_{S} H(\omega)=\sqrt{s} H(s \omega)
\end{gathered}
$$

Time shear, el * indica un producto de convolución:

$$
\begin{gathered}
P_{p} h(t)=(i p)^{-\frac{1}{2}} \exp \left(\frac{i}{2 p} t^{2}\right) * h(t) \\
P_{p} H(\omega)=\exp \left(\frac{i p}{2} \omega^{2}\right) H(\omega)
\end{gathered}
$$

Frequency shear, el * indica un producto de convolución:

$$
\begin{gathered}
Q_{q} h(t)=h(t) \exp \left(\frac{i q}{2} t^{2}\right) \\
Q_{q} H(\omega)=(i q)^{-\frac{1}{2}} \exp \left(\frac{i 2}{q} \omega^{2}\right) * H(\omega)
\end{gathered}
$$

Información adicional sobre la interpretación física de cada uno de estos operadores de la CT y de los coeficientes obtenidos se puede encontrar en las referencias [158][159].

Algunos de estos coeficientes se pueden relacionar con las modificaciones observadas en la forma de onda que llega al receptor producidas bien por las EOC o por la presencia de daño [158][159]:

- Time shift. Se puede correlacionar con el retraso inducido por la temperatura o el estado de carga de la estructura [164]. 
- Frequency shift. Se puede generar por una migración entre los modos de propagación de la GLW o por cambios de espesor.

- Scaling. Relacionado fundamentalmente con la atenuación producida por la presencia de ciertos tipos de daño o en menor medida por las variaciones de temperatura [164].

Antes de utilizar la CT en el análisis de datos experimentales efectuaremos una serie de pruebas puramente analíticas para verificar el efecto del retraso y la atenuación en los coeficientes de dicha transformada.

Para el análisis mediante CT se están utilizando Chirplets Gaussianas de un conjunto de herramientas de libre distribución (GNU Matlab functions package) [165].

En la figura se definen una serie de señales muy similares a las que adquiere el sensor receptor de nuestro esquema y que han sido modificadas de dos maneras.

- Se añade un retraso para comprobar la relación de dicho retraso con el coeficiente de Time Shift de la CT. La variación del retraso se puede observar en la gráfica inferior de la figura.

- Se aplica una cierta atenuación al rango de la señal. Esta atenuación debería correlacionarse directamente con la parte real del coeficiente de Scaling de la CT. La variación de la atenuación para cada señal se indica en el gráfico izquierdo.
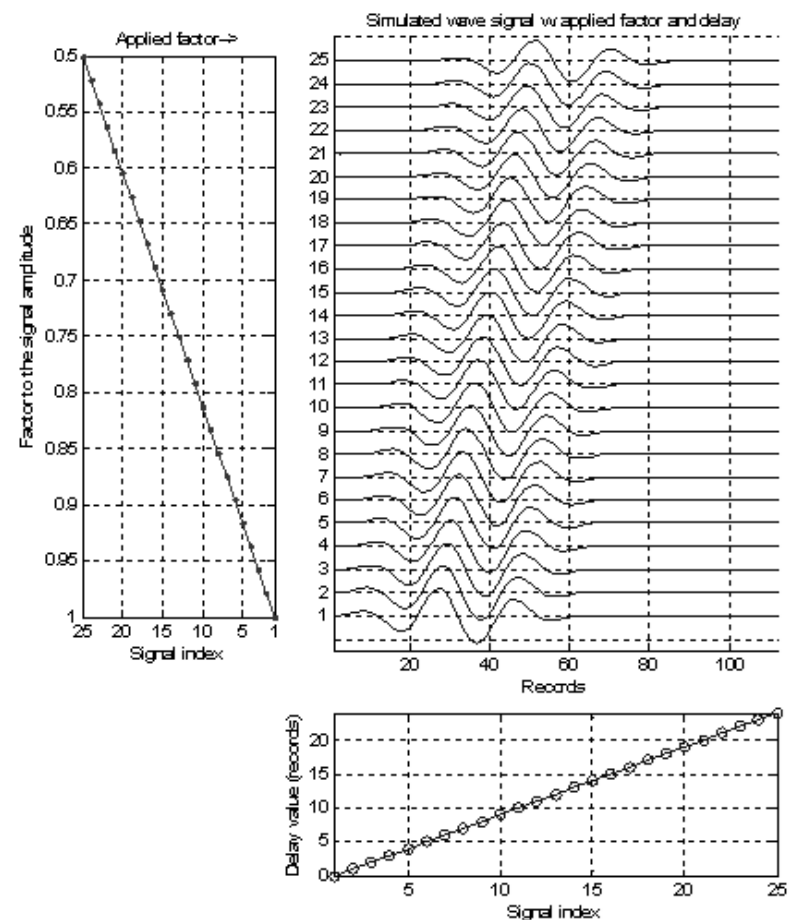

Figura 106 - Set de señales teóricas para la evaluación de los coeficientes de la CT. 

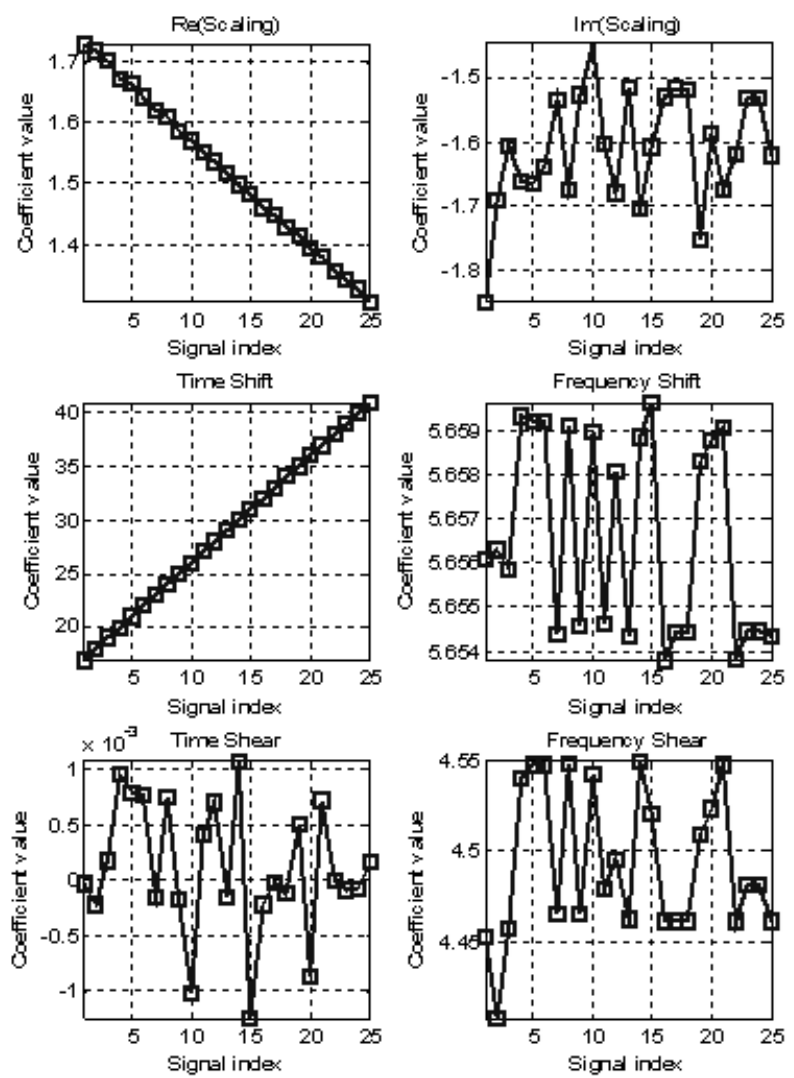

Figura 107 - Coefientes de la CT obtenidos para cada una de las señales teóricas propuestas.

En la Figura 107 se dibujan los diferentes coeficientes de cada una de las señales de la anterior frente al número de señal (eje vertical y eje horizontal, respectivamente, en cada una de las gráficas).

Se puede observar que la atenuación de la señal está claramente relacionada con la parte real del coeficiente Scaling y que el retraso inducido también está relacionado directamente con el coeficiente Time Shift. No se observa ninguna relación adicional en el resto de coeficientes.

A partir de este punto el análisis de las señales obtenidas de todos los experimentos se centrarán en estos dos coeficientes ya que es posible que estén directamente relacionados con los efectos de las EOC y el daño que queremos comprobar.

Las variaciones de temperatura modificarán el tiempo de llega de la GLW al receptor y por lo tanto añadirá un cierto retraso frente a la señal de referencia que quedará reflejado en el coeficiente Time Shift de la CT.

Asimismo el daño modificará principalmente la amplitud de dicha GLW y al receptor llegará una señal atenuada respecto a la referencia, dicho cambio se podrá observar en la parte real del coeficiente de Scaling. 


\section{Anexo 4: Sistemas de adquisición de datos}

Los sistemas de adquisición utilizados en la tesis son los siguientes:

- Acellent Technologies ScanGenie[175]. Para interrogar la estructura de manera activa mediante sensores piezoeléctricos permitiendo conectar hasta 10 sensores/actuadores.

- Sistema basado en la tarjeta de National Instruments Card NI6366. Realiza el mismo trabajo que el equipo ScanGenie pero de un modo más eficiente y rápido funcionando con un software creado específicamente para esta tesis. Sin embargo sólo permite un canal de actuación y otro de recepción, lo que obliga a usar un switch intermedio para cambiar entre los diferentes sensores. Además permite la sincronización con el equipo de medición de FBGs de alta velocidad, usando como sensores redes de Bragg.

- Sistema basado en Arduino. Para la adquisición de las EOC en algunos ensayos:

○ Medición de temperatura mediante un termopar.

- Medición de carga mediante la conexión a un puente de Wheatstone.

En los siguientes apartados se indican las características particulares de cada sistema de adquisición y los elementos de software y hardware adicionales utilizados para la adquisición de datos.

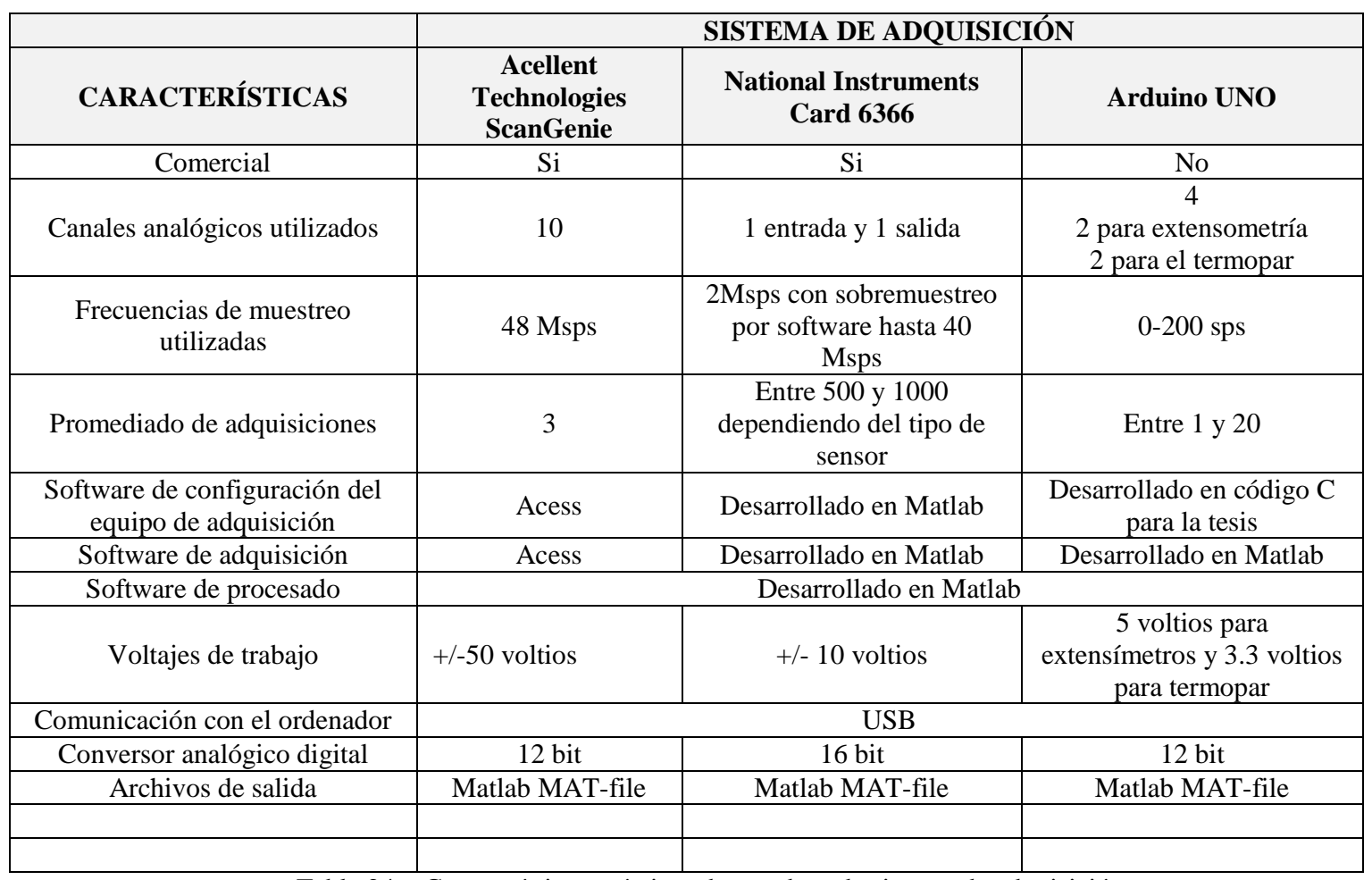

Tabla 24 - Características prácticas de uso de cada sistema de adquisición. 


\subsection{DAQ Acellent Technologies ScanGenie para GLW}

Este sistema de interrogación activa de la estructura es comercial (Acellent Technologies [175]). Para su utilización el sistema trae un software específico denominado Acess [174]. Con este software se pueden configurar las interrogaciones activas de la estructura para un conjunto de piezoeléctricos.

El funcionamiento básico de este equipo es el siguiente:

1. Se configuran los siguientes parámetros:

a. Posición e identificación de los canales de sensores/actuadores PZT

b. Configuración de la interrogación:

i. Forma de onda

ii. Frecuencia de trabajo

iii. Promediado

iv. Voltajes de interrogación

c. Esquema de interrogación, pares actuador/sensor

2. Se lanza la adquisición indicando el nombre del fichero de salida

3. Interrogación activa en los pares actuador/sensor

4. Escritura de resultados en el fichero de salida, este fichero tendrá el siguiente contenido:

a. Estructura "setup", con la siguiente información:

i. Definición global de la adquisición

ii. Identificación de cada una de las interrogaciones guardadas en el fichero

b. Variables "a" que contienen la señal de actuación del par actuador/sensor

c. Variables "s" que contienen la señal del sensor del par actuador/sensor

5. Procesado de los resultados, existen dos opciones:

a. Utilizar Acess.

b. Utilizar un programa independiente.

En el ámbito de esta tesis se utilizará únicamente como sistema de adquisición de datos. Configurando dicha adquisición mediante el denominado programa Acess. La adquisición producirá ficheros de salida accesibles desde Matlab. Para el procesado de dicha información se utilizará, en vez del programa Acess, programas específicos diseñados en Matlab. 
Para la sincronización posterior de la información con los datos de EOC adquiridos con otro sistema se indica en el nombre del fichero el tiempo de inicio de la misma (en horas y minutos). Puesto que las EOC variarán muy lentamente con esta información de tiempo es suficiente para sincronizar ambos conjuntos de datos.

Las especificaciones del equipo son las siguientes.

\begin{tabular}{|c|c|}
\hline CARACTERÍSTICA & VALOR \\
\hline Forma de onda de interrogación & $\begin{array}{c}\text { Configurable con frecuencias entre } 10 \mathrm{kHz} \text { y } 700 \mathrm{kHz} \\
\text { Hasta un máximo de } 1024 \mathrm{puntos}\end{array}$ \\
\hline Frecuencias de interrogación & $150 \mathrm{kHz}, 1.5 \mathrm{MHz}, 6 \mathrm{MHz}, 12 \mathrm{MHz}, 24 \mathrm{MHz}, 48 \mathrm{MHz}$ \\
\hline Voltaje de salida máximo, en actuadores & $+/-80$ voltios \\
\hline Número máximo de canales & 64 \\
\hline Frecuencias de adquisición & 32000 \\
\hline Puntos máximos de adquisición & $150 \mathrm{ksps}, 1.5 \mathrm{Msps}, 6 \mathrm{Msps}, 12 \mathrm{Msps}, 24 \mathrm{Msps}, 48 \mathrm{Msps}$ \\
\hline Conversor analógico digital & 0 bit ajustado automáticamente a $+/ 1$ voltio \\
\hline Temperatura de operación & $0^{\circ} \mathrm{C}-45^{\circ} \mathrm{C}$ \\
\hline Comunicación con el ordenador & USB $1.1 / 2.0$ \\
\hline Alimentación & 220 voltios \\
\hline
\end{tabular}

Tabla 25 - Especificaciones del equipo de adquisición ScanGenie [175].

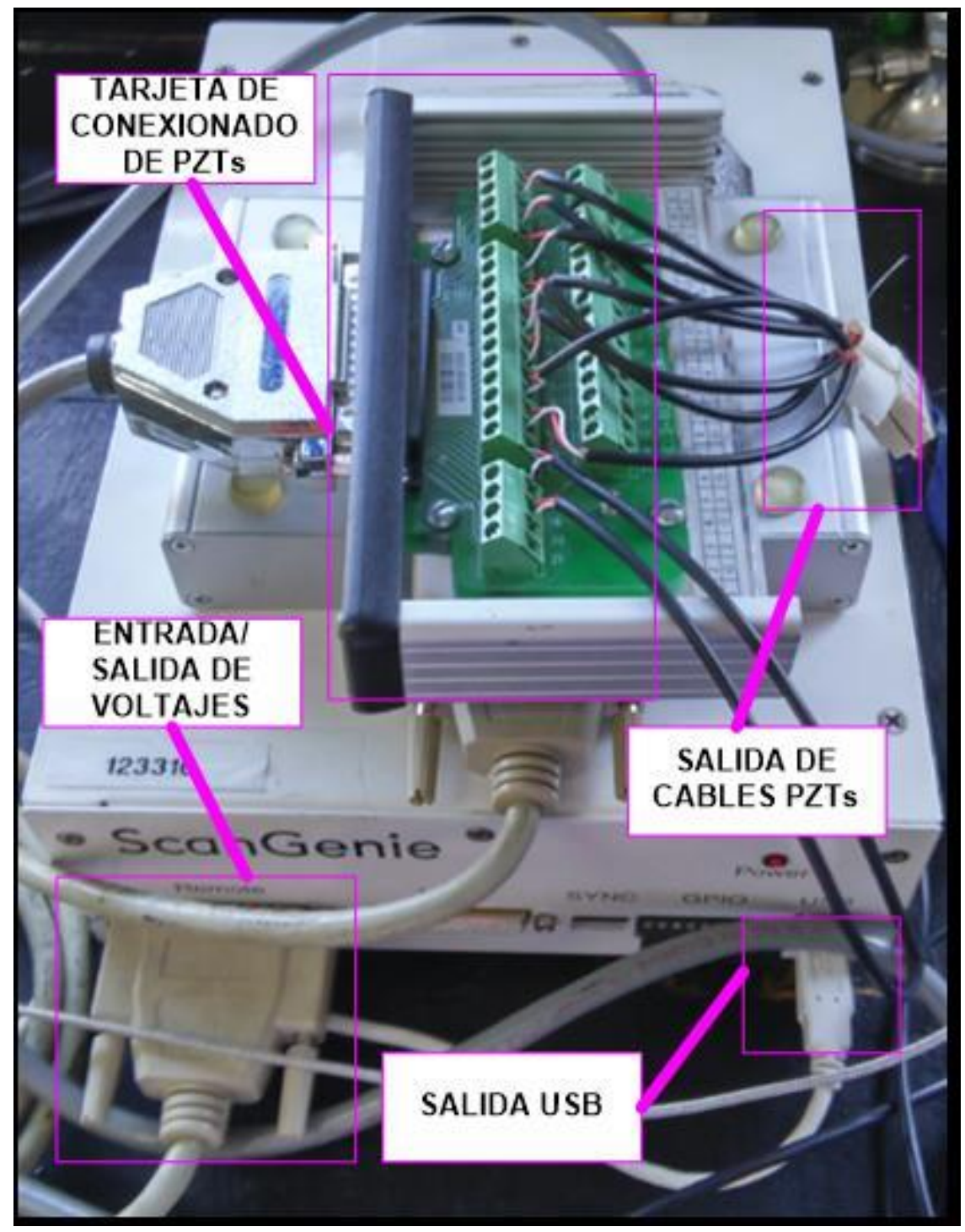

Figura 108 - ScanGenie con sus conexiones para las pruebas en fuselaje. 


\subsection{DAQ propio basado en National Instruments para GLW}

Como resultado de trabajos previos a la tesis [22] se vio la necesidad de reproducir el comportamiento del equipo Acellent Technologies ScanGenie por las siguientes razones:

- Para comprender en profundidad todo el proceso de adquisición de datos de un equipo de muy alta frecuencia. Con esto se aumenta el conocimiento sobre los datos experimentales que se adquieren para trabajar. Los detalles de funcionamiento del equipo Acellent ScanGenie son propietarios de dicha compañía y no son de uso público. Este hecho hace que no se conozca en detalle lo que el equipo está realmente adquiriendo, información que era de vital importancia para el desarrollo de esta tesis.

- Para poder utilizar sensores adicionales como por ejemplo FBGs. En este caso se utiliza la tarjeta de adquisición para adquirir los datos provenientes de un equipo óptico de alta velocidad para la medición de GLW[169].

Por estas razones se ha desarrollado un sistema de adquisición basado en los siguientes elementos:

- Hardware. Tarjeta de adquisición de propósito general NI 6366. Con la siguientes posibilidades de uso:

○ Sensores/actuadores piezoeléctricos, PZT.

- Sensores FGB y actuadores PZT.

- Software. Desarrollado utilizando la "data adquisition toolbox" de Matlab. Con las siguientes funcionalidades:

- Configuración de la interrogación de la estructura:

- Señal de actuación

- Promediado, muy importante en este caso ya que no se utiliza amplificación de voltaje.

- Adquisición

○ Guardado, visualización y edición de los datos.

El uso de este sistema es muy similar al indicado para el Acellent ScanGenie:

1. Configuración de la interrogación.

2. Interrogación de la estructura.

3. Guardado de los datos para su posterior procesado

Estos procesos son equivalentes a los que realiza el ScanGenie, realizados de un modo distinto. 
Veamos en primer lugar las especificaciones de la tarjeta NI 6366[176].

\begin{tabular}{|c|c|}
\hline CARACTERÍSTICA & VALOR \\
\hline Conversor analógico digital de entrada & 16 bits \\
\hline Rango de entrada & $\pm 10 \mathrm{~V}, \pm 5 \mathrm{~V}, \pm 2 \mathrm{~V}, \pm 1 \mathrm{~V}$ \\
\hline Canales analógicos de entrada & $2 \mathrm{Msps}$ \\
\hline Muestreo de entrada & 16 bits \\
\hline Conversor analógico digital de salida & $\pm 10 \mathrm{~V}, \pm 5 \mathrm{~V}$ \\
\hline Rango de salida & 2 \\
\hline Canales analógicos de salida & $3.33 \mathrm{Msps}$ \\
\hline Muestreo de salida & 24 \\
\hline Canales de entrada / Salida digital & $1 \mathrm{MHz}$ \\
\hline Velocidad de reloj & USB 2.0 \\
\hline Comunicación con el ordenador & Adaptador 220 voltios $-12 \mathrm{~V}$ \\
\hline Alimentación & .
\end{tabular}

Tabla 26 - Especificaciones técnicas tarjeta de adquisición NI-6366.
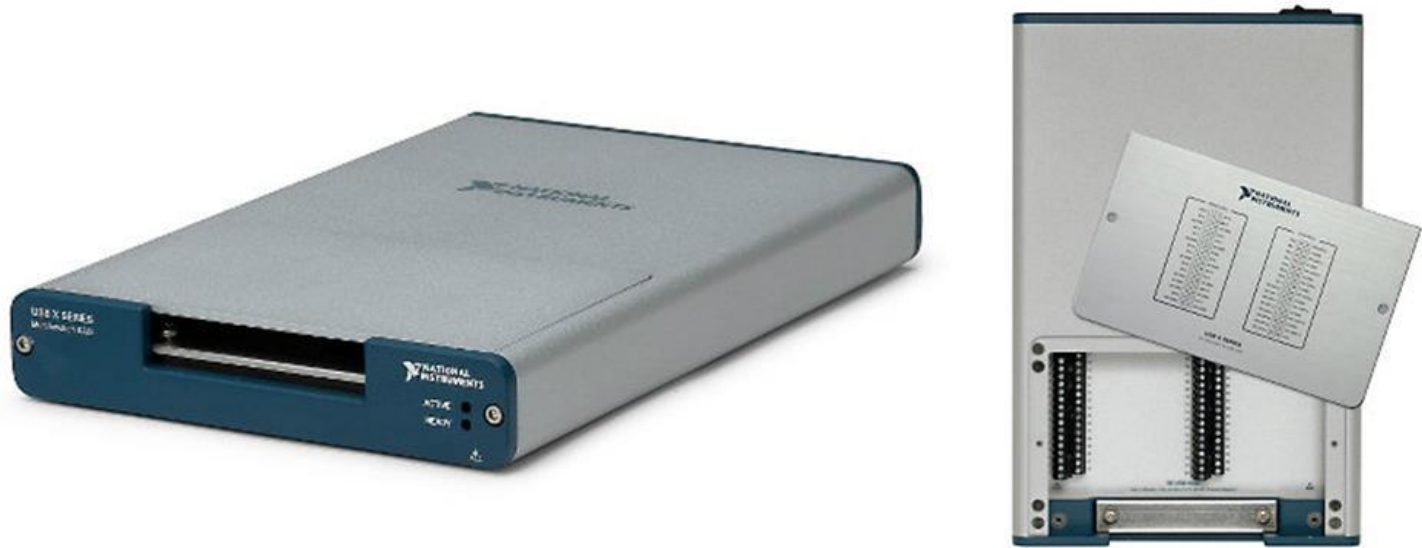

Figura 109 - Tarjeta de adquisición NI-6366, vista general (izquierda) y panel de conexionado (derecha).

Para esta tarjeta de adquisición de datos se desarrolló un software específico de control en Matlab. Este software permite utilizar PZT y cualquier otro sensor de medida para GLW como por ejemplo FBGs. En general permite efectuar las siguientes tareas:

- Configurar la adquisición de datos.

- Guardar los datos de la interrogación de la estructura.

- Recuperar los datos y efectuar tareas de preproceso:

○ Representación de grupos de señales frente a una referencia.

○ Remuestrear las señales.

○ Eliminar zonas de las señales.

○ Extraer zonas de interés de las señales.

- Efectuar ciertas transformadas sobre las señales, FFT (pwelch), Hilbert.

- Pintar conjunto de señales o sus transformadas. 
En la siguiente figura se puede ver la ventana principal de control del programa de adquisición de datos en Matlab para la tarjeta NI-6366.

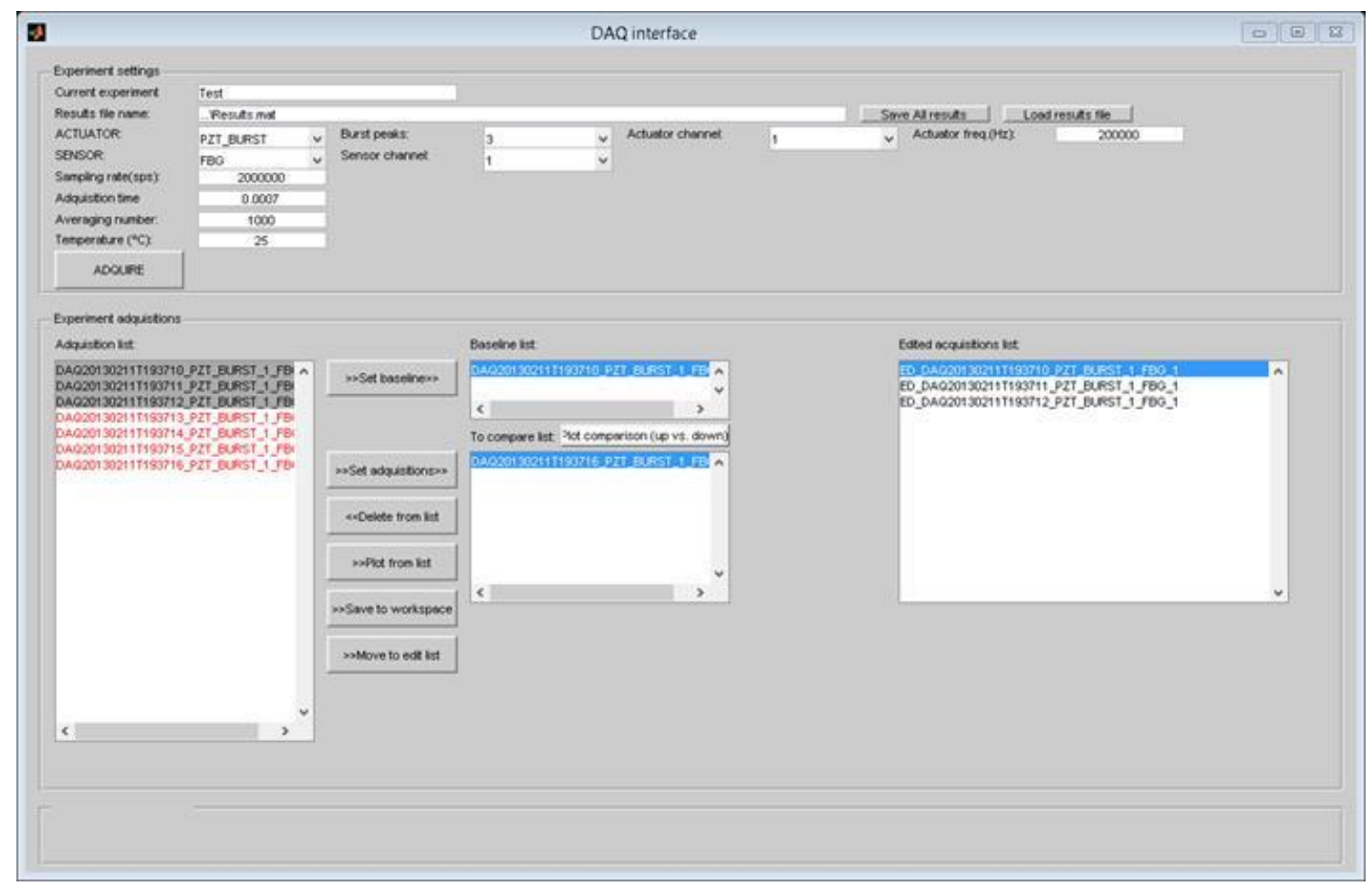

Figura 110 - Programa de adquisición de datos y preproceso para NI-6366

Muchas de las figuras que se muestran en esta tesis se han generado mediante este programa.

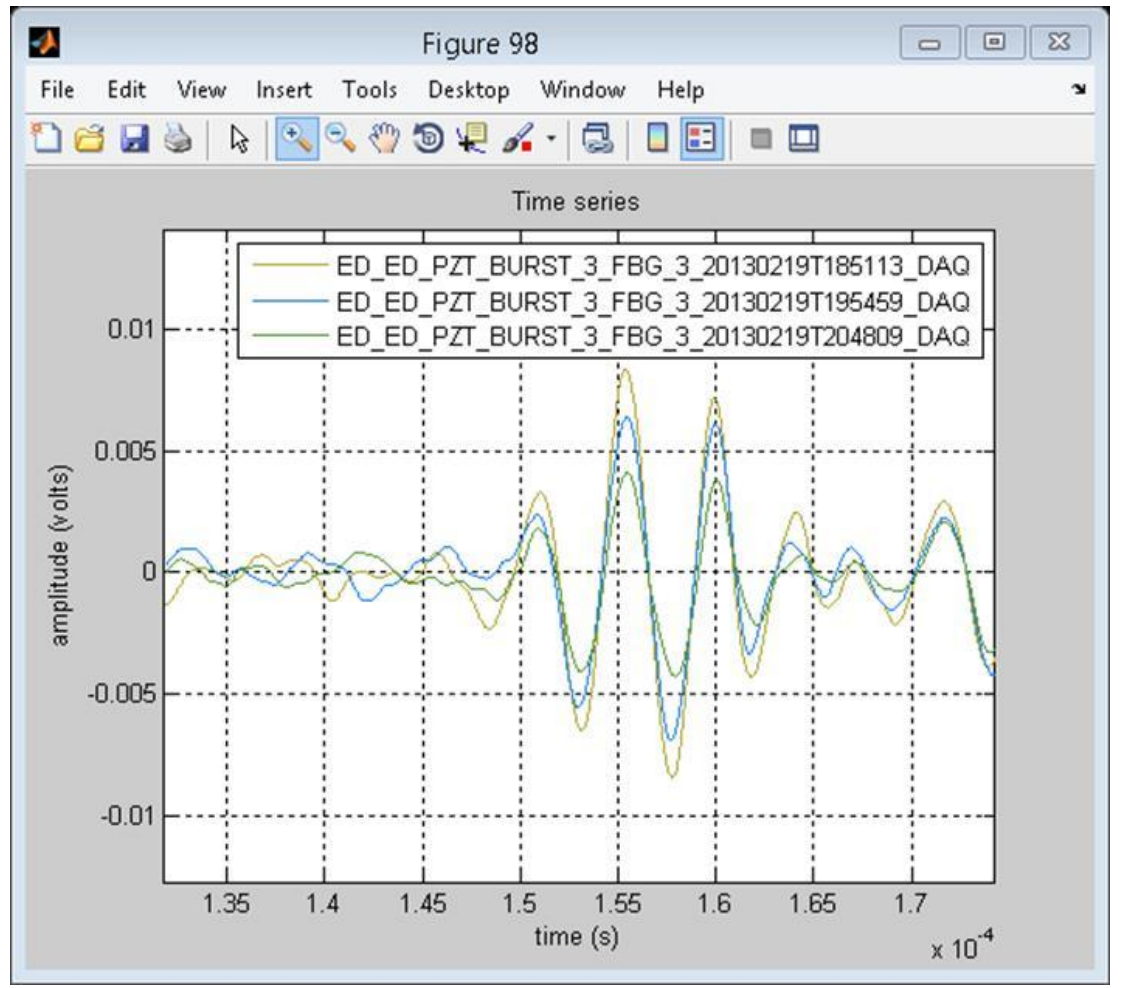

Figura 111 - Gráfica típica generada por el programa de adquisición para NI-6366 
El elemento más novedoso de este sistema de adquisición consiste en su eficiencia (superior al ScanGenie) en la interrogación por las siguientes razones:

- No necesita un amplificador de piezoeléctricos, lo que abarata su coste notablemente. Efectúa promediados con un valor de 500 a 1000 sobre las interrogaciones. Mediante estos promediados se obtiene un SNR similar al del ScanGenie pero con mucha mayor simplicidad.

- Permite el uso de sensores diferentes a los PZT, por ejemplo FBGs. Aunque en estos casos necesita un amplificador de piezoeléctricos.

- La interrogación del camino de daño entre el actuador y el sensor se efectúa con un tren de pulsos continuo y no de modo individual. Esto permite disminuir los tiempos de interrogación un orden de magnitud, de minutos a segundos.

- Utiliza una frecuencia de muestreo mucho menor que el ScanGenie y realiza un posterior sobremuestreo que reconstruye las adquisiciones realizadas. Esto permite utilizar equipos de adquisición con un coste mucho menor.

- Permite la adquisición de ondas elásticas en tiempo real. Se podría utilizar para la detección de impactos en tiempo real. No se muestra esta funcionalidad puesto que queda fuera del ámbito de la tesis.

Se muestran detalles adicionales sobre la interacción de este sistema con los sensores FBG en el Anexo 5, capítulo 12. No se describe el sistema en profundidad puesto que queda fuera del alcance de esta tesis ya que únicamente se han utilizado los datos adquiridos con sensores FBG para demostrar la independencia del tipo de sensor para las metodologías propuestas. Se pueden encontrar descripciones detalladas en la referencia [169].

En los ensayos combinados PZT-FBG se utilizó un amplificador de piezoeléctricos para poder obtener señales significativas en los FBG.

En los ensayos en los que únicamente participan PZTs no se utilizó el amplificador ya que no era imprescindible. 


\subsection{DAQ propio basado en Arduino UNO para temperatura y deformación}

Además de los sistemas de interrogación de la estructura mediante GLW es necesario medir también las condiciones ambientales y de operación. Los requerimientos para este sistema de adquisición son mucho menores que para las ondas elásticas. Los tiempos característicos de las EOC que se van a medir son más lentos. Mientras que en ScanGenie o NI-6366 los tiempos característicos del fenómeno a medir son del orden de micro segundos en el caso de las EOC (carga estática y temperatura) son del orden de segundos. Por esta razón se utilizará la plataforma de hardware libre Arduino UNO. Este sistema solo se utilizó junto con el ScanGenie en los experimentos relacionados con el fuselaje. En el resto de experimentos la única EOC es la temperatura y se adquirió mediante termopares directamente.

Los elementos de este sistema de adquisición son los siguientes:

- Hardware, Arduino UNO. En el que se integrará el sistema de amplificación para la extensometría y para la temperatura un termopar.

- Software. Dos elementos básicos:

- Configuración de la adquisición. Se utilizará el lenguaje de programación y el IDE de Arduino (basado en wiring, $\mathrm{C} / \mathrm{C}++$ ). Con este entorno se programa el software que ejecuta la placa para poder adquirir los voltajes asociados a la temperatura y a la extensometría. Estos datos se enviarán a través del puerto USB al ordenador.

- Adquisición de datos, y guardado. El software para esta tarea se desarrolla en Matlab utilizando la "data acquisition toolbox" y las librerías específicas de interface para Matlab desarrolladas por National Instruments. Este programa captura la información que llega por el puerto USB la promedia según configuración y la guarda en un fichero de datos de texto junto con la referencia temporal. Esta referencia temporal servirá para la sincronización posterior con los datos de interrogación GLW del equipo ScanGenie.

- La información producida se procesa de modo conjunto con los datos del ScanGenie mediante programas específicos creados en Matlab.

El uso de sistema es muy simple:

1. Se conecta el Arduino UNO al ordenador.

2. Se sube mediante la IDE de Arduino el programa de ejecución de la adquisición. 
3. Se abre Matlab y se lanza el programa de adquisición de datos del puerto USB. Este programa mostrará en pantalla los datos adquiridos durante todo el experimento y los irá guardando en un fichero de texto.

4. Al finalizar el experimento se cierra el programa y se guarda el fichero de texto junto con las interrogaciones de la estructura efectuadas con el ScanGenie.

Las especificaciones del Arduino UNO son las siguientes[178]:

\begin{tabular}{|c|c|}
\hline CARACTERÍSTICA & VALOR \\
\hline Conversor analógico digital de entrada & 10 bits \\
\hline Rango de entrada & $0-5 \mathrm{~V}$ \\
\hline Canales analógicos de entrada & 6 \\
\hline Muestreo de entrada & 7200 sps (115200 baudios) \\
\hline Conversor analógico digital de salida & 8 bits \\
\hline Rango de salida & $6-5 \mathrm{~V}$ \\
\hline Canales analógicos de salida & 7200 sps (115200 baudios) \\
\hline Muestreo de salida & 14 \\
\hline Canales de entrada / Salida digital & $16 \mathrm{MHz}$ \\
\hline Velocidad de reloj & USB 2.0 \\
\hline Comunicación con el ordenador & USB \\
\hline Alimentación & UNO \\
\hline
\end{tabular}

Tabla 27 - Especificaciones técnicas del Arduino UNO.

El esquema de conexionado utilizado se puede ver en la siguiente figura.

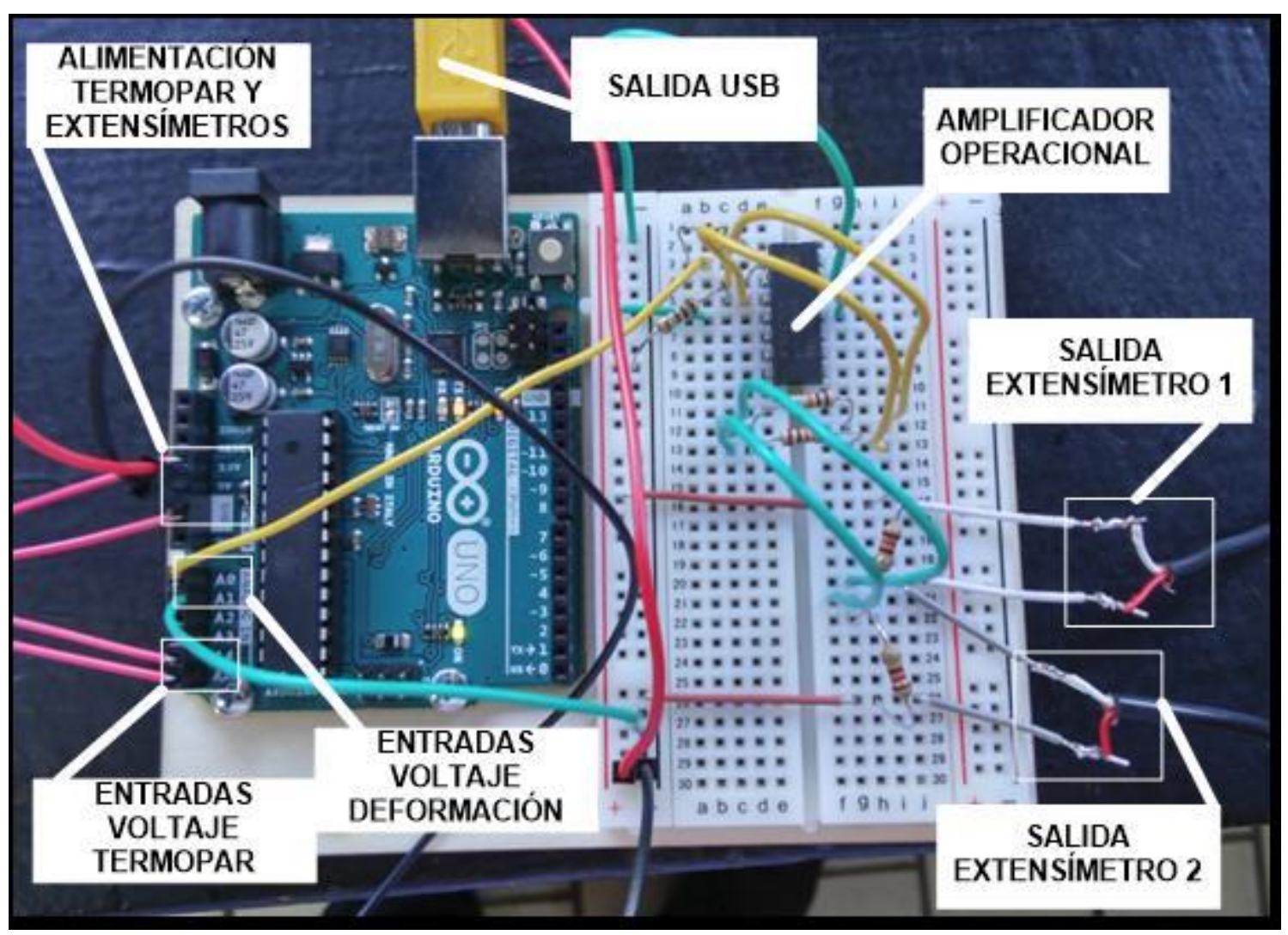

Figura 112 - Conexionado de Arduino UNO y la placa de prototipaje. 
El termopar utilizado tiene una placa electrónica dedicada que se conecta directamente a la alimentación y entradas analógicas del Arduino UNO. Es un termopar tipo k con compensación de la temperatura ambiente. Se muestra en la siguiente figura.

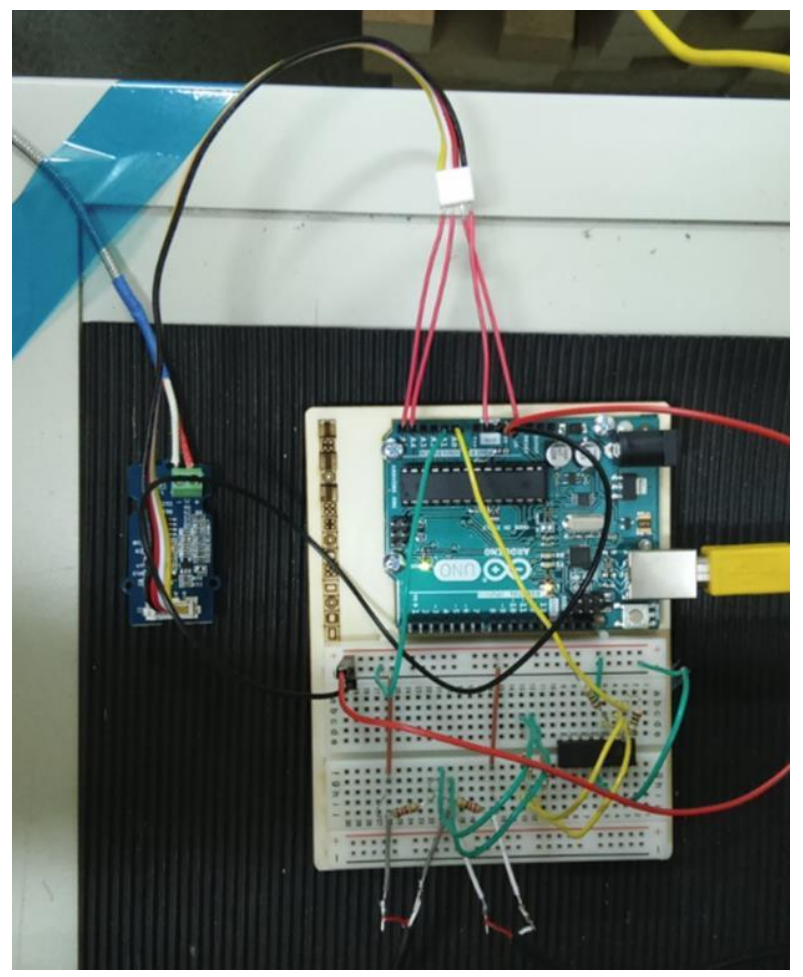

Figura 113 - Arduino UNO con el termopar conectado en el lado izquierdo

En la siguiente figura se muestra el programa de adquisición y visualización de temperatura y carga en tiempo real.

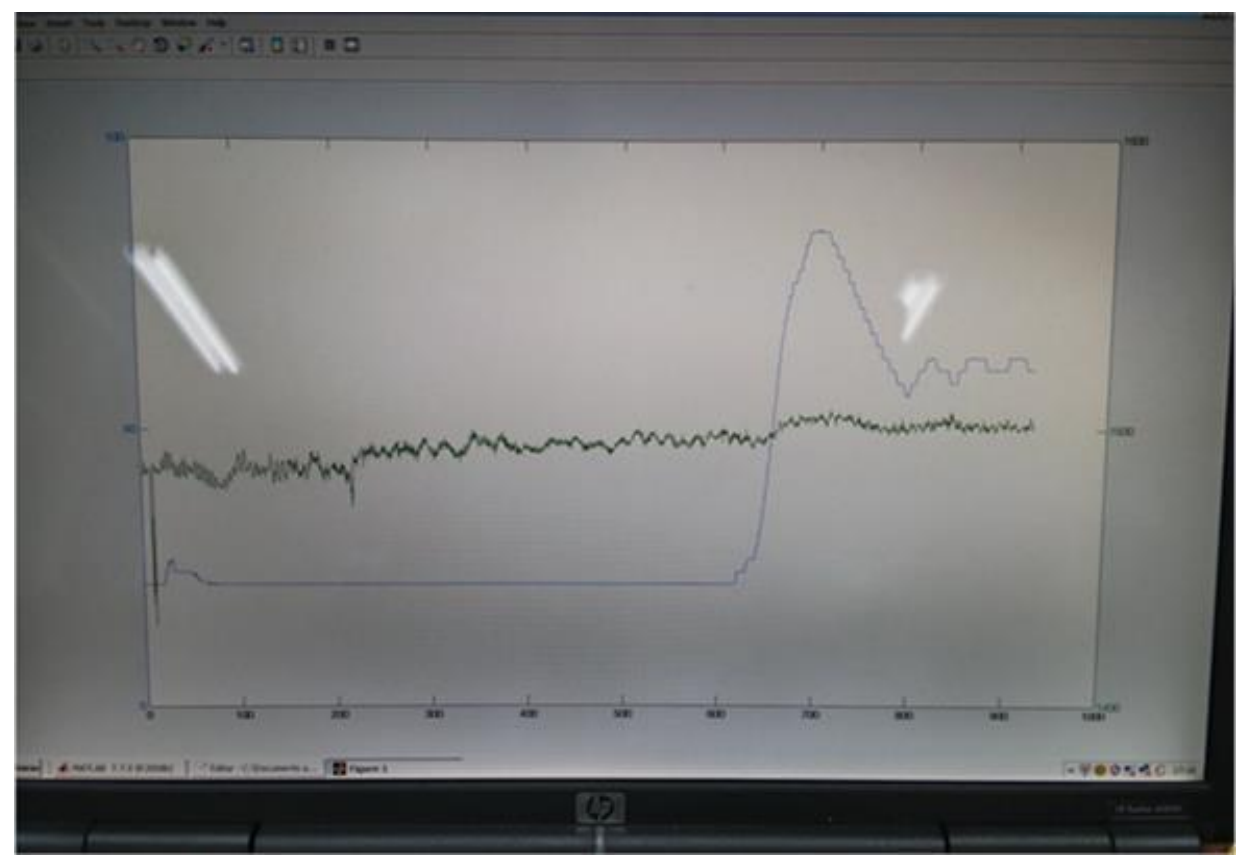

Figura 114 - Sistema Arduino UNO adquiriendo temperatura (azul) y carga (verde) durante un ensayo. 
Finalmente mostramos el formato del archivo de salida de datos (archivo, 20150916T171733ardu_data.txt).

$\begin{array}{llll}2015-09-16 & 17: 17: 34 & 19.007500 & 1497.857143 \\ 2015-09-16 & 17: 17: 34 & 18.800000 & 1496.363636 \\ 2015-09-16 & 17: 17: 37 & 18.660000 & 1497.121212 \\ 2015-09-16 & 17: 17: 38 & 19.051176 & 1496.764706 \\ 2015-09-16 & 17: 17: 38 & 19.360000 & 1497.121212 \\ 2015-09-16 & 17: 17: 39 & 19.150000 & 1495.606061 \\ 2015-09-16 & 17: 17: 39 & 18.730000 & 1498.030303 \\ 2015-09-16 & 17: 17: 40 & 19.080000 & 1495.454545 \\ 2015-09-16 & 17: 17: 40 & 18.590000 & 1495.606061 \\ 2015-09-16 & 17: 17: 41 & 18.870000 & 1497.878788 \\ 2015-09-16 & 17: 17: 41 & 18.660000 & 1492.303030 \\ 2015-09-16 & 17: 17: 42 & 18.915294 & 1497.941176 \\ 2015-09-16 & 17: 17: 42 & 18.380000 & 1497.727273 \\ 2015-09-16 & 17: 17: 43 & 18.380000 & 1494.242424 \\ 2015-09-16 & 17: 17: 43 & 18.800000 & 1496.060606 \\ 2015-09-16 & 17: 17: 44 & 18.660000 & 1497.424242 \\ 2015-09-16 & 17: 17: 45 & 19.150000 & 1493.818182 \\ 2015-09-16 & 17: 17: 45 & 18.380000 & 1497.878788 \\ 2015-09-16 & 17: 17: 46 & 18.507647 & 1494.147059 \\ 2015-09-16 & 17: 17: 46 & 18.660000 & 1496.969697 \\ 2015-09-16 & 17: 17: 47 & 18.590000 & 1494.696970 \\ 2015-09-16 & 17: 17: 47 & 18.520000 & 1496.212121 \\ 2015-09-16 & 17: 17: 48 & 18.590000 & 1493.636364 \\ 2015-09-16 & 17: 17: 48 & 18.590000 & 1497.575758 \\ 2015-09-16 & 17: 17: 49 & 18.730000 & 1495.303030 \\ 2015-09-16 & 17: 17: 50 & 18.730000 & 1492.727273 \\ 2015-09-16 & 17: 17: 50 & 18.575588 & 1497.352941 \\ 2015-09-16 & 17: 17: 50 & 18.590000 & 1495.909091 \\ 2015-09-16 & 17: 17: 51 & 18.520000 & 1493.181818 \\ 2015-09-16 & 17: 17: 51 & 18.660000 & 1495.000000 \\ 2015-09-16 & 17: 17: 52 & 18.940000 & 1497.424242 \\ 2015-09-16 & 17: 17: 53 & 18.730000 & 1495.000000 \\ 2015-09-16 & 17: 17: 53 & 18.800000 & 1492.575758\end{array}$

La primera columna de datos será el tiempo, la segunda la temperatura en ${ }^{\circ} \mathrm{C}$ y la tercera la salida de los extensímetros en $\mathrm{mV}$.

Los extensímetros son estándar TML tipo FLA-6-11, axiales[179]. Se conectan en "half bridge" usando un amplificador operacional LM224N para obtener una variación clara de la señal entre los diferentes estados de carga. Al ser un sistema que en el que solo se necesita una magnitud relacionada con la carga es indiferente que transformemos los datos a microdeformaciones o los dejemos directamente en mili voltios. Por lo tanto se dejan las medidas en milivoltios. 


\section{Anexo 5: Medición de GLW mediante sensores FBG}

Se muestra un pequeño esquema del sistema híbrido de interrogación de la estructura mediante sensores PZT como actuadores y FBG como sensores.

El sistema se conecta directamente a la tarjeta NI-6366 y se adquieren los datos del sistema de medición de FBG como si se tratase de un voltaje proveniente de un sensor PZT.

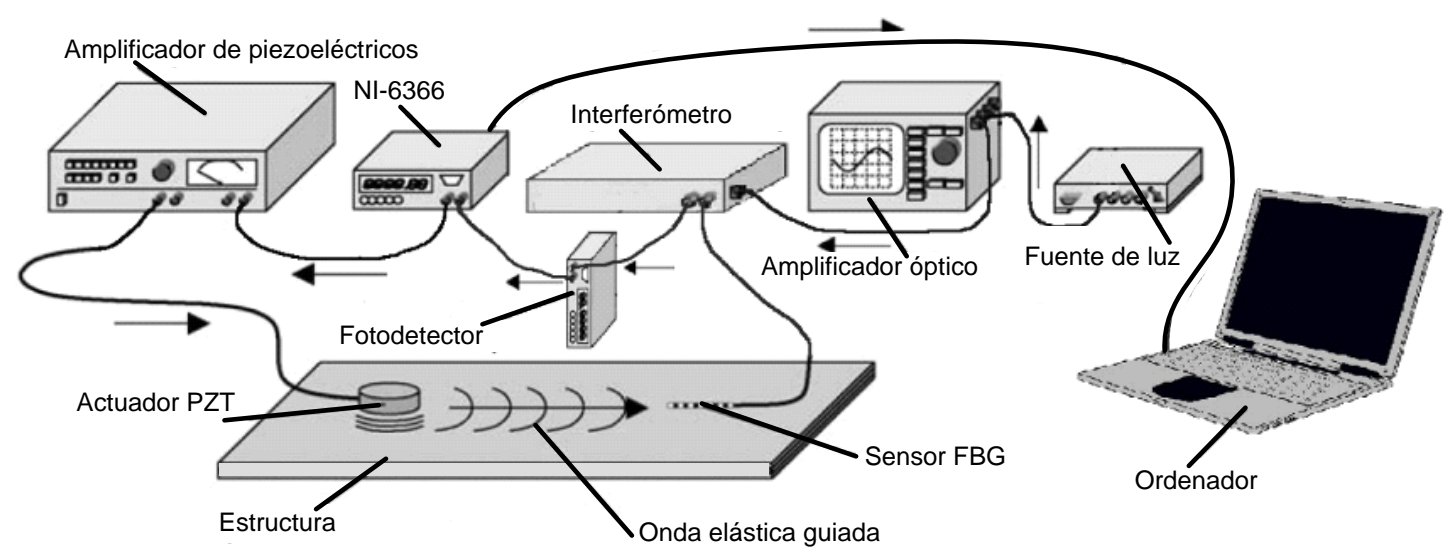

Figura 115 - Sistema híbrido PZT-FBG.

Para ver en detalle la utilización práctica y los resultados de este tipo de esquema ver la referencia[177]. 
